\title{
One stop shop: backbones trees for important phytopathogenic genera: I (2014)
}

\author{
Kevin D. Hyde • R. Henrik Nilsson • S. Aisyah Alias • Hiran A. Ariyawansa • \\ Jaime E. Blair • Lei Cai • Arthur W. A. M. de Cock • Asha J. Dissanayake • \\ Sally L. Glockling • Ishani D. Goonasekara • Michał Gorczak • Matthias Hahn • \\ Ruvishika S. Jayawardena • Jan A. L. van Kan • Matthew H. Laurence • \\ C. André Lévesque • Xinghong Li • Jian-Kui Liu • Sajeewa S. N. Maharachchikumbura • \\ Dimuthu S. Manamgoda • Frank N. Martin • Eric H. C. McKenzie • \\ Alistair R. McTaggart • Peter E. Mortimer • Prakash V. R. Nair • Julia Pawłowska • \\ Tara L. Rintoul • Roger G. Shivas • Christoffel F. J. Spies • Brett A. Summerell • \\ Paul W. J. Taylor • Razak B. Terhem • Dhanushka Udayanga • Niloofar Vaghefi • \\ Grit Walther • Mateusz Wilk • Marta Wrzosek • Jian-Chu Xu • JiYe Yan • Nan Zhou
}

Received: 6 June 2014 / Accepted: 16 July 2014 / Published online: 17 September 2014

(C) The Author(s) 2014. This article is published with open access at Springerlink.com

\begin{abstract}
Many fungi are pathogenic on plants and cause significant damage in agriculture and forestry. They are also part of the natural ecosystem and may play a role in regulating plant numbers/density. Morphological identification and analysis of plant pathogenic fungi, while important, is often hampered by the scarcity of discriminatory taxonomic characters and the endophytic or inconspicuous nature of these fungi. Molecular (DNA sequence) data for plant pathogenic fungi have emerged as key information for diagnostic and classification studies, although hampered in part by non-standard laboratory practices and analytical methods. To facilitate current
\end{abstract}

K. D. Hyde $(\bowtie) \cdot$ P. E. Mortimer · J.-C. Xu

Key Laboratory for Plant Diversity and Biogeography of East Asia, Kunming Institute of Botany, Chinese Academy of Sciences,

Kunming 650201, People's Republic of China

e-mail: kdhyde3@gmail.com

K. D. Hyde • P. E. Mortimer · J.-C. Xu

World Agroforestry Centre, East Asia Node, Heilongtan,

Kunming 650201, People's Republic of China

K. D. Hyde $\cdot$ H. A. Ariyawansa $\cdot$ A. J. Dissanayake

I. D. Goonasekara $\cdot$ R. S. Jayawardena $\cdot$ J.-K. Liu $\cdot$

S. S. N. Maharachchikumbura $\cdot$ D. S. Manamgoda $\cdot$ D. Udayanga

Institute of Excellence in Fungal Research, and School of Science,

Mae Fah Luang University, Chiang Rai 57100, Thailand

K. D. Hyde

Botany and Microbiology Department, College of Science, King

Saud University, Riyadh 1145, Saudi Arabia and future research, this study provides phylogenetic synopses for 25 groups of plant pathogenic fungi in the Ascomycota, Basidiomycota, Mucormycotina (Fungi), and Oomycota, using recent molecular data, up-to-date names, and the latest taxonomic insights. Lineagespecific laboratory protocols together with advice on their application, as well as general observations, are also provided. We hope to maintain updated backbone trees of these fungal lineages over time and to publish them jointly as new data emerge. Researchers of plant pathogenic fungi not covered by the present study are invited to join this future effort. Bipolaris, Botryosphaeriaceae,

\section{R. H. Nilsson}

Department of Biological and Environmental Sciences, University of Gothenburg, Box 461, 40530 Göteborg, Sweden

K. D. Hyde - S. A. Alias - S. S. N. Maharachchikumbura Institute of Ocean and Earth Sciences (IOES), C308, Institute of Postgraduate Studies Building, University of Malaya, 50603 Kuala Lumpur, Malaysia

\section{J. E. Blair}

Department of Biology, Franklin \& Marshall College, Lancaster, PA, USA

L. Cai $\cdot$ N. Zhou

State Key Laboratory of Mycology, Institute of Microbiology,

Chinese Academy of Sciences, Beijing 100101

People's Republic of China 
Botryosphaeria, Botrytis, Choanephora, Colletotrichum, Curvularia, Diaporthe, Diplodia, Dothiorella, Fusarium, Gilbertella, Lasiodiplodia, Mucor, Neofusicoccum, Pestalotiopsis, Phyllosticta, Phytophthora, Puccinia, Pyrenophora, Pythium, Rhizopus, Stagonosporopsis, Ustilago and Verticillium are dealt with in this paper.

Keywords Ascomycota $\cdot$ Basidiomycota $\cdot$ Endophytes . Mucormycotina $\cdot$ Molecular identification $\cdot$ Oomycota $\cdot$ Plant pathogens $\cdot$ Protozoa

\section{Contents and contributors (main contributors underlined)}

1. Bipolaris-DS Manamgoda, KD Hyde

2. Botryosphaeriaceae-AJ Dissanayake, JK Liu, JY Yan, XH $\mathrm{Li}$, KD Hyde

3. Botryosphaeria-AJ Dissanayake, JK Liu, JY Yan, XH Li, KD Hyde

4. Botrytis - RB Terhem, M Hahn, JAL van Kan

5. Choanephora-J Pawłowska, G Walther, M Wilk, M Gorczak, M Wrzosek

6. Colletotrichum-RS Jayawardena, DS Manamgoda, L Cai, XH Li, JY Yan, KD Hyde

7. Curvularia-DS Manamgoda, KD Hyde

$\overline{\text { A. W. A. M. de Cock }}$

CBS-KNAW Fungal Biodiversity Centre, Uppsalalaan 8,

3584CT Utrecht, The Netherlands

\section{A. J. Dissanayake $\cdot$ R. S. Jayawardena $\cdot$ X. Li $\cdot$ J. Yan}

Beijing Academy of Agriculture and Forestry Sciences, Institute of Plant and Environment Protection, No. 9 of

Shuguanghuayuanzhonglu, Haidian District, Beijing 100097,

People's Republic of China

S. L. Glockling

135 Brodrick Road, Eastbourne BN22 9RA, East Sussex, UK

M. Gorczak · J. Pawłowska • M. Wrzosek

Department of Plant Systematics and Geography, Faculty of Biology,

University of Warsaw, Al. Ujazdowskie 4, 00-478, Warsaw, Poland

M. Hahn

Department of Biology, TU Kaiserslautern,

Erwin-Schrödinger-Straße, 67663 Kaiserslautern, Germany

J. A. L. van Kan · R. B. Terhem

Laboratory of Phytopathology, Wageningen University,

Droevendaalsesteeg 1, 6708 PB Wageningen, The Netherlands

C. A. Lévesque • T. L. Rintoul • C. F. J. Spies

Agriculture and Agri-Food Canada, Central Experimental Farm, Ottawa, ON, Canada

M. H. Laurence $\cdot$ B. A. Summerell

Royal Botanic Gardens and Domain Trust, Mrs Macquaries Rd, Sydney, New South Wales 2000, Australia
8. Diaporthe-AJ Dissanayake, D Udayanga, JY Yan, XH Li, KD Hyde

9. Diplodia AJ Dissanayake, JK Liu, JY Yan, XH Li, KD Hyde

10. Dothiorella JK Liu, KD Hyde

11. Fusarium-B Summerell, MH Laurence

12. Gilbertella-J Pawłowska, G Walther, M Wilk, M Gorczak, M Wrzosek

13. Lasiodiplodia JK Liu, KD Hyde

14. Mucor-J Pawłowska, G Walther, M Wilk, M Gorczak, M Wrzosek

15. Neofusicoccum AJ Dissanayake, JK Liu, JY Yan, XH Li, KD Hyde

16. Pestalotiopsis-SSN Maharachchikumbura SA Alias KD Hyde

17. Phyllosticta-N Zhou, L Cai

18. Phytophthora-F Martin, JE Blair

19. Puccinia-AR McTaggart, RG Shivas

20. Pyrenophora-HA Ariyawansa, KD Hyde

21. Pythium-CFJ Spies, TL Rintoul, AWAM de Cock, SL Glockling, CA Lévesque

22. Rhizopus-M Gorczak, G Walther, J Pawłowska, M Wilk, M Wrzosek

23. Stagonosporopsis-N Vaghefi, PWJ Taylor

24. Ustilago-AR McTaggart, $\mathrm{RG}$ Shivas

25. Verticillium-PWJ Taylor, PVR Nair

F. N. Martin

United States Department of Agriculture, Agriculture Research

Service, Salinas, CA, USA

E. H. C. McKenzie

Landcare Research, Private Bag, 92170 Auckland, New Zealand

P. V. R. Nair $\cdot$ P. W. J. Taylor $\cdot$ N. Vaghefi

Faculty of Veterinary and Agricultural Sciences, The University of Melbourne, Parkville, Victoria 3010, Australia

A. R. McTaggart • R. G. Shivas

Department of Agriculture, Fisheries and Forestry, Ecosciences

Precinct, Dutton Park, Queensland 4102, Australia

\section{R. B. Terhem}

Department of Forest Management, Faculty of Forestry, Universiti Putra Malaysia, 43400 Serdang, Malaysia

G. Walther

Leibniz-Institute for Natural Product Research and Infection

Biology-Hans-Knöll-Institute, Jena Microbial Resource Collection, Jena, Germany

G. Walther

Institute of Microbiology, Department of Microbiology and

Molecular Biology, University of Jena, Jena, Germany

M. Wilk

Inter-Faculty Interdisciplinary Doctoral Studies in Natural

Sciences and Mathematics, University of Warsaw, Warsaw, Poland 


\section{Introduction}

Fungi form a large and heterogeneous eukaryotic kingdom with an estimated 1.5 million extant species. While all fungi are heterotrophic, a wide range of nutritional strategies is known in the kingdom. Most of the ca. 100,000 described species of fungi are associated with plants through interactions including symbiosis, endophytism, saprotrophy and parasitism (Stajich et al. 2009; Delaye et al. 2013; Persoh 2013; Hyde et al. 2013b). As plant parasites, fungi can cause significant economic loss with far-reaching social implications and consequences in agriculture, forestry and natural ecosystems (Fisher et al. 2012). They are also part of the natural ecosystem and play an important role in regulation of species (Hantsch et al. 2014).

The study of plant pathogenic fungi-their systematics, biology, and biological control-has a long and rich history (Udayanga et al. 2011; Maharachchikumbura et al. 2011; Manamgoda et al. 2011). The inconspicuous nature of most fungi makes their study difficult. For example, there are typically few discriminatory morphological characters, which often makes precise field- or laboratory-based identification problematic. Morphological characters that vary with the choice of host or environmental conditions form an additional, serious concern. Many species are difficult or impossible to keep alive in culture, which excludes them from physiological and often molecular tests that are available. The formation of sexual fruiting bodies is rarely observed in many plant pathogenic fungi, which has hampered their integration in the fungal tree of life, resulting in the proliferation of polyphyletic asexual genera. The biology of most plant pathogenic fungi remains poorly understood.

The last 25 years have witnessed the emergence of molecular data (DNA sequences) as a source of high fidelity information that has revolutionised mycology (Nilsson et al. 2014). DNA sequences offer a means by which to examine and compare fungi, independent of morphological plasticity, cultivability, and host-pathogen interactions. Since integration of molecular data in the study of plant pathogenic fungi in the early 1990s, there has been a much deeper understanding of the ecology, distribution, and systematics of plant pathogenic fungi (Bridge et al. 2005; Wingfield et al. 2012; Udayanga et al. 2013; Manamgoda et al. 2013). The use of molecular data in diagnostics and systematic studies is not without pitfalls and shortcomings that researchers must consider (Kang et al. 2010; Ko et al. 2011; Hyde et al. 2013a). Synonyms, homonyms, asexual-sexual relationships, ambiguous and misidentified specimens are rife in the plant pathology literature and public databases of DNA sequences, which posses an enormous challenge for the unwary. Equally challenging is the large number of unidentified and seemingly unidentifiable fungi and fungal sequences isolated from plants (Kõljalg et al. 2013; Unterseher et al. 2013). Certain plant pathogenic fungi require specialized extraction and PCR primers/protocols in order to amplify their DNA. Furthermore, the same genetic markers that give unparalleled phylogenetic resolution in some fungi may give none whatsoever in others. Many plant pathology studies focus on single species of fungi, and recent revisions or synopses at the generic or higher levels are lacking for the majority of plant pathogenic fungi.

The present study seeks to facilitate present and future studies of plant pathogenic fungi by providing phylogenetic backbone trees for as many groups of fungi as our expertise allowed. Our ambition is to synthesize all recent molecular data, recommendations on correct names, type material, geo/ ecological observations, literature, and lineage-specific laboratory advice into a comprehensive, uniform molecular treatise for some of the largest and most widely encountered lineages of plant pathogenic fungi.

\section{Material and methods}

The phylogenetic analyses were performed based on up to date ex-type, ex-epitype or otherwise authentic sequence data available in GenBank as a concerted effort of the multiple contributors listed in authors section. By authentic sequence data we refer to those sequences used for names that are considered by the current working groups with the support of reliable publications in each genus as representative for each species. Sequences for the genes and genetic markers recommended for each genus were selected based on the current publications and have commonly been used for each of the genera (Table 1). The single gene sequence alignments were initially aligned with Clustal $\mathrm{X}$ and improved in MAFFTv. 7.017 (Katoh et al. 2002). Individual alignments were then concatenated and used to construct the backbone trees of each pathogenic genus listed. The phylogenetic analyses were performed for maximum parsimony in PAUP v. 4.0b10 (Swofford 2002), maximum likelihood in RAxML 7.4.2 Black Box or RAxMl GUI (Stamatakis 2006; Stamatakis et al. 2008), PhyML 3.0 (Guindon et al. 2010) or Bayesian inference in MrBayes v. 3.1.2 (Huelsenbeck and Ronquist 2001) as specified in the legend of each phylogenetic tree. The trees used to represent each genus were analyzed by multiple contributors based on the selection of genes in given publications under each description.

\section{Backbone tree for important phytopathogens}

Condensed synopses are provided for 25 important plant pathogenic group or genera. Each synopsis includes notes on background, species identifications and numbers, molecular phylogeny, recommended genetic markers, tables of species 


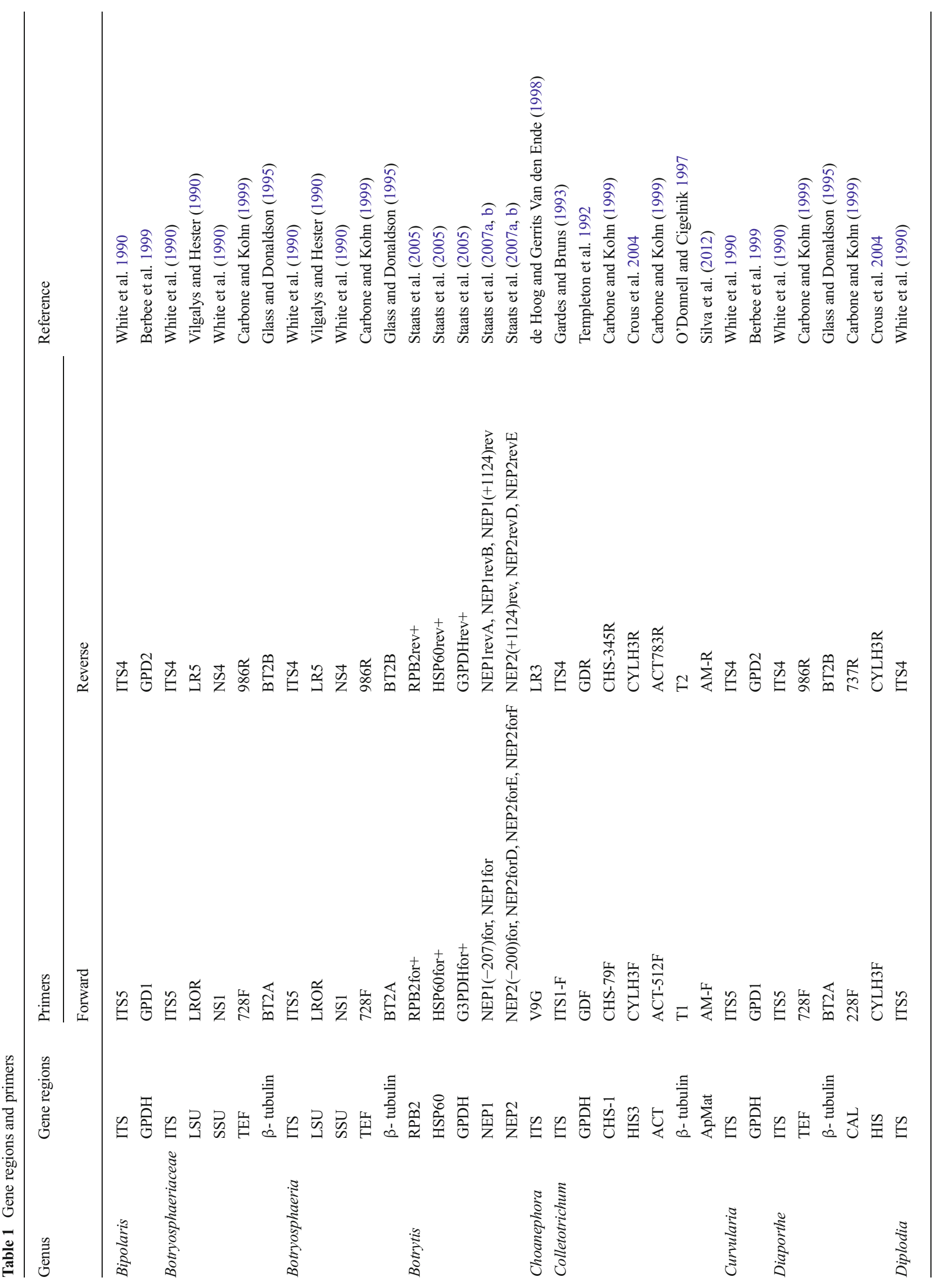




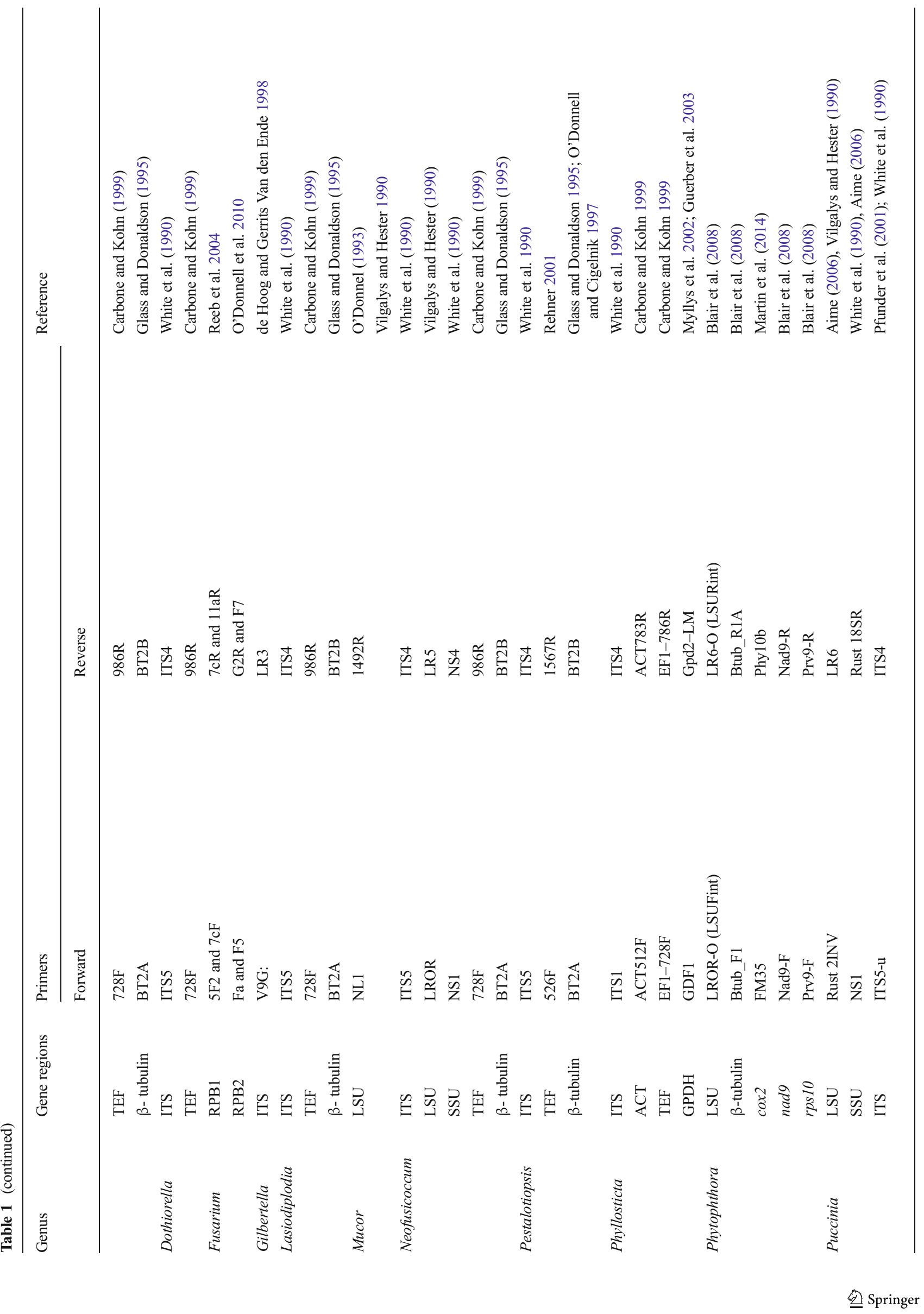




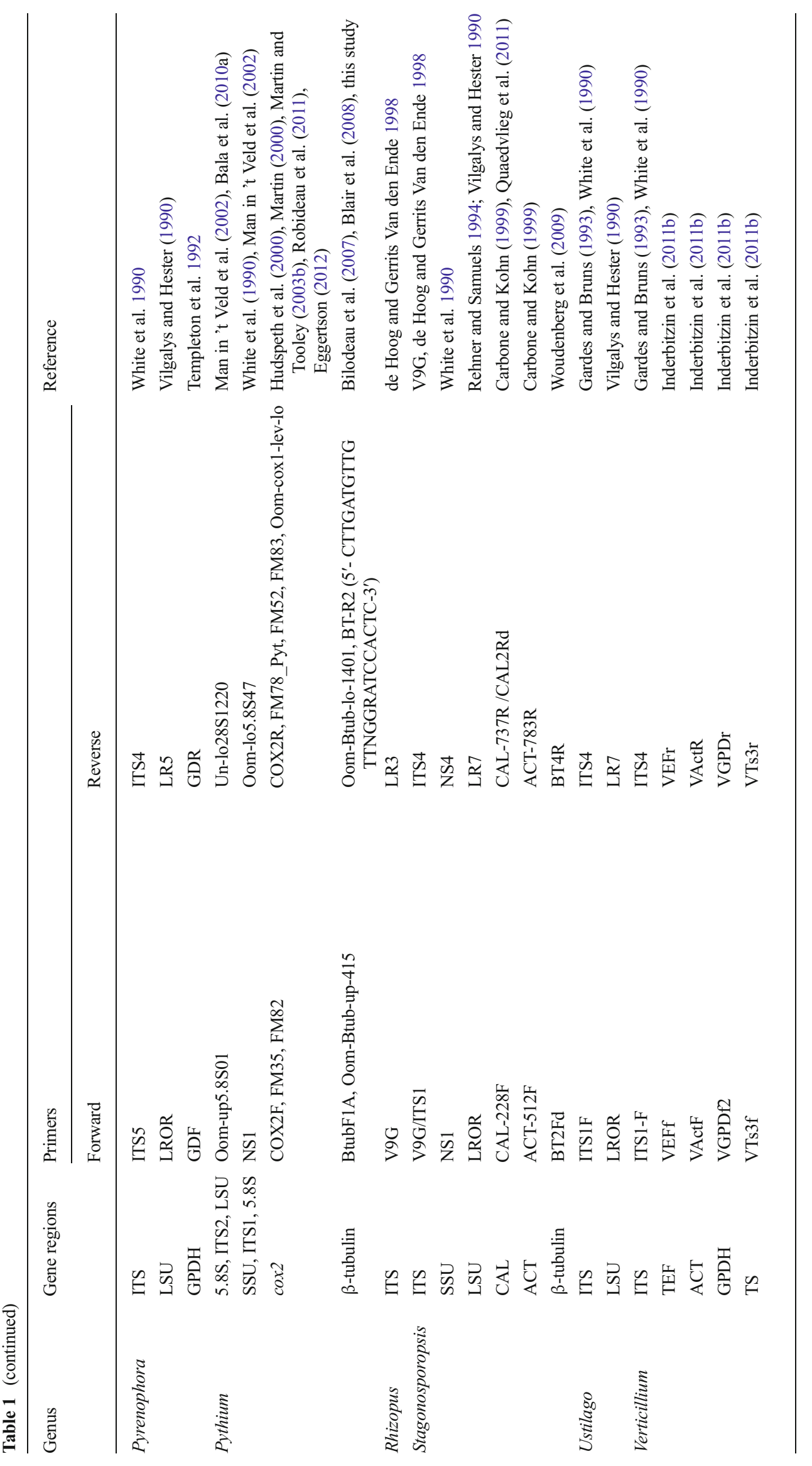


and the latest phylogenetic trees. We have not been able to include all important phytopathogenic genera (e.g. Alternaria, powdery mildews), but intend to update or add these in future publications. Interested parties should contact the corresponding author.

\section{Bipolaris}

\section{Background}

The genus Bipolaris belongs to the family Pleosporaceae of the Pleosporales in Dothideomycetes (Ascomycota). Bipolaris was introduced by Shoemaker (1959) and typified with B. maydis. Bipolaris species are pathogens, saprobes or endophytes mostly associated with grasses including cultivated cereals. Some species are important plant pathogens. The Bengal famine in 1943 was caused by $B$. oryzae and caused $90 \%$ of crop losses in India as well as the loss of 1.5 million human lives (Scheffer 1997). In the 1970s, around 19 million metric tons of wheat were destroyed in the USA due to southern corn leaf blight caused by B. maydis. Bipolaris sorokiniana causes southern leaf blotch, seedling blight and crown rot. Bipolaris sorokiniana was confirmed as the most economically important foliar pathogen in warm areas by the conference "Wheat for the national warm areas" held in Brazil in 1990. Bipolaris species have also been recorded from other plant families such as Alliaceae, Anacardiaceae, Araceae, Euphorbiaceae, Fabaceae, Malvaceae, Rutaceae and Zingiberaceae (Manamgoda et al. 2011).

Species identification and numbers

Bipolaris species were formerly described in Helminthosporium, however, species associated with grasses were morphologically distinct from $H$. velutinum, the type species (Luttrell 1963; Ellis 1971; Alcorn 1988). In several taxonomic refinements, these graminicolous Helminthosporium species were segregated into four genera; Bipolaris, Curvularia, Drechslera and Exserohilum (Sivanesan 1987). Later Subramanian and Jain (1966) placed all Bipolaris species in Drechslera, but this transfer was not accepted by later authors (Sivanesan 1987; Alcorn 1988). After molecular data became available, Drechslera was shown to be a phylogenetically different genus from Bipolaris (Berbee et al. 1999). The sexual state of Bipolaris is Cochliobolus (Drechsler 1934). Cochliobolus is the older name but conservation of the name Bipolaris over Cochliobolus has been proposed to avoid numerous name changes and Bipolaris is the most common name among plant pathologists (Manamgoda et al. 2012a; Rossman et al. 2013).
Morphology-based classification of Bipolaris species is challenging as the asexual state has overlapping conidia and conidiophore dimensions (Sivanesan 1987). A few Bipolaris species are known to be host-specific, while most of the other species are generalists (Manamgoda et al. 2011). However, some of the host-specific species are known only from limited collections. Therefore, the information on host-specificity may change with further collections. Interspecific compatibility can be observed between some taxa. For example, successful hybridization leading to ascospore production has been reported between B. zeicola and B. victoriae (Nelson 1960a, b) as well as between B. maydis and B. oryzae (Alcorn 1988). However, the latter species are definitively distinct phylogenetic species and also they are commonly recorded pathogens, causing different symptoms on their respective hosts. Identification of Bipolaris species using morphological and biological species concepts is not always correct and it is essential to use molecular tools in identifying species. Lack of DNA sequences from type material/ex-type cultures (or other authentic material) in public sequence databases is a problematic issue regarding the molecular identification of the Bipolaris species (Nilsson et al. 2014). Currently there are 118 Bipolaris names listed in Index Fungorum (2014), but nine of them do not belong to this genus based on phylogenetic evidence.

Molecular phylogeny

The first phylogenetic analysis for Bipolaris with its sister genus Curvularia was carried out by Berbee et al. (1999) and Goh et al. (1998) using a combined ITS and GPDH analysis. These studies showed that Bipolaris species cluster in two clades. Combined ITS, GPDH, EF and LSU phylogenetic analysis for Bipolaris and Curvularia by Manamgoda et al. (2012a) showed that Bipolaris and Curvularia cluster into two major clades. Nine Bipolaris species clustered with the generic type, Curvularia lunata Boedijn, while other species of Bipolaris clustered with the generic type, Bipolaris maydis. Accordingly, the nine Bipolaris species were moved to Curvularia, and Bipolaris was maintained as a distinct genus based on the generic type and those species that clustered with it. In this section we provide a backbone tree (Table 2, Fig. 1) for Bipolaris using combined ITS and GPDH sequence data.

Recommended genetic markers

GPDH is the best single genetic marker for the genus Bipolaris (Manamgoda et al. 2012a). Combined ITS, EF and GPDH can resolve almost all species of Bipolaris currently known from sequence data (Manamgoda et al. 2012a). 
Table 2 Bipolaris. Details of the isolates used in the phylogenetic tree

\begin{tabular}{|c|c|c|c|c|c|}
\hline \multirow[t]{2}{*}{ Species } & \multirow[t]{2}{*}{ Isolate } & \multirow[t]{2}{*}{ Host } & \multicolumn{3}{|c|}{ GenBank accession number } \\
\hline & & & ITS & GPDH & TEF \\
\hline Bipolaris chloridis & CBS 242.77* & Chloris gayana & JN192372 & JN600961 & \\
\hline B. cynodontis & ICMP 6128* & Cynodon dactylon & JX256412 & JX276427 & JX266581 \\
\hline B. drechsleri & CBS 136207 & Microstegium vimineum & KF500530 & KF500533 & \\
\hline B. drechsleri & CBS 136208 & Microstegium vimineum & KF500532 & KF500535 & \\
\hline B. eleusines & $8749 C^{*}$ & Eleusine indica & AF081451 & AF081405 & \\
\hline B. luttrellii & $14643-1^{*}$ & Dactyloctenium aegyptium & AF071350 & AF081402 & \\
\hline B. maydis & $\mathrm{C5}^{*}$ & Zea mays & AF071325 & AF081380 & \\
\hline B. melinidis & BRIP 12898 & Melinis minutiflora & JN601035 & JN600972 & \\
\hline B. microlenae & CBS 280.91 & Microlaena stipoides & JN601032 & JN600974 & JN601017 \\
\hline B. oryzae & MFLUCC 100694* & Oryza sativa & $\mathrm{JX} 256413$ & JX276428 & JX266582 \\
\hline B. oryzae & MFLUCC 100716 & O. sativa & JX256415 & JX276429 & JX266584 \\
\hline B. peregianensis & BRIP 12970 & Cynodon dactylon & JN601034 & JN600977 & JN601022 \\
\hline B. sorghicola & MAFF511378* & Sorghum sudanense & AF071332 & AF081387 & \\
\hline B. sorokiniana & ICMP 6233a & Lolium perenne & JX256418 & & \\
\hline B. urochloae & DAOM 171970* & Urochloa panicoides & AF071334 & AF081389 & \\
\hline B. victoriae & CBS $174.57^{*}$ & Avena sativa & JN601027 & & JN601005 \\
\hline Curvularia lunata & CBS 730.96 & Unknown & JX256429 & JX276441 & JX266596 \\
\hline
\end{tabular}

Ex-type (ex-epitype) strains are bolded and marked with an * and voucher stains are bolded

Fig. 1 Phylogram generated from parsimony analysis based on combined ITS and GPDH sequenced data of Bipolaris. Bootstrap support values greater than $50 \%$ are indicated above the nodes. The ex-type (ex-epitype) and voucher strains are in bold. The tree is rooted with Curvularia lunata

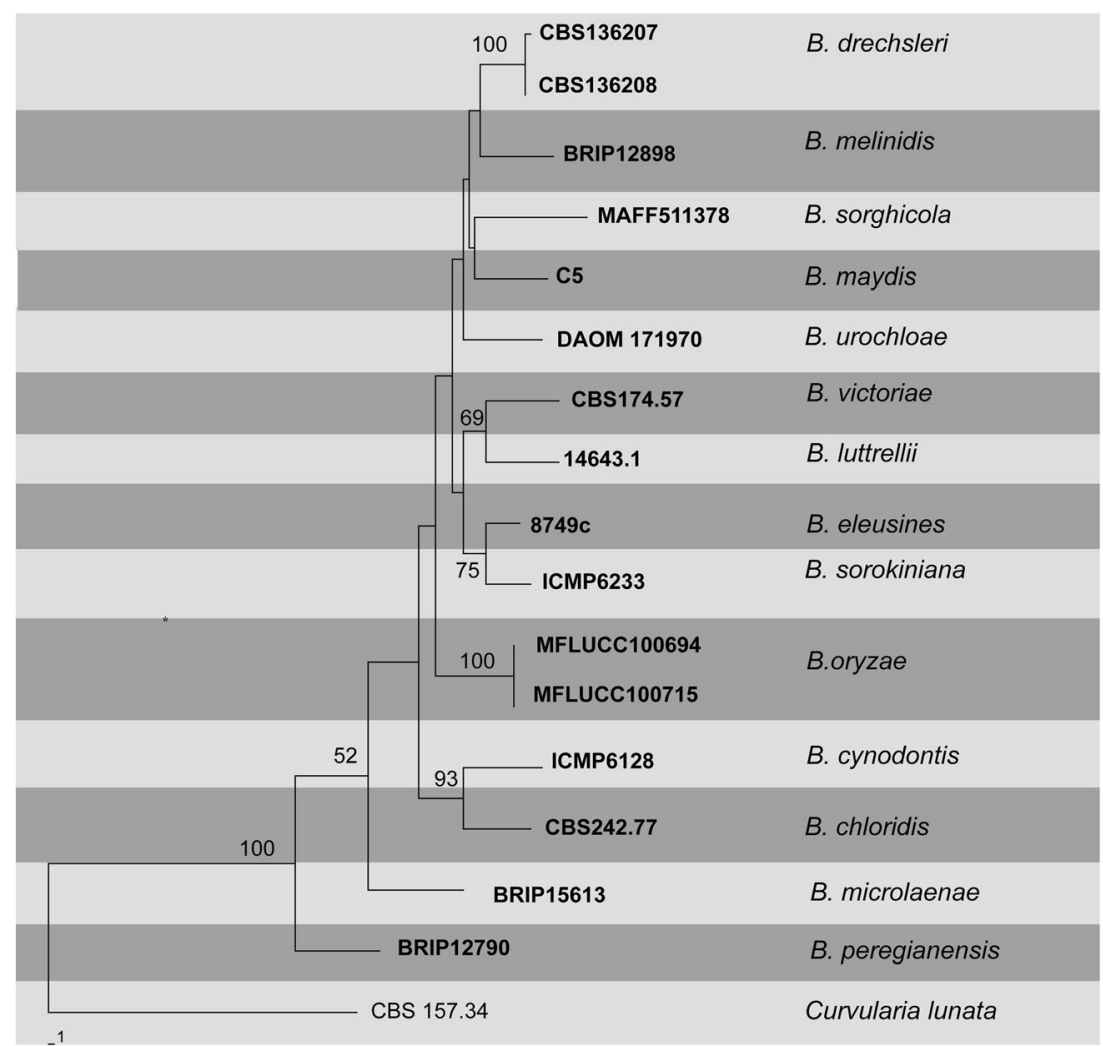




\section{Botryosphaeriaceae}

The family Botryosphaeriaceae is classified in the order Botryosphaeriales of the Dothideomycetes (Ascomycota). Members of the fungal family Botryosphaeriaceae were described in the 1820's as species of Sphaeria (Fr.) (Crous et al. 2006; Schoch et al. 2006). There have subsequently been various treatments of the family. von Arx and Müller (1954) included 15 genera, but later reduced it to 14 genera (von Arx and Müller 1975). Barr (1987) included only nine genera, which are mostly different from those of von Arx and Müller (1954). Hawksworth et al. (1995) listed five genera. Lumbsch and Huhndorf (2010) included 11 genera, while Hyde et al. (2011) and Wijayawardene et al. (2012) listed 16 genera. Liu et al. (2012) included 17 genera in the family based on molecular data and examination of generic types. Species of Botryosphaeriaceae range in habit from saprobic to parasitic or endophytic (Smith et al. 1996; Denman et al. 2000; Phillips et al. 2006; Slippers and Wingfield 2007; Huang et al. 2008; Pérez et al. 2010; Ghimire et al. 2011; González and Tello 2011). Members are cosmopolitan in distribution and occur on a wide range of monocotyledonous, dicotyledonous and gymnosperm hosts; on woody branches, herbaceous leaves, stems and culms of grasses; and on twigs and in the thalli of lichens (Barr 1987; Denman et al. 2000; Mohali et al. 2007; Lazzizera et al. 2008; Marincowitz et al. 2008).

Species identification and numbers

Currently, more than 2,000 species names are linked to Botryosphaeriaceae, including sexual and asexual states of Diplodia, Botryosphaeria, Fusicoccum, Dothiorella, Lasiodiplodia and Sphaeropsis. Identification to genus and species is presently undergoing major revision and it is likely that many older names will not be used in modern treatments. Identification of species in Botryosphaeria, Diplodia, Dothiorella, Lasiodiplodia and Neofusicoccum are dealt separately under this family entry.

\section{Molecular phylogeny}

Recent advances in DNA-based molecular techniques have begun to provide efficient tools to characterize the presence and identity of species of the Botryosphaeriaceae (Slippers and Wingfield 2007). Studies applying these tools are revealing significantly greater diversity on some hosts than was previously realized. Recent studies on the taxonomy of Botryosphaeria have employed molecular methods to reveal phylogenetic relationships among species (Jacobs and Rehner 1998) and to resolve species complexes (Denman et al. 2003; Alves et al. 2004; Phillips et al. 2005). Two major clades corresponding to species with Diplodia and Fusicoccum asexual morphs were revealed based on ITS phylogenies (Jacobs and Rehner 1998; Denman et al. 2003). Later studies, including additional species and a larger suite of genetic markers, supported this grouping (Zhou and Stanosz 2001; Alves et al. 2004; Slippers et al. 2004d). Lasiodiplodia has been treated as a distinct genus from Diplodia by many authors due to its distinct phylogeny (usually ITS or EF-1 $\alpha$ ) and morphology (striated or smooth conidia and presence or absence of pseudoparaphyses). Pavlic et al. (2004) employed morphological and phylogenetic data to separate Lasiodiplodia from Diplodia. The value of the introndominated sequences of the ITS, $\beta$-tubulin and TEF markers (on which most previous studies were based) to infer phylogenetic relationships across the diversity of the genus is, however, unclear. The more conserved mtSSU data have, for example, suggested that B. dothidea and B. corticis (Demaree and Wilcox) are unrelated to Fusicoccum (Zhou and Stanosz 2001) even though they are typically assigned to this genus.

Most taxonomic studies on Botryosphaeriaceae using molecular data have employed ITS rDNA phylogenies, but this single marker can underestimate the species diversity among closely related or cryptic species. Multiple gene sequence concordance phylogenies have therefore been applied to identify cryptic or previously overlooked species of Botryosphaeriaceae (Slippers et al. 2004a, b, c; Burgess et al. 2005; Phillips et al. 2005). As the elongation fctor 1alpha (TEF) gene is consistently more variable than the ITS rDNA region in these fungi, most commonly data from TEF have been combined with ITS sequence data. Unfortunately no single genetic region is sufficient to distinguish all species, because not all single nucleotide polymorphisms (SNPs) represent restriction sites, especially between some closely related species.

The Botryosphaeriaceae has been separated into numerous distinct genera (Crous et al. 2006; Liu et al. 2012). A natural classification is needed for a more stable and accurate taxonomic framework and this will strongly influence the understanding of the ecology of the Botryosphaeriaceae. In this part we provide a tree to the genera of Botryosphaeriaceae (Table 3, Fig. 2) and deal with the important genera Botryosphaeria, Diplodia, Dothiorella, Lasiodiplodia and Neofusicoccum in the following parts.

Recommended genetic markers

- $\quad$ LSU, SSU, $\beta$-tubulin and ITS-generic level

- $\mathrm{TEF}-$ species level

LSU has been shown to be suitable for distinguishing many ascomycetes at the generic level due to its relatively conserved nature (Crous et al. 2006; Schoch et al. 2006; Hibbett et al. 2007). The study of Liu et al. (2012) suggested that the combined TEF and $\beta$ - tubulin gene 
Table 3 Botryosphaeriaceae. Details of the isolates used in the phylogenetic tree

\begin{tabular}{|c|c|c|c|c|c|c|}
\hline Species & Isolate & ITS & $\beta$ - tubulin & TEF & SSU & LSU \\
\hline Barriopsis fusca & CBS 174.26* & EU673330 & EU673109 & EU673296 & EU673182 & DQ377857 \\
\hline B. iraniana & IRAN1448C* & KF766150 & KF766127 & FJ919652 & KF766231 & KF766318 \\
\hline Botryobambusa fusicoccum & MFLUCC 11-0143* & JX646792 & - & JX646857 & JX646826 & JX646809 \\
\hline Botryosphaeria agaves & MFLUCC 11-0125* & JX646791 & JX646841 & JX646856 & JX646825 & JX646808 \\
\hline B. corticis & CBS 119047* & DQ299245 & EU673107 & EU017539 & EU673175 & EU673244 \\
\hline B. dothidea & CMW 8000* & AY236949 & AY236927 & AY236898 & EU673173 & AY928047 \\
\hline B. fusispora & MFLUCC 10-0098* & JX646789 & JX646839 & JX646854 & JX646823 & JX646806 \\
\hline Cophinforma eucalypti & MFLUCC 11-0425* & JX646800 & JX646848 & JX646865 & JX646833 & JX646817 \\
\hline Diplodia corticola & CBS 112549* & AY259100 & DQ458853 & AY573227 & EU673206 & AY928051 \\
\hline D. cupressi & CBS 168.87* & DQ458893 & DQ458861 & DQ458878 & EU673209 & EU673263 \\
\hline D. mutila & CBS 112553* & AY259093 & DQ458850 & AY573219 & EU673213 & AY928049 \\
\hline Dothiorella iberica & CBS 115041* & AY573202 & EU673096 & AY573222 & EU673155 & AY928053 \\
\hline D. sarmentorum & IMI 63581b* & AY573212 & EU673102 & AY573235 & EU673158 & AY928052 \\
\hline D. thailandica & MFLUCC11-0438* & JX646796 & JX646844 & JX646861 & JX646829 & JX646813 \\
\hline Endomelanconiopsis endophytica & CBS 120397* & KF766164 & KF766131 & EU683637 & KF766249 & EU683629 \\
\hline E. microspora & CBS 353.97* & KF766165 & - & EU683636 & KF766250 & KF766330 \\
\hline Lasiodiplodia crassispora & CBS 118741* & DQ103550 & EU673133 & EU673303 & EU673190 & DQ377901 \\
\hline L. gonubiensis & CBS 115812* & DQ458892 & DQ458860 & DQ458877 & EU673193 & DQ377902 \\
\hline L. parva & CBS 494.78* & EF622084 & EU673114 & EF622064 & EU673201 & EU673258 \\
\hline L. pseudotheobromae & CBS 116459* & EF622077 & EU673111 & EF622057 & EU673199 & EU673256 \\
\hline L. theobromae & CBS 164.96* & AY640255 & EU673110 & AY640258 & EU673196 & EU673253 \\
\hline Macrophomina phaseolina & CBS 227.33* & KF766195 & - & KF766422 & KF766281 & KF766364 \\
\hline Neodeightonia palmicola & MFLUCC 10-0822* & HQ199221 & - & - & HQ199223 & HQ199222 \\
\hline N. phoenicum & CBS 122528* & EU673340 & EU673116 & EU673309 & EU673205 & EU673261 \\
\hline N. subglobosa & MFLUCC11-0163* & JX646794 & JX646842 & JX646859 & - & JX646811 \\
\hline Neofusicoccum luteum & CBS 110299* & AY259091 & DQ458848 & AY573217 & EU673148 & AY928043 \\
\hline N. mangiferae & CBS 118532* & AY615186 & AY615173 & DQ093220 & EU673154 & DQ377921 \\
\hline N. parvum & CMW 9081* & AY236943 & AY236917 & AY236888 & EU673151 & AY928045 \\
\hline Neoscytalidium dimidiatum & IP127881 & AF258603 & FM211167 & EU144063 & AF258603 & DQ377925 \\
\hline N. hyalinum & CBS145.78* & KF531816 & KF531796 & KF531795 & KF531815 & DQ377922 \\
\hline N. novaehollandiae & WAC 12691* & EF585543 & - & EF585574 & - & EF585548 \\
\hline Phaeobotryon mamane & CPC 12440* & EU673332 & EU673121 & EU673298 & EU673184 & EU673248 \\
\hline Pseudofusicoccum adansoniae & WAC 12689* & EF585534 & - & EF585567 & - & EF585554 \\
\hline P. ardesiacum & CMW 26159* & KF766221 & - & EU144075 & KF766307 & KF766387 \\
\hline P. kimberleyense & CMW 26156* & KF766222 & - & EU144072 & KF766308 & KF766388 \\
\hline P. stromaticum & CMW13434* & KF766223 & EU673094 & KF766437 & KF766309 & KF766389 \\
\hline Spencermartinsia viticola & CBS 117009* & AY905554 & EU673104 & AY905559 & EU673165 & DQ377873 \\
\hline Sphaeropsis citrigena & ICMP 16812* & EU673328 & EU673140 & EU673294 & EU673180 & EU673246 \\
\hline S. eucalypticola & CBS 133993* & JX646802 & JX646850 & JX646867 & JX646835 & JX646819 \\
\hline S. porosa & CBS 110496* & AY343379 & EU673130 & AY343340 & EU673179 & DQ377894 \\
\hline S. visci & CBS 186.97* & EU673325 & EU673128 & EU673293 & EU673178 & DQ377868 \\
\hline Tiarosporella graminis var. karoo & CBS 118718 & KF531828 & KF531808 & KF531807 & KF531827 & DQ377939 \\
\hline T. tritici & CBS 118719* & KF531830 & KF531810 & KF531809 & KF531829 & DQ377941 \\
\hline T. urbis-rosarum & CMW 36479* & JQ239408 & JQ239382 & JQ239395 & - & JQ239421 \\
\hline Melanops tulasnei & CBS 116805* & FJ824769 & - & KF766423 & KF766474 & KF766365 \\
\hline
\end{tabular}

Ex-type (ex-epitype) strains are bolded and marked with an * and voucher stains are bolded 
Fig. 2 Phylogram generated from parsimony analysis based on combined SSU, LSU, TEF, $\beta$ tubulin and ITS sequence data of Botryosphaeriaceae. Parsimony bootstrap support values greater than $50 \%$ and Bayesian posterior probabilities greater than 0.5 are indicated above the nodes. The ex-type (ex-epitype) and voucher strains are in bold. The scale bar indicates ten changes. The tree is rooted with Melanops tulasnei CBS 116805

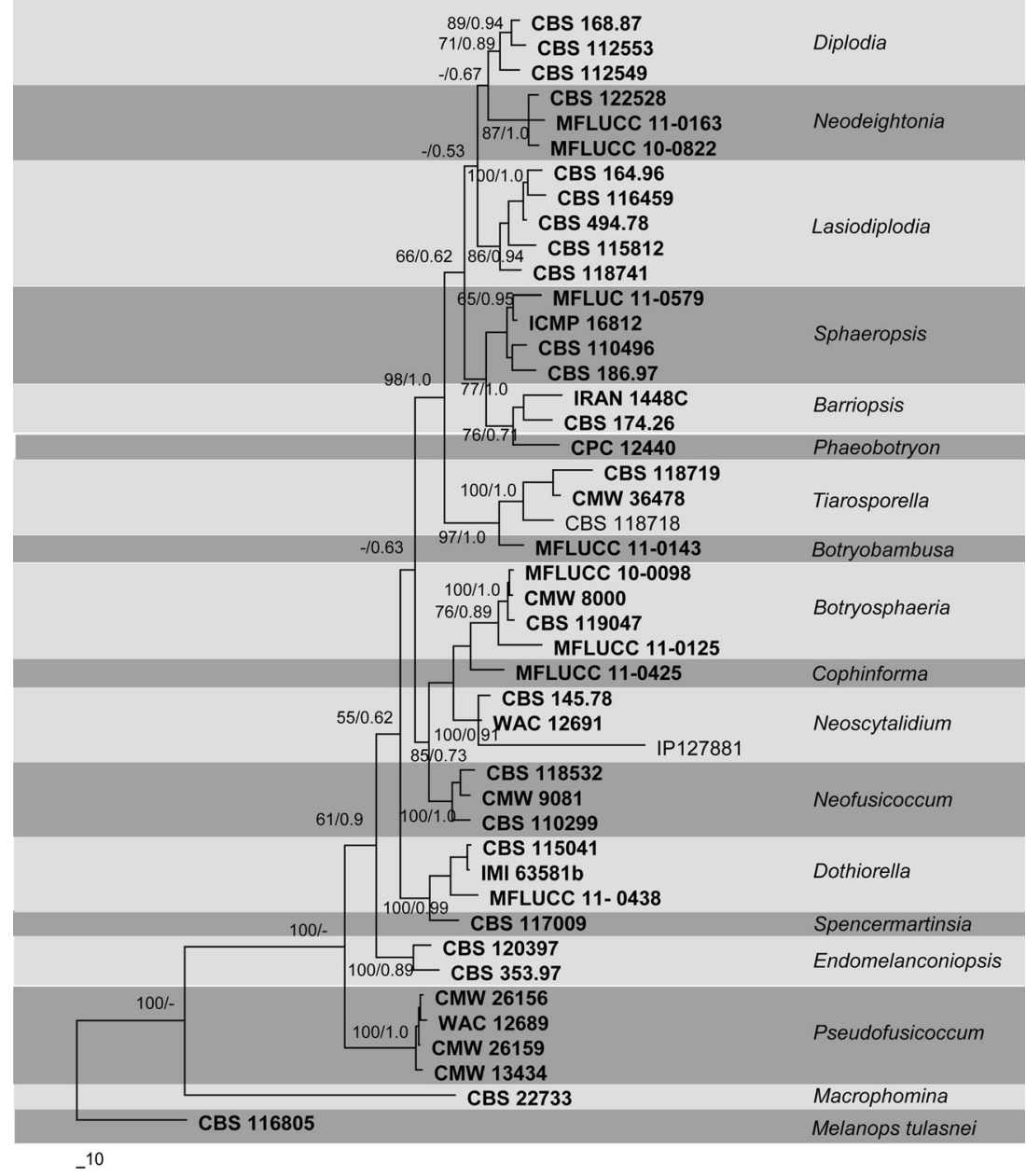

analysis is best for delimiting genera of Botryosphaeriaceae. It has also been recommended that the RPB2 gene should be considered in similar combined analyses of genus and species levels of Botryosphaeriaceae (Pavlic et al. 2009a, b).

\section{Botryosphaeria}

\section{Background}

The genus Botryosphaeria (Botryosphaeriaceae) was introduced by Cesati and de Notaris (1863), amended by Saccardo (1877), and is based on the type species Botryosphaeria dothidea (Barr 1972; Slippers et al. 2004c). Species in Botryosphaeria were described largely on the basis of the morphology of their ascomata and host associations, and this has led to a proliferation of names. von Arx and Müller (1954) examined 183 taxa of Botryosphaeriales and reduced them to 11 species, with extensive synonymies under $B$. dothidea and $B$. quercuum, together with nine new combinations. In later studies these synonymies were not always accepted (Shoemaker 1964; Sivanesan 1984; Slippers et al. 2004a).
Slippers et al. (2004b) epitypified the type species Botryosphaeria dothidea based on morphology and phylogeny (combined ITS, TEF and $\beta$-tubulin analysis) and this enabled a better resolution of species. Species of Botryosphaeria occur on a wide range of monocotyledonous, dicotyledonous and gymnosperm hosts, on woody branches, herbaceous leaves and grasses (Barr 1987). The life styles may be saprobic, parasitic and endophytic (Smith et al. 1996; Denman et al. 2000), and species can cause die-back and canker diseases of numerous woody hosts (von Arx 1987). Species in the genus Botryosphaeria have hyaline to dark ascospores, multiloculate ascomata, and a wide range of asexual morphs that typically lack a mucoid sheath and apical appendage.

Species identification and numbers

More than 18 asexual genera have been associated with Botryosphaeria. A phylogenetic study based on part of the $28 \mathrm{~S}$ ribosomal DNA gene together with morphological characters revealed that Botryosphaeria comprises several distinct lineages, each comprising individual genera (Crous et al. 2006). In that study, only $B$. dothidea and $B$. corticis were retained in Botryosphaeria, while most species were reduced 
to synonymy under Diplodia (conidia mostly ovoid, pigmented, thick-walled), or Fusicoccum (conidia mostly fusoid, hyaline, thin-walled). Studies have also linked Botryosphaeria to species with pigmented, septate ascospores and Dothiorella asexual morphs, or Fusicoccum asexual morphs with Dichomera synanamorphs. More recently $B$. agaves (which has been epitypified), B. fusispora (Liu et al. 2012), and B. schariffi (Abdollahzadeh et al. 2013) were described in the genus Botryosphaeria, while B. fabicerciana was illustrated from Eucalyptus sp. in southern China (Chen et al. 2011). Phylogenetically, B. fabicerciana is closely related to $B$. corticis, $B$. dothidea, $B$ schariffi and B. ramosa. The present phylogenetic analysis was performed based on up to date holotype or ex-epitype sequence data available in GenBank (Table 4).

\section{Molecular phylogeny}

Recent studies on the taxonomy of Botryosphaeria have employed molecular methods to reveal phylogenetic relationships among species (Jacobs and Rehner 1998) and to resolve species complexes (Smith and Stanosz 2001; Phillips et al. 2002, 2005; Denman et al. 2003; Alves et al. 2004; Slippers et al. 2004c). Studies including additional species and a larger suite of DNA-based markers supported this grouping (Zhou and Stanosz 2001; Alves et al. 2004; Slippers et al. 2004c). Based on combined ITS and TEF sequence data seven species are currently recognised in Botryosphaeria (Phillips et al. 2013). The phylogenetic tree constructed with holotype or ex-epitype sequences is presented in Fig. 3.

Recommended genetic markers

- LSU, SSU and ITS-generic level

- $\beta$-tubulin and TEF-species level

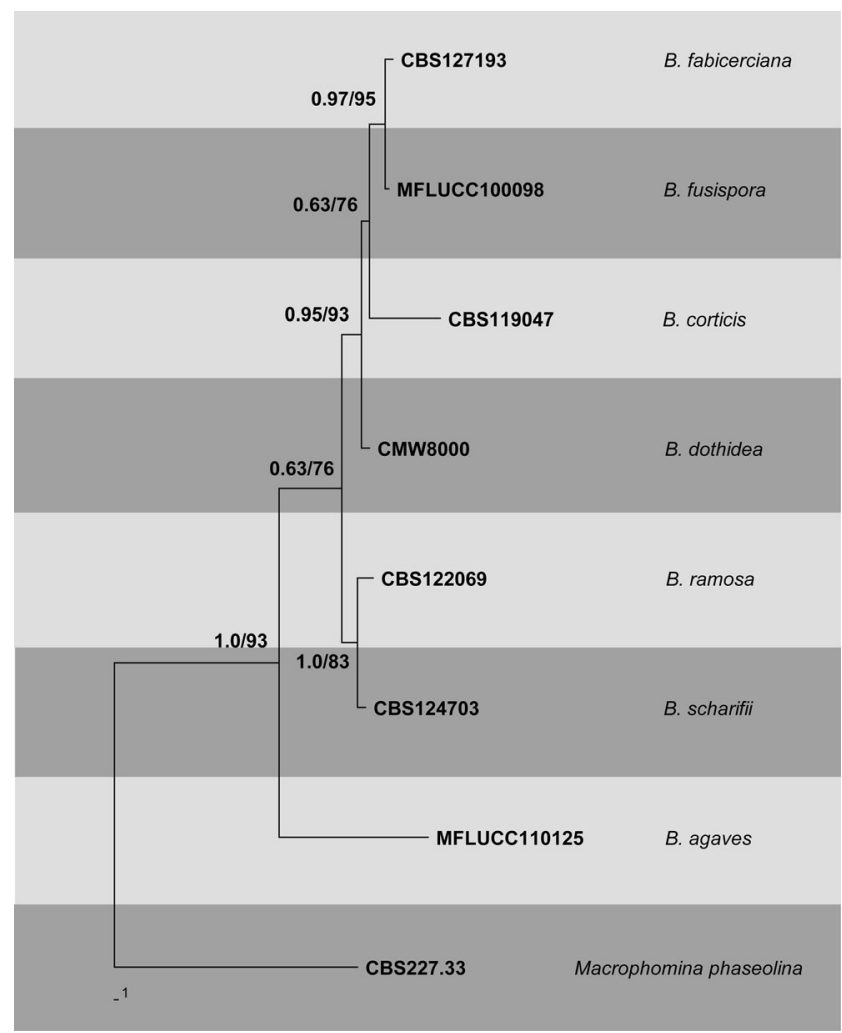

Fig. 3 Phylogram generated from parsimony analysis based on combined ITS, TEF, $\beta$ - tubulin, LSU and SSU sequenced data of Botryosphaeria. Parsimony bootstrap support values greater than $50 \%$ and Bayesian posterior probabilities greater than 0.5 are indicated near the nodes. The ex-type (ex-epitype) and voucher strains are in bold. The tree is rooted with Macrophomina phaseolina CBS 227.33

\section{Botrytis}

Background

Erected by Micheli in 1729, the genus Botrytis is one of the first described genera of fungi. Persoon (1801) designated five

Table 4 Botryosphaeria. Details of the ex-type and voucher isolates used in the phylogenetic tree

\begin{tabular}{|c|c|c|c|c|c|c|}
\hline \multirow[t]{2}{*}{ Species } & \multirow[t]{2}{*}{ Isolate } & \multicolumn{5}{|c|}{ GenBank accession numbers } \\
\hline & & SSU & ITS & LSU & TEF & $\beta$-tubulin \\
\hline Botryosphaeria agaves & CBS 133992* & JX646825 & JX646825 & JX646808 & JX646856 & JX646841 \\
\hline B. corticis & CBS 119047* & EU673175 & DQ299245 & EU673244 & EU017539 & EU673107 \\
\hline B. dothidea & CBS 115476* & EU673173 & AY236949 & AY928047 & AY236898 & AY236927 \\
\hline B. fabicerciana & CBS 127193* & N/A & HQ332197 & N/A & HQ332213 & N/A \\
\hline B. fusispora & MFLUCC 10-0098* & JX646823 & JX646789 & JX646806 & JX646854 & JX646839 \\
\hline B. ramose & CBS 122069* & N/A & EU144055 & $\mathrm{N} / \mathrm{A}$ & EU144070 & N/A \\
\hline B. scharifii & CBS 124703* & N/A & JQ772020 & $\mathrm{N} / \mathrm{A}$ & JQ772057 & N/A \\
\hline Macrophomina phaseolina & CBS 227.33* & KF531823 & KF531825 & DQ377906 & KF531804 & KF531806 \\
\hline
\end{tabular}

Type strains and voucher stains are bolded 
species under the binomial system of Linnaeus, validated the genus, and included one of Micheli's species, $B$. cinerea, so named by Von Haller (1771). The genus name refers to the structure of the macroconidia, which rise and form clusters with the shape of grape bunches: 'botryose'. Botrytis is the asexual stage of Botryotinia. The Botrytis community has in its recent meeting (Italy, 23-28 June 2013) unanimously recommended the exclusive use of the asexual name Botrytis over Botryotinia, the name of the sexual stage, since Botrytis is historically the oldest name and it is commonly used by plant pathologists, breeders and growers. In line with this recommendation, a list of generic names of fungi for protection under the International Code of Nomenclature has included this genus under the name Botrytis and not Botryotinia (Kirk et al. 2013). We therefore follow this recommendation in this paper and use Botrytis. Species of the genus Botrytis infect $>250$ host species, including major greenhouse and field crops such as tomato, grape, strawberry, onion and ornamentals such as rose, lily, and tulip (Staats et al. 2005). Most Botrytis species are necrotrophic pathogens that (are able to) kill the host tissue during infection. Interestingly, an endophytic species (B. deweyae) has recently been discovered, which under appropriate conditions can cause 'spring sickness' in ornamental Hemerocallis (daylily) hybrids (GrantDownton et al. 2014). Botrytis cinerea is the best-studied species in the genus (Williamson et al. 2007) and was recently elected as the second most important plant pathogenic fungal species (Dean et al. 2012).

In the asexual state, Botrytis produces different tissues including mycelia, macroconidia, microconidia, and sclerotia. Macroconidia are ellipsoidal to obovoid shape and rise from conidiophore branches into botryose clusters. They are pale brown and range in size from $9-23 \times 8-15 \mu \mathrm{m}$. Microconidia are more sphaerical and much smaller than macroconidia (about $1 \mu \mathrm{m}$ ), and function as male spermatia (Groves and Loveland 1953; Faretra et al. 1988; Beever and Parkes 1993; Fukumori et al. 2004). Sclerotia are irregularly hemispherical, convex and normally have a concave surface. They are usually black, with sizes ranging between 1 and $10 \mathrm{~mm}$ (Whetzel 1945), and function as survival structures during winter and serve as maternal parent in the production of apothecia.

The sexual state forms fruiting bodies called apothecia: a cup- or open saucer-shaped ascoma at the top of a stalk, that acts as a platform to discharge ascospores from the ascus. Botrytis apothecia vary in size depending on the species, between 1 and $25 \mathrm{~mm}$ high and 1-6 mm diam. (Hennebert and Groves 1963; Bergquist and Lorbeer 1972). Apothecia are brown and become darker when mature (Hennebert and Groves 1963; Bergquist and Lorbeer 1972; Faretra and Antonacci 1987). Generally multiple apothecia can develop on a single sclerotium. Mature apothecia normally can be observed 2 months after fertilization (Faretra et al. 1988; Hennebert and Groves 1963; Van Der Vlugt-Bergmans et al.
1993). In the genus Botrytis, both homothallic and heterothallic reproductive lifestyles have been reported. Homothallic (selffertile) species can undergo sexual reproduction and form apothecia and generate progeny in the absence of a mating partner, e.g. B. porri and B. globosa (Buchwald 1953; Elliott 1964). By contrast, heterothallic (self-sterile, self-incompatible) species require isolates with compatible mating types in order to complete the sexual cycle. $B$. cinerea is considered a typical heterothallic fungus (Elliott 1964; Faretra et al. 1988). Mating is controlled by the mating type locus with two alleles, MAT1-1 and MAT1-2 (Faretra et al. 1988), each carrying two distinct, non-homologous genes (Amselem et al. 2011).

Species identification and numbers

Approximately half of the Botrytis species are named after the host that they are derived from (listed in Table 5). One hybrid species, $B$. allii which originated from hybridization between B. byssoidea and B. aclada (Nielsen and Yohalem 2001; Yohalem et al. 2003) could not be placed in the phylogeny (Staats et al. 2005) and was omitted from Table 3. The genus Botrytis predominantly comprises narrow host range pathogens that infect a single, or a few (often related) host species. There are two exceptions to this rule: $B$. cinerea can infect more than 200 host species (Jarvis 1977), and B. pseudocinerea has been isolated from several unrelated host species (Fournier et al. 2005; Leroch et al. 2013).

The taxonomic classification and nomenclature in Botrytis have rarely been comprehensively reviewed. Morphological descriptions of most species have been published in the 19th and first half of the 20th century in separate papers, many of which are not easily accessible. The most recent taxonomic compilation of the genus is in a monograph by Jarvis (1977), which also lists $\sim 25$ excluded or doubtful species, and briefly describes the historical debates between mycologists and the confusion in classification of Botrytis species. Morphological features were often inadequate to distinguish species and the variability among isolates of the same species further complicated the situation (Jarvis 1977). Recent studies have identified B. cinerea and B. pseudocinerea as species that are very similar in morphology, yet recognized as distinct taxa that diverged several million years ago (Walker et al. 2011). Even more puzzling, the morphology and narrow host range of $B$. fabae separate this species clearly from $B$. cinerea and $B$. pseudocinerea, but phylogenetic studies revealed it to be a sister species of $B$. cinerea (see below). These examples illustrate the limitations of morphological characters for Botrytis species identification.

Molecular phylogeny

Holst-Jensen et al. (1998) were the first to use nuclear ribosomal ITS sequences to infer a phylogeny of the family 
Table 5 Botrytis. Details of the isolates used in the phylogenetic tree

\begin{tabular}{|c|c|c|c|c|c|c|c|}
\hline \multirow[t]{2}{*}{ Species } & \multirow[t]{2}{*}{ Isolate } & \multirow[t]{2}{*}{ Host } & \multicolumn{5}{|c|}{ GenBank accession numbers } \\
\hline & & & RPB2 & HSP60 & G3DPDH & NEP1 & NEP2 \\
\hline Botrytis aclada & MUCL8415 & Allium spp. & AJ745664 & AJ716050 & AJ704992 & AM087059 & AM087087 \\
\hline B. byssoidea & MUCL94 & Allium spp. & AJ745670 & AJ716059 & AJ704998 & AM087045 & AM087079 \\
\hline B. calthae & MUCL1089 & Caltha palustris & AJ745672 & AJ716061 & AJ705000 & $\mathrm{AM} 087031^{\mathrm{a}}$ & AM087088 \\
\hline B. cinerea & MUCL87 & $>200$ species & AJ745676 & AJ716065 & AJ705004 & DQ211824 ${ }^{\mathrm{a}}$ & $\mathrm{DQ} 211825^{\mathrm{a}}$ \\
\hline B. caroliniana & CB15* & Rubus fruticosus & JF811590 & JF811587 & JF811584 & JF811593 & NA \\
\hline B. convoluta & MUCL11595 & Iris spp. & AJ745680 & AJ716069 & AJ705008 & AM087035 & AM087062 \\
\hline B. croci & MUCL436 & Crocus spp. & AJ745681 & AJ716070 & AJ705009 & AM087047 & AM087065 \\
\hline B. deweyae & CBS134649* & Hemerocallis spp. & HG799518 & HG799519 & HG799521 & HG799527 & HG799520 \\
\hline B. elliptica & BE9714 & Lilium spp. & AJ745684 & AJ716073 & AJ705012 & AM087049 & AM087080 \\
\hline B. fabae & MUCL98 & Vicia spp. & AJ745686 & AJ716075 & AJ705014 & DQ211829 & DQ211831 \\
\hline B. ficariarum & MUCL376 & Ficaria verna & AJ745688 & AJ716077 & AJ705016 & AM087056 & AM087085a \\
\hline B. fabiopsis & BC-2* & Vicia faba & EU514473 & EU514482 & EU519211 & NA & NA \\
\hline B. galanthina & MUCL435 & Galanthus spp. & AJ745689 & AJ716079 & AJ705018 & AM087057 & $\mathrm{AM} 087067^{\mathrm{a}}$ \\
\hline B. gladiolorum & MUCL3865 & Gladiolus spp. & AJ745692 & AJ716081 & AJ705020 & AM087041 & $\mathrm{AM} 087072^{\mathrm{a}}$ \\
\hline B. globosa & MUCL444 & Allium ursinum & AJ745693 & AJ716083 & AJ705022 & AM087044 & AM087071 \\
\hline B. hyacinthi & MUCL442 & Hyacinthus spp. & AJ745696 & AJ716085 & AJ705024 & AM087048 & AM087066 \\
\hline B. narcissicola & MUCL2120 & Narcissus spp. & AJ745697 & AJ716087 & AJ705026 & AM087046 & AM087078 \\
\hline B. paeoniae & MUCL16084 & Paeonia spp. & AJ745700 & AJ716089 & AJ705028 & AM087033 & AM087064 \\
\hline B. pelargonii & CBS 497.50 & Pelargonium spp. & AJ745662 & AJ716046 & AJ704990 & AM087030 & DQ211834 ${ }^{\mathrm{a}}$ \\
\hline B. polyblastis & CBS287.38 & Narcissus spp. & AJ745702 & AJ716091 & AJ705030 & AM087039 & AM087074 \\
\hline B. porri & MUCL3234 & Allium spp. & AJ745704 & AJ716093 & AJ705032 & AM087060 & AM087063 \\
\hline B. pseudocinerea & VD110 & Vitis vinifera & Unpublished & Unpublished & Unpublished & NA & NA \\
\hline B. ranunculi & CBS178.63 & Ranunculus spp. & AJ745706 & AJ716095 & AJ705034 & AM087054 & AM087086 \\
\hline B. sinoallii & HMAS250008 & Allium spp. & EU514479 & EU514488 & EU519217 & NA & NA \\
\hline B. sphaerosperma & MUCL21481 & Allium triquetrum & AJ745708 & AJ716096 & AJ705035 & AM087042 & AM087068 \\
\hline B. squamosa & MUCL1107 & Allium сера & AJ745710 & AJ716098 & AJ705037 & AM087052 & AM087084 \\
\hline B. tulipae & ВT9830 & Tulipa spp. & AJ745713 & AJ716102 & AJ705041 & AM087037 & AM087077 \\
\hline Monilinia fructigena & 9201 & Stone fruit and pome fruit & AJ745715 & AJ716047 & AJ705043 & NA & NA \\
\hline Sclerotinia sclerotiorum & 484 & $>400$ species & AJ745716 & AJ716048 & AJ705044 & NA & NA \\
\hline
\end{tabular}

Ex-type (ex-epitype) strains are bolded and marked with an * and voucher stains are bolded

a sequences obtained from a different isolate than the one listed in the table.

Sclerotiniaceae, including several members of the genus Botrytis. The relationships among many Botrytis species could not be resolved because of the limited number of informative characters, however the study permitted the conclusion that Botryotinia asexual morphs along with Botrytis sexual morphs constitute a monophyletic lineage (Holst-Jensen et al. 1998). The phylogeny of the Sclerotiniaceae was further refined by Andrew et al. (2012) using three protein-coding genes: calmodulin, glyceraldehyde 3-phosphate dehydrogenase G3PDH and heat shock protein HSP60.

Staats et al. (2005) performed a comprehensive phylogenetic analysis of the genus Botrytis, at that time comprising 22 recognized species and one hybrid. Using three protein-coding genes (G3PDH, HSP60 and the DNA-dependent RNA polymerase subunit II gene RPB2), they corroborated the morphological and host plant-based classification of Botrytis spp. and divided the genus into two (rather widely separated) clades. Clade I contained species that only infect eudicot plants, while Clade II contained species that can infect either eudicotyledonous or monocotyledonous plants. The use of the same three genes facilitated the discovery of Botrytis sinoallii, a new species infecting Allium spp., and its distinction from other Botrytis spp. infecting the same hosts (Zhang et al. 2010b); B. fabiopsis, a new species infecting broad bean, very distant from B. fabae (Zhang et al. 2010a); and B. caroliniana, a new species infecting blackberry ( $\mathrm{Li}$ et al. 2012).

Two genes, encoding phytotoxic proteins NEP1 and NEP2, were shown to provide higher resolution in distinguishing species in the genus Botrytis because they seem to be the subject of higher evolutionary rates than the housekeeping 
genes G3PDH, HSP60 and RPB2 (Staats et al. 2007a). The NEP1 and NEP2 genes were shown to have evolved under positive selection which suggested a role of these proteins in the infection process (Staats et al. 2007a). One might therefore infer that such genes cannot serve as neutral phylogenetic markers. Functional analysis in B. cinerea and B. elliptica using targeted knockout mutants failed to reveal a role of NEP genes in virulence of these two species (Staats et al. 2007b; Cuesta Arenas et al. 2010), which would lend support to considering these genes as neutral markers and adequate tools in phylogeny.

The studies by Staats et al. (2005) revealed incongruence between the phylogenies of Botrytis spp. and their hosts. Species infecting the same host clustered in different (sub) clades, e.g. B. aclada, B. squamosa, B. porri, B. byssoidea and $B$. sinoallii all infecting Allium. Conversely, closely related species can infect very different hosts, e.g. B. elliptica infecting the monocotyledonous host Lilium and B. ficariarum infecting the dicotyledonous host Ficaria (Staats et al. 2005). More recently, similar incongruence has been reported for newly described species, e.g. B. fabiopsis infecting Vicia faba is very distant from B. fabae infecting the same host (Zhang et al. 2010a), and B. caroliniana infecting blackberries and strawberries is very distant from $B$. cinerea ( $\mathrm{Li}$ et al. 2012).

Recently, Khan et al. (2013) combined data from ITS and IGS regions with the G3PHD gene, with the aim of improving molecular identification of Botrytis species that cause neck rot disease on onion. ITS and IGS regions were insufficiently informative to distinguish $B$. allii and $B$. byssoidea. The sequences of ITS and IGS for $B$. allii and B. byssoidea confirmed that they have a close relationship, but G3PDH sequences of several $B$. allii isolates were clearly distinct, some clustering with $B$. aclada and others clustering with B. byssoidea (Khan et al. 2013), as might be expected for a hybrid species.

Sequence analysis of the G3PDH and $\beta$-tubulin genes amplified from herbarium specimens of Botrytis collected from grey mould-infected apple (deposited in 1932) enabled O'Gorman et al. (2008) to corroborate the existence of B. mali, a species that had been published (Ruehle 1931), but by lack of description was considered doubtful.

Figure 4 shows a maximum likelihood tree of Botrytis spp., based on concatenated sequences of parts of the three genes G3PDH, HSP60 and RPB2 (amplified using primers defined by Staats et al. (2005). Five species described after publication of the phylogeny by Staats et al. (2005), i.e. B. caroliniana, $B$. deweyae, B. fabiopsis, B. pseudocinerea and B. sinoallii, clearly cluster within the genus and are genuine Botrytis species. Botrytis mali could not be included in the tree due to lack of sequences for the HSP60 and RPB2 genes. Based on G3PDH and $B$-tubulin sequences it would cluster with B. paeoniae (O'Gorman et al. 2008).
Fig. 4 Phylogram generated from Maximum likelihood analysis based on combined sequences of G3PDH, HSP 60 and RPB2 from 28 recognized Botrytis species. Bootstrap support values greater than $50 \%$ are indicated above/below the nodes. The ex-type (ex-epitype) and voucher strains are in bold. The tree is rooted with Monilinia fructigena and Sclerotinia sclerotiorum

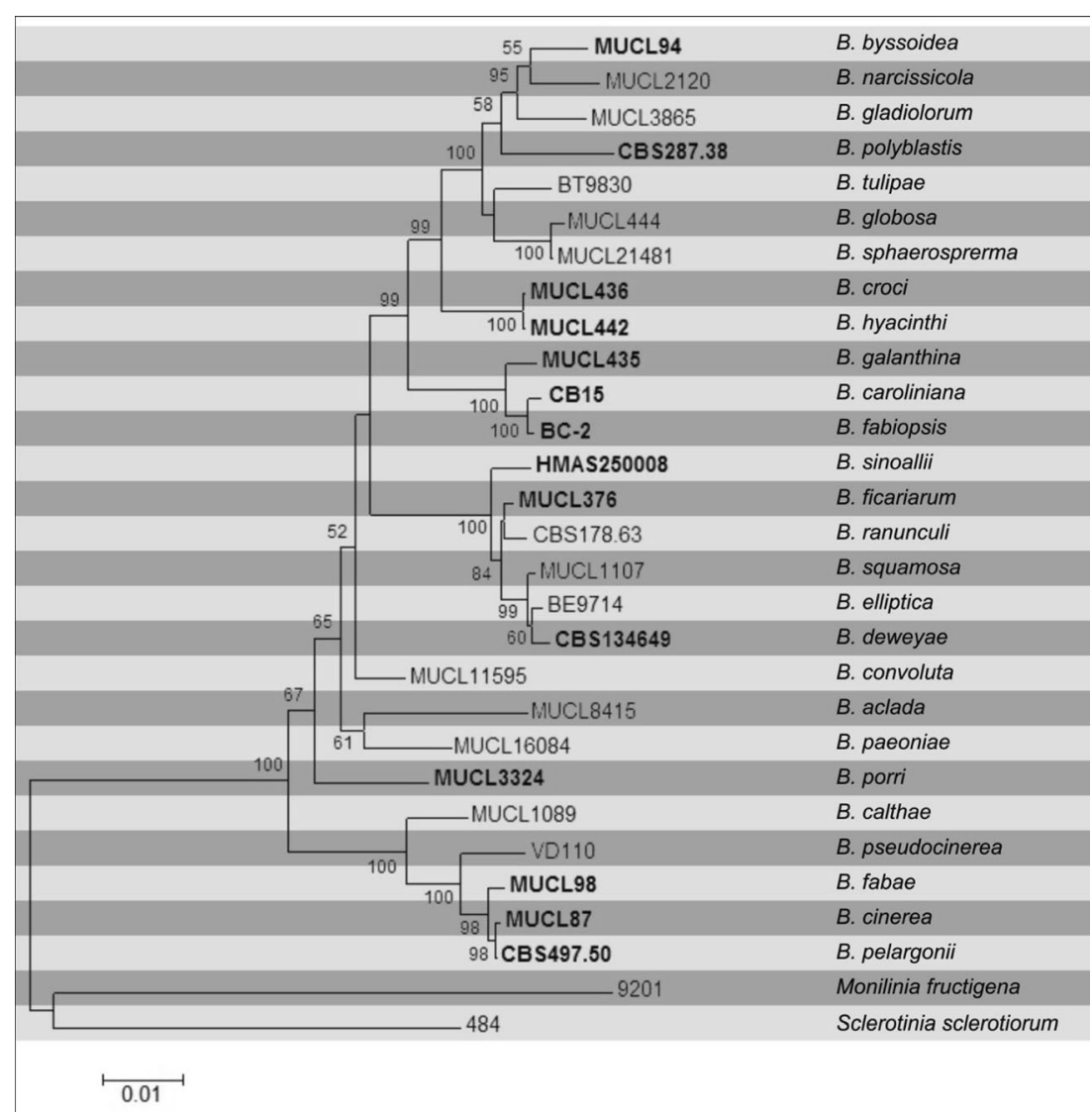


The Botrytis cinerea species complex

The Botrytis 'dicot' clade I consists of $B$. cinerea, B. pelargonii, B. fabae, B. pseudocinerea and B. calthae. Molecular data do not fully support a separation between B. pelargonii and B. cinerea (Staats et al. 2005, 2007a; Plesken et al. 2014), and the existence of B. pelargonii as a separate species is therefore doubtful. As mentioned above, $B$. cinerea and $B$. pseudocinerea are morphologically very similar yet phylogenetically more distant from each other than $B$. cinerea and B. fabae. All genes tested so far place $B$. calthae as most remote to all other clade I species.

Botrytis cinerea not only has a broad host range, but also shows considerable phenotypic variability in vegetative growth, conidiation and sclerotium formation (Kerssies et al. 1997; Martinez et al. 2003; Schumacher et al. 2013). Numerous studies have documented a similar variability in genotypic characters, such as amplified restriction length polymorphism, detection of transposable elements and microsatellite heterogeneity. Recently, B. cinerea strains have been described that produce bikaverin, a reddish pigment. These strains contain an intact bikaverin biosynthesis gene cluster (presumably acquired by horizontal gene transfer from Fusarium), which is partially deleted and nonfunctional in most non-bikaverin producing $B$. cinerea strains (Campbell et al. 2012; Schumacher et al. 2013

A subdivision of $B$. cinerea into genetically distinct groups has proved to be difficult. Analysis of the presence or absence of two types of transposable elements, named Boty (Diolez et al. 1995) and Flipper (Levis et al. 1997), was adopted as a tool to divide isolates into four transposon types, Transposa (isolates having both elements), Vacuma (isolates having neither element), Boty and Flipper (Giraud et al. 1997, 1999). This classification led to the discovery of B. pseudocinerea, which is usually Vacuma, but the transposon-based classification turned out to be of limited use since $B$. cinerea populations appear to consist of mixtures of different transposon types. Intriguingly, predominance of a certain type appears to be influenced by the host. While on grapes, strawberries and tomatoes, Transposa types are predominant, whereas $B$. cinerea populations from kiwi and apples are dominated by Vacuma types (Esterio et al. 2011; Johnston et al. 2013; Muñoz et al. 2002; Samuel et al. 2012; M. Hahn, unpublished). Reasons for this observation are unknown.

Evidence for genetic differentiation of $B$. cinerea populations with different host preference was obtained with microsatellite markers. In France, isolates from grapes and blackberries were shown to be divergent, indicating limited gene flow between populations on these host plants (Fournier and Giraud 2008). A recent study on grey mould isolates from fungicide-treated strawberry fields revealed the existence of a predominant $B$. cinerea genotype, named group $\mathrm{S}$, that is closely related to but distinct from the common genotype of
B. cinerea (Leroch et al. 2013). Sequencing of the highly polymorphic MRR1 gene revealed that group $\mathrm{S}$ isolates show more than $4 \%$ divergence from $B$. cinerea strains B05.10 and T4, which have MRR1 genes with $99.9 \%$ identity. Further sequencing of HSP 60 and NEP2, and of two FUNYBASE genes that are suitable for phylogenetic studies (Marthey et al. 2008), partially supported the genetic separation of group $S$ isolates (Johnston et al. 2013; Leroch et al. 2013). Genome sequencing of several $B$. cinerea and group $\mathrm{S}$ strains, and the analysis of additional polymorphic genes in isolates collected from various host plants in different countries, revealed at least two subclades that could be separated from the common B. cinerea genotype (Plesken and Hahn, unpublished). In fungicide-treated strawberry fields group $\mathrm{S}$ isolates dominated, whereas grapes were infected almost exclusively by common $B$. cinerea genotypes. These data, together with those of putative new endophytic Botrytis taxa that grouped close to B. cinerea (Shipunov et al. 2008), support the idea that $B$. cinerea represents a species complex, comprising genetically and phenotypically distinct groups.

\section{Recommended genetic markers}

G3PDH, RPB2 and HSP60-placement within the Sclerotiniaceae and the ascomycetes

NEP1 and NEP2 - for higher resolution within the genus Botrytis,

The NEP1 and NEP2 genes are under positive selection (Staats et al. 2007a) and potentially influence interactions with the host plants. The NEP genes should therefore be used with caution.

Research is ongoing to identify a set of highly polymorphic genes that better resolve the phylogeny of taxa in clade I (Hahn et al., unpublished). It remains to be established whether those gene are equally useful for resolving the clade II species, and whether universal primers can be designed before these genes can be employed to infer a comprehensive phylogeny of the entire genus.

\section{Choanephora}

\section{Background}

The genus Choanephora belongs to family Choanephoraceae in the order Mucorales (former Zygomycota). The genus was introduced by Currey (1873) for C. cunninghamii, to replace the generic name of his newly described species Cunninghamia infundibulifera, as Cunninghamia already existed as a genus of conifers. Because the specific epithet could not be retained, Choanephora cunninghamia remained invalid, based on the same type as Cunninghamia infundibulifera. The proper name Choanephora 
infundibulifera was validly published by Saccardo (1891), so the correct authorship of the species is "(Currey) Sacc." It is also the type species of the genus. Choanephora was monographed by Hesseltine (1953), Milko and Beljakova (1970) and Kirk (1984). Currently the genus is classified within the family Choanephoraceae which can be distinguished by the presence of a persistent sporangium wall that ruptures at preformed sutures. It is furthermore placed in the subfamily Choanephoroideae, which is characterized by the presence of apposed suspensors and smooth zygospores (Hoffmann et al. 2013).

Both species of the genus can grow as saprobes, but they frequently become plant pathogens causing various leaf and fruit rots and blights and are commonly reported from a wide range of plant hosts, including angiosperms (monocotyledons and dicotyledons) and gymnosperms (Farr and Rossman 2014). Their distribution is worldwide, however, disease development is more common in tropical and subtropical regions characterized by high temperatures and humidity. Choanephora cucurbitarum is the causal agent of fruit and blossom rot of various cucurbits, e.g. yellow crookneck squash (Kucharek and Simone 1983). This species is also known from crop plants such as green beans (McMillan 1972), garden peas (Oikawa et al. 1986), and okra (El-Sayed and El-Sajed 2013) and is reported as an agent of wet rot of Mesembryanthemum crystallinum in hydroponic greenhouse culture in Japan (Kagiwada et al. 2010). It is very common during rainy summers in the southeastern United States and globally in other regions with similar climates. Recently it was isolated also from cultivated Hyoscyamus muticus in Japan (Abdel-Motaal et al. 2010) and Withania in India (Saroj et al. 2012). Choanephora often attacks tissues that have been damaged mechanically by insects or otherwise; plants that are poorly adapted to a hot humid climate are particularly prone to infection by the genus. The general appearance of Choanephora rot is similar to that of blights caused by other Mucorales representatives. Signs of infections on fruits or leaves include water-soaked, necrotic lesions, which progress rapidly under wet conditions. As the fungus begins to produce spores, affected tissues become dark grey-brown and hairy. This specific appearance results from the tall sporangiophores that produce a cluster of brown, one-spored sporangiola at their tips (Turkensteen 1979).

Species identification and numbers

Although more than ten species (and many varieties) have been described within this genus, only two species (viz. Choanephora infundibulifera and Choanephora cucurbitarum) were finally recognized in a monograph of the genus (Kirk 1984). These two species can be distinguished by shape and ornamentation of indehiscent sporangiola. C. cucurbitarum produces ellipsoid sporangiola, which are usually distinctly longitudinally striate, whereas C. infundibulifera forms subglobose to obovoid sporangiola with usually smooth or faint striate ornamentation. The remaining species were synonymized under these taxa (e.g. C. mandshurica is currently a synonym of $C$. cucurbitarum) or were moved to other genera (e.g. C. persicaria is a synonym of Gilbertella persicaria). Choanephora circinans with its two varieties $(C$. circinans var. indica and $C$. circinans var. prolifera) were moved by Kirk (1984) to Poitrasia. Poitrasia was established for those species belonging to the family Choanephoraceae that do not form dehiscent or indehiscent sporangiola (Kirk 1984). Although Poitrasia is primarily a soil-borne genus, it has been isolated from Equisteum arvense (Rai 1990). Recent molecular studies confirmed the taxonomic position of Poitrasia proposed by Kirk (1984).

Molecular phylogeny

All Choanephora strains available in CBS culture collection (three strains of $C$. infundibulifera and five strains of C. cucurbitarum) have been sequenced for their ITS sequences and included in molecular analysis by Walther et al. (2013). These studies showed that the universal fungal DNA barcoding marker-the ITS region (Schoch et al. 2012)-is sufficient for Choanephora species identification (Table 6, Fig. 5). Multigene phylogenetic analysis including representatives of this genus was performed by Hoffmann et al. (2013).

Recommended genetic markers

- The internal transcribed spacer(ITS)-generic and species level

- The large and small subunits (LSU and SSU) of nrDNAplacement within the Mucorales order, higher-level phylogeny

Table 6 Choanephora. Details of the isolates used in the phylogenetic tree

\begin{tabular}{llll}
\hline Species & Isolate & Host & GenBank no \\
\hline Choanephora infundibilifera & CBS 153.51 & - & JN206236 \\
C. infundibilifera & CBS 155.51 & - & JN206237 \\
C. infundibilifera & CBS 155.58 & - & JN206238 \\
C. cucurbitarum & CBS 445.72 & - & JN206234 \\
C. cucurbitarum & CBS 178.76 & Dead insect & JN206235 \\
C. cucurbitarum & CBS 674.93 & - & JN206233 \\
C. cucurbitarum & CBS 120.25 & - & JN206231 \\
C. cucurbitarum & CBS 150.51 & - & JN206232 \\
Poitrasia circinans & CBS 153.58* & Soil & JN206239 \\
P. circinans & CBS 647.70 & Soil & JN206240 \\
\hline
\end{tabular}

Ex-type (ex-epitype) strains are bolded and marked with an * and voucher stains are bolded 
Fig. 5 Phylogram generated from Maximum likelihood analysis based on ITS sequenced data of Choanephora. Bootstrap support values greater than $50 \%$ are indicated above the nodes. The ex-type (ex-epitype) and voucher strains are in bold

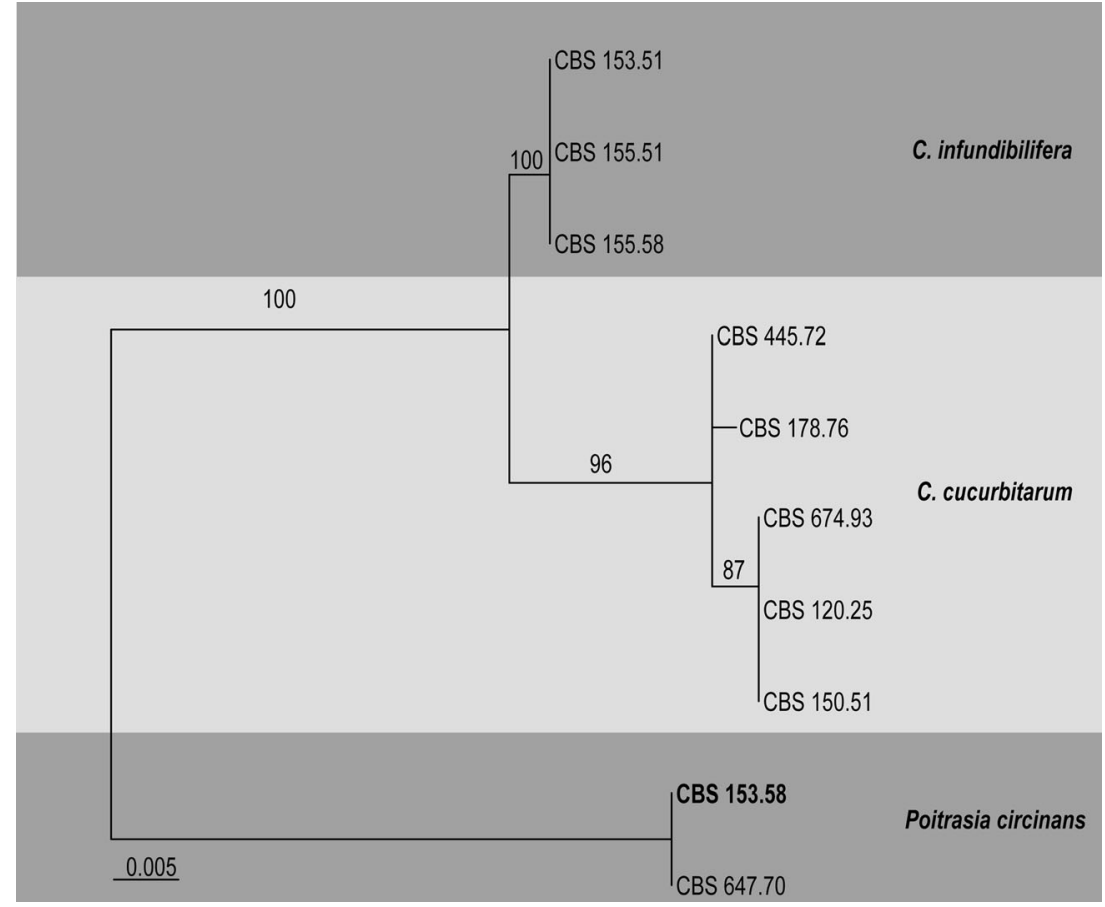

- The partial actin gene (ACT) and the partial translation elongation factor 1-alpha gene (TEF)-higher-level phylogeny

\section{Colletotrichum}

\section{Background}

The genus Colletotrichum was introduced by Corda (1831) and belongs to the family Glomerellaceae (Glomerellales, Ascomycota). Colletotrichum is a coelomycetous phytopathogenic genus with a Glomerella sexual state that includes a number of important pathogens causing diseases of crops and fruits worldwide (Cai et al. 2009; Cannon et al. 2012; Doyle et al. 2013). Colletotrichum species have furthermore been recorded as endophytes in angiosperms, conifers, ferns, lichens and grasses (Hofstetter et al. 2012; Damm et al. 2012b; Cannon et al. 2012; McKenzie et al. 2009; Petrini et al. 1990; Manamgoda et al. 2013; Tao et al. 2013). This genus was voted the eighth most important group of plant pathogenic fungi in the world, based on perceived scientific and economic importance (Dean et al. 2012). Colletotrichum species commonly cause anthracnose resulting in sunken necrotic lesions on leaves, stems, flowers and fruits of numerous hosts, including important crops (Lenne 2002; Waller et al. 2002; Agrios 2005; Cai et al. 2009; Than et al. 2008; Peng et al. 2012; Doyle et al. 2013). It is therefore important to plant health disease practitioners, quarantine personnel and plant breeders to know what species infect which crops (Huang et al. 2013b; Lima et al. 2013; Giaretta et al. 2010; Sangeetha and Rawal 2010; Liu et al. 2009a; Akinbode and
Ikotun 2008; Adegbite and Amusa 2008; Peres et al. 2002). Therefore, having a rigid and stable taxonomy for the identification of Colletotrichum species is a significant practical concern (Shenoy et al. 2007). Identification of Colletotrichum species has been difficult due to the lack of reliable morphological features and confused, ambiguous species boundaries (Hyde et al. 2009a, b; Cai et al. 2009). Difficulties in recognising Colletotrichum species has resulted from having a few and variable morphological characters, widespread host ranges and pathogenicity, lost specimens or type specimens in poor condition and incorrectly named sequences in NCBI (Freeman et al. 2000; Du et al. 2005; Thaung 2008; Crouch et al. 2009a, b; Damm et al. 2009; Cai et al. 2009).

Colletotrichum species are extensively studied as model organisms for research in genetics (Cannon et al. 2012). The pathogenicity genes of $C$. higginsianum were discovered by random mutagenesis (Huser et al. 2009). Genomes and transcriptomes of $C$. higginsianum and $C$. graminicola were studied through the use of two different infection strategies by O'Connell et al. (2012). Work on the genetics of pathogenicity in the $C$. orbiculare species aggregate led to transformation of pathogenic strains to endophytic forms (Cannon et al. 2012). Gene manipulation techniques such as Agrobacterium tumefacien-mediated transformation or protoplast transformation were established (Tsuji et al. 2003). Peroxisome biogenesis genes, PEX6 and PEX13 were identified and their pathogenesis was functionally analyzed (Fujihara et al. 2010). The importance of the pexophagy factor ATG26 for apressorium formation was discovered by Asakura et al. (2009). Whole genomes of $C$. higginsianum and $C$. graminicola have been 
sequenced (O'Connell et al. 2012). Correct species identification is essential in plant pathogenic genera. In order to have effective measures to prevent the unwanted entry of diseases in to a country, the plant pathologists should be able to name the Colletotrichum species confidently. Therefore, pathologists need to be able to clarify and identify the species of Colletotrichum using the wide genetic variation among the taxa (Cannon et al. 2000).

\section{Species identification and numbers}

Colletotrichum species have been traditionally named after their hosts. The history of naming Colletotrichum species has been reviewed in several key papers (Cannon et al. 2008, 2012; Hyde et al. 2009a). Cai et al. (2009) outlined the recent polyphasic protocols for species identification: A total of 25 Colletotrichum species have been epitypified, one has been neotypified and three have been lectotypified (Cannon et al. 2008; Damm et al. 2009, 2012a, b, 2013; Doyle et al. 2013; Liu et al. 2011a, b, 2013; Su et al. 2011; Weir and Johnston 2010; Weir et al. 2012). Significant changes to the understanding of Colletotrichum species took place with incorporation of these polyphasic approaches, especially the use of multimarker phylogenetic analysis, classification and knowledge of species complexes, as well as epitypifications for many species (Cai et al. 2009; Cannon et al. 2012; Damm et al. 2012a, b, 2013; Doyle et al. 2013; Su et al. 2011; Weir et al. 2012). Cannon et al. (2012) studied nearly all presently sequenced species in the genus using a six-gene analysis, and revealed at least nine clades; 119 species previously thought to be well circumscribed proved to be polyphyletic. Colletotrichum gloeosporioides (Cannon et al. 2008; Phoulivong et al. 2010a, b; Weir et al. 2012), C. acutatum (Marcelino et al. 2008; Shivas and Tan 2009; Damm et al. 2012a), C. boninense (Moriwaki et al. 2003; Yang et al. 2009; Damm et al. 2012b), C. orbiculare (Damm et al. 2013) form important species complexes within Colletotrichum and well-resolved among all the nine clades. Further studies in the $C$. gloeosporioides species complex led to identification of C. murrayae (Peng et al. 2012), C. viniferum (Peng et al. 2013), C. citricola (Huang et al. 2013b), C. fructivorum (Doyle et al. 2013), C. melanocaulon (Doyle et al. 2013), C. temperatum (Doyle et al. 2013), C. endophyticta (Manamgoda et al. 2013) and C. syzygicola (Udayanga et al. 2013). Tao et al. (2013) introduced seven new species; four species belonging to the graminicola clade, two species belonging to the spaethianum clade and one singleton species. Damm et al. (2013) resolved C. orbiculare and introduced four new species. Crouch (2014) introduced a new species complex, C. caudatum, with five new species found on warm-season grasses, characterized by the conidial apex reducing into a filiform appendage. The current numbers of species recognised in the genus are listed in Table 7.

\section{Molecular phylogeny}

Some species such as Colletotrichum gloeosporioides were defined using ITS sequence data, but the outcome was not good partially due to prolific misidentification in GenBank and because ITS does not resolve Colletotrichum species well. In Colletotrichum, species definitions based on ITS sequence data, the "universal" DNA barcoding marker for fungal species has proved unsatisfactory (Du et al. 2005; Crouch et al. 2009b; García et al. 2009; Cannon et al. 2012; Doyle et al. 2013; Gunjan et al. 2013). Comparison of a phylogenetic tree of Colletotrichum species derived from ITS sequence alone and one generated from multi-marker data confirms that ITS resolves major clades well, although it does not reflect their higher-order relationships accurately in all cases (Cannon et al. 2012). Cannon et al. (2012) suggested that a robust sequence-based identification system for Colletotrichum species must therefore use an alternative molecular marker or a combination of markers. Damm et al. (2012a) indicated that the most diagnostic markers are $\beta$-tubulin and GPDH. $\beta$ tubulin performed marginally better than GPDH due to a larger overall number of base pair differences, but even so, some clades differed only by one base pair in the $\beta$-tubulin alignment. As single genes that were used are not efficient to differentiate the species, Cai et al. (2009) suggested using multiple markers. Cannon et al. (2012), Weir et al. (2012), and Damm et al. (2012a, b) used several genetic markers: actin (act), chitin synthase (chs1 $\beta$-tubulin and ITS which revealed that Colletotrichum comprises nine major clades as well as a number of small clusters and singleton species. Many recent studies used multimarker phylogeny including actin (act), chitin synthase (chs1), $\beta$-tubulin, calmodulin (cal), glyceraldehydes-3-phosphate dehydogenase (gadph), histamine (HIS3), glutamine synthetase (GS), DNA lyase (apn2), intergenic region of apn2 and MAT1-2-1 genes (ApMat) (Weir et al. 2012; Damm et al. 2012a, b; Cannon et al. 2012; Peng et al. 2012; Doyle et al. 2013; Gunjan et al. 2013) to understand the phylogenetic divergence of Colletotrichum species. There is, however, no agreement among mycologists as to which genetic markers should be used (Doyle et al. 2013; Gunjan et al. 2013). Silva et al. (2012) stressed the need to use 'powerful genes' such as ApMat and Apn25L. The Apmat marker provides better resolution as compared to the genetic markers used by Weir et al. (2012), Silva et al. (2012), Doyle et al. (2013) and Gunjan et al. (2013). Up to now it has been a better gene-marker for resolving species within C. gloeosporioides species complex (Doyle et al. 2013; Gunjan et al. 2013). Only ITS sequences are available for several species of Colletotrichum showing the need of sequencing the other important gene regions and those species 
Table 7 Colletotrichum. Details of the isolates used in the phylogenetic tree

\begin{tabular}{|c|c|c|c|c|c|c|c|c|}
\hline \multirow[t]{2}{*}{ Species } & \multirow[t]{2}{*}{ Isolate } & \multicolumn{6}{|c|}{ GenBank Accession Number } & \multirow[t]{2}{*}{ ApMat } \\
\hline & & ITS & GPDH & CHS-1 & HIS3 & $\mathrm{ACT}$ & $\beta$-tubulin & \\
\hline C. acerbum* & CBS 128530 & JQ948459 & JQ948790 & JQ949120 & JQ949450 & JQ949780 & JQ950110 & - \\
\hline C. acutatum* & CBS112996 & JQ005776 & JQ948677 & JQ005797 & JQ005818 & JQ005839 & JQ005860 & - \\
\hline C. aenigma* & ICMP 18608 & JX010244 & JX010044 & JX009774 & - & JX009443 & JX010389 & - \\
\hline C. aeschynomenes* & ICMP 17673 & JX010176 & JX009930 & JX009799 & - & JX009483 & JX010392 & - \\
\hline C. agaves & CBS 118190 & DQ286221 & - & - & - & - & - & - \\
\hline C. alatae* & ICMP 17919 & JX010190 & JX009990 & JX009837 & - & JX009471 & JX010383 & KC888932 \\
\hline C. alcorni* & IMI 176619 & JX076858 & & & & & & \\
\hline C. alienum* & ICMP 12071 & JX010251 & JX010028 & JX009882 & - & JX009572 & JX010411 & KC888927 \\
\hline C. annellatum* & CBS 129826 & JQ005222 & JQ005309 & JQ005396 & JQ005483 & JQ005570 & JQ005656 & - \\
\hline C. anthrisci* & CBS 125334 & GU227845 & GU228237 & GU228335 & GU228041 & GU227943 & GU228139 & - \\
\hline C. aotearoa* & ICMP 18537 & JX010205 & JX010005 & JX009853 & - & JX009564 & JX010420 & KC888930 \\
\hline C. asianum* & ICMP 18580 & FJ972612 & JX010053 & JX009867 & - & JX009584 & JX010406 & FR718814 \\
\hline C. australe* & CBS116478 & JQ948455 & JQ948786 & JQ949116 & JQ949446 & JQ949776 & JQ950106 & - \\
\hline C. axonopodi & IMI 279189 & EU554086 & - & - & - & - & - & - \\
\hline C. baltimorense* & SD11 & JX076866 & - & - & - & - & - & - \\
\hline C. beeveri* & CBS 128527 & JQ005171 & JQ005258 & JQ005345 & JQ005432 & JQ005519 & JQ005605 & - \\
\hline C. bletillum* & CGMCC 3.15117 & JX625178 & KC843506 & - & - & KC843542 & JX625207 & - \\
\hline C. bidentis* & COAD 1020 & KF178481 & KF178506 & KF148530 & KF178554 & KF178578 & KF178602 & \\
\hline C. boninense* & CBS 123755 & JQ005153 & JQ005240 & JQ005327 & JQ005414 & JQ005501 & JQ005588 & - \\
\hline C. brasiliense* & CBS 128501 & JQ005235 & JQ005322 & JQ005409 & JQ005496 & JQ005583 & JQ005669 & - \\
\hline C. brassicola* & CBS 101059 & JQ005172 & JQ005259 & JQ005346 & JQ005433 & JQ005520 & JQ005606 & - \\
\hline C. brevisporum* & BCC 38876 & JQ247623 & JQ247599 & - & - & JQ247647 & JQ247635 & - \\
\hline C. brisbanense* & CBS292.67 & JQ948291 & JQ948621 & JQ948952 & JQ949282 & JQ949612 & JQ949942 & - \\
\hline C. carthami* & SAPA100011 & AB696998 & - & - & - & - & AB696992 & - \\
\hline C. caudasporum* & CGMCC 3.15106 & JX625162 & KC843512 & - & - & KC843526 & JX625190 & - \\
\hline C. caudatum* & BPI423339 & JX076860 & - & - & - & - & - & - \\
\hline C. cereale & CBS 129663 & JQ005774 & - & JQ005795 & JQ005816 & JQ005837 & JQ005858 & - \\
\hline C.chlorophyti* & IMI 103806 & GU227894 & GU228286 & GU228384 & GU228090 & GU227992 & GU228188 & - \\
\hline C. chrysanthemi & IMI364540 & JQ948273 & JQ948603 & JQ948934 & JQ949264 & JQ949594 & JQ949924 & - \\
\hline $\begin{array}{l}\text { Glomerella cingulata } \\
\text { "f.sp. camelliae" }\end{array}$ & ICMP 10643 & JX010224 & JX009908 & JX009891 & - & JX009540 & JX010436 & - \\
\hline C. circinans* & CBS 221.81 & GU227855 & GU228247 & GU228345 & GU228051 & GU227953 & GU228149 & - \\
\hline C. citri* & ZJUC41 & KC293581 & KC293741 & - & - & KC293621 & KC293661 & - \\
\hline C. citricola* & SXC151 & KC293576 & KC293736 & KC293792 & - & KC293616 & KC293656 & - \\
\hline C. clidemiae* $^{*}$ & ICMP 18658 & JX010265 & JX009989 & JX009877 & - & JX009537 & JX010438 & KC888929 \\
\hline C.cliviae* & CBS 125375 & JX519223 & GQ856756 & JX519232 & - & JX519240 & JX519249 & - \\
\hline C.coccodes & CBS 369.75 & JQ005775 & HM171673 & JQ005796 & JQ005817 & JQ005838 & JQ005859 & - \\
\hline C. coccodes & ITCC 6079 & - & - & - & - & - & - & KC790652 \\
\hline C. colombiense* & CBS 129818 & JQ005174 & JQ005261 & JQ005348 & JQ005435 & JQ005522 & JQ005608 & - \\
\hline C. constrictum* & CBS 128504 & JQ005238 & JQ005325 & JQ005412 & JQ005499 & JQ005586 & JQ005672 & - \\
\hline C. cordylinicola* & ICMP 18579 & JX010226 & JX009975 & JX009864 & - & HM470234 & JX010440 & JQ899274 \\
\hline C. $\cos m i^{*}$ & CBS 853.73 & JQ948274 & JQ948604 & JQ948935 & JQ948604 & JQ949595 & JQ949925 & - \\
\hline C. costaricense* $^{*}$ & CBS 330.75 & JQ948180 & JQ948510 & JQ948841 & JQ949171 & JQ949501 & JQ949831 & - \\
\hline C. curcumae* & IMI 288937 & GU227893 & GU228285 & GU228383 & GU228089 & GU227991 & GU228187 & - \\
\hline C. cuscutae* & IMI 304802 & JQ948195 & JQ948525 & JQ948856 & JQ949186 & JQ949516 & JQ949846 & - \\
\hline C. cymbidiicola * & IMI 347923 & JQ005166 & JQ005253 & JQ005340 & JQ005427 & JQ005514 & JQ005600 & - \\
\hline C. dacrycarpi* & CBS 130241 & JQ005236 & JQ005323 & JQ005410 & JQ005497 & JQ005584 & JQ005670 & - \\
\hline
\end{tabular}


Table 7 (continued)

\begin{tabular}{|c|c|c|c|c|c|c|c|c|}
\hline \multirow[t]{2}{*}{ Species } & \multirow[t]{2}{*}{ Isolate } & \multicolumn{6}{|c|}{ GenBank Accession Number } & \multirow[t]{2}{*}{ ApMat } \\
\hline & & ITS & GPDH & CHS-1 & HIS3 & $\mathrm{ACT}$ & $\beta$-tubulin & \\
\hline C. dematium* & CBS 125.25 & GU227819 & GU228211 & GU228309 & GU228015 & GU227917 & GU228113 & - \\
\hline C. destructivum & CBS 149.34 & AJ301942 & - & JQ005785 & JQ005806 & JQ005827 & JQ005848 & - \\
\hline C. dianensei* & CMM4083 & KC329779 & KC517194 & - & - & KC517298 & KC517254 & KJ155461 \\
\hline C.dracaenophilum* & CBS 118199 & JX519222 & - & JX519230 & - & JX519238 & JX519247 & - \\
\hline C. duyunensis* & CGMCC 3.15105 & JX625160 & KC843515 & - & - & KC843530 & JX625187 & - \\
\hline C. echinochloae* & MAFF 511473 & AB439811 & - & - & - & - & - & - \\
\hline C. eleusines* & MAFF 511155 & JX519218 & - & JX519226 & - & JX519234 & JX519243 & - \\
\hline C. endomagniferae* & MFLUCC 14-0563 & KC702994 & KC702955 & KC598113 & - & KC702922 & KC702922 & KJ155453 \\
\hline C. endophytica* & LC0324 & KC633854 & KC832854 & - & - & KF306258 & - & - \\
\hline C. endophytum* & CGMCC 3.15108 & JX625177 & KC843521 & - & - & KC843533 & JX625206 & - \\
\hline C. eremochloae* & CBS 129661 & JX519220 & - & JX519228 & - & JX519236 & JX519245 & - \\
\hline C. excelsum altitudum* & CGMCC 3.15130 & HM751815 & KC843502 & - & - & KC843548 & JX625211 & - \\
\hline C. falcatum & CBS 147945 & JQ005772 & - & JQ005793 & JQ005814 & JQ005835 & JQ005856 & - \\
\hline C. fioriniae* & CBS 128517 & JQ948292 & JQ948622 & JQ948953 & JQ949283 & JQ949613 & JQ949943 & - \\
\hline C. fructi* & CBS 346.37 & GU227844 & GU228236 & GU228334 & GU228040 & GU227942 & GU228138 & - \\
\hline C. fructicola* & ICMP 18581 & JX010165 & JX010033 & JX009866 & - & FJ907426 & JX010405 & JQ807838 \\
\hline C. fructivorum* & Coll1414 & JX145145 & - & - & - & - & JX145196 & - \\
\hline C. fuscum & CBS 130.57 & JQ005762 & - & JQ005783 & JQ005804 & JQ005825 & JQ005846 & - \\
\hline C. gigasporum* & MUCL 44947 & AM982797 & - & - & - & - & FN557442 & - \\
\hline C. gloeosporioides* & CBS 112999 & JQ005152 & JQ005239 & JQ005326 & JQ005413 & JQ005500 & JQ005587 & JQ807843 \\
\hline C. godetiae* & CBS 133.44 & JQ948402 & JQ948733 & JQ949063 & JQ949393 & JQ949723 & JQ950053 & - \\
\hline C. graminicola* & CBS 130836 & JQ005767 & - & JQ005788 & JQ005809 & JQ005830 & JQ005851 & - \\
\hline C. grevilleae* & CBS 132879 & KC297078 & KC297010 & KC296987 & KC297056 & KC296941 & KC297102 & - \\
\hline C. guajave* & IMI 350839 & JQ948270 & JQ948600 & JQ948931 & JQ949261 & JQ949591 & JQ949921 & - \\
\hline C. guizhouensis* & CGMCC 3.15112 & JX625158 & KC843507 & - & - & KC843536 & JX625185 & - \\
\hline C. hanaui* & MAFF 305404 & JX519217 & - & JX519225 & - & - & JX519242 & - \\
\hline C. hemerocallidis* & CDLG5 & JQ400005 & JQ400012 & JQ399998 & - & JQ399991 & JQ400019 & - \\
\hline C. higginsianum & IMI 349063 & JQ005760 & - & JQ005781 & JQ005802 & JQ005823 & JQ005844 & - \\
\hline C. hippeastri* & CBS 125376 & JQ005231 & JQ005318 & JQ005405 & JQ005492 & JQ005579 & JQ005665 & - \\
\hline C. horii & ICMP 10492 & GQ329690 & GQ329681 & JX009752 & - & JX009438 & JX010450 & JQ807840 \\
\hline C. hsienjenchng & MAFF 243051 & AB738855 & - & AB738846 & AB738847 & AB738845 & - & - \\
\hline C. incanum* & ATCC 64682 & KC110789 & KC110807 & - & KC110798 & KC110825 & KC110816 & - \\
\hline C. indonesiense $e^{*}$ & CBS 127551 & JQ948288 & JQ948618 & JQ948949 & JQ949279 & JQ949609 & JQ949939 & - \\
\hline C. jacksonii* & MAFF 305460 & JX519216 & - & JX519224 & - & JX519233 & JX519241 & - \\
\hline C. jasiminigenum* & MFU 10-0273 & HM131513 & HM131499 & - & - & HM131508 & HM153770 & - \\
\hline C. johnstonii* & CBS 128532 & JQ948444 & JQ948775 & JQ949105 & JQ949435 & JQ949765 & JQ950095 & - \\
\hline C. kahawae* & ICMP17816 & JX010231 & JX010012 & JX009813 & - & JX009452 & JX010444 & JQ899282 \\
\hline C. kartsii* & CORCG6 & HM585409 & HM585391 & HM582023 & - & HM581995 & HM585428 & - \\
\hline C. kinghornii* & CBS 198.35 & JQ948454 & JQ948785 & JQ949115 & JQ949445 & JQ949775 & JQ950105 & - \\
\hline C. lacticiphilum* & CBS 112989 & JQ948289 & JQ948619 & JQ948950 & JQ949280 & JQ949610 & JQ949940 & - \\
\hline C. lilii & CBS 109214 & GU227810 & GU228202 & GU228300 & GU228006 & GU227908 & GU228104 & - \\
\hline C. limetticola* & CBS 114.14 & JQ948193 & JQ948523 & JQ948854 & JQ949184 & JQ949514 & JQ949844 & - \\
\hline C. lindemuthianum* & CBS 144.31 & JQ005779 & JX546712 & JQ005800 & JQ005821 & JQ005842 & JQ005863 & - \\
\hline C. lineola* & CBS 125337 & GU227829 & GU228221 & GU228319 & GU228025 & GU227927 & GU228123 & - \\
\hline C. linicola & CBS 172.51 & JQ005765 & - & JQ005786 & JQ005807 & JQ005828 & JQ005849 & - \\
\hline C. liriopes* & CBS 119444 & GU227804 & GU228196 & GU228294 & GU228000 & GU227902 & GU228098 & - \\
\hline C. lupini & CBS 109225 & JQ948155 & JQ948485 & JQ948816 & JQ949146 & JQ949476 & JQ949806 & - \\
\hline
\end{tabular}


Table 7 (continued)

\begin{tabular}{|c|c|c|c|c|c|c|c|c|}
\hline \multirow[t]{2}{*}{ Species } & \multirow[t]{2}{*}{ Isolate } & \multicolumn{6}{|c|}{ GenBank Accession Number } & \multirow[t]{2}{*}{ ApMat } \\
\hline & & ITS & GPDH & CHS-1 & HIS3 & $\mathrm{ACT}$ & $\beta$-tubulin & \\
\hline C. melanocaulon* & Coll131 & - & - & - & - & - & - & JX145313 \\
\hline C. malvarum* & CBS 527.97 & KF178480 & KF178504 & KF178529 & KF178553 & KF178577 & KF178601 & \\
\hline C. melonis* & CBS 159.84 & JQ948194 & JQ948524 & JQ948855 & JQ949185 & JQ949515 & JQ949845 & - \\
\hline C. metake & NBRC 8974 & AB738859 & - & - & - & - & - & - \\
\hline C. miscanthi* & MAFF 510857 & JX519221 & - & JX519229 & - & JX519237 & JX519246 & - \\
\hline C. musae* & ICMP19119 & JX010146 & JX010050 & JX009896 & - & JX009433 & HQ596280 & KC888926 \\
\hline C. murrayae* & GZAAS5.09506 & JQ247633 & JQ247609 & - & - & JQ247657 & JQ247644 & - \\
\hline C. navitas* & CBS 125086 & JQ005769 & - & JQ005790 & JQ005811 & JQ005832 & JQ005853 & - \\
\hline C. nicholsonii * & MAFF 511115 & JQ005770 & - & JQ005791 & JQ005812 & JQ005833 & JQ005854 & - \\
\hline C. nigrum* & CBS 169.49 & JX546838 & JX546742 & JX546693 & JX546791 & JX546646 & JX546885 & - \\
\hline C. novae-zelandiae* & CBS 128505 & JQ005228 & JQ005315 & JQ005402 & JQ005489 & JQ005576 & JQ005662 & - \\
\hline C. nupharicola* & ICMP 18187 & JX010187 & JX009972 & JX009835 & - & JX009437 & JX010398 & JX145319 \\
\hline C. nymphaeae* & CBS 515.78 & JQ948197 & JQ948527 & JQ948858 & JQ949188 & JQ949518 & JQ949848 & - \\
\hline C. ochracea* & CGMCC 3.15104 & JX625156 & KC843513 & - & - & KC843527 & JX625183 & - \\
\hline C. oncidii* & CBS 129828 & JQ005169 & JQ005256 & JQ005343 & JQ005430 & JQ005517 & JQ005603 & - \\
\hline C. orbiculare* & CBS 570.97 & KF178466 & KF178490 & KF178515 & KF178539 & KF178563 & KF178587 & - \\
\hline C.orchidophilum* & CBS 632.80 & JQ948151 & JQ948481 & JQ948812 & JQ949142 & JQ949472 & JQ949802 & - \\
\hline C. parsonsiae* & CBS 128525 & JQ005233 & JQ005320 & JQ005407 & JQ005494 & JQ005581 & JQ005667 & - \\
\hline C. paspali* & MAFF 305403 & JX519219 & - & JX519227 & - & JX519235 & JX519244 & - \\
\hline C. paxtonii* & IMI 165753 & JQ948285 & JQ948615 & JQ948946 & JQ949276 & JQ949606 & JQ949936 & - \\
\hline C. petchiï* & CBS 378.94 & JQ005223 & JQ005310 & JQ005397 & JQ005484 & JQ005571 & JQ005657 & - \\
\hline C.phaseolorum & CBS 157.36 & GU227896 & GU228288 & GU228386 & GU228092 & GU227994 & GU228190 & - \\
\hline C. phormii * & CBS 118194 & JQ948446 & JQ948777 & JQ949107 & JQ949437 & JQ949767 & JQ950097 & - \\
\hline C. phyllanthi* & CBS 175.67 & JQ005221 & JQ005308 & JQ005395 & JQ005482 & JQ005569 & JQ005655 & - \\
\hline C. proteae & CBS132882 & KC297079 & KC297009 & KC296986 & KC297045 & KC296940 & KC297101 & - \\
\hline C.pseudoacutatum* & CBS 436.77 & JQ948480 & JQ948811 & JQ949141 & JQ949471 & JQ949801 & JQ950131 & - \\
\hline C. psidii & ICMP 19120 & JX010219 & JX009967 & JX009901 & - & JX009515 & JX010443 & - \\
\hline C. pyricola* & CBS 128531 & JQ948445 & JQ948776 & JQ949106 & JQ949436 & JQ949766 & JQ950096 & - \\
\hline C. queenslandium* & ICMP 1778 & JX010276 & JX009934 & JX009899 & - & JX009447 & JX010414 & KC888928 \\
\hline C. rhexiae* & Coll 1026 & JX145128 & - & - & - & - & JX145179 & JX145290 \\
\hline C. rhombiforme* & CBS 129953 & JQ948457 & JQ948788 & JQ949118 & JQ949448 & JQ949778 & JQ950108 & - \\
\hline C. rusci* & CBS 119206 & GU227818 & GU228210 & GU228308 & GU228014 & GU227916 & GU228112 & - \\
\hline C. salicis* & CBS 607.94 & JQ948460 & JQ948791 & JQ949121 & JQ949451 & JQ949781 & JQ950111 & - \\
\hline C. salsolae* & ICMP 19051 & JX010242 & JX009916 & JX009863 & - & JX009562 & JX010403 & KC888925 \\
\hline C. sansevieriae & MAFF 239721 & AB212991 & - & - & - & - & - & - \\
\hline C. scovillei* & CBS 126529 & JQ948267 & JQ948597 & JQ948928 & JQ949258 & JQ949588 & JQ949918 & - \\
\hline C. siamense* & ICMP 18578 & JX010171 & JX009924 & JX009865 & - & FJ907423 & JX010404 & JQ899289 \\
\hline C. sidae* & CBS 504.97 & KF178472 & KF178497 & KF178521 & KF178545 & KF178569 & KF178593 & - \\
\hline C. simmondsiï* & CBS 122122 & JQ948276 & JQ948606 & JQ948937 & JQ949267 & JQ949597 & JQ949927 & - \\
\hline C. sloanei* & IMI 364297 & JQ948287 & JQ948617 & JQ948948 & JQ949278 & JQ949608 & JQ949938 & - \\
\hline C. somersetense* & JAC 11-11 & JX076862 & - & - & - & - & - & - \\
\hline C. spaethianum* & CBS 167.49 & GU227847 & GU228239 & GU228337 & GU228043 & GU227945 & GU228141 & - \\
\hline C. spinaceae & CBS 128.57 & GU227847 & GU228239 & GU228337 & GU228043 & GU227945 & GU228141 & - \\
\hline C. spinosum* & CBS 515.97 & KF178474 & KF178498 & KF178523 & KF178547 & KF178571 & KF178595 & - \\
\hline C. sublineola* & CBS 131301 & JQ005771 & - & JQ005792 & JQ005813 & JQ005834 & JQ005855 & - \\
\hline C. syzygicola* & DNCL021 & KF242094 & KF242156 & - & - & KF157801 & KF254880 & - \\
\hline C. tabacum & CBS 161.53 & JQ005763 & - & JQ005784 & JQ005805 & JQ005826 & JQ005847 & - \\
\hline
\end{tabular}


Table 7 (continued)

\begin{tabular}{|c|c|c|c|c|c|c|c|c|}
\hline \multirow[t]{2}{*}{ Species } & \multirow[t]{2}{*}{ Isolate } & \multicolumn{6}{|c|}{ GenBank Accession Number } & \multirow[t]{2}{*}{ ApMat } \\
\hline & & ITS & GPDH & CHS-1 & HIS3 & $\mathrm{ACT}$ & $\beta$-tubulin & \\
\hline C. tamarilloi* & CBS 129814 & JQ948184 & JQ948514 & JQ948845 & JQ949175 & JQ949505 & JQ949835 & - \\
\hline C. tanaceti* & CBS 132693 & - & JX218243 & - & - & JX218238 & JX218233 & - \\
\hline C. tebeestii* & CBS 522.97 & KF178473 & KF178505 & KF178522 & KF178546 & KF178570 & KF178594 & - \\
\hline C. temperatum* & Coll883 & JX145159 & - & - & - & - & JX145211 & JX145298 \\
\hline C. thailandicum* & MFUCC110113 & JN050242 & JN050231 & - & - & JN050220 & JN050248 & - \\
\hline C. theobromicola & ICMP 18649 & JX010294 & JX010006 & JX009869 & - & JX009444 & JX010447 & KC790726 \\
\hline C. $t i^{*}$ & ICMP 4832 & JX010269 & JX009952 & JX009898 & - & JX009520 & JX010442 & - \\
\hline C. tofieldiae & CBS 495.85 & GU227801 & GU228193 & GU228291 & GU227997 & GU227899 & GU228095 & - \\
\hline C. torulosum* & CBS 128544 & JQ005164 & JQ005251 & JQ005338 & JQ005425 & JQ005512 & JQ005598 & - \\
\hline C.trichellum & CBS 217.64 & GU227812 & GU228204 & GU228302 & GU228008 & GU227910 & GU228106 & - \\
\hline C. trifolii* & CBS 158.83 & KF178478 & KF178502 & KF178527 & KF178551 & KF178575 & KF178599 & - \\
\hline C. tropicale* & ICMP18653 & JX010264 & JX010007 & JX009870 & - & JX009489 & JX010407 & KC790728 \\
\hline C.tropicicola* & BCC 38877 & JN050240 & JN050229 & & & JN050218 & JN050246 & - \\
\hline C. truncatum* & CBS 151.35 & GU227862 & GU228254 & GU228352 & GU228058 & GU227960 & GU228156 & - \\
\hline C. verruculosm* & IMI 45525 & GU227806 & GU228198 & GU228296 & GU228002 & GU227904 & GU228100 & - \\
\hline C. viniferum* & GZAAS5.08601 & JN412804 & JN412798 & - & - & JN412795 & JN412813 & - \\
\hline C. viniferum & GZAAS5.08608 & - & - & - & - & - & - & KJ623242 \\
\hline C. walleri* & CBS 125472 & JQ948275 & JQ948605 & JQ948936 & JQ949266 & JQ949596 & JQ949926 & - \\
\hline C. xanthorrhoeae* & ICMP 17903 & JX010261 & JX009927 & JX009823 & - & JX009478 & JX010448 & KC790689 \\
\hline C. yunnanense* & CGMCC AS3.9167 & EF369490 & - & JX519231 & - & JX519239 & JX519248 & - \\
\hline C. zoysia* & MAFF 238573 & JX076871 & - & - & - & - & - & - \\
\hline
\end{tabular}

Ex-Type (ex-epitype) strains are bolded and marked with an * and authentic stains are bolded

were not included in this analysis. Here we present an analysis using six genetic markers for all the Colletotrichum species that are accepted (Fig. 6) and for the C. acutatum species complex (Fig. 7). Figure 8 presents the analysis of $C$. gloeosporioides species complex using the apmat gene. The whole genomes of several species of Colletotrichum have been sequenced, such that it is now possible to carry out whole-genome analysis, and compare this with single gene analysis to establish a gene (or gene combinations) that can really resolve species in the genus.

Recommended genetic markers

- ITS alone will not resolve species in the genus, but it can separate taxa to species complexes. Multigene analysis using the following genes has been recommended for a backbone tree for species of Colletotrichum:

- GPDH-Glyceraldehyde-3-phosphate dehydrogenase- resolves to species level, more accurate.

- $\quad \beta$-tubulin-Beta-tubulin resolves to species level

- ApMat-Intergenic region of apn2 and MAT1-2-1 genes can resolve within the $C$. gloeosporioides complex

- GS-glutamine synthetase-CHS-1. HIS3-Histone3 and ACT-Actin-Placement within the genus and also some species-level delineation.
These marker combinations can resolve the phylogenetic positions of most species in the genus. GPDH alone can delineate the majority of species. However, research is ongoing to identify better genetic markers to resolve the phylogenetic position of many species of Colletotrichum.

\section{Curvularia}

\section{Background}

Curvularia is a dematiaceous hyphomycete genus in the family Pleosporaceae, Pleosporales, Dothideomycetes (Ascomycota) (Boedijn 1933). It is typified by C. lunata. Curvularia species have been recorded as saprobes and also plant, human and animal pathogens. Bipolaris and Curvularia species are associated with Cochliobolus sexual states (Sivanesan 1987). Curvularia species are found as plant pathogens especially associated with the family Poaceae. Species such as $C$. lunata, $C$. tuberculata and $C$. trifolii cause leaf spots and leaf blights of some cereal crops such as maize, rice and horticultural crops such as Bermuda grasses and turf grasses (de Luna et al. 2002). The most frequent human and animal pathogens within the genus are C. aeria, C. geniculata, 


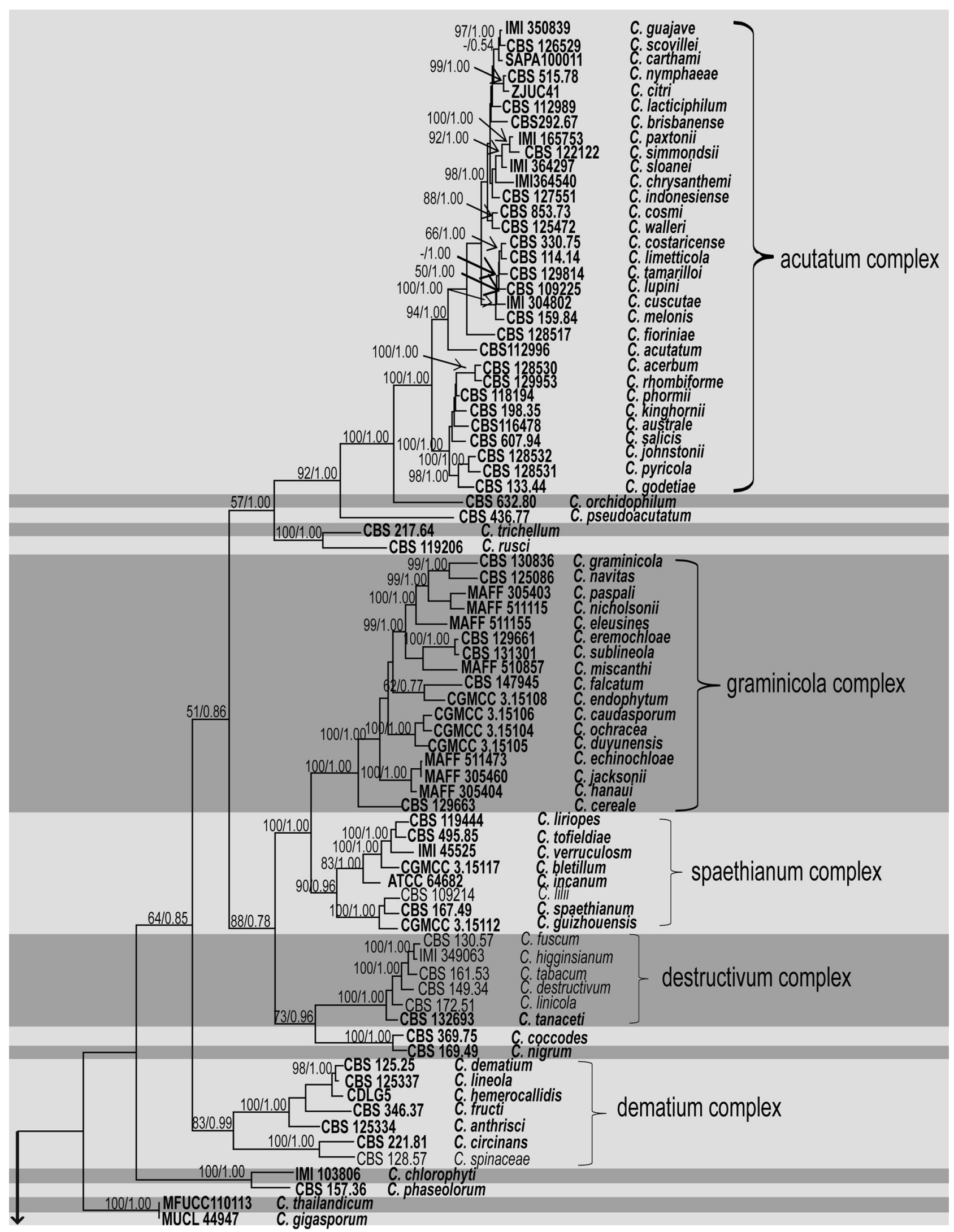

Fig. 6 Phylogram generated from parsimony analysis based on combined ITS, GADPH, CHS-1, ACT, HIS and $\beta$ - tubulin data of Colletotrichum. Parsimony bootstrap support values and Bayesian posterior probabilities greater than $50 \%$ are indicated above the nodes. The ex-type (ex-epitype) and voucher strains are in bold. The tree is rooted with Monilochaetes infuscans CBS 869.96 


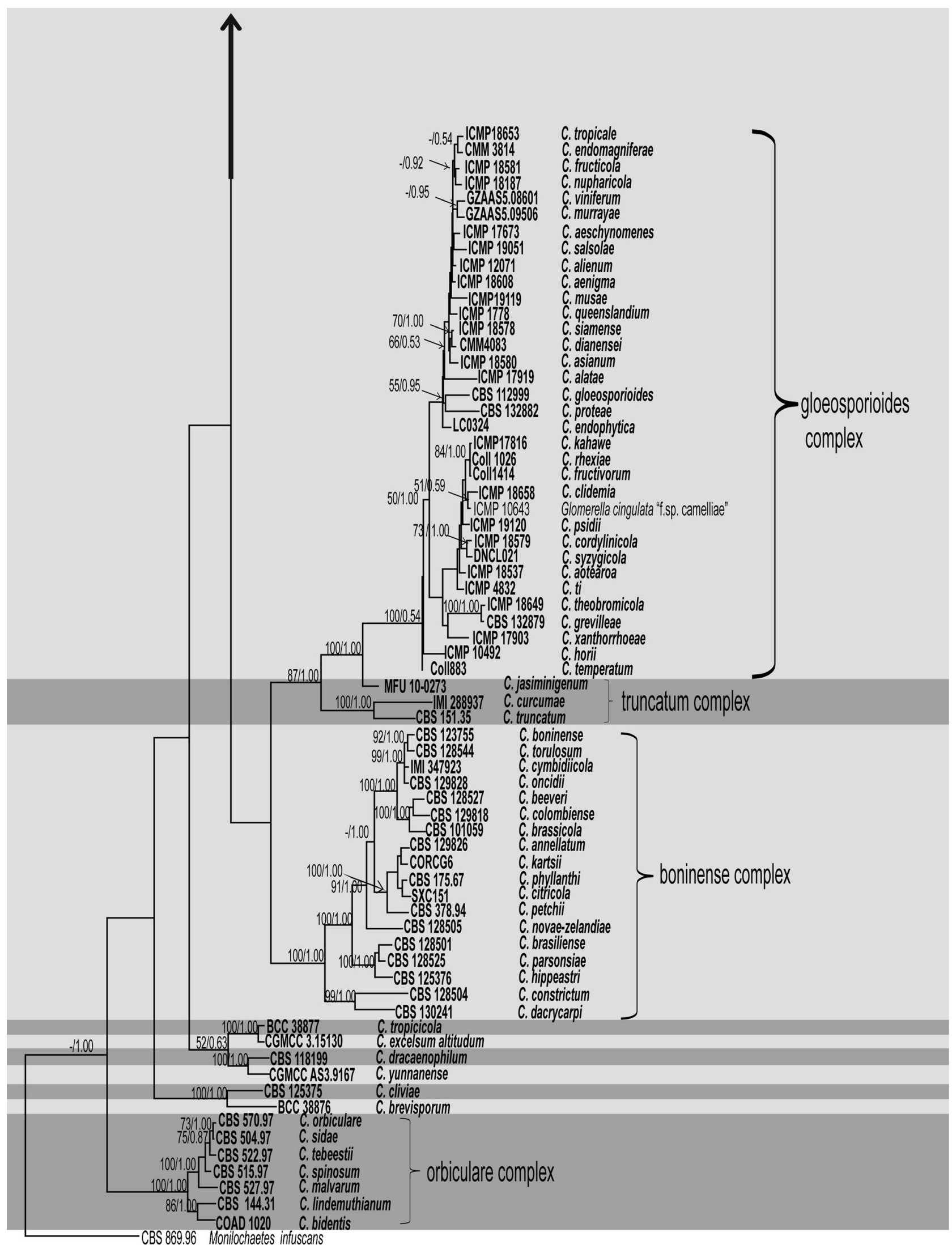

100

Fig. 6 (continued) 
Fig. 7 Phylogram generated from parsimony analysis based on combined ITS, GADPH, CHS-1, ACT, HIS and $\beta$ - tubulin sequenced data of Colletotrichum acutatum complex. Parsimony bootstrap support values and Bayesian posterior probabilities greater than $50 \%$ are indicated above the nodes. The ex-type (exepitype) and voucher strains are in bold. The tree is rooted with C. orchidophilum

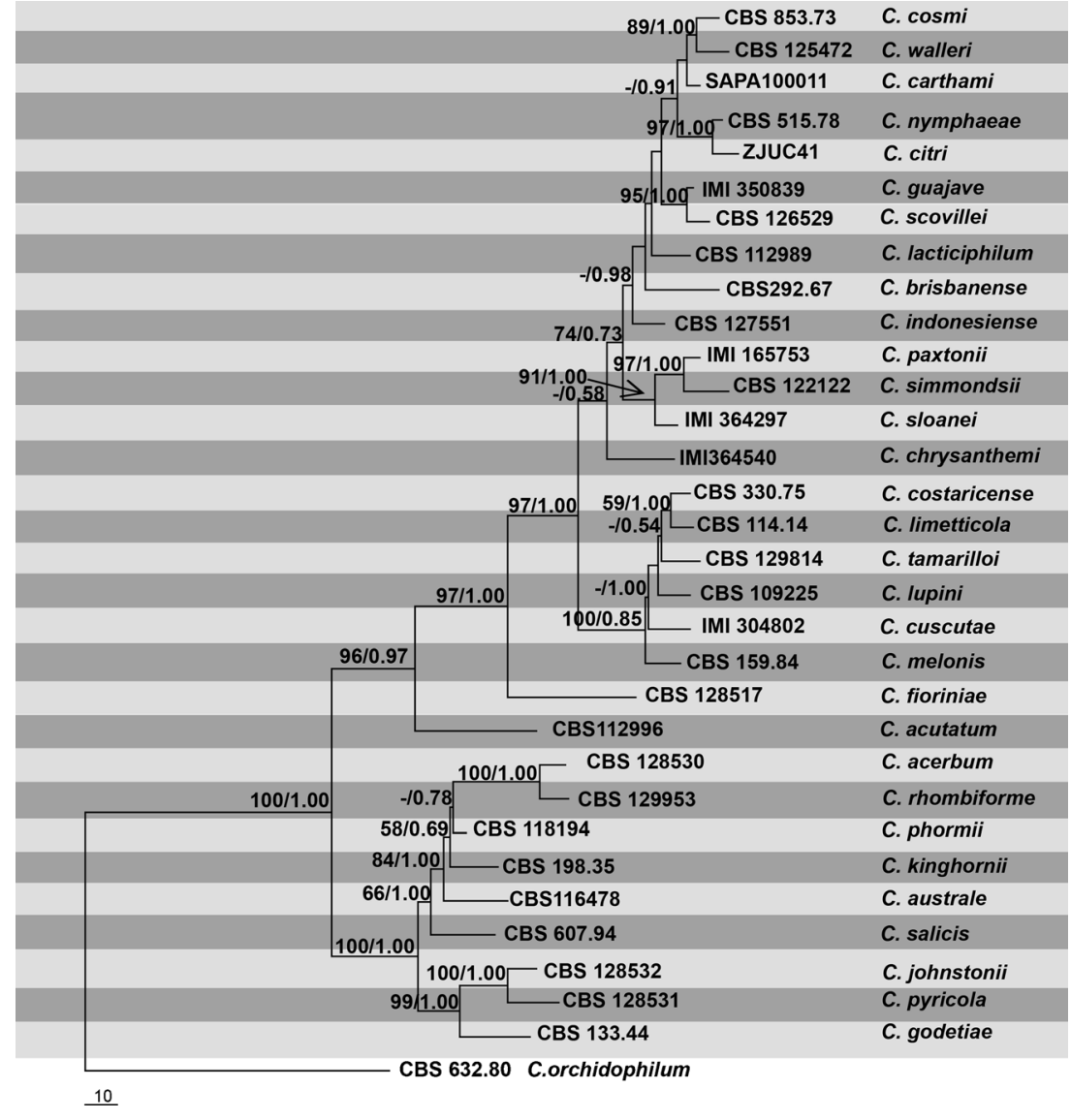

Molecular phylogeny

Phylogenetic recognition is crucial for species identification in Curvularia. Former morphological identifications do not correlate with the phylogeny (Manamgoda et al. 2012a, b). Combined ITS and GPDH analysis for Curvularia and its sister genus Bipolaris by Berbee et al. (1999) revealed that some Bipolaris species cluster within the genus Curvularia. Curvularia was therefore redefined by Manamgoda et al. (2012a) based on a combined phylogenetic analysis of ITS, GPDH, TEF and LSU. Nine Bipolaris species clustering within Curvularia were transferred and their nomenclature redefined (Manamgoda et al. 2012a). Lack of ex-type cultures and epitypifications form limitations for phylogenetic species recognition. In this paper we present a phylogenetic tree with combined ITS and GPDH sequences obtained from available type material and voucher cultures (Table 8, Fig. 9). This can be used as a backbone in the identification of Curvularia species.

Recommended genetic markers

- GPDH is the best single genetic marker for the genus Bipolaris (Manamgoda et al. 2012a). It is recommended to use a combination of ITS and GPDH. Another useful gene is TEF. 


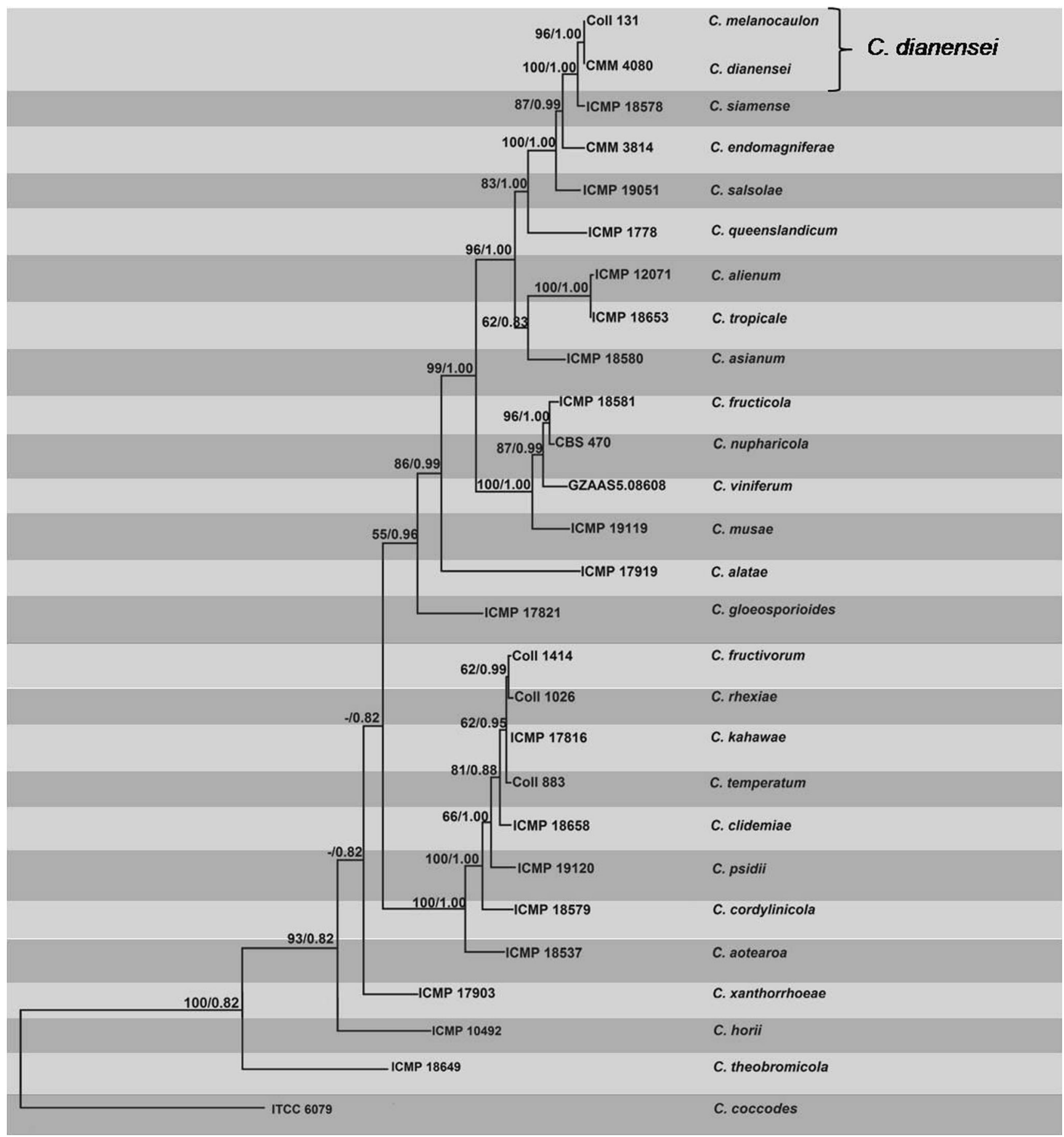

Fig. 8 Phylogram generated from parsimony analysis based on combined ITS, GADPH, CHS-1, ACT, HIS and $\beta$ - tubulin sequenced data of Colletotrichum gloeosporioides complex. Parsimony bootstrap support

\section{Diaporthe}

\section{Background}

Diaporthe (=Phomopsis) is a cosmopolitan genus of fungi comprised of endophytes, plant pathogens, and saprobes occurring on a wide range of annual and perennial hosts, values and Bayesian posterior probabilities greater than $50 \%$ are indicated above the nodes. The ex-type (ex-epitype) and voucher strains are in bold. The tree is rooted with C. coccodes ITCC6079

including economically important crops (Uecker 1988; Farr and Rossman 2014; Udayanga et al. 2011). The genus belongs to class Sordariomycetes, order Diaporthales and the family Diaporthaceae, typified by the species Diaporthe eres Nitschke (Wehmeyer 1933). With the change to one scientific name for fungi (McNeill et al. 2012), Diaporthe has priority, being the older generic name compared to Phomopsis. Many 
Table 8 Details of the isolates used in the phylogenetic tree

\begin{tabular}{|c|c|c|c|c|c|}
\hline \multirow[t]{2}{*}{ Species } & \multirow[t]{2}{*}{ Code } & \multirow[t]{2}{*}{ Host } & \multicolumn{3}{|c|}{ Gene bank accession numbers } \\
\hline & & & ITS & GPDH & TEF \\
\hline Curvularia affinis & DAOM 46365 & & AF071335 & AF081390 & \\
\hline \multirow[t]{2}{*}{ C. alcornii } & MFLUCC10703* & Zea mays & JX256420 & JX276433 & JX266589 \\
\hline & MFLUCC10705 & Panicum sp. & JX256421 & JX276434 & JX266590 \\
\hline C. australiensis & CBS 172.57 & Oryza sativa & JN601026 & JN601036 & JN601003 \\
\hline C. clavata & ICMP 103444 & Lawn & JX256444 & JX276455 & \\
\hline C. cymbopogonis & $88109-1$ & & AF071351 & AF081403 & \\
\hline C. ellisii & CBS 193.62* & Air & JN192375 & JN600963 & JN601007 \\
\hline C. gladioli & ICMP 6160 & Gladiolus sp. & JX256426 & JX276438 & JX266595 \\
\hline C. graminicola & BRIP 23186 & & JN192376 & JN600964 & JN601008 \\
\hline C. gudauskasii & DAOM165085 & & AF071338 & AF081393 & \\
\hline \multirow[t]{2}{*}{ C. hawaiiensis } & BRIP 15933 & Chloris gayana & JN601028 & JN600965 & JN601009 \\
\hline & BRIP 10972 & Chloris gayana & JN192377 & JN600968 & JN601012 \\
\hline C. heteropogonis & CBS 284.91* & Heteropogon contortus & JN192379 & JN600969 & JN601013 \\
\hline C. intermedia & $8797-1$ & & AF071327 & AF081383 & \\
\hline C. lunata & CBS 730.96* & Human lung biopsy & JX256429 & JX276441 & JX266596 \\
\hline C. ovariicola & CBS 470.90* & Eragrostis interrupta & JN601031 & JN600976 & JN601020 \\
\hline C. perotidis & CBS 7846-2 & Perotis rara & AF071320 & AF081374 & \\
\hline C. ravenelii & BRIP 13165* & Sporobolus fertilis & JN192386 & JN600978 & JN601024 \\
\hline C. spicifera & CBS 274.52 & Soil & JN192387 & JN600979 & JN601023 \\
\hline C. trifolii & ICMP 6149 & Setaria glauca & JX256434 & JX276457 & JX266600 \\
\hline C. tripogonis & BRIP 12375* & Dactyloctenii aeygeptii & JN192388 & JN600980 & JX266600 \\
\hline C. tuberculata & CBS 146.63* & Zea mays & JN192374 & JN601037 & JX266599 \\
\hline C. verrucosa & MAFF235540 & Triticum aestivum & AB444667 & AF081388 & \\
\hline Alternaria alternata & EGS 34.0160* & & AF017346 & AF081400 & \\
\hline
\end{tabular}

Ex-type (ex-epitype) strains are bolded and marked with an * and voucher stains are bolded

species are able to colonise diverse hosts as opportunists; some species are host specific and multiple species can even co-occur on the same host (Mostert et al. 2001; Farr et al. 2002a; Crous and Groenewald 2005). Species of Diaporthe cause cankers, diebacks, root rots, fruit rots, leaf spots, blights and wilts on a wide range of plant host including some economically important hosts and have been the subject of considerable phytopathological research. Examples of diseases on major crops include Diaporthe/Phomopsis complex causing soybean seed decay, pod and stem blight and cankers, sunflower stem canker (D. helianthi), dead arm of grapevines (D. ampelina) and melanose in Citrus (D. citri) (Van Niekerk et al. 2005; Santos et al. 2011; Thompson et al. 2011; Udayanga et al. 2014a, b). In addition, several species of Diaporthe are known from clinical reports of immunocompromised patients, although these pathogens are only provisionally identified to species level (Garcia-Reyne et al. 2011; Mattei et al. 2013). Diaporthe comprises a major component of endophytes in tropical and temperate trees, and several species have been used in secondary metabolite research (Isaka et al. 2001; Li et al. 2010a, b; Kaul et al. 2012).
Species identification and numbers

The Genealogical Concordance Phylogenetic Species Recognition (GCPSR) has been applied in the genus Diaporthe to define the species boundaries in recent studies (Udayanga et al. 2012b; Gomes et al. 2013; Tan et al. 2012). Therefore species delimitation is currently based on DNA sequence data and comparison of morphological characters (Santos and Phillips 2009; Santos et al. 2010; Diogo et al. 2010; Udayanga et al. 2014a, b). Although the genus Diaporthe has received much attention, few phylogenetic studies have thus far been conducted; hence the taxonomy of some of the species in this genus is still uncertain including many of the common plant pathogens. Index Fungorum lists 892 Diaporthe names and 983 Phomopsis names whereas MycoBank (2014) lists 919 Diaporthe names and 1,040 Phomopsis names. However, the names available in the literature are mostly applied based on host association and morphology except fewer species described in last two decades based on DNA sequence data. Ex-type cultures are available for less than 100 species known despite the large number of 
Fig. 9 Phylogram generated from parsimony analysis based on combined ITS and GPDH sequenced data of Curvularia. Parsimony bootstrap support values greater than $50 \%$ are indicated above the nodes. The ex-type (ex-epitype) and voucher strains are in bold. The scale bar indicates ten changes. The tree is rooted with Alternaria alternata

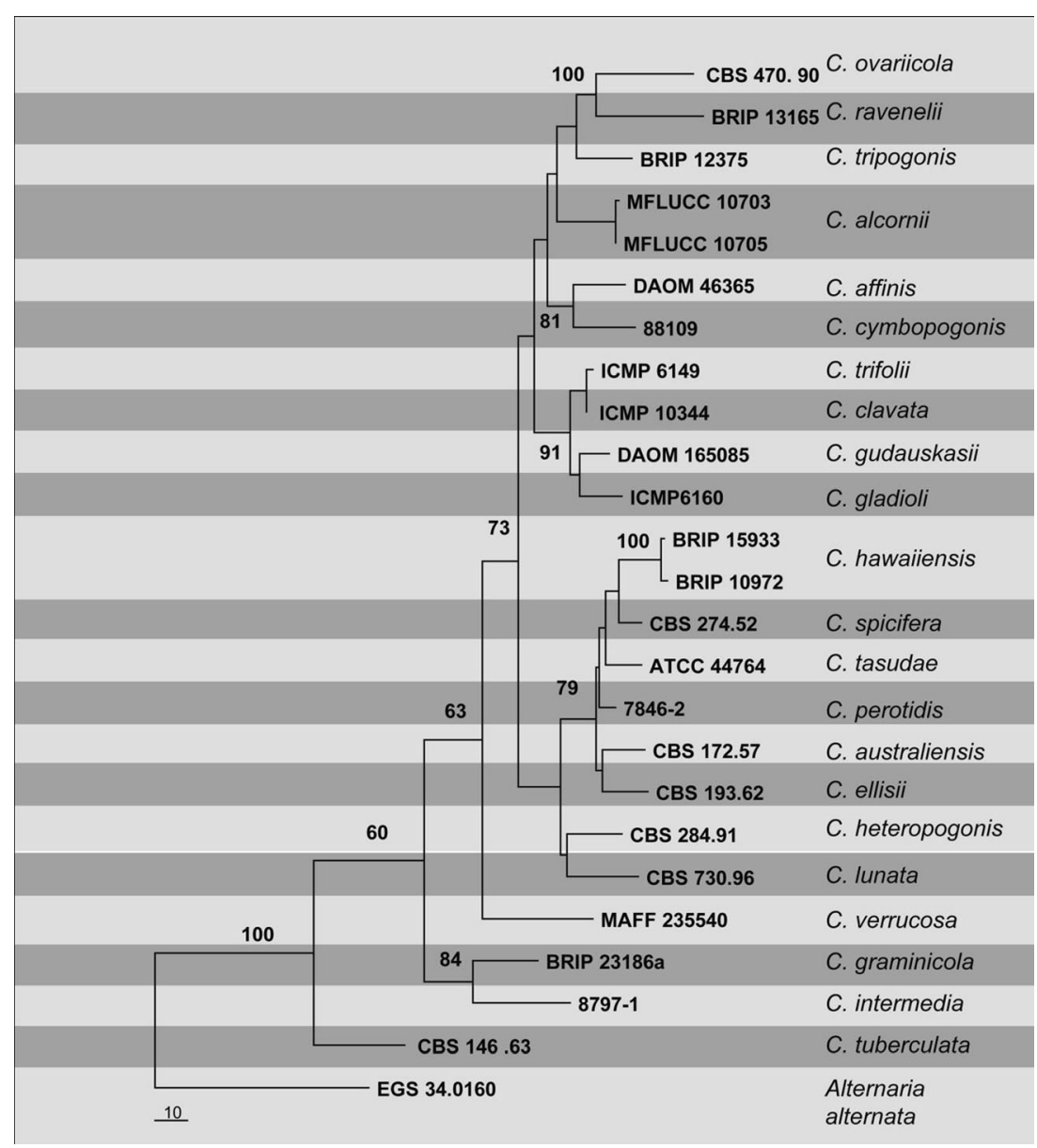

species listed in databases and literature. The delimitation of species within the genus Diaporthe improved once DNA sequence data were incorporated (Castlebury and Mengistu 2006; Van Rensburg et al. 2006; Santos et al. 2010; Udayanga et al. 2012b, 2014a, b), since this facilitates obtaining detailed insight into complex evolutionary relationships.

\section{Molecular phylogeny}

Since the first molecular phylogenetic study in Diaporthe (Rehner and Uecker 1994), rDNA ITS, partial sequences of translation elongation factor $1-\alpha$ (TEF) and mating type genes (MAT 1-1-1/1-2-1) have commonly been used in molecular phylogenetic studies in this genus (Van Niekerk et al. 2005; Van Rensburg et al. 2006; Santos et al. 2010; Udayanga et al. 2011; Sun et al. 2012). Udayanga et al. (2012a) used ITS, TEF, $\beta$ - tubulin and CAL genes with a selected set of ex-type cultures and additional isolates to infer the phylogeny of the genus. In a parallel study, a multi-marker phylogeny was effectively used to describe novel species in Diaporthe based on fresh collections from Thailand (Udayanga et al. 2012b). Gomes et al. (2013) used a Brazilian collection of isolates and existing ex-type cultures for a combined phylogenetic analysis of five genetic markers which included ITS, TEF, $\beta$ - tubulin, CAL and HIS. They introduced several novel taxa from Brazilian collections from medicinal plants with one epitype for Diaporthe anarcardi from Kenya. Udayanga et al. (2014a, b) revisited the Diaporthe species associated with Citrus worldwide with comprehensive assessment of the genes including ITS, TEF, $\beta$ - tubulin, CAL and ACT. The study revisited several important phytopathogens including D. citri, D. cytosporella, D. forniculina and $D$. rudis, with the epitypes designated with modern descriptions. The clarification of $D$. foeniculaina and $D$. rudis revealed the potential extensive host association of some species.

Udayanga et al. (2014a) further emphasized that ITS alone can cause much confusion in defining closely related taxa, which has also been noted by several previous researchers regarding closely related species in Diaporthe (Farr et al. 2002a, b; Murali et al. 2006; Santos et al. 2010). The variation of ITS sequences can result in superfluous, multiple terminal branches in combined analyses, even when other gene regions do not support these distinctions 
(Udayanga et al. 2014a, b). The TEF gene is informative when it comes to clarifying species limits in Diaporthe (Table 9, Fig. 10).

\section{Recommendations}

ITS and TEF are recommended for preliminary identification of the species (Castlebury et al. 2001; Castlebury 2005; Santos and Phillips 2009; Santos et al. 2010). ITS, TEF, $\beta$ - tubulin, CAL, HIS and ACT should be used in combined analysis (selection of 4-5 genes), with recommended primers in relevant publications (Udayanga et al. 2012b, 2014a, b; Gomes et al. 2013).

\section{Diplodia}

\section{Background}

Species of Diplodia (Botryosphaeriaceae) are endophytes, pathogens, or saprobes associated with cankers, dieback and fruit rot (Crous et al. 2006; Slippers and Wingfield 2007) in a wide range of hosts of agricultural and forestry importance (Farr and Rossman 2014). Cryptic speciation is common in the genus Diplodia, which makes species identification difficult if only based on morphological characters (Phillips et al. 2012, 2013). Denman et al. (2000) suggested that Lasiodiplodia could be a synonym of Diplodia, however recent studies accepted them as distinct genera (Pavlic et al. 2004; Burgess et al. 2006; Damm et al. 2007; Alves et al. 2008).

The genus Diplodia was introduced by Montagne (1834) with concepts altering over the years and has been regarded as including species with dark brown, 1-septate conidia (Phillips et al. 2005). Diplodia is defined by having uni or multilocular conidiomata lined with conidiogenous cells that form hyaline, aseptate, thick-walled conidia at their tips (Phillips et al. 2005). Diplodia mutila is the type species of Diplodia (Montagne 1834; Fries 1849), however, there are no living cultures linked to the holotype. As this has severely hampered studies on taxonomy and phylogeny of Diplodia, Alves et al. (2004) provided a detailed description of this species based on one isolate from grapevines in Portugal (CBS 112553).

Species identification and numbers

Diplodia is a large genus and a search in MycoBank (2014) revealed 1,317 names. Species in Diplodia were described, often based on host association, which later resulted in a proliferation of species names. According to Slippers et al. (2004d), host is not of primary importance in species differentiation, thus, many of the names in Diplodia are likely to be synonyms.

Based on DNA sequence data (single or multimarker) and minor differences in conidial morphology, there are currently about 20 Diplodia species (de Wet et al. 2003; Alves et al. 2004, 2006; Gure et al. 2005; Damm et al. 2007; Lazzizera et al. 2008; Pérez et al. 2010; Jami et al. 2012; Phillips et al. 2012, 2013; Linaldeddu et al. 2013; Lynch et al. 2013). The phylogenetic analysis was performed based on up to date holotype or ex-epitype sequence data available in GenBank (Table 10).

\section{Molecular phylogeny}

Studies on the taxonomy and phylogeny of Diplodia were hampered by a lack of an ex-type culture linked to the generic type, D. mutila. A collection of D. mutila from Populus with an ex-type culture was designated as epitype by Alves et al. (2014). They obtained a large collection of Diplodia strains from ash and other woody hosts showing V-shaped cankers and branch dieback. These strains were identified based on morphological characters and DNA sequence data. Since 2003 several new species have been described in Diplodia and these species were recognized mainly from DNA sequence data. Diplodia scrobiculata was differentiated from D. sapinea on the basis of multiple gene genealogies inferred from six protein coding genes and six microsatellite loci (de Wet et al. 2003). Diplodia africana (Damm et al. 2007), D. olivarum (Lazzizera et al. 2008) and D. cupressi (Alves et al. 2006) have been differentiated from D. mutila on the basis of formation of distinct clades in phylogenies based on ITS and TEF sequence data and due to their unique conidial morphology (Phillips et al. 2012).

Combined morphological and phylogenetic analyses of DNA sequence data from ITS and TEF (Alves et al. 2014) showed that the Fraxinus isolates from Italy, Netherlands, Portugal and Spain belong to three distinct species namely Diplodia fraxini, D. mutila and D. subglobosa. The phylogenetic tree constructed with holotype or ex-epitype sequences is presented in Fig. 11.

Recommended genetic markers

- LSU and SSU-generic level

- ITS, TEF and $\beta$-tubulin-species level

ITS, TEF and $\beta$-tubulin are the common genetic markers used in identification of Diplodia species. Combined ITS and TEF genes provide satisfactory resolution for resolving species.

\section{Dothiorella}

Background

Dothiorella (Botryosphaeriaceae) was proposed by Saccardo in 1880 (Crous and Palm 1999) with D. pyrenophora as the 
Table 9 Diaporthe. Details of the isolates used in the phylogenetic tree

\begin{tabular}{|c|c|c|c|c|c|c|}
\hline \multirow[t]{2}{*}{ Species } & \multirow[t]{2}{*}{ Isolate } & \multirow[t]{2}{*}{ Host } & \multicolumn{4}{|c|}{ GeneBank accession numbers } \\
\hline & & & ITS & $\beta$-tubulin & TEF $1-\alpha$ & CAL \\
\hline Diaporthe acaciigena & CBS 129521* & Acacia retinodes & KC343005 & KC343973 & KC343731 & KC343247 \\
\hline D. alleghaniensis & CBS 495.72* & Betula alleghaniensis & KC343007 & KC343975 & KC343733 & KC343249 \\
\hline D. alnea & CBS 146.46* & Alnus sp. & KC343008 & KC343976 & KC343734 & KC343250 \\
\hline D. ambigua & CBS 114015* & Pyrus communis & KC343010 & KC343978 & KC343736 & KC343252 \\
\hline D. ampelina & CBS 114016* & Vitis vinifera & AF230751 & JX275452 & AY745056 & AY230751 \\
\hline D. amygdali & CBS 126679* & Prunus dulcis & KC343022 & KC343990 & AY343748 & KC343264 \\
\hline D. anacardii & CBS 720.97* & Anacardium ocidentale & KC343024 & KC343992 & KC343750 & KC343266 \\
\hline D. angelicae & CBS 111592* & Heracleum sphondylium & KC343027 & KC343995 & KC343753 & KC343269 \\
\hline D. aquatica & IFRDCC 3051* & - & JQ797437 & - & - & - \\
\hline D. arecae & CBS 161.64* & Areca catechu & KC343032 & KC344000 & KC343758 & KC343274 \\
\hline D. arengae & CBS 114979* & Arenga engleri & KC343034 & KC344002 & КC343760 & KC343276 \\
\hline D. aspalathi & CBS 117169* & Aspalathus linearis & KC343036 & KC344004 & KC343762 & KC343278 \\
\hline D. australafricana & CBS 111886* & Vitis vinifera & KC343038 & KC344006 & KC343764 & KC343280 \\
\hline D. beilharziae & BRIP 54792* & Indigofera australis & JX862529 & KF170921 & JX862535 & - \\
\hline D. bicincta & CBS 121004* & Juglans sp. & KC343134 & KC344102 & KC343860 & KC343376 \\
\hline D. brasiliensis & CBS 133183* & Aspidosperma tomentosum & KC343042 & KC344010 & KC343768 & KC343284 \\
\hline D. caulivora & CBS 127268* & Glycine max & KC343045 & KC344013 & KC343771 & KC343287 \\
\hline D. celastrina & CBS 139.27* & Celastrus sp & KC343047 & KC344015 & KC343773 & KC343289 \\
\hline D. citri & CBS 135422* & Citrus sp. & KC843311 & KC843187 & KC843071 & KC843157 \\
\hline D. citriasiana & ZJUD 30* & Citrus sp. & JQ954645 & KC357459 & JQ954663 & КC357491 \\
\hline D. citrichinensis & ZJUD 34* & Citrus sp. & JQ954648 & & JQ954666 & КC357494 \\
\hline D. crotalariae & CBS 162.33* & Crotalaria spectabilis & KC343056 & KC344024 & KC343782 & KC343298 \\
\hline D. cuppatea & CBS 117499* & Aspalathus linearis & KC343057 & KC344025 & KC343783 & KC343299 \\
\hline D. cynaroidis & CBS 122676* & Protea cynaroides & KC343058 & KC344026 & KC343784 & KC343300 \\
\hline D. cytosporella & FAU461* & Citrus limon & KC843307 & KC843221 & KC843116 & KC843141 \\
\hline D. endophytica & CBS 133811* & Schinus terebinthifolius & KC343065 & KC343065 & KC343791 & KC343307 \\
\hline D. eres & AR5193* & Ulmus Sp. & KJ210529 & KJ420799 & $\mathrm{KJ} 210550$ & KJ434999 \\
\hline P. cotoneastri & CBS 439.82* & Cotoneaster sp. & KC343090 & KC344058 & KC343816 & KC343332 \\
\hline D. fraxini-angustifoliae & BRIP 54781* & Fraxinus angustifolia & JX862528 & KF170920 & JX862534 & - \\
\hline D. foeniculina & CBS 123208* & Foeniculum vulgare & KC343104 & KC344072 & KC343830 & KC343346 \\
\hline D. foeniculina & CBS 123209* & Foeniculum vulgare & KC343105 & KC344073 & KC343831 & KC343347 \\
\hline D. foeniculina & CBS 187.27* & Camellia sinensis & KC343107 & KC344075 & KC343833 & KC343349 \\
\hline D. ganjae & CBS 180.91* & Cannabis sativa & KC343112 & KC344080 & KC343838 & KC343354 \\
\hline D. gulyae & BRIP 54025* & Helianthus annuus & JF431299 & - & JN645803 & - \\
\hline D. helianthi & CBS 592.81* & Helianthus annuus & KC343115 & KC344083 & KC343841 & KC343357 \\
\hline D. helicis & AR5211* & Hedera helix & KJ210538 & KJ420828 & KJ210559 & KJ435043 \\
\hline D. hickoriae & CBS 145.26* & Carya glabra & KC343118 & KC344086 & KC343844 & KC343360 \\
\hline D. hongkongensis & CBS 115448* & Dichroa febrifuga & KC343119 & KC344087 & KC343845 & KC343361 \\
\hline D. inconspicua & CBS 133813* & Maytenus ilicifolia & KC343123 & KC344091 & KC343849 & KC343365 \\
\hline D. infecunda & CBS 133812* & Schinus terebinthifolius & KC343126 & KC344094 & KC343852 & KC343852 \\
\hline D. kochmanii & BRIP 54033* & Helianthus annuus & JF431295 & - & JN645809 & - \\
\hline D. kongii & BRIP 54031* & Helianthus annuus & JF431301 & - & JN645797 & - \\
\hline D. longispora & CBS 194.36* & Ribes sp. & KC343135 & KC344103 & KC343861 & KC343377 \\
\hline D. lusitanicae & CBS 123212* & Foeniculum vulgare & KC343136 & KC344104 & KC343862 & KC343378 \\
\hline D. mayteni & CBS 133185* & Maytenus ilicifolia & KC343139 & KC344107 & KC343865 & KC343381 \\
\hline D. melonis & CBS 507.78* & Glycine soja & KC343141 & KC344109 & $\mathrm{KC} 343867$ & KC343383 \\
\hline D. musigena & CBS 129519* & Musa sp. & KC343143 & KC344111 & КC343869 & KC343385 \\
\hline
\end{tabular}


Table 9 (continued)

\begin{tabular}{|c|c|c|c|c|c|c|}
\hline \multirow[t]{2}{*}{ Species } & \multirow[t]{2}{*}{ Isolate } & \multirow[t]{2}{*}{ Host } & \multicolumn{4}{|c|}{ GeneBank accession numbers } \\
\hline & & & ITS & $\beta$-tubulin & TEF $1-\alpha$ & CAL \\
\hline D. neoarctii & CBS 109490* & Ambrosia trifida & KC343145 & KC344113 & KC343871 & KC343387 \\
\hline D. nothofagi & BRIP 54801* & Nothofagus cunninghamii & JX862530 & KF170922 & JX862536 & - \\
\hline D. novem & CBS 127270* & Glycine $\max$ & KC343155 & $\mathrm{KC} 344123$ & KC343881 & KC343397 \\
\hline D. oxe & CBS 133186* & Maytenus ilicifolia & KC343164 & KC344132 & KC343890 & KC343406 \\
\hline D. paranensis & CBS 133184* & Maytenus ilicifolia & KC343171 & KC344139 & КC343897 & KC343413 \\
\hline D. pascoei & BRIP 54847* & Persea americana & JX862532 & KF170924 & JX862538 & - \\
\hline D. perjuncta & CBS 109745* & Ulmus glabra & KC343172 & KC344140 & KC343898 & KC343414 \\
\hline D. pseudomangiferae & CBS 101339* & Mangifera indica & KC343181 & KC344149 & KC343907 & KC343423 \\
\hline D. pseudophoenicicola & CBS 462.69* & Mangifera indica & KC343183 & KC344151 & KC343909 & KC343425 \\
\hline D. psoraleae & CBS 136412* & Psoralea pinnata & KF777158 & KF777251 & KF777245 & - \\
\hline D. psoraleae-pinnatae & CBS 136413 & Psoralea pinnata & KF777159 & KF777252 & - & - \\
\hline D. pterocarpi & MFLUCC 10-0571* & Pterocarpus indicus & JQ619899 & JX275460 & JX275416 & JX197451 \\
\hline D. pterocarpicola & MFLUCC 10-0580* & Pterocarpus indicus & JQ619887 & JX275441 & JX275403 & JX197433 \\
\hline D. pulla & CBS 338.89* & Hedera helix & KC343152 & KC344120 & KC343878 & KC343394 \\
\hline D. raonikayaporum & CBS 133182* & Spondias mombin & KC343188 & KC344156 & КC343914 & KC343430 \\
\hline D. rudis & CBS 109291* & Laburnum anagyroides & KC843331 & KC843177 & KC843090 & KC843146 \\
\hline D. rudis & CBS 113201* & Vitis vinifera & KC343234 & KC344202 & KC343960 & KC343476 \\
\hline D. saccarata & CBS 116311* & Protea repens & KC343190 & KC344158 & KC343916 & KC343432 \\
\hline D. salicicola & BRIP 54825* & Salix purpurea & JX862531 & JX862531 & JX862537 & - \\
\hline D. schini & CBS 133181* & Schinus terebinthifolius & KC343191 & KC344159 & KC343917 & KC343433 \\
\hline D. sclerotioides & CBS 296.67* & Cucumis sativus & KC343193 & KC344161 & KC343919 & KC343435 \\
\hline D. siamensis & MFLUCC 10-0573a* & Dasymaschalon sp. & JQ619879 & JX275429 & JX275393 & - \\
\hline D. terebinthifolii & CBS 133180* & Schinus terebinthifolius & KC343216 & KC344184 & KC343942 & KC343458 \\
\hline D. thunbergii & MFLUCC 10-0576* & Thunbergia grandifolia & JQ619893 & JX275449 & JX275409 & JX197440 \\
\hline D. toxica & CBS 534.93* & Lupinus angustifolius & KC343220 & KC344188 & KC343946 & KC343462 \\
\hline Diaporthella corylina & CBS 121124* & Corylus sp. & KC343004 & KC343972 & KC343730 & KC343246 \\
\hline P. lithocarpus & CGMCC 3.15175* & Lithocarpus glabra & KC153104 & - & KC153095 & - \\
\hline P. mahothocarpus & CGMCC 3.15181* & Lithocarpus glabra & KC153096 & - & $\mathrm{KC} 153087$ & - \\
\hline P. ternstroemia & CGMCC 3.15183* & Ternstroemia gymnanthera & KC153098 & - & KC153089 & - \\
\hline
\end{tabular}

Ex-type (ex-epitype) strains are bolded and marked with an * and voucher stains are bolded

generic type. The delimitation of the genus has been in a state of flux since it was introduced, and detailed explanations of its taxonomy have been given by Sutton (1977), Crous and Palm (1999) and Phillips et al. (2008, 2013). Crous and Palm (1999) examined the holotype of $D$. pyrenophora and synonymised Dothiorella under Diplodia based on a broad morphological concept of Diplodia. That treatment was followed by Denman et al. (2000), Zhou and Stanosz (2001) and Slippers et al. (2004a). Phillips et al. (2005) re-examined the type of $D$. pyrenophora and found that the conidia become brown and 1-septate when they are still attached to the conidiogenous cells, while in Diplodia the conidia are hyaline and become dark and septate only after discharge from the conidiomata. Crous et al. (2006) confirmed these morphological differences by re-examining types of both Diplodia and Dothiorella. The sexual state of the species is rarely found in nature and no sexual morph was formed in culture for any of the species, except for $D$. sarmentorum and D. iberica. Therefore, differentiation of species is mostly derived based on the asexual morphs and cultural characteristics.

Species identification and numbers

As members of Botryosphaeriaceae, species of Dothiorella are known as endophytes, pathogens and saprobes in association with various woody plants, and species in Dothiorella were

Fig. 10 Phylogram generated from parsimony analysis based on combined ITS, EF1- $\alpha, \beta$ - tubulin, and CAL sequenced data of Diaporthe. Parsimony bootstrap support values and Bayesian posterior probabilities greater than $50 \%$ are indicated above the nodes. The ex-type (ex-epitype) and voucher strains are in bold. The tree is rooted with Diaporthella corylina CBS 121124 


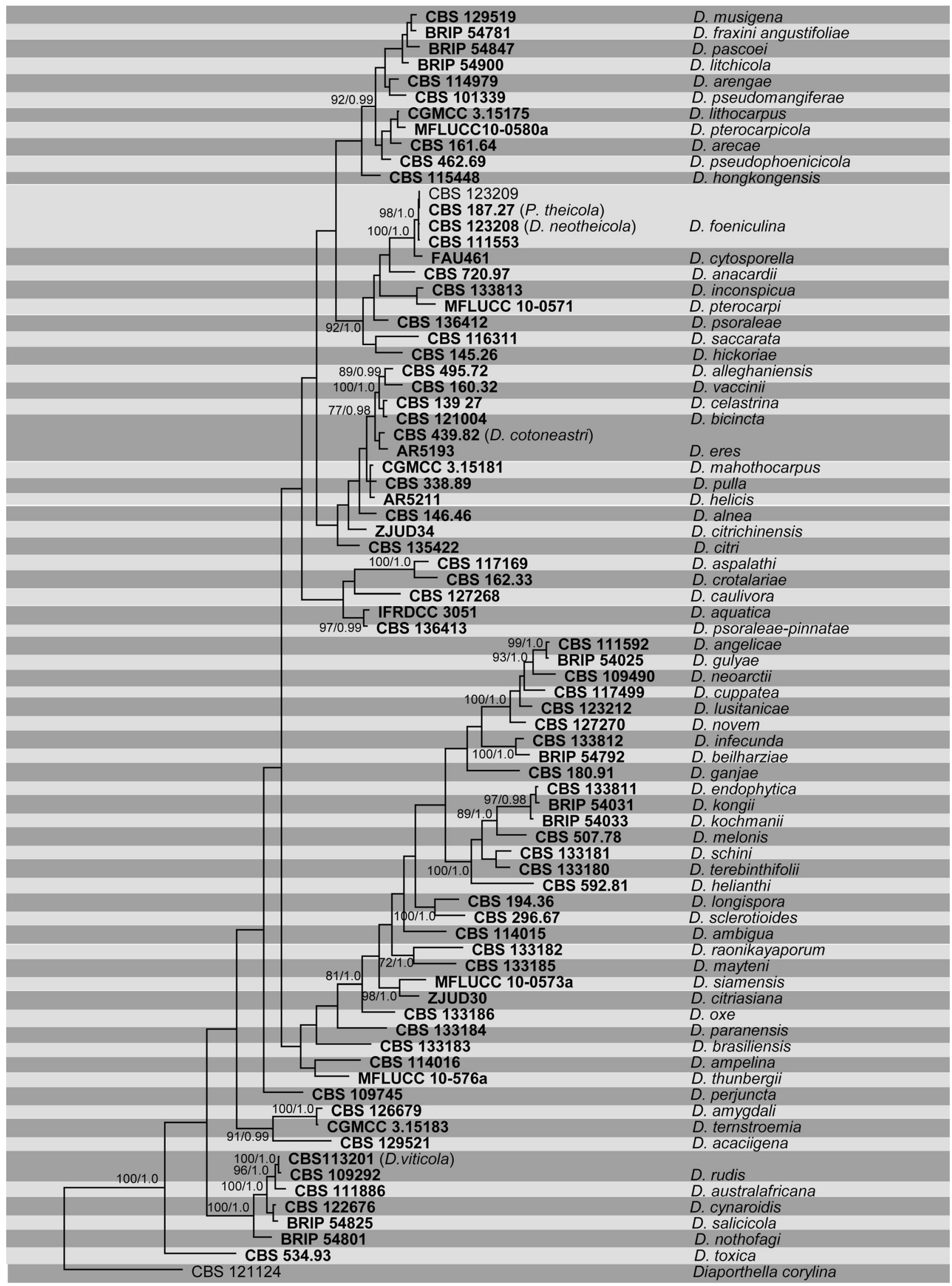

100 
Table 10 Diplodia. Details of the isolates used in the phylogenetic tree

\begin{tabular}{|c|c|c|c|c|c|}
\hline \multirow[t]{2}{*}{ Species } & \multirow[t]{2}{*}{ Isolate no. } & \multirow[t]{2}{*}{ Host } & \multicolumn{3}{|l|}{ GenBank } \\
\hline & & & ITS & TEF & $\beta$-tubulin \\
\hline Diplodia africana & CBS 120835* & Prunus persica & EF445343 & EF445382 & - \\
\hline D. agrifolia & CBS 132777* & Quercus agrifolia & JN693507 & JQ517317 & JQ411459 \\
\hline D. alatafructa & CBS 124931* & Pterocarpus angolensis & FJ888460 & FJ888444 & - \\
\hline D. allocellula & CBS 130408* & Acacia karroo & JQ239397 & JQ239384 & JQ239378 \\
\hline D. bulgarica & CBS 124254* & Malus sylvestris & GQ923853 & GQ923821 & - \\
\hline D. corticola & CBS 112549* & Quercus suber & AY259100 & AY573227 & DQ458853 \\
\hline D. cupressi & CBS 168.87* & Cupressus sempervirens & DQ458893 & DQ458878 & DQ458861 \\
\hline D. fraxini & CBS 136010* & Fraxinus angustifolia & KF307700 & KF318747 & - \\
\hline D. intermedia & CBS 124462* & Malus sylvestris & GQ923858 & GQ923826 & - \\
\hline D. malorum & CBS 124130* & Malus sylvestris & GQ923865 & GQ923833 & - \\
\hline D. mutila & CBS 112553* & Vitis vinifera & AY259093 & AY573219 & DQ458850 \\
\hline D. olivarum & CBS 121887* & Olea europaea & EU392302 & EU392279 & HQ660079 \\
\hline D. sapinea & CBS 393.84* & Pinus nigra & DQ458895 & DQ458880 & - \\
\hline D. pseudoseriata & CBS 124906* & Blepharocalyx salicifolius & EU080927 & EU863181 & - \\
\hline D. quercivora & CBS 133852* & Quercus canariensis & JX894205 & JX894229 & - \\
\hline D. rosulata & CBS 116470* & Prunus africana & EU430265 & EU430267 & EU673132 \\
\hline D. scrobiculata & CBS 109944* & Pinus greggii & DQ458899 & DQ458884 & AY624258 \\
\hline D. seriata & CBS 112555* & Vitis vinifera & AY259093 & AY573219 & DQ458856 \\
\hline D. subglobosa & CBS 124133* & Lonicera nigra & GQ923856 & GQ923824 & - \\
\hline D. tsugae & CBS 418.64* & Tsuga heterophylla & DQ458888 & DQ458873 & DQ458855 \\
\hline Lasiodiplodia theobromae & CBS 164.96* & Fruit along coral reef coast & AY640255 & AY640258 & EU673110 \\
\hline
\end{tabular}

Ex-type (ex-epitype) strains are bolded and marked with an * and voucher stains are bolded

mostly described based on host association, much as for other members of Botryosphaeriaceae. This led to the introduction of many species names, and there are 368 epithets for Dothiorella in Index Fungorum (2014) and 393 species names in MycoBank (2014). Slippers et al. (2013) suggested that host association should not be considered an important factor in species definition of the Botryosphaeriaceae, therefore most of these names are likely synonyms. There are 19 described species with available cultures, and with the exception of $D$. sarmentorum all have been described after 2005. The phylogenetic analysis was performed based on up to date holotype or ex-epitype sequence data available in GenBank (Table 11).

\section{Molecular phylogeny}

Phillips et al. (2005) broadened the concept of Botryosphaeria and included Dothiorella in Botryosphaeria based on ITS analysis. Crous et al. (2006) recognised ten lineages within Botryosphaeriaceae corresponding to different genera based on phylogenetic analysis of 28S rDNA, and the three species $D$. iberica, D. sarmentorum and D. viticola formed a clade within Botryosphaeriaceae. These were assigned to Dothidotthia. Subsequently, Phillips et al. (2008) showed that
Do. symphoricarpa (the type species of Dothidotthia) belongs in a distinct family within the Pleosporales, while $D$. sarmentorum, D. iberica and D. viticola fall within two separate genera in the Botryosphaeriaceae and a new genus, Spencermartinsia was introduced to accommodate D. viticola. Phillips et al. (2013) listed all cultures of available Dothiorella species, and provided a key to species, as well as a phylogenetic tree. Abdollahzadeh et al. (2014) introduced five new Dothiorella species which were associated with woody plants in Iran, New Zealand, Portugal and Spain. The phylogenetic tree constructed with holotype or ex-epitype sequences is presented in Fig. 12.

Recommended genetic markers

- ITS-placement within the Botryosphaeriaceae (the generic level), and also some specific delineation.

- TEF-the generic level and inter-specific delineation.

- $\beta$-tubulin-inter-specific delineation.

Slippers et al. (2013) suggested that all of the known species of Dothiorella in culture can be separated based solely on ITS, but bootstrap support values for some of the internal nodes are quite low. Due to the studies on the other members 
Fig. 11 Phylogram generated from parsimony analysis based on combined ITS, TEF and $\beta$ tubulin sequenced data of Diplodia. Parsimony bootstrap support values and Bayesian posterior probabilities greater than $50 \%$ are indicated above the nodes. The ex-type (ex-epitype) and voucher strains are in bold. The tree is rooted with Lasiodiplodia theobromae CBS 164.96

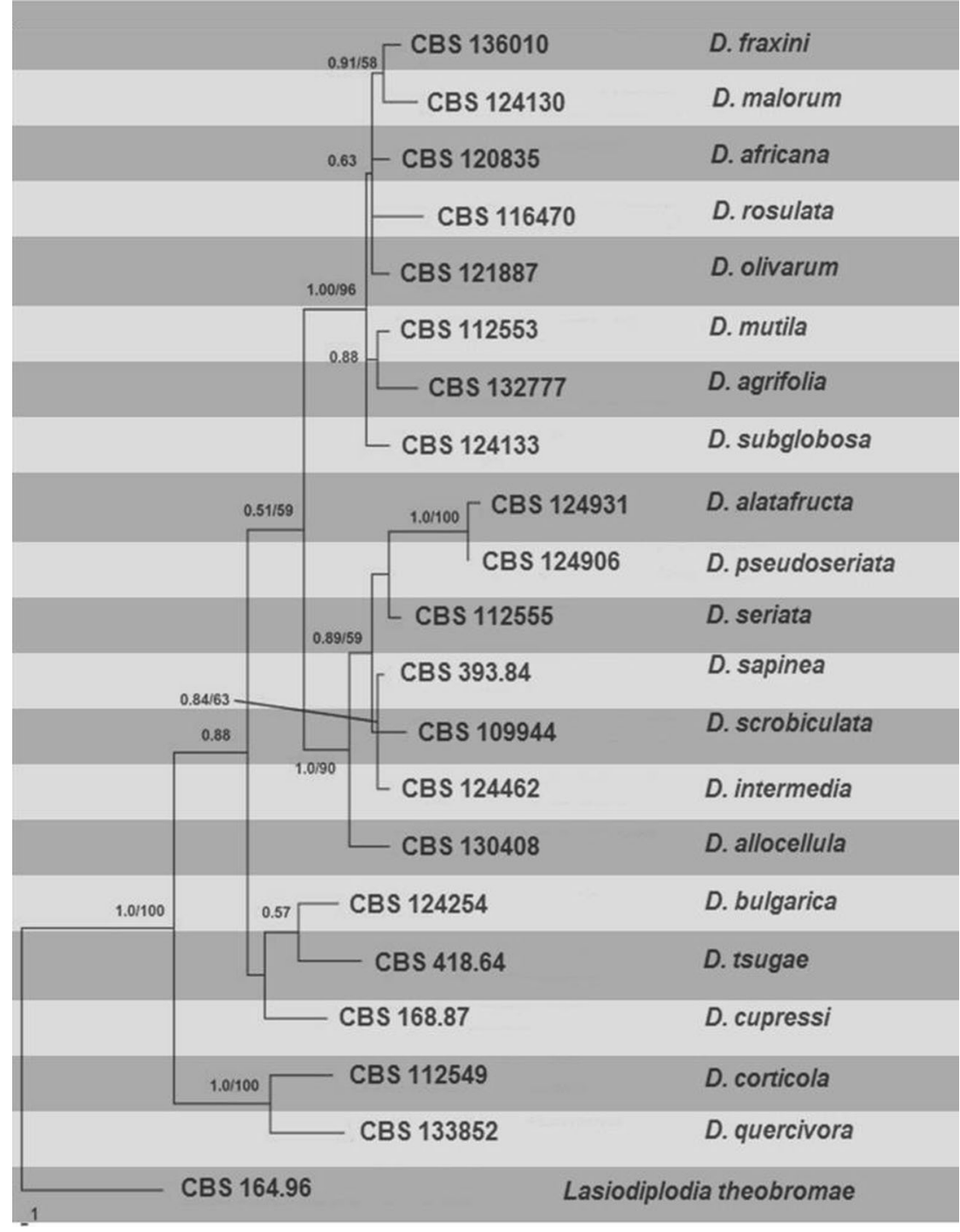

of Botryosphaeriaceae, therefore, we strongly recommend that it is necessary to combine ITS and TEF (or intended $\beta$ tubulin gene) when molecular studies are carried out on Dothiorella.

\section{Fusarium}

\section{Background}

The genus Fusarium was described by Link (1809) and later became a sanctioned name (Fries 1821). It is based on the type species Fusarium sambucinum (Nirenberg 1995). Species in Fusarium were described largely on the basis of the morphology of the canoe shaped septate conidia produced by most species as well as the shape and formation of other asexual spores Leslie and Summerell 2006). The sexual morphs (ascospores produced in perithecia) have played little role in the differentiation of most species as they are rare, if produced at all (Seifert 2001). Fusarium includes a number of species that are very important plant pathogens, some that are potent producers of an array of mycotoxins and several species or species complexes that are involved in diseases of humans (Leslie and Summerell 2006). There are also many species that are apparently endophytic in plants as well as species that are saprobes in soil and in organic matter.

Two species, $F$. graminearum and $F$. oxysporum, were included in an assessment of the top 10 fungal plant pathogens by Dean et al. (2012). Fusarium graminearum is the cause of head blight of wheat (Windels 2000), and $F$. oxysporum causes wilt diseases in a range of crops including bananas, tomatoes and other vegetables as well as cotton (Beckman 1987). Other species of Fusarium cause stalk and cob rots in maize and sorghum, canker diseases in woody plants and root and crown diseases across a vast spectrum of plant species (Summerell et al. 
Table 11 Dothiorella. Details of the isolates used in the phylogenetic tree
Ex-type (ex-epitype) strains are bolded and marked with an * and voucher stains are bolded

\begin{tabular}{|c|c|c|c|c|}
\hline Species name & Strain no. & Host & ITS & TEF \\
\hline Dothiorella americana & CBS 128309* & Vitis sp. & HQ288218 & HQ288262 \\
\hline D. americana & CBS 128310 & Vitis sp. & HQ288219 & HQ288263 \\
\hline D. brevicollis & CBS 130411* & Acacia karroo & JQ239403 & JQ239390 \\
\hline D. brevicollis & CBS 130412 & Acacia karroo & JQ239404 & JQ239391 \\
\hline D. casuarinae & CBS 120688* & Casuarina sp. & DQ846773 & DQ875331 \\
\hline D. casuarinae & CBS 120690 & Casuarina $\mathrm{sp}$. & DQ846774 & DQ875333 \\
\hline D. dulcispinae & CBS 130413* & Acacia karroo & JQ239400 & JQ239387 \\
\hline D. dulcispinae & CBS 130414 & Acacia karroo & JQ239401 & JQ239388 \\
\hline D. dulcispinae & CBS 130415 & Acacia karroo & JQ239402 & JQ239389 \\
\hline D. iberica & CBS 115041* & Quercus ilex & AY573202 & AY573222 \\
\hline D. iberica & CBS 113188 & Quercus ilex & AY573198 & EU673278 \\
\hline D. iberica & CAA 005 & Quercus ilex & EU673312 & EU673279 \\
\hline D. iranica & IRAN1587C* & Olea europaea & KC898231 & KC898214 \\
\hline D. longicollis & CBS 122068* & Lysiphyllum cunninghamii & EU144054 & EU144069 \\
\hline D. longicollis & CBS 122067 & Lysiphyllum cunninghamii & EU144052 & EU144067 \\
\hline D. moneti & MUCC 505* & Acacia rostellifera & EF591920 & EF591971 \\
\hline D. moneti & MUCC 507 & Acacia rostellifera & EF591922 & EF591973 \\
\hline D. parva & IRAN1579C* & Corylus avellana & KC898234 & KC898217 \\
\hline D. parva & IRAN1585C & Corylus avellana & KC898235 & KC898218 \\
\hline D. pretoriensis & CBS 130404* & Acacia karroo & JQ239405 & JQ239392 \\
\hline D. pretoriensis & CBS 130403 & Acacia karroo & JQ239406 & JQ239393 \\
\hline D. prunicola & IRAN1541* & Prunus dulcis & EU673313 & EU673280 \\
\hline D. Santali & MUCC 509* & Santalum acuminatum & EF591924 & EF591975 \\
\hline D. santali & MUCC 508 & Santalum acuminatum & EF591923 & EF591974 \\
\hline D. sarmentorum & IMI $63581 b^{*}$ & Ulmus sp. & AY573212 & AY573235 \\
\hline D. sarmentorum & CBS 115038 & Malus pumila & AY573206 & AY573223 \\
\hline D. sempervirentis & IRAN1581C & Cupressus sempervirens & KC898237 & KC898220 \\
\hline D. sempervirentis & IRAN1583C* & Cupressus sempervirens & KC898236 & KC898219 \\
\hline D. striata & ICMP16819 & Citrus sinensis & EU673320 & EU673287 \\
\hline D. striata* & ICMP16824* & Citrus sinensis & EU673321 & EU673288 \\
\hline D. thailandica & MFLUCC 11-0438* & Unknown & JX646796 & JX646861 \\
\hline D. thripsita & BRIP 51876* & Acacia harpophylla & FJ824738 & \\
\hline D. uruguayensis & CBS 124908* & Hexalamis edulis & EU080923 & EU863180 \\
\hline D. vidmadera & DAR78992* & Vitis vinifera & EU768874 & EU768881 \\
\hline D. vidmadera & DAR78993 & Vitis vinifera & EU768876 & EU768882 \\
\hline D. vidmadera & DAR78994 & Vitis vinifera & EU768877 & EU768883 \\
\hline Spencermartinsia viticola & CBS 117009* & Vitis vinifera & AY905554 & AY905559 \\
\hline
\end{tabular}

2011). Species of Fusarium produce a very large number of secondary metabolites, but two toxin groups, trichothecenes and fumonisins, are particularly detrimental to livestock and humans (through consumption) and as such are heavily regulated in many parts of the world (Desjardins 2005). As a result of the importance of these diseases, the genus is one of the most heavily researched of all genera of fungi and an enormous body of work on all facets of its biology exists (Leslie and Summerell 2006).

Several sexual morph genera are associated with Fusarium, the most important of which is Gibberella
(Desjardins 2003). Most Fusarium species, particularly the plant pathogenic species, have a Gibberella sexual morph. Other sexual morph genera include Albonectria, Haematonectria and Neocosmospora as well as a number of other generic names (Gräfenhan et al. 2011). With the changes to the International Code of Nomenclature for Algae, Fungi and Plants providing the opportunity to have a single name for fungi of this nature there has been a strong consensus amongst the community of researchers working on Fusarium that this name be used for all the fungi in the so-called 
Fig. 12 Phylogram generated from parsimony analysis based on combined ITS and TEF sequenced data of Dothiorella. Parsimony bootstrap support values greater than $50 \%$ are indicated above the nodes, and branches with Bayesian posterior probabilities greater than 0.95 are given in bold. The ex-type (exepitype) and voucher strains are in bold. The scale bar indicates ten changes. The tree is rooted with Spencermartinsia viticola CBS 117009

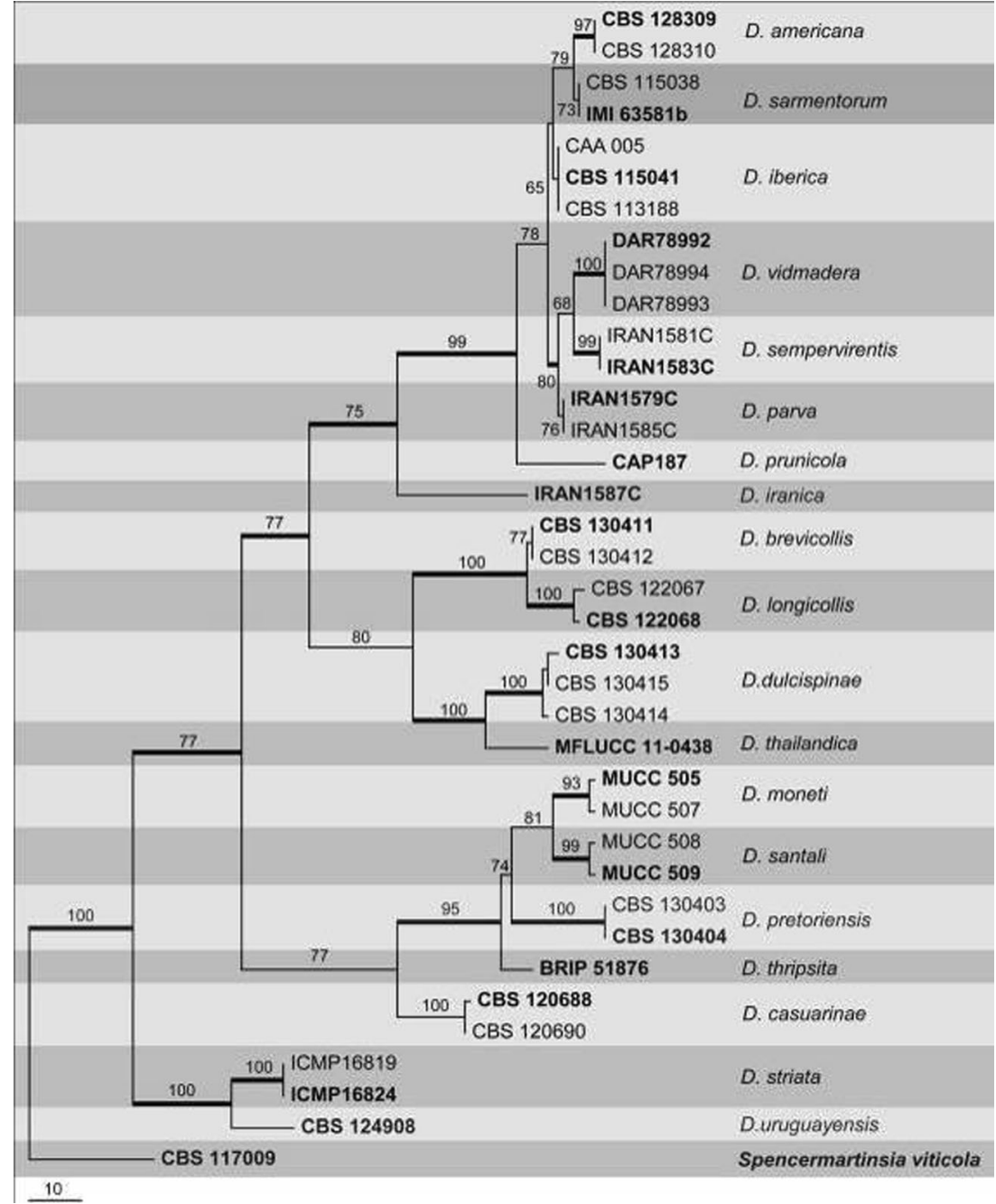

terminal Fusarium clade (Geiser et al. 2013). The end result of this is that species of Fusarium such as $F$. solani, $F$. decemcellulare and $F$. dimerum are included with species with Gibberella sexual morphs in the current generic definition of Fusarium (Geiser et al. 2013).

Species identification and numbers

It is difficult to accurately quantify the number of extant, currently recognized species of Fusarium. Over 1,500 names are listed in MycoBank; Leslie and Summerell (2006) documented 72 species, although this was not intended as a monograph, and many of species have been described in the intervening period (e.g. Jacobs et al. 2010; Laurence et al. 2011; Schroers et al. 2009; Walsh et al. 2010). Recent investigations into a number of important species (e.g. F. graminearum, F. incarnatum, F. oxysporum, F. solani) have provided evidence that they are complexes of phylogenetically distinct lineages that have been, or will eventually be described as species (Aoki et al. 2005; O'Donnell et al. 2004, 2008, 2009).

\section{Molecular phylogeny}

There has been substantial work on understanding the phylogenetic relationships within Fusarium, and in defining generic boundaries (e.g. Geiser et al. 2013; O'Donnell et al. 2013). This has provided refined concepts for several important plant pathogenic species (e.g. F. graminearum, $F$. pseudograminearum, F. subglutinans, F. verticillioides) and it has also shown that several important plant pathogens (especially $F$. oxysporum and $F$. solani) are in fact species complexes (Laurence et al. 2014; O’Donnell et al. 2008). A genus-wide phylogeny was inferred using the RNA polymerase largest subunit (RPB1) and RNA polymerase second largest subunit (RPB2) (O'Donnell et al. 2013), as these genes are very informative from a phylogenetic perspective across the whole genus (Table 12, Fig. 13) 
Table 12 Fusarium. Details of the isolates used in the phylogenetic tree

\begin{tabular}{lll}
\hline Species & Isolate & \multicolumn{2}{l}{ GenBank accession numbers } \\
\cline { 3 - 3 } & RPB1
\end{tabular}

Fusarium falciforme

F. solani

Fusarium sp.

F. ambrosium

F. phaseoli

F. virguliforme

Fusarium sp.

Fusarium sp.

Fusarium sp.

Fusarium sp.

F. aywerte

F. longipes

F. longipes

F. longipes

Fusarium cf. compactum

Fusarium sp.

F. sambucinum

F. venenatum

F. poae

F. sporotrichioides

F. langsethiae

F. armeniacum

F. asiaticum

F. graminearum

F. culmorum

F. pseudograminearum

F. equiseti

F. lacertarum

F. equiseti

Fusarium sp.

Fusarium sp.

F. subglutinans

F. circinatum

F. guttiforme

F. fujikuroi

F. proliferatum

F. mangiferae

F. sacchari

F. verticillioides

F. thapsinum

F. xylarioides

Fusarium sp.

F. nisikadoi

F. miscanthi

F. gaditjirrii

F. lyarnte

F. commune
NRRL 45880 JX171543

NRRL 22436 JX171497

NRRL 20438 JX171470

NRRL 22276 JX171495

NRRL $31041 \quad$ JX171530

NRRL 22632 JX171501

NRRL 13444 JX171454

NRRL 28578 JX171526

NRRL 13338 JX171447

NRRL 25410 JX171513

NRRL 13368 JX171448

NRRL 13374 JX171450

NRRL 20723 JX171483

NRRL 13829 JX171460

NRRL 31008 JX171529

NRRL 22187 JX171493

NRRL 22196 JX171494

NRRL 13714 JX171458

NRRL 3299 JX171444

NRRL $54940 \quad$ JX171550

NRRL 6227 JX171446

NRRL 13818 JX171459

NRRL 31084 JX171531

NRRL 25475 JX171515

NRRL 28062 JX171524

NRRL 13402 JX171452

NRRL 20423 JX171567

NRRL 20697 JX171481

NRRL 26417 JX171522

NRRL 32175 JX171532

NRRL 22016 JX171486

NRRL 25331 JX171510

NRRL 22945 JX171505

NRRL 13566 JX171456

NRRL 22944 JX171504

NRRL 25226 JX171509

NRRL 13999 JX171466

NRRL 20956 JX171485

NRRL $22045 \quad J X 171487$

NRRL 25486 JX171517

NRRL $52700 \quad$ JX171544

NRRL 25179 JX171507

NRRL $26231 \quad$ JX171521

NRRL 45417 JX171542

NRRL 54252 JX171549

NRRL 28387 JX171525

NRRL 43529 JX171541

Table 12 (continued)

\begin{tabular}{|c|c|c|c|}
\hline \multirow[t]{2}{*}{ Species } & \multirow[t]{2}{*}{ Isolate } & \multicolumn{2}{|c|}{ GenBank accession numbers } \\
\hline & & RPB1 & RPB2 \\
\hline F. inflexum & NRRL 20433 & JX171469 & JX171583 \\
\hline F. oxysporum & NRRL 25387 & JX171512 & JX171625 \\
\hline F. oxysporum & NRRL 34936 & JX171533 & JX171646 \\
\hline F. foetens & NRRL 38302 & JX171540 & JX171652 \\
\hline Fusarium sp. & NRRL 25184 & JX171508 & JX171621 \\
\hline F. redolens & NRRL 22901 & JX171503 & JX171616 \\
\hline F. hostae & NRRL 29889 & JX171527 & JX171640 \\
\hline Fusarium sp. & RBG 5116 & KJ716216 & HQ646395 \\
\hline F. burgessii & RBG 5319 & KJ716217 & HQ646392 \\
\hline F. beomiforme & NRRL 25174 & JX171506 & JX171619 \\
\hline F. concolor & NRRL 13459 & JX171455 & JX171569 \\
\hline F. anguioides & NRRL 25385 & JX171511 & JX171624 \\
\hline Fusarium sp. & NRRL 25533 & JX171518 & JX171631 \\
\hline F. babinda & NRRL 25539 & JX171519 & JX171632 \\
\hline Fusarium sp. & NRRL 22566 & JX171500 & JX171613 \\
\hline F. torulosum & NRRL 22748 & JX171502 & JX171615 \\
\hline F. flocciferum & NRRL 25473 & JX171514 & JX171627 \\
\hline F. tricinctum & NRRL 25481 & JX171516 & JX171629 \\
\hline F. nurragi & NRRL 36452 & JX171538 & JX171650 \\
\hline F. heterosporum & NRRL 20693 & JX171480 & JX171594 \\
\hline F. buharicum & NRRL 13371 & JX171449 & JX171563 \\
\hline F. sublunatum & NRRL 13384 & JX171451 & JX171565 \\
\hline F. lateritium & NRRL 13622 & JX171457 & JX171571 \\
\hline F. sarcochroum & NRRL 20472 & JX171472 & JX171586 \\
\hline F. stilbioides & NRRL 20429 & JX171468 & JX171582 \\
\hline Fusarium sp. & NRRL 54149 & JX171548 & JX171660 \\
\hline F. dimerum & NRRL 20691 & JX171478 & JX171592 \\
\hline F. lunatum & NRRL 36168 & JX171536 & JX171648 \\
\hline
\end{tabular}

Ex-type (ex-epitype) strains are bolded and marked with an * and voucher stains are bolded

Recommended genetic markers

The recommended and most frequently used gene for identification of species of Fusarium is the translation elongation factor $1 \alpha$ gene (TEF) and this is generally used for routine identifications, effectively performing a DNA barcoding function, and forms a significant component of the FUSARIUMID database (http://isolate.fusariumdb.org/; Geiser et al. 2004). This database provides a similar facility to GenBank but is based on sequences from accurately identified and validated cultures held in reference collections (Geiser et al. 2004). Using a standard approach (Summerell et al. 2003), sequencing the TEF gene and comparing the sequence with the FUSARIUM-ID database makes it possible to rapidly and accurately identify most pathogenic Fusarium species. The ITS region is less informative in Fusarium from both a 


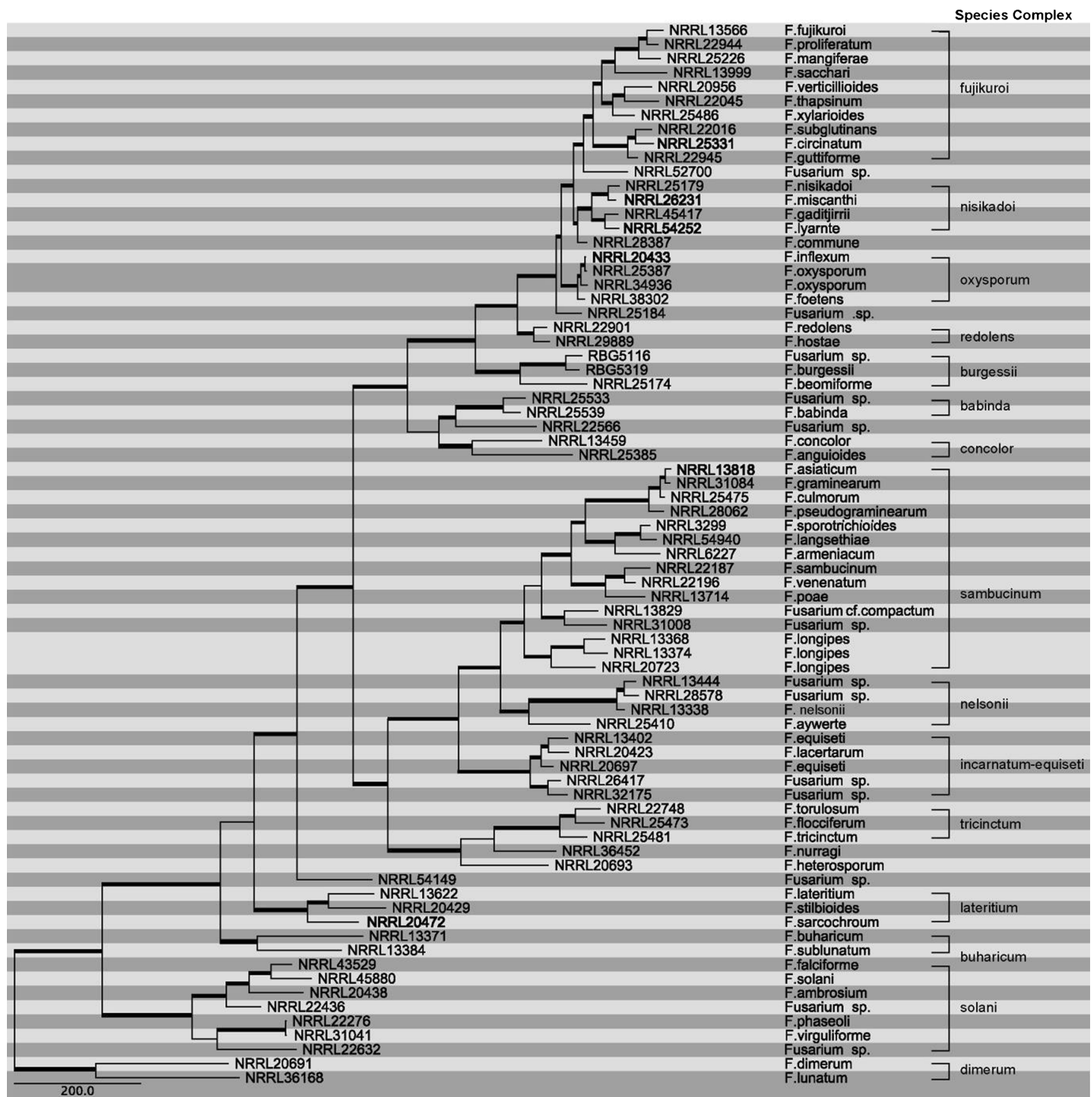

Fig. 13 Fusarium The single most parsimonious tree inferred from a combined $R P B 1$ and $R P B 2$ dataset indicating the phylogenetic relationships among species complexes in the genus Fusarium. Branches with bootstrap intervals greater than $70 \%$ and Bayesian posterior probabilities

barcoding and phylogenetic perspective and as a result it has not been used extensively. This is primarily because there are nonorthologous copies of ITS2 that are incongruent with species phylogenies derived from other unlinked loci in species of economic importance \{O'Donnell and Cigelnik (1997) $\# 1278$. As a consequence it is not recommended that ITS be used for differentiation or identification of Fusarium species (Summerell et al. 2003). greater than 0.95 are indicated in bold. The NRRL (Agricultural Research Service Culture Collection, Peoria, Illinois USA) and RBG (Royal Botanic Gardens Trust Culture Collection, Sydney, New South Wales, Australia) numbers are indicated for all reference taxa

\section{Gilbertella}

\section{Background}

The monotypic genus Gilbertella belongs to the family Choanephoraceae and subfamily Gilbertelloideae (Mucorales, former Zygomycota). It was established by Hesseltine (1960) for species described earlier as Choanephora persicaria by Eddy 
(1925), and consequently the type species of the genus is Gilbertella persicaria. Benny (1991) proposed a new family, Gilbertellaceae to accommodate this genus. Currently, the genus belongs to the family Choanephoraceae and subfamily Gilbertelloideae that can be distinguished from Choanephoroideae (Voigt and Kirk 2012) by ornamented zygospores and opposed suspensors (Voigt 2012). Although G. persicaria was originally described as Choanephora persicaria (Eddy 1925), its separate position within the family has been confirmed in several studies (Papp et al. 2003; Hoffmann et al. 2013).

In tropical and subtropical regions Gilbertella is a common postharvest pathogen, causing rots of pears (Mehrotra 1963a), peaches (Hesseltine 1960; Mehrotra 1963b; Ginting et al. 1996) and tomatoes (Mehrotra 1966). It was reported by Butler et al. (1960) and Hesseltine (1960) from mulberry (Morus sp.) in USA. It was also recently isolated from pitaya fruits (Hylocereus undatus, Cactaceae) in Japan (Taba et al. 2011) and China (Guo et al. 2012).

Species identification and numbers

Currently, Gilbertella persicaria is the only species within the genus. Although another species-Gilbertella hainanensis-has been described (Cheng and $\mathrm{Hu}$ 1965), after recent molecular studies of its ITS sequence, it is not currently recognized as a separate species (Walther et al. 2013). Two varieties of G. persicaria have been described: G. persicaria var. persicaria and G. persicaria var. indica, however only the former was accepted in the monograph published by Benny (1991).

Gilbertella persicaria produces sporangia with a persistent wall that ruptures at preformed sutures in two halves. Ellipsoid, smooth-walled, hyaline sporangiospores with polar appendages are released in droplet of fluid. Light brown ornamented zygospores are formed on opposed suspensors (Hesseltine 1960). Examination of morphology is usually enough for correct species identification. Moreover, the morphological identification may be easily confirmed by ITS sequencing (Table 13, Fig. 14).

Molecular phylogeny

The phylogenetic relationships based on the complete ITS region of Gilbertella representatives and related Mucorales taxa was completed by Papp et al. (2003). All Gilbertella cultures available in the CBS culture collection have been sequenced for their ITS region and were included in a molecular analysis by Walther et al. (2013). These studies showed that the universal fungal DNA barcoding marker-the ITS region (Schoch et al. 2012)-is sufficient for Gilbertella species identification (Fig. 16). The multi-marker phylogenetic analysis including representatives of this genus performed by Hoffmann et al. (2013), confirmed a distinct, well-supported position of Gilbertella within Choanephoraceae family.

Recommended genetic markers

- The internal transcribed spacer (ITS) region-generic and species level

- The large and small subunits (LSU and SSU) of nrDNAplacement within the Mucorales order, higher-level phylogeny

\section{Lasiodiplodia}

Background

Lasiodiplodia (Botryosphaeriaceae) was introduced by Ellis in 1894 with $L$. tubericola as the type species. Clendenin (1896) provided a description of the genus and the species, but did not refer to any type or other specimens of the genus or
Table 13 Gilbertella. Details of the isolates used in the phylogenetic tree

Ex-type (ex-epitype) strains are bolded and marked with an * and voucher stains are bolded

\begin{tabular}{llll}
\hline Species & Isolate & Host & GenBank no \\
\hline Gilbertella persicaria & CBS 190.32* & Prunus persica & HM999958 \\
G. persicaria & CBS 785.97 & - & JN206218 \\
G. persicaria & CBS 442.64 & - & JN206219 \\
G. persicaria & CBS 325.71A & Saccharum officinarum & JN206220 \\
G. persicaria & CBS 403.51 & - & JN206221 \\
G. persicaria & CBS 246.59 & Trickling filter plant system & JN206222 \\
G. persicaria & CBS 421.77 & Soil & JN206223 \\
G. persicaria & CBS 532.77 & Dung of mouse & JN206224 \\
G. persicaria & CBS 325.71D & Wood & JN206225 \\
G. persicaria & CBS 565.91 & Dung of swine & JN206226 \\
Choanephora cucurbitarum & CBS 120.25 & - & JN2062231 \\
C. cucurbitarum & CBS 150.51 & - & JN206232
\end{tabular}




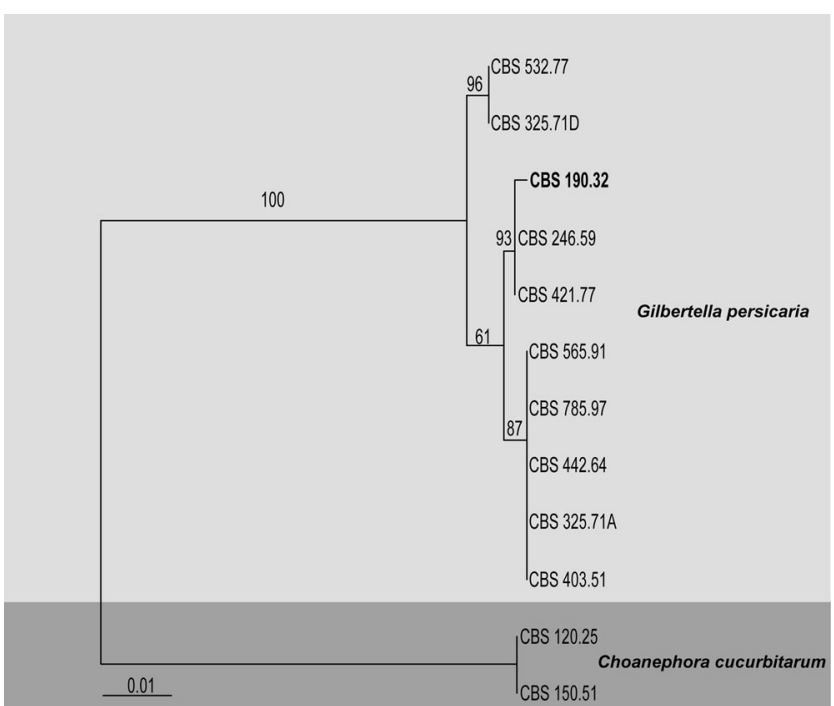

Fig. 14 Phylogram generated from Maximum likelihood analysis based on ITS sequenced data of Gilbertella. Bootstrap support values greater than $50 \%$ are indicated above the nodes. The ex-type (ex-epitype) and voucher strains are in bold

species. Pavlic et al. (2004) could not locate the types, nor find any specimens from the original hosts or origins, but gave a clear concept of the genus and the type. A new status for the type species of Lasiodiplodia has been proposed by Phillips et al. (2013) and they designated CBS 164.96 as ex-neotype culture, and deposited a dried specimen as neotype with convincing reasons, although this specimen was collected from an unidentified fruit in Papua New Guinea, whereas the type was collected in Ecuador on cocoa plant. Twenty new species have been described since 2004; however the generic application of the name, $L$. theobromae, has not been resolved.

Species identification and numbers

Lasiodiplodia differs from Diplodia species in having striations on the conidia, and differs from Neodeightonia as Lasiodiplodia has conidiomatal paraphyses. Barriopsis differs as it has unique striate conidia, with the striations present on immature, hyaline conidia. A sexual morph has been reported for $L$. theobromae, which has been linked to Botryodiplodia rhodina (Cooke) Arx, but this link has not been unequivocally proven (Alves et al. 2008; Phillips et al. 2008). Phillips et al. (2013) transferred Auerswaldia lignicola (Liu et al. 2012) to Lasiodiplodia, and this is the only species where the asexual morph and sexual have been definitively linked. There are 30 epithets of Lasiodiplodia recorded in Index Fungorum (2014) and 32 species names in MycoBank (March 2014), and 24 species are currently kept in culture. Species can be differentiated based on conidial morphology (especially dimensions) and morphology of the paraphyses. The phylogenetic analysis was performed based on up to date holotype or ex-epitype sequence data available in GenBank (Table 14).

Molecular phylogeny

Denman et al. (2000) suggested that Lasiodiplodia could be a possible synonym of Diplodia based on the ITS data analysis. However, phylogenetic studies by Zhou and Stanosz (2001), Slippers et al. (2004a) and Phillips et al. (2008) show that it clusters separately from Diplodia. As more genes and molecular data have become available, more complex sections within Botryosphaeriaceae have been resolved. By combining TEF and $\beta$-tubulin genes with ITS, Phillips et al. $(2005,2008)$ reinstated the genus Neodeightonia in the Diplodia/Lasiodiplodia complex and also showed that the latter asexual genera are morphologically and phylogenetically distinct. Most of the known species with available cultures have been described based on at least two genetic markers (ITS, TEF/ $\beta$-tubulin). The phylogenetic tree constructed with holotype or ex-epitype sequences is presented in Fig. 15.

\section{Recommended genetic markers}

- ITS-placement within the Botryosphaeriaceae (the generic level), and also some species-level delineation.

- TEF-generic level and inter-specific delineation.

- $\beta$-tubulin-generic level and inter-specific delineation, mostly for inter-specific delineation.

In most cases, a combination of ITS and TEF will separate all species and a minimal requirement for Lasiodiplodia species separation. However, for some groups, such as $L$. theobromae, $\beta$-tubulin is needed.

\section{Mucor}

\section{Background}

The genus Mucor belongs to the Mucoraceae, which is the largest and the most diverse family within Mucorales (former Zygomycota; Hoffmann et al. 2013). It was described by Fresenius (1850). The type species of the genus is Mucor mucedo, although the name Mucor had been used long before also by other authors to describe species currently classified as Rhizopus stolonifer (syn. Mucor mисеdo L. 1753 or Mucor mucedo (Tode) Pers. 1801).

There has been no comprehensive molecular phylogenetic study in the genus Mucor and consequently its taxonomy is still widely based on morphological characters. Mucor representatives produce nonapophysate sporangia arising directly from the substrate and they do not form stolons. Rhizoids 
Table 14 Lasiodiplodia. Details of the isolates used in the phylogenetic tree
Ex-type (ex-epitype) strains are bolded and marked with an * and voucher stains are bolded

\begin{tabular}{|c|c|c|c|c|}
\hline Species name & Strain no. & Host & ITS & TEF \\
\hline Diplodia mutila & CBS 112553* & Vitis vinifera & AY259093 & AY573219 \\
\hline Lasiodiplodia brasiliense & CMM 4015* & Mangifera indica & JX464063 & JX464049 \\
\hline L. brasiliense & CMM 2320 & Mangifera indica & KC484814 & KC481544 \\
\hline L. brasiliense & CMM 2319 & Mangifera indica & KC484798 & KC481529 \\
\hline L. brasiliense & CMM 2314 & Mangifera indica & $\mathrm{KC} 484813$ & KC481543 \\
\hline L. citricola & CBS 124707* & Citrus sp. & GU945354 & GU945340 \\
\hline L. citricola & CBS 124706 & Citrus sp. & GU945353 & GU945339 \\
\hline L. crassispora & CBS 118741* & Santalum album & DQ103550 & EU673303 \\
\hline L. crassispora & WAC 12534 & Eucalyptus urophylla & DQ103551 & DQ103558 \\
\hline L. egyptiacae & CBS 130992* & Mangifera indica & JN814397 & JN814424 \\
\hline L. egyptiacae & BOT 29 & Mangifera indica & JN814401 & JN814428 \\
\hline L. euphorbicola & СМM3609* & Jatropha curcas & KF234543 & KF226689 \\
\hline L. euphorbicola & CMM3652 & Jatropha curcas & KF234554 & KF226715 \\
\hline L. gilanensis & CBS 124704* & Unknown & GU945351 & GU945342 \\
\hline L. gilanensis & CBS 124705 & Unknown & GU945352 & GU945341 \\
\hline L. gonubiensis & CBS 115812* & Syzigium cordatum & AY639595 & DQ103566 \\
\hline L. gonubiensis & CBS 116355 & Syzigium cordatum & AY639594 & DQ103567 \\
\hline L. hormozganensis & CBS 124709* & Olea sp. & GU945355 & GU945343 \\
\hline L. hormozganensis & CBS 124708 & Mangifera indica & GU945356 & GU945344 \\
\hline L. iraniensis & CBS 124710* & Salvadora persica & GU945346 & GU945334 \\
\hline L. jatrophicola & CMM3610 & Jatropha curcas & KF234544 & KF226690 \\
\hline L. lignicola & MFLUCC 11-0435* & Unknown & JX646797 & JX646862 \\
\hline L. lignicola & MFLUCC 11-0656 & Unknown & JX646798 & JX646863 \\
\hline L. macrospora & СМM3833* & Jatropha curcas & KF234557 & KF226718 \\
\hline L. mahajangana & CBS 124927* & Terminalia catappa & FJ900597 & FJ900643 \\
\hline L. mahajangana & CBS 124925 & Terminalia catappa & FJ900595 & FJ900641 \\
\hline L. margaritacea & CBS 122519* & Adansonia gibbosa & EU144050 & EU144065 \\
\hline L. margaritacea & CBS 122065 & Adansonia gibbosa & EU144051 & EU144066 \\
\hline L. marypalme & CMM 2275* & Carica papaya & KC484843 & KC481567 \\
\hline L. marypalme & CMM 2274 & Carica papaya & KC484841 & KC481565 \\
\hline L. marypalme & CMM 2272 & Carica papaya & KC484842 & KC481566 \\
\hline L. marypalme & CMM 2271 & Carica papaya & KC484844 & KC481568 \\
\hline L. missouriana & CBS 128311* & Vitis vinifera & HQ288225 & HQ288267 \\
\hline L. missouriana & CBS 128312 & Vitis vinifera & HQ288226 & HQ288268 \\
\hline L. parva & CBS 456.78* & Cassava-field soil & EF622083 & EF622063 \\
\hline L. parva & CBS 494.78 & Cassava-field soil & EF622084 & EF622064 \\
\hline L. plurivora & CBS 120832* & Prunus salicina & EF445362 & EF445395 \\
\hline L. plurivora & CBS 121103 & Prunus salicina & AY343482 & EF445396 \\
\hline L. pseudotheobromae & CBS 116459* & Gmelina arborea & EF622077 & EF622057 \\
\hline L. pseudotheobromae & CBS 447.62 & Citrus aurantium & EF622081 & EF622060 \\
\hline L. rubropurpurea & CBS 118740* & Eucalyptus grandis & DQ103553 & EU673304 \\
\hline L. rubropurpurea & WAC 12536 & Eucalyptus grandis & DQ103554 & DQ103572 \\
\hline L. subglobose & СМM3872* & Jatropha curcas & KF234558 & KF226721 \\
\hline L. subglobosa & CMM4046 & Jatropha curcas & KF234560 & KF226723 \\
\hline L. theobromae & CBS 164.96* & Fruit on coral reef coast & AY640255 & AY640258 \\
\hline L. theobromae & CBS 111530 & Unknown & EF622074 & EF622054 \\
\hline L. venezuelensis & CBS 118739* & Acacia mangium & DQ103547 & EU673305 \\
\hline L. venezuelensis & WAC 12540 & Acacia mangium & DQ103548 & DQ103569 \\
\hline L. viticola & CBS 128313* & Vitis vinifera & HQ288227 & HQ288269 \\
\hline L. viticola & CBS 128315 & Vitis vinifera & HQ288228 & HQ288270 \\
\hline
\end{tabular}


Fig. 15 Phylogram generated from parsimony analysis based on combined ITS and TEF sequenced data of Lasiodiplodia. Parsimony bootstrap support values greater than $50 \%$ are indicated above the nodes, and branches with Bayesian posterior probabilities greater than 0.95 are given in bold. The ex-type (exepitype) and voucher strains are in bold. The scale bar indicates ten changes. The tree is rooted with Diplodia mutila CBS 112553

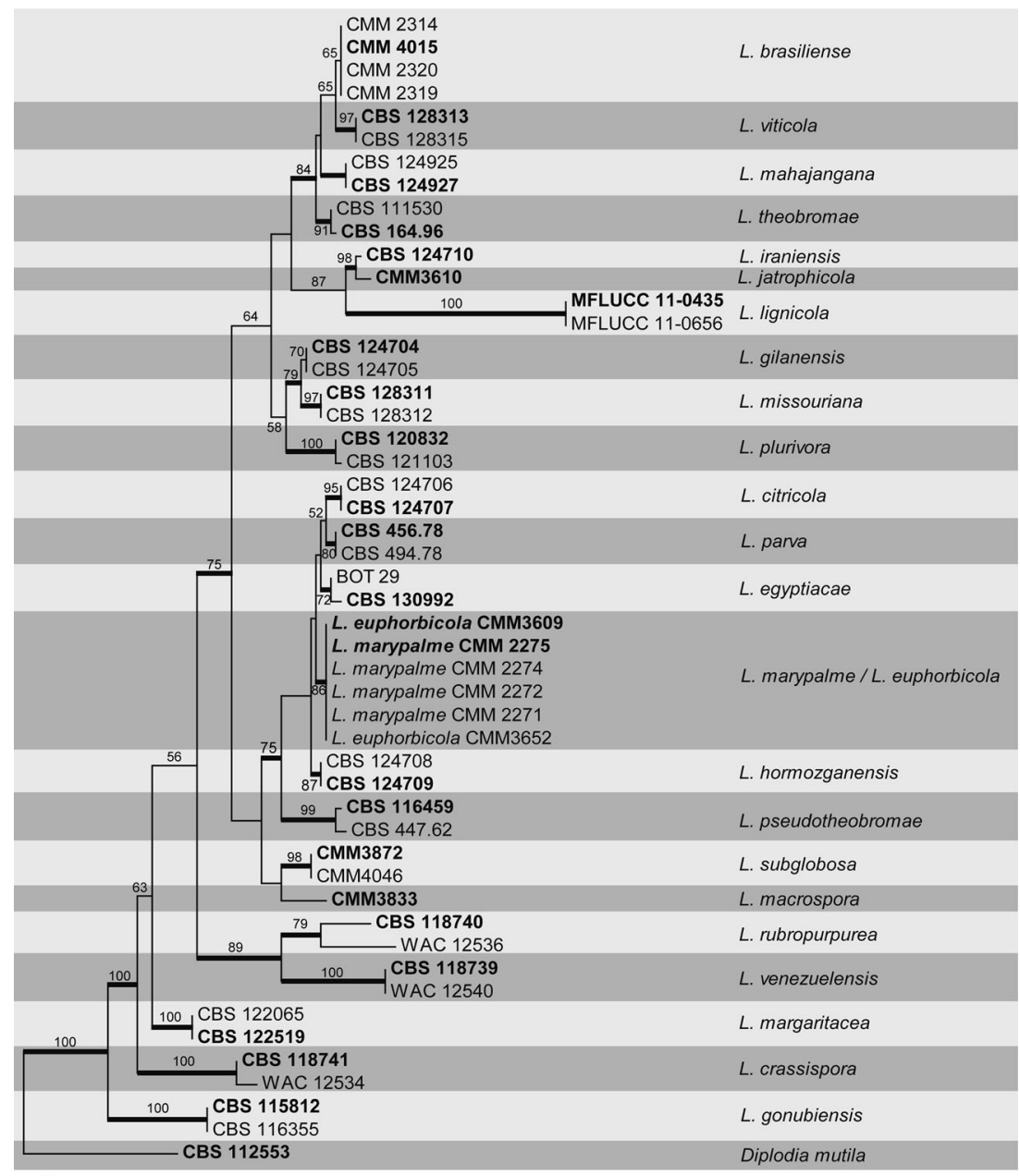

10

were also considered to be absent in Mucor, but it is now known that they can be produced under certain conditions (Walther et al. 2013).

Mucor representatives are saprotrophs that can be found mainly in soil or on plant debris. They are also known as postharvest plant pathogens, e.g. M. mucedo (Moline and Millner 1981) and M. piriformis (Michailides and Spotts 1990a). In case of peach and nectarine rots, Michailides and Spotts (1990b), Spotts (1990) and Michailides et al. (1992) regarded flies (especially Drosophila melanogaster) and nitidulid beetles (Carpophilus hemipterus and C. freemani) as effective vectors. Mucor rot symptoms include softening of juicy decayed tissue, often with a sweet odour, lesions with a sharp margin and eventually developing of grey mycelium with sporangia. Mucor isolated from several different plant hosts, angiosperms and gymnosperms, monocots as well as dicotyledons. USDA Fungus-Host Database reports 375 cases of Mucor infections from plants from approximately 40 countries in Europe, Central and South-East Asia, Australia, Africa, and North and South America (Farr and Rossman 2014). Mucor circinelloides causes rots in tomatoes (Smith et al.
1976), mangoes (Johnson 2008), yam (Amusa et al. 2003) and peaches (Restuccia et al. 2006). Mucor hiemalis can be pathogenic on guavas (Kunimoto et al. 1977), carrots and cassava (Snowdon 1991). Mucor piriformis is a destructive pathogen of fresh strawberries (Snowdon 1990; Pitt and Hocking 2009) and a major cause of rotting of coldstored pears, apples, peaches, nectarines and tomatoes (Smith et al. 1979; Bertrand and Saulie-Carter 1980; Michailides and Spotts 1986; Michailides 1991; Mari et al. 2000; Pitt and Hocking 2009; Ukeh and Chiejina 2012), plums (Børve and Vangdal 2007), sweet persimmons (Kwon et al. 2004) and yams (Amusa and Baiyewu 1999; Iwama 2006). Mucor piriformis may infect the stem, calyx or wounds on the skin of fruits (Michailides and Spotts 1990a, b). Muсоr mисеdo was reported as important postharvest pathogen of strawberries (Dennis and Davis 1977), and from tomatoes (Moline and Kuti 1984). Mucor racemosus was noted causing soft rot of cherry tomato fruits in Korea (Kwon and Hong 2005). Some Mucor species (e.g. M. circinelloides) are also human opportunistic pathogens, especially dangerous to immunodeficient patients (Walther et al. 2013). 
Species identification and numbers

The last extensive studies of the genus Mucor (Schipper 1973, 1975) are from the pre-molecular era. Based on morphological features and mating experiments Schipper $(1976,1978)$ recognized 39 species, 4 varieties and 11 formae. In the following years further species were described (e.g. Watanabe 1994; Zalar et al. 1997). Molecular phylogenetic analyses of the entire Mucorales revealed the polyphyly of the genus (Voigt and Wöstemeyer 2001; O'Donnell et al. 2001). The study of Walther et al. (2013) on the genetic diversity within the Mucorales based on sequences of the nuclear ribosomal internal transcribed spacer region (ITS) and the large ribosomal subunit (LSU) strongly supported the polyphyly of Mucor. The genus was split into several morphological groups differing in the size of the sporangia and the branching mode of the sporangiophores that are widely in agreement with the intrageneric classification of Schipper (1973). However, ?in molecular analyses these groups are intermingled by other sporangia-forming genera such as Pilaira und Pirella and sporangiola-forming genera such as Ellisomyces, Chaetocladium, Helicostylum and Thamnidium (Walther et al. 2013). The position of the Mycotyphaceae and the Choanephoraceae in relation to the Mucoraceae is still not resolved (Hoffmann et al. 2013).

Recently, the introduction of new species or changes of the taxonomic status were supported by sequence analyses of the ITS and/or rDNA genes (Jacobs and Botha 2008; Budziszewska et al. 2010; Álvarez et al. 2011; Madden et al. 2011). Several studies on certain species or species complexes (Li et al. 2011; Lu et al. 2013) or a particular ecological group (Hermet et al. 2012) used multi-marker approaches for phylogenetic species recognition in the genus Mucor. However, a comprehensive study on the entire genus is still lacking. As a consequence, species and even generic boundaries are still unclear for Mucor. Currently 58 species are recognised within the genus (Walther et al. 2013) (Table 15, Fig. 16).

\section{Molecular phylogeny}

The ITS region allows identification to species level for most mucoralean representatives (Walther et al. 2013). Detailed molecular species identification is currently not possible for species complexes such as $M$. circinelloides or M. flavus because of unclear species boundaries (Walther et al. 2013).

Along with the ITS region for species identification, the LSU (e.g. Fig. 16, Álvarez et al. 2011) or the SSU (e.g. Budziszewska et al. 2010) genes have frequently been used in molecular phylogenetic analyses of Mucor because the ITS is too variable to be confidently aligned across the entire genus (Walther et al. 2013). In addition, the RNA polymerase subunit gene (rpb1) was successfully used for multi-marker studies at the species level ( $\mathrm{Li}$ et al. 2011; Hermet et al. 2012; Lu et al. 2013). Hermet et al. (2012) also used the fragment of a mini-chromosome maintenance protein (MCM7) and of the $20 \mathrm{~S}$ rRNA accumulation protein (tsr1). The multi-marker analysis of the entire Mucorales including representatives of genus Mucor by Hoffmann et al. (2013) were based on partial genes of actin and the translation elongation factor 1-alpha in addition to the rRNA genes.

\section{Recommended genetic markers}

- The internal transcribed spacer (ITS)-genus and species level

- The RNA polymerase II largest subunit gene (RPB1)species level

- The large and small subunits (LSU and SSU) of nrDNAplacement within the Mucorales order, higher-level phylogeny

- The mini-chromosome maintenance proteins gene (MCM7-higher-level phylogeny)

\section{Neofusicoccum}

\section{Background}

Pennycook and Samuels (1985) listed Fusicoccum parvum as the asexual morph when they described Botryosphaeria parvum. Neofusicoccum was introduced by Crous et al. (2006) for species that have an asexual morph that occurs with a "Dichomera" like synanamorph (morphologically similar, but phylogenetically distinct from Botryosphaeria). They suggested the name as it provides more information of the morphological state.

Species identification and numbers

On the basis of conidial dimensions and pigmentation, pigment production in media and ITS sequence data, 22 species are currently recognized in Neofusicoccum, although some of these characters have recently been questioned (Abdollahzadeh et al. 2013). Four new species, $N$. batangarum, $N$. cordaticola, $N$. kwambonambiense and $N$. umdonicola were identified in this complex based on congruence between genealogies of multiple genes (Pavlic et al. 2009a, b; Begoude et al. 2010). Though many species of Neofusicoccum are morphologically similar and can be very difficult to distinguish from one another, an attempt has been made to differentiate all species in a key by Phillips et al. (2013) (Table 16). 
Table 15 Mucor. Details of the isolates used in the phylogenetic tree

\begin{tabular}{|c|c|c|c|}
\hline Species & Isolate & Country of collection & GenBank accession no \\
\hline Mucor abundans & CBS 521.66 & Germany & JN206457 \\
\hline M. aligarensis & CBS 993.70* & UK & JN206461 \\
\hline M. amphibiorum & CBS 763.74* & Germany & HM849688 \\
\hline M. ardhlaengiktus & CBS 210.80* & India & JN206504 \\
\hline M.azygosporus & CBS 292.63* & USA & JN206497 \\
\hline M. bacilliformis & CBS 251.53* & USA & JN206451 \\
\hline M. bainieri & CBS 293.63* & India & JN206424 \\
\hline M. brunneogriseus ${ }^{1}$ & CBS 129.41 & Netherlands & \\
\hline M. circinelloides $f$. circinelloides & CBS 195.68* & Netherlands & HM849680 \\
\hline M. circinelloides f. griseocyanus & CBS 116.08 & Norway & JN206421 \\
\hline M. circinelloides $f$. janssenii & CBS 205.68* & South Africa & JN206425 \\
\hline M.circinelloides f. lusitanicus & CBS 968.68 & - & JN206419 \\
\hline M. ctenidius & CBS 293.66 & USA & JN206417 \\
\hline M. durus & CBS 156.51* & Ukraine & JN206456 \\
\hline M. endophyticus & CBS 385.95* & China & JN206448 \\
\hline M. exponens & CBS 141.20* & Germany & JN206441 \\
\hline M. falcatus & CBS 251.35* & Germany & JN206509 \\
\hline M. flavus & CBS 234.35* & Germany & JN206468 \\
\hline M. fuscus & CBS 282.78 & France & JN206442 \\
\hline M.fusiformis & CBS 336.68* & Finland & JN206447 \\
\hline M. genevensis & CBS 114.08* & Switzerland & JN206435 \\
\hline M.gigasporus & CBS 566.91* & China & JN206494 \\
\hline M. guiliermondii & CBS 174.27* & Russia & JN206475 \\
\hline M.heterogamus & CBS 405.58* & - & JN206487 \\
\hline M. hiemalis f. corticola & CBS 362.68 & Norway & JN206449 \\
\hline M. hiemalis f. hiemalis & CBS 201.65* & USA & HM849683 \\
\hline M. inaequisporus & CBS 255.36* & Ghana & JN206502 \\
\hline M. indicus & CBS 226.29* & Switzerland & HM849690 \\
\hline M.irregularis & CBS 103.93 & India & HM849684 \\
\hline M. japonicus & CBS 154.69* & Russia & JN206446 \\
\hline M. lanceolatus & CBS 638.74 & France & JN206443 \\
\hline M. laxorrhizus & CBS 143.85* & United Kingdom & JN206444 \\
\hline M. luteus ${ }^{1}$ & CBS 243.35* & Germany & \\
\hline M. megalocarpus & CBS 215.27* & France & JN206489 \\
\hline M. microsporus ${ }^{1}$ & CBS 204.28 & France & \\
\hline M. minutes & CBS 586.67 & India & JN206463 \\
\hline M. moelleri & CBS 444.65* & USA & HM849682 \\
\hline M. mousanensis & CBS 999.70* & India & JN206434 \\
\hline M. mucedo & CBS 640.67* & Netherlands & HM849687 \\
\hline M. multiplex & CBS 110662* & China & JN206484 \\
\hline M. nederlandicus & CBS 735.70 & - & JN206503 \\
\hline M. odoratus & CBS 130.41* & Denmark & JN206495 \\
\hline M. parviseptatus & CBS 417.77 & Australia & JN206453 \\
\hline M. piriformis & CBS 169.25* & - & HM849681 \\
\hline M. plasmaticus & CBS 275.49 & Netherlands & JN206483 \\
\hline M. plumbeus & CBS 634.74 & Germany & HM849677 \\
\hline M. prayagensis & CBS 652.78 & India & JN206498 \\
\hline M. racemosus f. racemosus & CBS 260.68* & Switzerland & HM849676 \\
\hline M. racemosus $f$. sphaerosporus & CBS 115.08* & Norway & JN206433 \\
\hline M. ramosissimus & CBS 135.65* & Uruguay & HM849678 \\
\hline
\end{tabular}


Table 15 (continued)

\begin{tabular}{|c|c|c|c|c|}
\hline \multirow{8}{*}{ Table 15 (continued) } & Species & Isolate & Country of collection & GenBank accession no \\
\hline & M. saturninus & CBS 974.68* & Netherlands & JN206458 \\
\hline & M. silvaticus & CBS 249.35* & Denmark & JN206455 \\
\hline & M. strictus & CBS 100.66 & Austria & JN206477 \\
\hline & M. ucrainicus & CBS 674.88 & Ukraine & JN206507 \\
\hline & M. variisporus & CBS 837.70* & India & JN206508 \\
\hline & M. zonatus & CBS 148.69* & Germany & JN206454 \\
\hline & M. zychae & CBS 416.67* & India & JN206505 \\
\hline \multirow{2}{*}{$\begin{array}{l}\text { Ex-type (ex-epitype) strains are } \\
\text { bolded and marked with an * and } \\
\text { voucher stains are bolded }\end{array}$} & Backusella lamprospora & CBS 195.28 & USA & JN206530 \\
\hline & B. grandis & CBS 186.87* & India & JN206527 \\
\hline
\end{tabular}

Molecular phylogeny

Crous et al. (2006) proposed new combinations for 13 species based on the sequence data from cultures. Based on DNA sequence data for five nuclear markers, Pavlic et al. (2009a, b) identified three new species of Neofusicoccum within the $N$. parvum $/ N$. ribis species complex in South Africa. $N$. batangarum was described from Terminalia catappa by Begoude et al. (2010). Analysis of TEF, $\beta$-tubulin and LSU gene sequences (Alves et al. 2008; Abdollahzadeh et al. 2010) and Genealogical Sorting Index (GSI) has been used to resolve the asexual morph of Neofusicoccum (Sakalidis et al. 2011) (Fig. 17).

\section{Recommended genetic markers}

- LSU, SSU and ITS-genus level

- $\beta$-tubulin and TEF-species level

Common genetic markers that are used for the identification of Botryosphaeriaceae species are ITS, TEF, $\beta$ - tubulin, LSU and SSU. Recent studies have shown that the combination of TEF, ITS and $\beta$ - tubulin is sufficient to characterize species in this lineage. However, even when using only the TEF gene, it is possible to identify distinct species. The unavailability of the TEF sequence of several type species makes species identification using molecular phylogeny problematic. Therefore, in future research, it is recommended to use the combination of TEF, ITS and $\beta$ - tubulin for better species level delimitation.

\section{Pestalotiopsis}

Background

Pestalotiopsis is an appendage-bearing conidial asexual coelomycetous genus in the family Amphisphaeriaceae, Xylariales, Sordariomycetes (Ascomycota) (Barr 1975;
Kang et al. 1998) that is common in tropical and temperate ecosystems (Maharachchikumbura et al. 2011, 2012). The sexual state is Pestalosphaeria and only 13 species are known as compared to the asexual state ( 253 species names). Species of Pestalotiopsis cause a variety of disease in plants, including canker lesions, shoot dieback, leaf spots, needle blight, tip blight, grey blight, scabby canker, severe chlorosis, fruit rots and leaf spots (Espinoza et al. 2008; Maharachchikumbura et al. 2013a, b; Tagne and Mathur 2001). Species belonging to the genus Pestalotiopsis are thought to be a rich source for bioprospecting, and chemical exploration of endophytic Pestalotiopsis species is on the increase (Aly et al. 2010; Xu et al. 2010, 2014). Pestalotiopsis species have been recorded as saprobes where they are recyclers of dead plant material (Maharachchikumbura et al. 2012) and are also known to cause human and animal infections (Pestalotiopsis clavispora) (Monden et al. 2013).

Most Pestalotiopsis names in the literature are described based on host association. However, molecular data have shown that the genus needs revision (Maharachchikumbura et al. 2011, 2012; Zhang et al. 2013c), and many of the traditional species may be spurious. There are also numerous cryptic species, very few distinct species, species with wide host ranges, those with cosmopolitan distribution and some species being opportunistic pathogens. This calls for critical re-examination of the genus, using both morphological studies and a multi-marker phylogeny based on ex-type and exepitype cultures (Maharachchikumbura et al. 2012, 2013c).

Species identification and numbers

According to Index Fungorum (2014) there are 253 Pestalotiopsis names, while in MycoBank (2014) there are 264 names. The reason for the large number of names is historical and may not reflect the actual number of species (Jeewon et al. 2004). Kohlmeyer and Kohlmeyer (2001) described P. juncestris, which was isolated from the host Juncus roemerianus; this species is morphologically similar to P. versicolor and several other species of Pestalotiopsis, but 


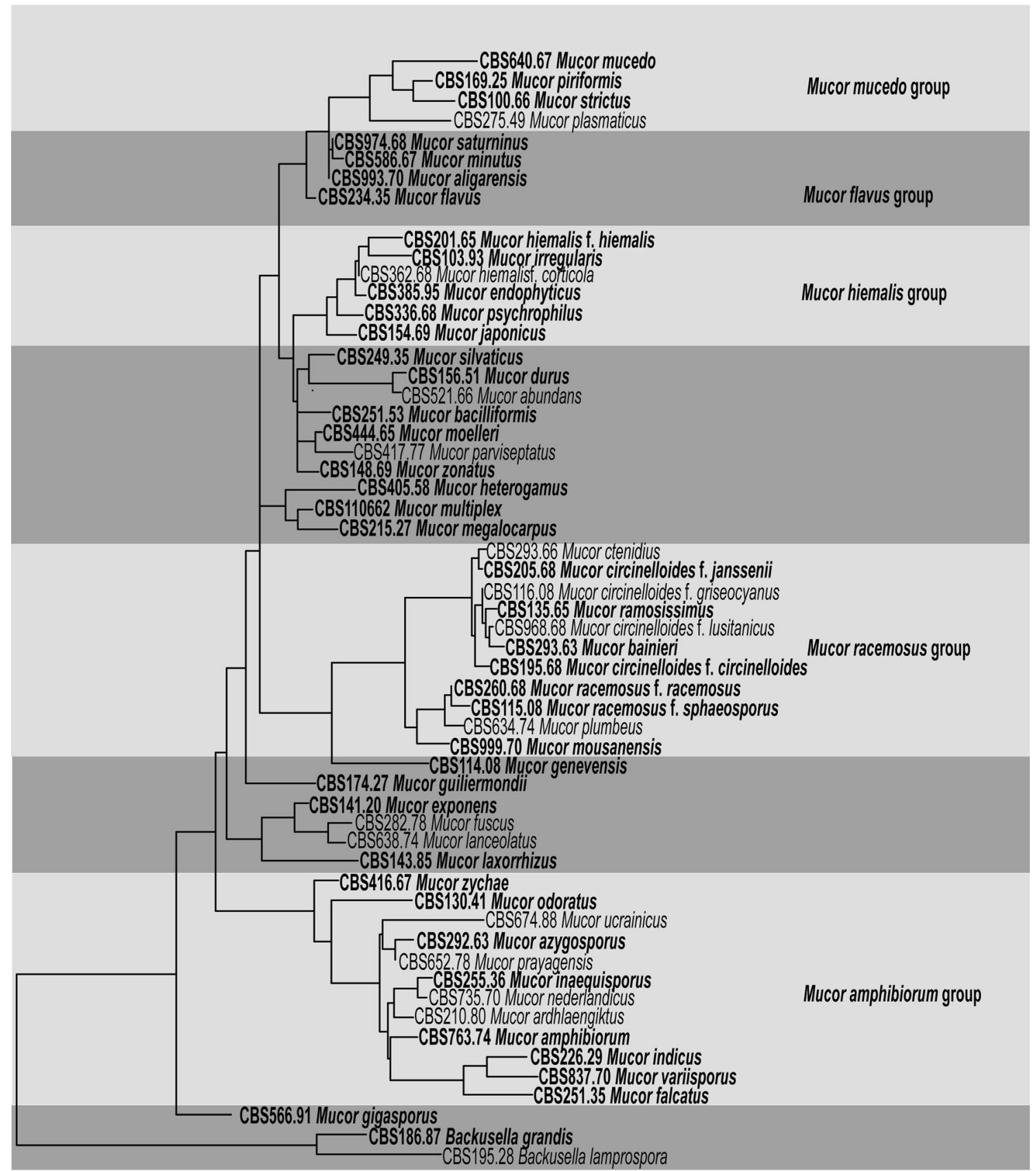

Fig. 16 Maximum likelihood tree based on partial LSU sequences for Mucor species and main groups within the genus. Detailed phylogenetic trees for each group may be found in Walther et al. (2013)

the taxon was described as a new species based on the host occurrence. However, recent molecular data have shown that host association and geographical location is less informative for distinguishing taxa (Jeewon et al. 2004; Hu et al. 2007). Isolation of endophytic Pestalotiopsis strains for bioprospecting for new biochemical compounds has shown that the same species can be found in a range of hosts. It has been shown that most of the key conidial characters used in species level separation are not stable and vary with host range, generation, culture and other environmental conditions
(Hu et al. 2007). Furthermore, the arrangement of species by Steyaert (1949) and Guba (1961) in various coloured groupings is problematic because this character has been shown to be variable within a species (Liu et al. 2010). Thus, most species in the above arrangements may be confused and many species are probably synonyms. Therefore, most of the species recorded in checklists and the literature may not reflect what actually occurs. Thus, many names assigned to Pestalotiopsis probably lack any accurate taxonomic basis, leaving the taxonomy of the genus markedly confused. Until 1990, 
Table 16 Neofusicoccum. Details of the isolates used in the phylogenetic tree

\begin{tabular}{|c|c|c|c|c|c|c|}
\hline \multirow[t]{2}{*}{ Species } & \multirow[t]{2}{*}{ Isolate } & \multicolumn{5}{|c|}{ GenBank accession numbers } \\
\hline & & SSU & ITS & LSU & TEF & $\beta$-tubulin \\
\hline Neofusicoccum andinum & CBS 117453* & N/A & AY693976 & $\mathrm{N} / \mathrm{A}$ & AY693977 & $\mathrm{N} / \mathrm{A}$ \\
\hline N. arbuti & CBS 116131* & KF531814 & AY819720 & DQ377915 & KF531792 & KF531792 \\
\hline N. australe & CMW 6837* & N/A & AY339262 & N/A & AY339270 & AY339254 \\
\hline N. batangarum & CBS 124924* & N/A & FJ900607 & N/A & FJ900653 & FJ900634 \\
\hline N. cordaticola & CBS 123634* & $\mathrm{N} / \mathrm{A}$ & EU821898 & $\mathrm{N} / \mathrm{A}$ & EU821868 & EU821838 \\
\hline N. corticosae & CBS 120081* & $\mathrm{N} / \mathrm{A}$ & DQ923533 & $\mathrm{N} / \mathrm{A}$ & N/A & $\mathrm{N} / \mathrm{A}$ \\
\hline N. eucalypticola & CBS 115679* & $\mathrm{N} / \mathrm{A}$ & AY615141 & $\mathrm{N} / \mathrm{A}$ & AY615133 & AY615125 \\
\hline N. grevilleae & CBS 129518* & $\mathrm{N} / \mathrm{A}$ & JF951137 & JF951157 & N/A & $\mathrm{N} / \mathrm{A}$ \\
\hline N. kwambonambiense & CBS 123639* & N/A & EU821900 & $\mathrm{N} / \mathrm{A}$ & EU821870 & EU821840 \\
\hline N. luteum & CBS 110299* & EU673148 & AY259091 & AY928043 & AY573217 & DQ458848 \\
\hline N. macroclavatum & CBS 118223* & N/A & DQ093196 & N/A & DQ093217 & DQ093206 \\
\hline N. mangiferae & CBS 118532* & EU673154 & AY615186 & DQ377921 & DQ093220 & AY615173 \\
\hline N. mediterraneum & CBS 121718* & N/A & GU251176 & N/A & GU251308 & GU251836 \\
\hline N. nonquaesitum & CBS 126655* & $\mathrm{N} / \mathrm{A}$ & GU251163 & $\mathrm{N} / \mathrm{A}$ & GU251295 & GU251823 \\
\hline N. occulatum & CBS 128008* & N/A & EU301030 & $\mathrm{N} / \mathrm{A}$ & EU339509 & EU339472 \\
\hline N. parvum & CMW 9081* & EU673151 & AY236943 & AY928045 & AY236888 & AY236917 \\
\hline N. pennatisporum & WAC 13153* & N/A & EF591925 & EF591942 & EF591976 & EF591959 \\
\hline N. protearum & CBS 114176* & N/A & AF452539 & N/A & N/A & N/A \\
\hline N. ribis & CBS 115475* & N/A & AY236935 & $\mathrm{N} / \mathrm{A}$ & AY236877 & AY236906 \\
\hline N. umdonicola & CBS 123645* & $\mathrm{N} / \mathrm{A}$ & EU821904 & N/A & EU821874 & EU821844 \\
\hline N. viticlavatum & CBS 112878* & N/A & AY343381 & N/A & AY343342 & $\mathrm{N} / \mathrm{A}$ \\
\hline N. vitifusiforme & CBS 110887* & $\mathrm{N} / \mathrm{A}$ & AY343383 & N/A & AY343343 & N/A \\
\hline Spencermartinsia viticola & CBS 117009* & EU673165 & AY905554 & DQ377873 & AY905559 & EU673104 \\
\hline
\end{tabular}

Ex-type (ex-epitype) strains are bolded and marked with an * and voucher stains are bolded

phylogenetic understanding of the taxonomy associated with Pestalotiopsis and allied genera was based mainly on conidial characters (Steyaert 1949; Guba 1961; Nag Rag 1993), conidiogenesis (Sutton 1980) and sexual state association (Barr 1975). More recently, some new species have been introduced based on host occurrence, plus morphological and molecular data (Maharachchikumbura et al. 2012, 2013a, b; Strobel et al. 2000). Furthermore, currently only 36 Pestalotiopsis species have either ex-type or ex-epitype sequences.

\section{Molecular phylogeny}

Recently, many Pestalotiopsis species have been defined using ITS sequence data, however, there are only a few type cultures available for Pestalotiopsis. For example, Pestalotiopsis clavispora, $P$. disseminata, $P$. microspora, $P$. neglecta, $P$. photiniae, P. theae, $P$. virgatula and $P$. vismiae have numerous ITS sequences in GenBank. However, in phylogenetic studies all these species scattered throughout the phylogram and there appears to be no living ex-type strain for any of these species
(Maharachchikumbura et al. 2011). Therefore it is unwise to use GenBank sequences to represent any of these names. Rapid development in molecular phylogeny has had a great impact on Pestalotiopsis taxonomy. For example, random amplification of polymorphic DNA (RAPD) can be used to detect genetic diversity in the genus (Tejesvi et al. 2007). Watanabe et al. (2012) evaluated the use of the ITS2 region and showed that it is conserved at the level of secondary structure rather than the level of primary sequence, which can be used for classification of the Pestalotiopsis. Hu et al. (2007) showed that the ITS region is less informative than the $\beta$-tubulin gene in differentiating endophytic species of Pestalotiopsis in Pinus armandii and Ribes spp. A combination of $\beta$-tubulin and ITS gave improved phylogenetic resolution, and they suggested that at least two genetic markers should be used to resolve the phylogeny of species of Pestalotiopsis. However, Liu et al. (2010) disagreed with above statement concerning the ITS region as being less informative when compared to the $\beta$ tubulin region. They indicated that alignment of the ITS region can be a useful character in grouping Pestalotiopsis to different types of pigmentation, which can be used as a key character for 


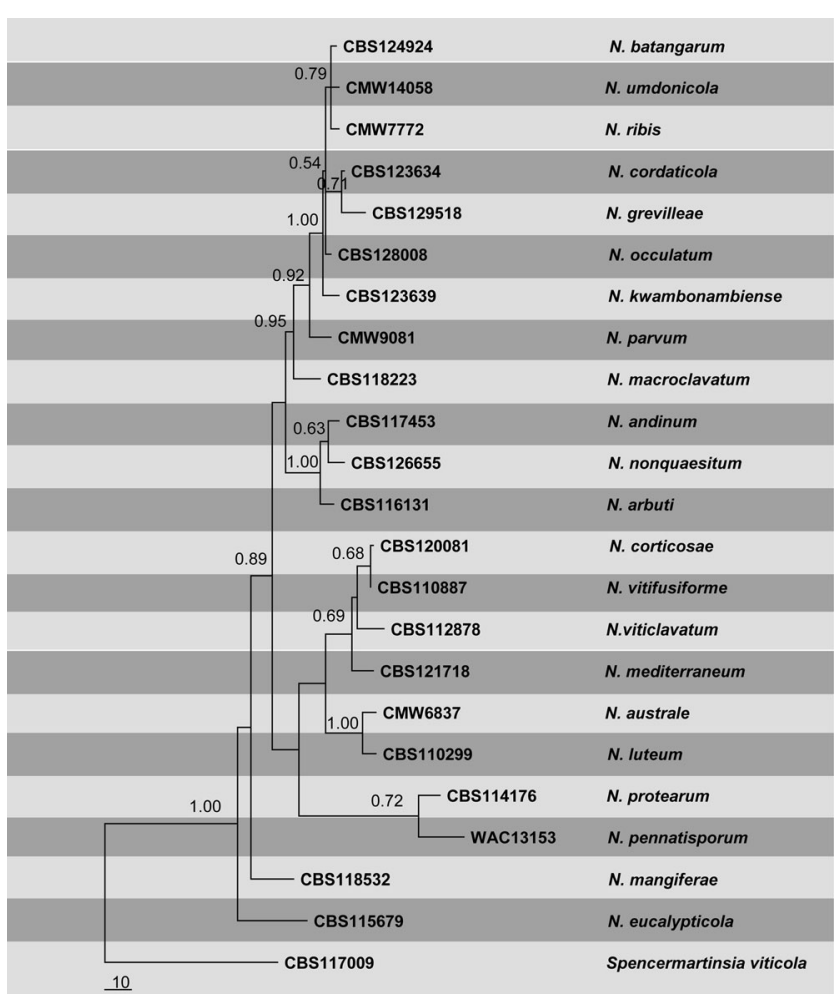

Fig. 17 Phylogram generated from parsimony analysis based on combined ITS, TEF, $\beta$ - tubulin, LSU and SSU sequenced data of Neofusicoccum. Parsimony bootstrap support values and Bayesian posterior probabilities greater than $50 \%$ are indicated above the nodes. The ex-type (ex-epitype) and voucher strains are in bold. The scale bar indicates ten changes. The tree is rooted with Spencermartinsia viticola CBS 117009

the phylogeny of the species. In order to select suitable markers for better species resolution, Maharachchikumbura et al. (2012) analyzed a combined ACT, $\beta$-tubulin, CAL, GPDH, GS, ITS, LSU, RPB 1, SSU and TEF dataset. They compared the morphological data versus the sequence data from each gene to establish which characters satisfactorily resolve the species. They narrowed down the 10 gene regions to three most applicable regions (ITS, $\beta$-tubulin and TEF), which were tested individually and in combination, to evaluate the differences between species. The species sequenced with ITS had a high PCR and sequence success rate and $\beta$-tubulin and TEF gene regions proved to be favourable taxonomic markers for Pestalotiopsis since they resolved the taxonomic relationships of most species studied. Further, TEF had better PCR amplification success rates and was found to be superior to $\beta$-tubulin. TEF is therefore a powerful tool to resolve lineages within Pestalotiopsis. Because of the better PCR and sequencing success rate and fewer difficulties with alignment, editing and better resolution, the TEF gene appears to be a very good molecular marker for phylogenetic investigation of Pestalotiopsis. Furthermore, a combination of ITS, $\beta$-tubulin and TEF gene data gave the best resolution as compared to any single marker (Table 17, Fig. 18). In addition to the above three markers, the authors also tested LSU, SSU, ACT and GPDH (low resolution), GS and RPB1 (cannot be synthesized using available primers or multiple copies) and CAL (species resolution is high, PCR success rate low).

\section{Recommended genetic markers}

- The large subunits of nrDNA (LSU)-placement within the Amphisphaeriaceae (generic level)

- The internal transcribed spacer (ITS), $\beta$-tubulin and TEFspecies level (as outlined in Maharachchikumbura et al. 2012)

\section{Phyllosticta}

\section{Background}

Phyllosticta is an important plant pathogenic genus with coelomycetes asexual states. It was previously placed in Botryosphaeriaceae, Botryosphaeriales, Dothideomycetes, Ascomycota. However following phylogenetic analysis, Wikee et al. (2013c) placed this genus in Phyllostictaceae which is sister to the Botryosphaeriaceae. Phyllosticta species are known to cause leaf spots and various fruit diseases worldwide on a diverse range of hosts including some economically important crops and ornamentals such as citrus, banana, apple, grapes, cranberry, orchids, mai dong and maple (Uchida and Aragaki 1980; Paul and Blackburn 1986; Baayen et al. 2002; McManus 1998; Olatinwo et al. 2003; Paul et al. 2005; Liu et al. 2009b; Wikee et al. 2011, 2012; Shivas et al. 2013b). Some species such as P. capitalensis are endophytes and weak pathogens (Baayen et al. 2002; Glienke et al. 2011; Wikee et al. 2013a), while others such as $P$. cocoicola are saprobes (Punithalingam 1974; Taylor and Hyde 2003). Phyllosticta species have been also used as bio-control agents and produce novel bioactive metabolites such as phyllostine and phyllostoxin (Yan et al. 2011; Evidente et al. 2008a, b; Wikee et al. 2011, 2013b).

The sexual state of Phyllosticta was named Guignardia which comprises 353 records in MycoBank (Hyde 1995; Crous et al. 1996; Hyde et al. 2010). Phyllosticta species have sometimes been named in Leptodothiorella after their spermatial state (Van der Aa 1973). Most species of Phyllosticta and Guignardia have been described independently, and only a few Phyllosticta species have been linked to their Guignardia sexual morphs (Wulandari et al. 2010). On the other hand, the host ranges of many diseases are poorly understood (Van der Aa and Vanev 2002; Wikee et al. 2011). It has been recommended that Phyllosticta which is the older, more commonly used and more species-rich, should 
Table 17 Pestalotiopsis. Details of the isolates used in the phylogenetic tree

\begin{tabular}{|c|c|c|c|c|c|}
\hline \multirow[t]{2}{*}{ Species } & \multirow[t]{2}{*}{ Isolates } & \multirow[t]{2}{*}{ Host } & \multicolumn{3}{|c|}{ GenBank accession number } \\
\hline & & & ITS & $\beta$-tubulin & TEF \\
\hline Pestalotiopsis adusta & ICMP6088* & On refrigerator door PVC gasket & JX399006 & JX399037 & JX399070 \\
\hline P. adusta & MFLUCC10-146 & Syzygium sp. & JX399007 & JX399038 & JX399071 \\
\hline P. anacardiacearum & IFRDCC2397* & Mangifera indica & KC247154 & KC247155 & KC247156 \\
\hline P. asiatica & MFLUCC12-0286* & Unidentified tree & JX398983 & JX399018 & JX399049 \\
\hline P. camelliae & MFLUCC12-0277* & Camellia japonica & JX399010 & JX399041 & JX399074 \\
\hline P. camelliae & MFLUCC12-0278 & Camellia japonica & JX399011 & JX399042 & JX399075 \\
\hline P. chrysea & MFLUCC12-0261* & Dead plant & JX398985 & JX399020 & JX399051 \\
\hline P. chrysea & MFLUCC12-0262 & Dead plant & JX398986 & JX399021 & JX399052 \\
\hline P. clavata & MFLUCC12-0268* & Buxus sp. & JX398990 & JX399025 & JX399056 \\
\hline P. clavispora & MFLUCC12-0280 & Magnolia sp. & JX398978 & JX399013 & JX399044 \\
\hline P. clavispora & MFLUCC12-0281* & Magnolia sp. & JX398979 & JX399014 & JX399045 \\
\hline P. coffeae-arabicae & HGUP4015* & Coffeae arabica & KF412647 & KF412641 & KF412644 \\
\hline P. coffeae-arabicae & HGUP4019 & Coffeae arabica & KF412649 & KF412643 & KF412646 \\
\hline P. diversiseta & MFLUCC12-0287* & Rhododendron sp. & JX399009 & JX399040 & JX399073 \\
\hline P. ellipsospora & MFLUCC12-0283* & Dead plant & JX398980 & JX399016 & JX399047 \\
\hline P. ellipsospora & MFLUCC12-0284 & Dead plant & JX398981 & JX399015 & JX399046 \\
\hline P. ericacearum & IFRDCC2439* & Rhododendron delavayi & KC537807 & KC537821 & KC537814 \\
\hline P. foedans & CGMCC3.9178 & Neodypsis decaryi & JX398989 & JX399024 & JX399055 \\
\hline P. foedans & CGMCC3.9123* & Mangrove leaves & JX398987 & JX399022 & JX399053 \\
\hline P. foedans & CGMCC3.9202 & Calliandra haematocephala & JX398988 & JX399023 & JX399054 \\
\hline P. furcata & MFLUCC12-0054* & Camellia sinensis & JQ683724 & JQ683708 & JQ683740 \\
\hline P. gaultheria & IFRD411-014* & Gaultheria forrestii & KC537805 & KC537819 & KC537812 \\
\hline$P$. inflexa & MFLUCC12-0270* & Unidentified tree & JX399008 & JX399039 & JX399072 \\
\hline P. intermedia & MFLUCC12-0259* & Unidentified tree & JX398993 & JX399028 & JX399059 \\
\hline P. licualacola* & HGUP4057* & Licuala grandis & KC436006 & KC481683 & KC481684 \\
\hline P. linearis & MFLUCC12-0271* & Trachelospermum sp. & JX398992 & JX399027 & JX399058 \\
\hline P. magna & MFLUCC12-652* & Pteridium sp. & KF582795 & KF582793 & KF582791 \\
\hline P. rhododendri & IFRDCC2399* & Rhododendron sinogrande & KC537804 & KC537818 & KC537811 \\
\hline P. rhodomyrtus & HGUP4230* & Rhodomyrtus tomentosa & KF412648 & KF412642 & KF412645 \\
\hline P. rosea & MFLUCC12-0258* & Pinus sp. & JX399005 & JX399036 & JX399069 \\
\hline P. samarangensis & MFLUCC12-0233* & Syzygium samarangense & JQ968609 & JQ968610 & JQ968611 \\
\hline P. saprophyta & MFLUCC12-0282* & Litsea rotundifolia & JX398982 & JX399017 & JX399048 \\
\hline P. simitheae & MFLUCC12-0121* & Pandanus odoratissimus & KJ503812 & KJ503815 & KJ503818 \\
\hline P. simitheae & MFLUCC12-0125 & Pandanus odoratissimus & KJ503813 & KJ503816 & KJ503819 \\
\hline P. shorea & MFLUCC12-0314* & Shorea obtuse & KJ503811 & KJ503814 & KJ503817 \\
\hline P. steyaertii & IMI192475* & Eucalyptus viminalis & KF582796 & KF582794 & KF582792 \\
\hline P. theae & MFLUCC12-0055* & Camellia sinensis & JQ683727 & JQ683711 & JQ683743 \\
\hline P. theae & SC011 & Camellia sinensis & JQ683726 & JQ683710 & JQ683742 \\
\hline P. trachicarpicola & MFLUCC12-0263 & Unidentified tree & JX399000 & JX399031 & JX399064 \\
\hline P. trachicarpicola & MFLUCC12-0264 & Chrysophyllum sp. & JX399004 & JX399035 & JX399068 \\
\hline P. trachicarpicola & MFLUCC12-0265 & Schima sp. & JX399003 & JX399034 & JX399067 \\
\hline P. trachicarpicola & MFLUCC12-0266 & Sympolocos sp. & JX399002 & JX399033 & JX399066 \\
\hline P. trachicarpicola & MFLUCC12-0267 & Unidentified tree & JX399001 & JX399032 & JX399065 \\
\hline P. trachicarpicola & IFRDCC2403 & Podocarpus macrophyllus & KC537809 & KC537823 & KC537816 \\
\hline P. trachicarpicola & OP068* & Trachycarpus fortunei & JQ845947 & JQ845945 & JQ845946 \\
\hline P. umberspora & MFLUCC12-0285* & Unidentified tree & JX398984 & JX399019 & JX399050 \\
\hline P. unicolor & MFLUCC12-0275 & Unidentified tree & JX398998 & JX399029 & JX399063 \\
\hline
\end{tabular}


Table 17 (continued)

\begin{tabular}{|c|c|c|c|c|c|}
\hline \multirow[t]{2}{*}{ Species } & \multirow[t]{2}{*}{ Isolates } & \multirow[t]{2}{*}{ Host } & \multicolumn{3}{|c|}{ GenBank accession number } \\
\hline & & & ITS & $\beta$-tubulin & TEF \\
\hline P. unicolor & MFLUCC12-0276* & Rhododendron sp. & JX398999 & JX399030 & - \\
\hline P. verruculosa & MFLUCC12-0274* & Rhododendron $\mathrm{sp}$. & JX398996 & - & JX399061 \\
\hline Seiridium sp. & SD096 & - & JQ683725 & JQ683709 & JQ683741 \\
\hline
\end{tabular}

Ex-type (ex-epitype) strains are bolded and marked with an * and voucher stains are bolded

have priority over Guignardia (Zhang et al. 2013a, b, c; Wikee et al. 2013c).

Phyllosticta species have been historically indentified based on morphology, culture characters as well as host association, which has resulted in several taxonomic revisions (Van der Aa 1973; Van der Aa and Vanev 2002). Fresh collections and future molecular analyses should help resolve species relationships (Hyde et al. 2010). Phylogenetic analysis has been routinely used in species identification, in combination with morphological characters (Crous and Groenewald 2005; Hyde et al. 2010; Wikee et al. 2013c). To create a stable and workable taxonomy, neo- or epitypification are required for many species of Phyllosticta (Hyde et al. 2010; Wikee et al. 2013c).

Species identification and numbers

The genus Phyllosticta was first introduced as the generic name for Sphaeria lichenoides by Persoon (1818). Desmazieres (1847) re-defined Phyllosticta, in which he did not restrict the genus to species with one-celled conidia. Consequently, many fungi with one-celled or septate conidia were named as Phyllosticta (Desmazieres 1847; Van der Aa 1973). Saccardo (1878) however, restricted Phyllosticta to species with one-celled conidia, and after that Phyllosticta was further restricted to leaf inhabiting species (Saccardo 1878, 1884; Van der Aa 1973; Petrak and Sydow (1927) published a compilation of Phyllosticta names, and gave extensive descriptions of 28 species. Van der Aa (1973) proposed a morphological identification criterion for the genus and detailed 46 Phyllosticta species based mostly on material collected in Europe and North America. The genus was revised by Van der Aa and Vanev (2002) and they accepted 141 species. The currently used generic circumscription of Phyllosticta is: "pycnidia globose, subglobose or tympaniform, conidiogenous cells holoblastic, with percurrent proliferation, conidia hyaline, 1-celled, ovoid, overate, ellipsoid, short cylindrical, or globose to subglobose, usually bearing a slime layer and an apical appendage" (Van der Aa 1973; Van der Aa and Vanev 2002). During 2002-2014, about 30 new species were described (Motohashi et al. 2008; Wulandari et al. 2009, 2010; Glienke et al. 2011; Wang et al. 2012; Su and Cai 2012; Wong et al. 2012; Wikee et al. 2012, 2013c; Zhang et al. 2013b; Shivas et al. 2013b), with the currently accepted species possibly being more than 171. Unfortunately, molecular data are currently available for about only 69 species (Table 18).

Molecular phylogeny

Phylogenetic analysis has become a standard approach in fungal identification and has been well applied in several other coelomycetous genera such as Colletotrichum (Cai et al. 2009; Crouch et al. 2009b, c; Hyde et al. 2009a, b) and Phoma (Aveskamp et al. 2008, 2010; de Gruyter et al. 2010). Recent reports on Phyllosticta have shown that molecular phylogenetic tools have significantly improved species identification and delimitation; similarly it has improved the resolution in species complexes (Wulandari et al. 2009; Glienke et al. 2011; Wicht et al. 2012).

Baayen et al. (2002) evaluated the P. citricarpa sensu lato from Citrus and associated hosts based on ITS sequence analysis and found that two phylogenetically distinct groups existed: a slowly growing pathogenic group and morphologically similar but fast-growing, non-pathogenic group which latter proved to be P. capitalensis. Wicht et al. (2012) used a polyphasic approach including morphological, molecular and proteomic techniques to analyze samples of G. bidwellii collected from grapevine cultivars and ornamental plants of various geographic origins, and showed that $P$. ampelicida isolated from grapevine cultivars should be split into two species.

Recent studies have provided clear phylogenetic relationships in the group. These efforts primarily used intron-dominated genes (ITS, ACT, TEF), and highly conserved gene coding regions (LSU, GPDH) that can recognize cryptic species in traditionally morphologically circumscribed species complexes, e.g. $P$. citricarpa on citrus, $P$. musarum on banana, $P$. vaccinii on 


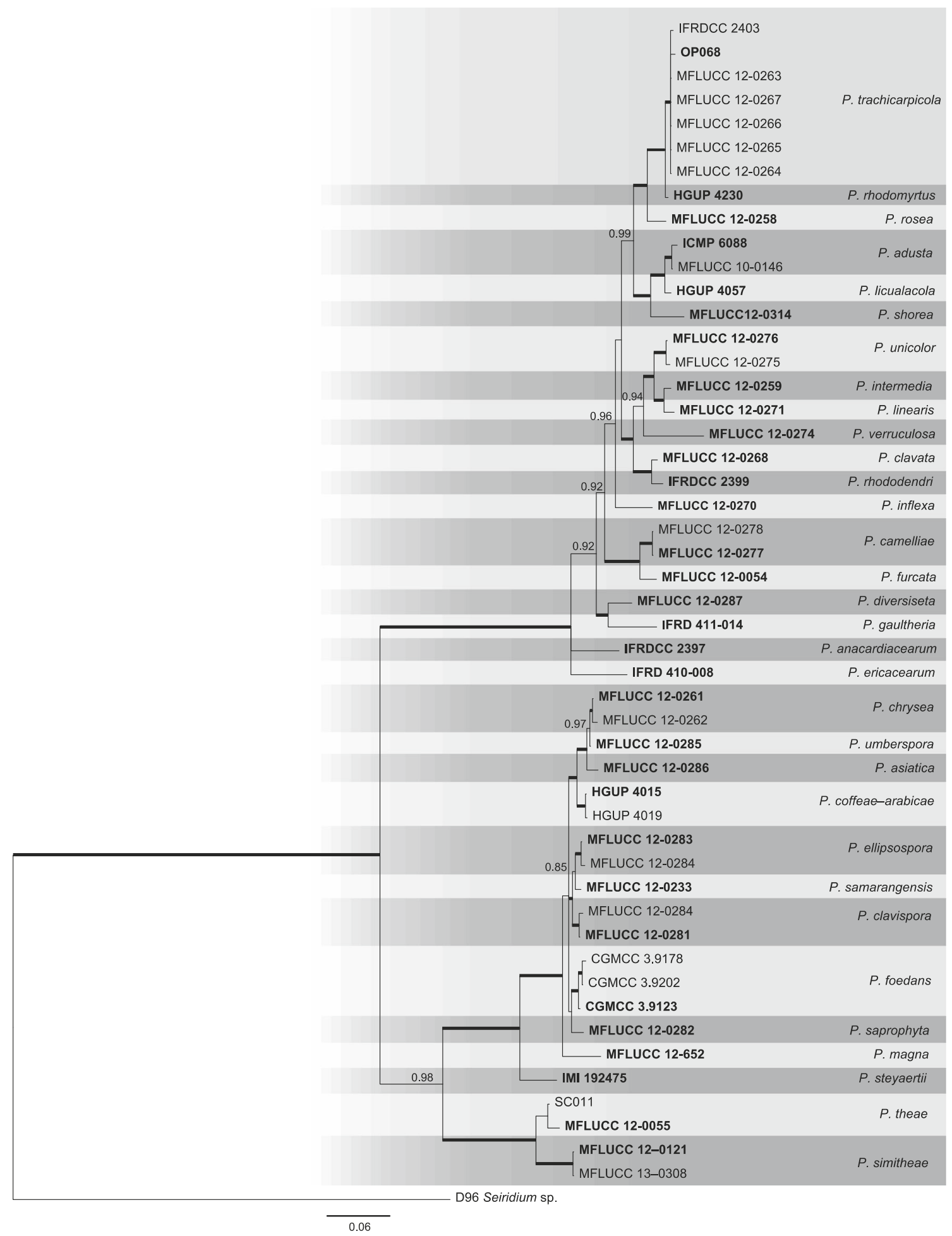

Fig. 18 Strict consensus combined (ITS $+\beta$-tubulin + TEF) tree from Bayesian analysis of the analyzed Pestalotiopsis. Thickened lines indicate Bayesian posterior probabilities (PP) of $100 \%$. Strain accession numbers

Vaccinium, G. philoprina on Rhododendron, Hedera, Ilex, Magnolia and Taxus (Glienke et al. 2011; Wang et al. 2012; Wulandari et al. 2009; Wikee et al. 2013c, a, b, c; Wong et al. 2012; Zhang et al. 2013a) (Fig. 19). (ex-type are in bold) are followed by the species name. The scale bar represents the expected changes per site. The tree is rooted to Seiridium spp. (D96)

\section{Recommendations}

- $\quad$ The large and small subunits of nrDNA (LSU and SSU)placement within the ascomycetes (generic and family level) 
Table 18 Phyllosticta. Details of the voucher and extype isolates used in the phylogenetic tree

\begin{tabular}{|c|c|c|c|c|c|c|c|}
\hline \multirow[t]{2}{*}{ Species } & \multirow[t]{2}{*}{ Strain no. } & \multirow[t]{2}{*}{ Host } & \multirow[t]{2}{*}{ Locality } & \multicolumn{4}{|c|}{ GenBank accession number } \\
\hline & & & & ITS & ACT & TEF & GPDH \\
\hline $\begin{array}{l}\text { Botryosphaeria } \\
\text { obtusa }\end{array}$ & CMW8232 & Conifers & South Africa & AY972105 & AY972111 & DQ280419 & \\
\hline Guignardia alliacea & MUCC0014* & Allium fistulosum & Japan & AB454263 & & & \\
\hline G. bidwellii & NBRC9757 & $\begin{array}{c}\text { Parthenocissus } \\
\text { tricuspidata }\end{array}$ & Japan & AB095510 & & & \\
\hline G. gaultheriae & CBS447.70* & Gaultheria humifusa & USA & JN692543 & JN692519 & JN692531 & JN692508 \\
\hline G. mangiferae & IMI260.576* & Manifera indica & India & JF261459 & JF343641 & JF261501 & JF343748 \\
\hline G. philoprina & CBS447.68* & Taxus baccata & Netherlands & AF312014 & & & \\
\hline G. vaccinii & CBS126.22* & Oxycoccus macrocarpos & USA & FJ538353 & & & \\
\hline $\begin{array}{r}\text { Phyllosticta } \\
\text { abieticola }\end{array}$ & CBS112067* & Abies concolor & Canada & KF170306 & KF289238 & & \\
\hline P. aloeicola & CPC21020* & Aloe ferox & South Africa & KF154280 & KF289311 & KF289193 & KF289124 \\
\hline P. ampelicida & ATCC200578* & Vitis riparia & USA & KC193586 & KC193581 & & KC193584 \\
\hline P. ardisiicola & NBRC102261* & Ardisia crenata & Japan & AB454274 & & & \\
\hline P. aspidistricola & NBRC102244* & Aspidistra elatior & Japan & $\mathrm{AB} 454260$ & & & \\
\hline P. beaumarisii & CBS535.87=IMI 298910 * & Muehlenbekia adpressa & Australia & AY042927 & KF306232 & KF289170 & KF289074 \\
\hline P. bifrenariae & CBS128855* & Bifrenaria harrisoniae & Brazil & JF343565 & JF343649 & JF343586 & JF343744 \\
\hline P. brazilianiae & CBS126270* & Mangifera indica & Brazil & JF343572 & JF343656 & JF343593 & JF343758 \\
\hline \multirow[t]{2}{*}{ P. capitalensis } & CBS128856* & Stanhopea sp. & Brazil & JF261465 & JF343647 & JF261507 & JF343776 \\
\hline & CPC16592 & Citrus limon & Argentina & KF206187 & KF289273 & KF289178 & KF289092 \\
\hline P. cavendishii & BRIP554196* & Musa cv. Formosana & Taiwan & JQ743562 & & & \\
\hline P. citriasiana & CBS 120486* & Citrus maxima & Thailand & FJ538360 & FJ538476 & FJ538418 & JF343686 \\
\hline P. citribraziliensis & CBS100098* & Citrus limon & Brazil & FJ538352 & FJ538468 & FJ538410 & JF343691 \\
\hline \multirow[t]{2}{*}{ P. citricarpa } & CBS127454* & Citrus limon & Australia & JF343583 & JF343667 & JF343604 & JF343771 \\
\hline & СРC16603 & Citrus limon & Uruguay & KF170295 & KF289274 & KF289213 & KF289147 \\
\hline P. citrichinaensis & ZJUCC200956* & Citrus reticulata & China & JN791620 & JN791533 & JN791459 & \\
\hline P. citrimaxima & CBS136059* & Citrus maxima & Thailand & KF170304 & KF289300 & KF289222 & KF289157 \\
\hline P. concentrica & CBS 937.7* & Hedera helix & Italy & FJ538350 & KF289257 & FJ538408 & JF411745 \\
\hline P. cordylinophila & СРC20261* & Cordyline fruticosa & Thailand & KF170287 & KF289295 & KF289172 & KF289076 \\
\hline P. cornicola & CBS111639 & Cornus florida & USA & KF170307 & KF289234 & & \\
\hline P. cussoniae & CBS136060* & Cussonia sp. & South Africa & JF343578 & JF343662 & JF343599 & JF343764 \\
\hline P. ericarum & CBS132534* & Erica gracilis & South Africa & KF206170 & KF289291 & KF289227 & KF289162 \\
\hline P. fallopiae & NBRC102266* & Fallopia japonica & Japan & AB454307 & & & \\
\hline P. foliorum & CBS 447.68 & Taxus baccata & Netherlands & KF170309 & KF289247 & KF289201 & KF289132 \\
\hline P. hamamelidis & MUCC149 & Hamamelis japonica & Japan & KF170289 & KF289309 & & \\
\hline P. hostae & CGMCC3.14355* & Hosta plantaginea & China & JN692535 & JN692511 & JN692523 & JN692503 \\
\hline P. hubeiensis & CGMCC3.14986* & Viburnum odoratissimim & China & JX025037 & JX025032 & JX025042 & JX025027 \\
\hline P. hymenocallidicola & CBS 131309* & Hymenocallis littoralis & Australia & JQ044423 & KF289242 & KF289211 & KF289142 \\
\hline P. hypoglossi & CBS 434.92* & Ruscus aculeatus & Italy & FJ538367 & FJ538483 & FJ538425 & JF343695 \\
\hline P. ilicis-aquifolii & CGMCC3.14358* & Ilex aquifolium & China & JN692538 & JN692514 & JN692526 & \\
\hline P. kerriae & NBRC102251* & Kerria japonica & Japan & AB454266 & & & \\
\hline P. leucothoicola & CBS136073* & Leucothoe catesbaei & Japan & AB454370 & KF289310 & & \\
\hline P. ligustricola & MUCC0024* & Ligustrum obtusifolium & Japan & AB454269 & AB704212 & & \\
\hline P. maculate & CPC18347* & $\begin{array}{l}\text { Musa cv. Goly-goly } \\
\text { pot-pot }\end{array}$ & Australia & JQ743570 & & & \\
\hline P. mangifera-indica & СРC20264* & Mangifera indica & Thailand & KF170305 & KF289296 & KF289190 & KF289121 \\
\hline P. minima & CBS 585.84* & Acer rubrum & USA & KF206176 & KF289249 & KF289204 & KF289135 \\
\hline P. musarum & BRIP55434* & Hill banana & India & JQ743584 & & & \\
\hline P. musicola & CBS123405* & Musa acuminata & Thailand & FJ538334 & FJ538450 & FJ538392 & \\
\hline
\end{tabular}


Table 18 (continued)

\begin{tabular}{|c|c|c|c|c|c|c|c|}
\hline \multirow[t]{2}{*}{ Species } & \multirow[t]{2}{*}{ Strain no. } & \multirow[t]{2}{*}{ Host } & \multirow[t]{2}{*}{ Locality } & \multicolumn{4}{|c|}{ GenBank accession number } \\
\hline & & & & ITS & $\mathrm{ACT}$ & TEF & GPDH \\
\hline P. neopyrolae & СРC21879* & Pyrola asarifolia & Japan & AB454318 & AB704233 & & \\
\hline P. owaniana & CBS776.97* & Brabejum stellatifolium & South Africa & FJ538368 & KF289254 & FJ538426 & JF343767 \\
\hline P. pachysandricola & MUCC0124* & Pachysandra terminalis & Japan & AB454317 & AB704232 & & \\
\hline P. parthenocissi & CBS111645* & Parthenocissus quinquefolia & USA & EU683672 & JN692518 & JN692530 & \\
\hline P. paxistimae & CBS112527* & Paxistima mysinites & USA & KF206172 & KF289239 & KF289209 & KF289140 \\
\hline P. philoprina & CBS616.72 & Ilex aquifolium & Germany & KF154279 & KF289251 & KF289205 & KF289136 \\
\hline P. podocarpi & CBS111647 & Podocarpus lanceolata & South Africa & KF154276 & KF289235 & KF289232 & KF289168 \\
\hline P. podocarpicola & CBS728.79* & Podocarpus maki & USA & KF206173 & KF289252 & KF289203 & KF289134 \\
\hline P. pseudotsugae & CBS111649 & Pseudotsuga menziesii & USA & KF154277 & KF289236 & KF289231 & KF289167 \\
\hline P. rhaphiolepidis & MUCC0432* & Rhaphiolepis indica & Japan & AB454349 & AB704242 & & \\
\hline P. schimae & CGMCC3.14354* & Schima superb & China & JN692534 & JN692510 & JN692522 & JN692506 \\
\hline P. speewahensis & BRIP58044 & Orchids & $\begin{array}{l}\text { northern } \\
\text { Australia }\end{array}$ & KF017269 & & KF017268 & \\
\hline P. spinarum & CBS292.90 & Chamaecyparis pisifera & France & JF343585 & JF343669 & JF343606 & JF343773 \\
\hline P. styracicola & CGMCC3.14985* & Styrax grandiflorus & China & JX025040 & JX025035 & JX025045 & JX025030 \\
\hline P. telopeae & CBS777.97* & Telopea speciosissima & Tasmania & KF206205 & KF289255 & KF289210 & KF289141 \\
\hline P. vaccinii & ATCC46255* & Vaccinium macrocarpon & USA & KC193585 & KC193580 & KC193582 & KC193583 \\
\hline P. vacciniicola & CPC18590* & Vaccinium macrocarpum & USA & KF170312 & KF289287 & KF289229 & KF289165 \\
\hline P. yuccae & CBS117136 & Yucca elephantipes & New Zealand & JN692541 & JN692517 & JN692529 & JN692507 \\
\hline
\end{tabular}

Ex-type strains are bolded and marked with an * and voucher stains are bolded

- The internal transcribed spacer (ITS)-generic level

- Combined ITS, TEF, GPDH and ACT-inter-specific delineation

\section{Phytophthora}

\section{Background}

While resembling Eumycotan fungi with the production of hyphae, the genus is placed in the kingdom Straminipila, class Oomycetes, order Peronosporales, and family Peronosporacae. The type species is P. infestans described by de Bary in 1876 . Since this time over 128 species have been described, many of which are important plant pathogens capable of significantly impacting agricultural production and natural ecosystems. Some species have a rather narrow host range ( $P$. infestans, $P$. lateralis, $P$. sojae) while others are capable of infecting a wide range of plant host species (P. cinnamomi, $P$. nicotianae, $P$. ramorum). From a historical perspective, most investigations on the genus have focused on the impact of the genus on agricultural production systems, however, more recently there has been an increased interest in investigating the role this genus plays in natural ecosystems as exemplified by the number of publications concerning species such as $P$. ramorum and $P$. alni, as well as the description of many new species recovered from environmental sampling (Martin et al. 2012).

Although Phytophthora species resemble Eumycotan fungi with the production of hyphae, evolutionarily they are more closely related to chromophyte algae and plats than to Eumycotan fungi (Wainright et al. 1993). They have cell walls that are primarily cellulose rather than chitin as observed in fungi and they are incapable of synthesizing $\beta$-hydroxysterols (which are required for synthesis of hormones regulating sexual reproduction). In addition, Oomycetes are diploid throughout their life cycle in contrast to most true fungi.

An excellent overview of the ecology, biology and taxonomy of the genus (although missing more recently described species) can be found in Erwin and Ribeiro (1996), a review of the recent taxonomic status in Kroon et al. (2012) and an overview of the genus, including molecular identification and diagnostics, in Martin et al. (2012). There are several publically available databases that provide a wealth of up to date information on the genus, along with sequences useful for species identification via BLAST analysis, including the Phytophthora Database (www.phytophthoradb.org), Phytophthora ID (www.phytophthora-id.org) and Q-Bank (www.q-bank.eu). Cline et al. (2008) have published an online list of Phytophthora spp. with a hyperlink for each species to the USDA SMML database that includes host range, distribution and supporting literature. 
Fig. 19 Phylogram generated from parsimony analysis based on combined ITS, TEF, GPDH and ACT sequenced data of Phyllosticta. Parsimony bootstrap support values greater than $50 \%$ are indicated above the nodes. The ex-type (ex-epitype) and voucher strains are in bold
97 P. citribraziliensis CBS100098

$P$. ericarum CPC19744

$51-P$. concentrica CBS937.70

67 L $P$. kerriae NBRC102251

94 90 $P$. spinarum CBS292.90

- $P$. cussoniae CPC14873

51 - $P$. hypoglossi CBS434.92

P. citrichinaensis ZJUCC200956

$83 \leftarrow$ P. rhaphiolepidis MUCC0432

84 P. hostae CGMCC3.14355

L. speewahensis BRIP58044

$87 \quad P$. aspidistricola MUCC0010 90. P. citriasiana CBS120486 $100 \sim P$. citrimaxima CPC20276

$52 \quad 72 \quad 100$ P. citricarpa CPC16603

$63 \longleftarrow$ P. hymenocallidicola CBS131309 P. bifrenariae VIC30556

$62 \quad 65-P$. podocarpi CBS111647

100 - P. pseudotsugae CBS111649

P. owaniana CBS776.97

100 G. vaccinii CBS126.22

78 P. vacciniicola CPC18590 P. vaccinii ATCC46255

52 - P. pachysandricola MUCC0124

L P. yuccae CBS117136

G. gaultheriae CBS447.70

$P$. neopyrolae MUCC0125

9. $P$. leucothoicola MUCC0553

80 [ P. cornicola CBS111639

$P$. paxistimae CBS112527

$P$. abietis CBS112067

P. telopeae CBS777.97

$P$. ligustricola MUCC0024

P. minima CBS585.84

P. podocarpicola CBS728.79

62 P. foliorum CBS447.68

P. hubeiensis CGMCC3.14986

$P$. hamamelidis MUCC149

100 P. ilicis-aquifolii CGMCC3.14358

$P$. philoprina CBS 616.72

G. alliacea MUCC0014

P. capitalensis CPC16592

P. capitalensis CPC18848

P. fallopiae MUCC0113

P. musicola CBS123405

P. cordylinophila CPC20261

70 G. mangiferae IMI260.576

P. ardisiicola MUCC0031 60 G. bidwellii NBRC9757

85 - P. parthenocissi CBS111645

L . ampelicida ATCC200578

67 $P$. schimae CGMCC3.14354

63 - P. aloeicola CPC21020

61 - P. styracicola CGMCC3.14985

P. mangifera-indica CPC20264

100

$P$. brazilianiae LGMF330

80 $P$. cavendishii BRIP554196

P. maculata CPC18347

98 P. musarum BRIP55434

$P$. beaumarisii CBS535.87

Botryosphaeria obtusa CMW8232 
Species identification and numbers

A complicating factor when trying to identify Phytophthora species or investigate phylogenetic relationships is hybridization among distinct evolutionary lineages. While this does not appear to be a common occurrence, several stable hybrid species have been identified, e.g. P. andina (Goss et al. 2011; Blair et al. 2012); P. alni (Brasier et al. 1999); $P$. $x$ pelgrandis (Nirenberg et al. 2009); P. x serindipita (Man in 't Veld et al. 2012) as well as hybrid clade 1 species recovered from the field (Man in 't Veld et al. 1998, 2007; Hurtado-Gonzales et al. 2009; Bonants et al. 2000). While conducting a detailed evaluation of clade 6 Phytophthora spp. from natural ecosystems in Australia, Burgess et al. (2010) observed 'hybrid swarms' that contained mixtures of parent, offspring, and intermediate isolates with high tendencies for back-crossing and out crossing. The authors' concluded that the presence of such hybrid swarms was indicative of sexual and somatic hybridization events; the high proportion of these variant isolates within the population also suggested that these hybridization events were not uncommon. Recently four interspecific hybrid clade 6 species have been recovered from riparian ecosystems in Australia and South Africa that reflect outcrossing between P. amnicola, P. thermophila and $P$. taxon PgChlamydo (Nagel et al. 2013). Additional putative interspecific hybrids from riparian ecosystems in Australia were reported by Hüberli et al. (2013). Hybridization is a topic that requires a more detailed investigation as it could have a profound influence on gene flow among species and the evolution of new species with an expanded host range that could impact agricultural and natural ecosystems (as observed with P. alni).

Traditional classification to species level has been based on morphological characterization of reproductive structures (reviewed in Martin et al. 2012). This includes the sporangium (asexual) and oospore (sexual) as well as the production of chlamydospores (asexual structure not produced by all species). Important features of the sporangium include their dimensions (length and breadth), shape, thickening at the terminus (papilla), length of stalk (pedicle), whether or not the sporangium can be easily dislodged from the sporangiophore (caducity), and proliferation of sporangia (internal, external or nested).

The sexual reproductive structures consist of the antheridium and oogonium (paternal and maternal gametangia, respectively) and are produced when cultures are grown on the appropriate sterol-containing medium. Their fusion leads to the formation of an oogonium that matures into a thick-walled resting structure referred to as an oospore. While most species are homothallic and form oospores in single culture, there are heterothallic species where pairing with opposite mating types is essential to stimulate production of sexual reproductive structures. Since Phytophthora is sexually dimorphic (an isolate of a heterothallic species can function either as the maternal or paternal parent depending on the isolate it is paired with) it is advisable to pair self-sterile isolates with two tester isolates of opposite mating type. While the use of tester isolates of the same species is advisable, isolates of other heterothallic species (such as P. cryptogea or P. cambivora) may also be used. Characteristics such as the diameter of the oogonium and oospore, thickness of the oospore wall, whether or not the oospore fills the oogonium (plerotic), ornamentation on the oogonial wall, and mode of attachment of the antheridium are useful for species classification.

In an effort to simplify isolate identification and establish groupings of isolates for comparison of morphological features (but not phylogenetic relationships), Waterhouse (1963) introduced the concept of morphological groups I through VI based on a number of characteristics, and is still useful today. Unfortunately a dichotomous key that includes recently described species is not available for identification of isolates but there are several recent efforts to simplify morphological identification of species, including a manual for identification of 60 species of Phytophthora by integration of a dichotomous key with a DNA fingerprinting technique based on PCRsingle strand conformational polymorphism (SSCP) (Gallegly and Hong 2008). A LUCID key for identification of 55 common Phytophthora spp. is available (Ristaino 2011) and an expanded LUCID key including most described species should be available on a dedicated website in the near future (G. Abad and Y. Balci, personal communication). A tabular presentation of morphological features enabling comparison among 117 species may be found in Martin et al. (2012; a downloadable file of the table alone is available on the journal website).

In 1999 the number of described species in the genus Phytophthora was approximately 55 (Brasier 2007) but since then there has been a significant increase., Brasier (2007) reported a doubling in number to 105 described species, with this number recently increasing to 117 (Martin et al. 2012). Additional species have recently been described; P. lacustris (Nechwatal et al. 2012) P. pluvialis (Reeser et al. 2013), P. mississippiae (Yang et al. 2013), P. cichorii, P. dauci and P. lactucae (Bertier et al. 2013), P. pisi (Heyman et al. 2013), P. stricta and P. macilentosa (Yang et al. 2014) and the hybrid species $P$. x serendipita and $P$. x pelgrandis (Man in 't Veld et al. 2012), bringing the total to at least 128 described species. With the number of provisional species names used in the literature, and research efforts to evaluate the distribution of this genus in natural ecosystem, this number is likely to continue to increase in the future.

Molecular phylogeny

Historically the genus Phytophthora has been placed in the Pythialeswith Pythium and related genera but more recent 
phylogenetic analysis with the large (LSU) or small (SSU) rDNA sequences or $\operatorname{cox} 2$ gene has indicated a closer affiliation with downy mildews and white rusts (Albugo.) in the Peronosporales (Beakes and Sekimoto 2009; Thines et al. 2009). However, additional multigene analyses with a larger number of downy mildew species is needed to better characterize this relationship and the placement of Phytophthora spp. in clade 9 and 10 (Blair et al. 2008). The relationship between the Peronosporales and Pythium (Pythiales) needs clarification as well. A new genus, Phytopythium, was erected to accommodate an inconsistency between taxonomic and phylogenetic grouping for certain "intermediate" Pythium species (Bala et al. 2010), and it is likely that additional taxonomic revisions of the Peronosporomycetidae will be needed to fully resolve taxonomic conflicts.

Early efforts to understand phylogenetic relationships in Phytophthora focused on the use of the nuclear encoded rDNA, primarily the ITS region (Förster et al. 2000; Cooke and Duncan 1997; Crawford et al. 1996). Cooke et al. (2000) published the first comprehensive phylogenetic analysis of the genus using the ITS region to examine the phylogeny of 50 species. Most isolates grouped within eight primary clades (numbered 1 to 8 ) with several other species placed in two additional clades (clades 9 and 10). Kroon et al. (2004) expanded this analysis using two nuclear (translation elongation factor $1 \alpha, \beta$-tubulin) and two mitochondrial ( $\operatorname{cox} 1$ and nadl) genes. While in general the results were congruent with those reported by Cooke et al. (2000), there were some notable differences in the grouping of some species. Subsequent analysis by Blair et al. (2008) using seven nuclear genes (60S ribosomal protein L10, B-tubulin, enolase, heat shock protein 90, large subunit rDNA, TigA gene fusion and translation elongation factor $1 \alpha$ ) representing $8.1 \mathrm{~kb}$ of sequence data for 82 Phytophthora spp. clarified these differences. This larger, multi-marker analysis supported the observations of Cooke et al. (2000) with eight main clades plus two additional closely affiliated clades (clades 9 and 10) as the sister clades to the rest of the genus. More recently, Martin et al. (2014) expanded on this analysis by adding four mitochondrial genes (cox2, nad9, rps10 and $\sec Y$ ) and additional species. The resulting phylogeny from this 11 -marker analysis $(10,828 \mathrm{bp}$ per isolate) was similar to the prior observations of Blair et al. (2008) and subsequent analysis indicated that similar results could be obtained when using only five markers (LSU, $\beta$ tubulin, $\operatorname{cox} 2$, nad 9 and $r p s$ 10).

While the ITS region may be useful for species identification (see below), length variation among species makes it impossible to construct an unambiguous alignment across the entire genus, thus hampering the utility of this marker for phylogenetic analysis. Likewise, the translation elongation factor $1 \alpha$ has been used for phylogenetic analysis, but recent analysis of Phytophthora genomic data indicates that the gene is duplicated; divergence among duplicates may complicate phylogenetic interpretations of species evolution (J. E. Blair, unpublished).

While the above noted phylogenetic analyses have provided insight into the broader evolutionary relationships within the genus, there is still ambiguity when examining some closely related species and species complexes. Significant progress has been made with the clarification of the P. megasperma complex and other clade six species (Brasier et al. 2003; Durán et al. 2008; Hansen et al. 2009; Jung et al. 2011a, b) but there are still several provisional species awaiting more comprehensive analysis (for example, P. taxon PgChlamydo, P. taxon raspberry, P. taxon canalensis, $P$. taxon erwinii, $P$. taxon hungarica, $P$. taxon oregonsis and P. taxon paludosa). While there have been advances in understanding the relationships among some clade 2 species, there is need for additional analysis to clarify species complexes such as P. citricola and P. citrophthora. One clade 8 species complex where phylogenetic resolution has been elusive is P. cryptogea and the closely related species $P$. drechsleri. The multigene analysis of Mostowfizadeh-Ghalamfarsa et al. (2010) confirmed that while $P$. drechsleri was monophyletic, the $P$. cryptogea complex formed three well-defined phylogenetic groups with group I closely affiliated with $P$. erythroseptica and group II and III as a separate clade (group III isolates have been reported as the provisional species, P. sp. kelmania; Martin et al. 2014). Some isolates were placed intermediate between groups II and III and exhibited a greater amount of heterozygosity than the other isolates, suggesting possible outcrossing between these groups. Using a parsimony-based ancestral recombination graph and genealogies inferred from the $\beta$-tubulin and translation elongation factor $1-\alpha$ genes from greenhouse recovered isolates, Olson et al. (2011) suggested that divergence between P. cryptogea and $P$. drechsleri was recent and that speciation is still in progress.

In addition to the choice of markers to use for phylogenetic analysis, another important consideration is the type of analysis used for estimating phylogenetic relationships or for the description of new species. While traditional methods of phylogenetic analysis (maximum likelihood, neighbour-joining, Bayesian) have adequately described relationships among most species, they have been unable to fully resolve the deeper relationships among the ten Phytophthora clades or among related genera. A recent study by Martin et al. (2014) used a novel variation of a multispecies coalescent approach to evaluate the ten clades; in general support was higher than that observed in the phylogenetic analysis for the recovered relationships, but the position of certain clades (Clade 3 and the unique grouping of $P$. sp. ohioensis and $P$. quercina) remained ambiguous. Here we present an analysis using a more powerful and complex Bayesian method (Drummond et al. 2012) with five genetic markers (Fig. 20), and recover strong support for basal relationships among the clades that are quite similar to 


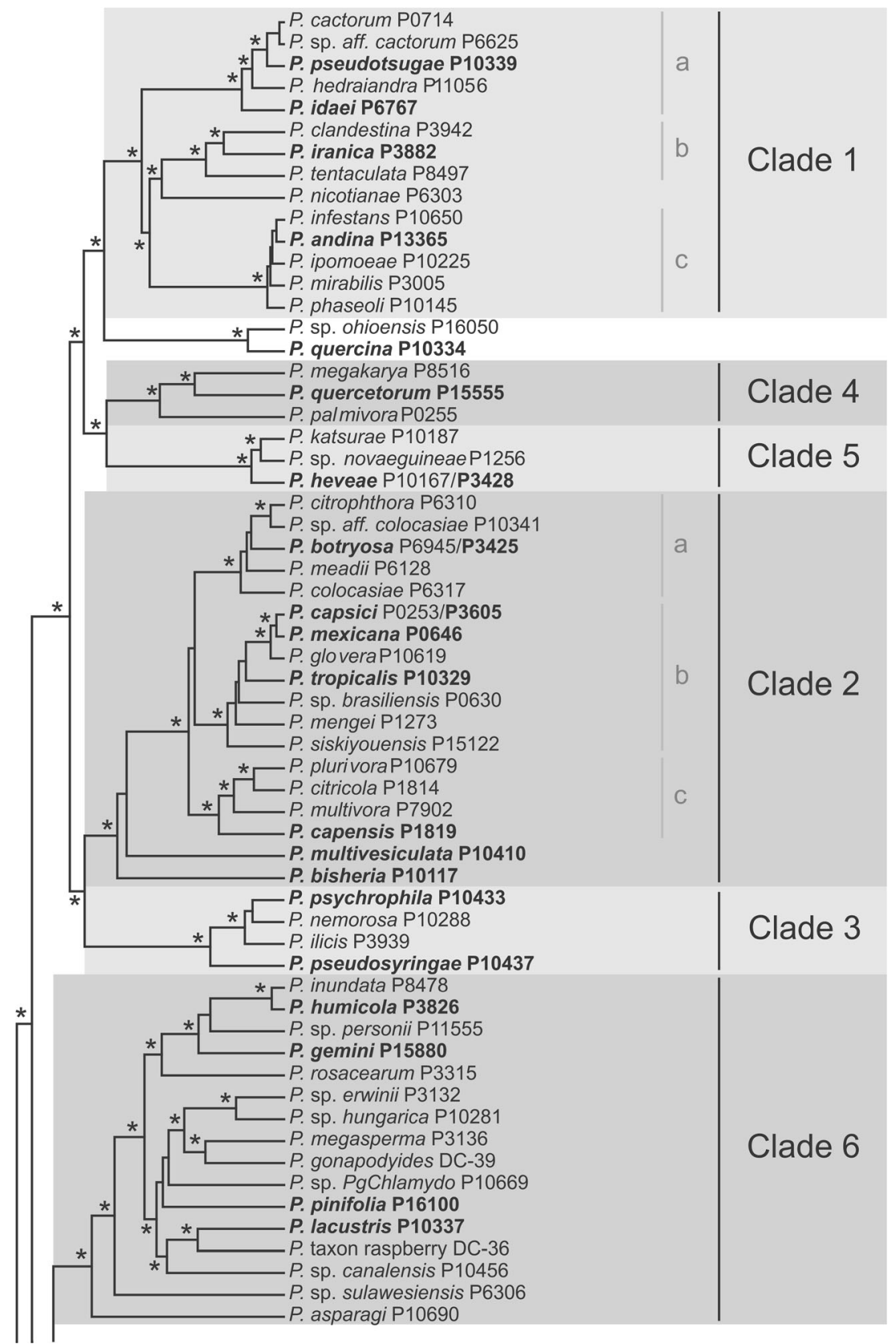

Fig. 20 Bayesian analysis of phylogenetic relationships within Phytophthora. Asterisks on nodes indicate posterior probabilities greater than 0.95 (95\%) generated from an analysis of five genes (nuclear LSU and $\beta$-tubulin; mitochondrial cox2, nad9, rps 10). Evolutionary rates were estimated under a GTR + I + G model for nuclear markers and an HKY + I + G model for mitochondrial gene; each marker was treated as a separate partition. The analysis was run twice with 50 million generations under a strict clock model in BEAST v1.7.5. A $20 \%$ burn in was removed before the maximum clade credibility tree was constructed. Ex-type isolates are shown in bold. Separate isolate numbers are shown for those few species that did not have sequence data available for both nuclear and mitochondrial genes from a single isolate

the 11-marker study of Martin et al. (2014). Newer phylogenetic methods may allow for more complex modelling of the evolutionary process, however they are still sensitive to the accuracy of a priori information provided by the user. Additional studies will be needed to provide more basic information on the tempo of molecular evolution within this group.

The description of new species is also an area were traditional phylogenetic methods may not accurately describe species relatedness. Aside from morphological characterization, recent species descriptions typically contain molecular evidence from one or a few genetic markers (primarily ITS and perhaps coxl or 2). However, as described above, alignment ambiguity and the presence of intraspecific polymorphisms can seriously impact the recovered phylogeny; recent hybridization events and incomplete lineage sorting of ancestral polymorphisms also violate the assumptions made by 


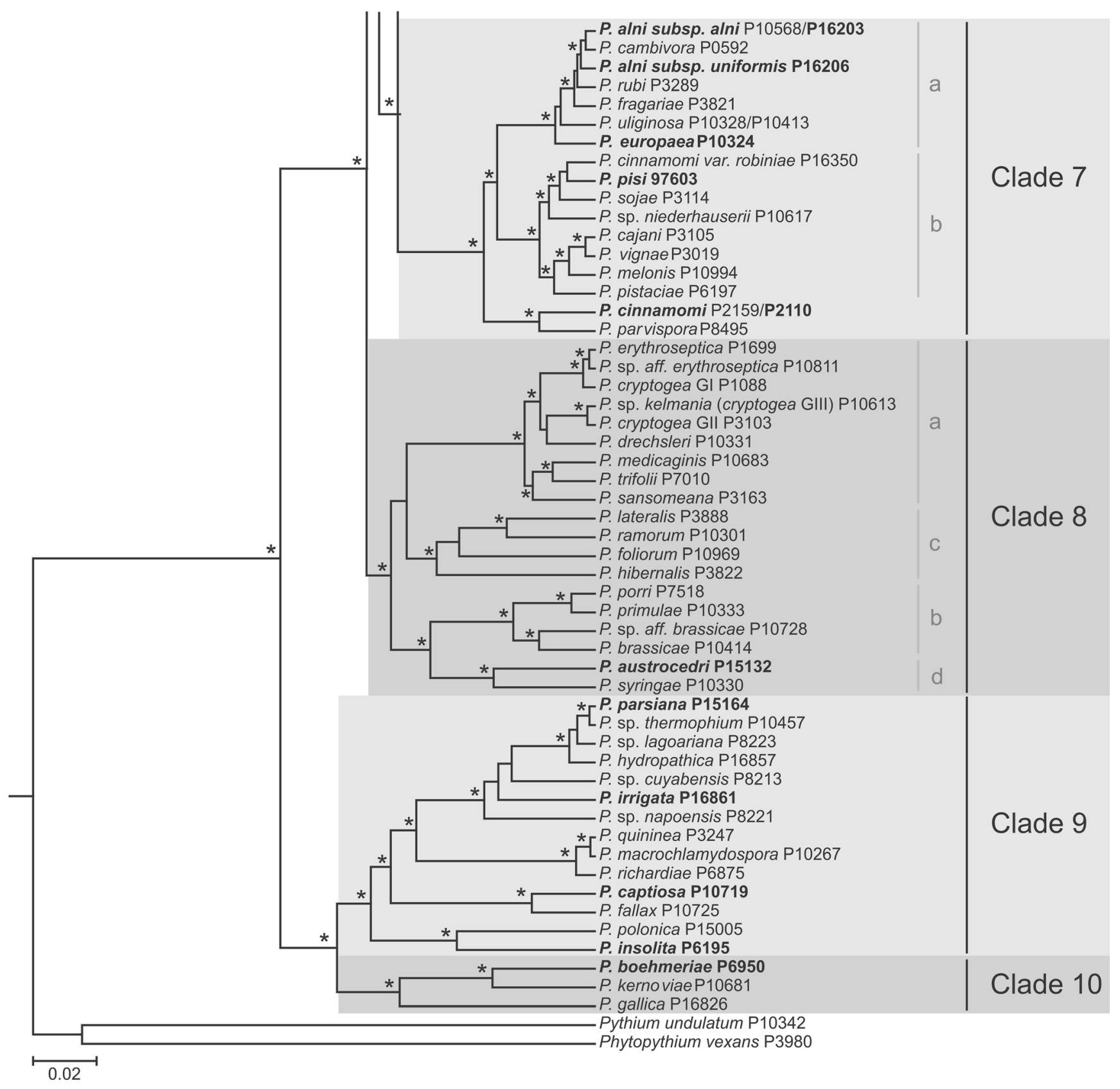

Fig. 20 (continued)

traditional phylogenetic methods. The use of coalescent-based approaches to estimate species trees from a collection of gene trees has been gaining popularity among many other taxonomic groups, but has seen little attention in Phytophthora or oomycete research in general. The recent description of $P$. pisi (Heyman et al. 2013) employed a multispecies coalescent approach, which confirmed the individual analyses of ITS and $\operatorname{cox} 2$ data. In addition, a recent study of the hybrid species $P$. andina (Blair et al. 2012) used several coalescent methods to determine the likely parental lineages of this species, one of which was clearly $P$. infestans. In the future, the use of more complex phylogenetic methods as well as coalescent-based approaches will be needed to clarify relationships at both ends of the spectrum, from deep basal nodes to recently evolved and potentially interbreeding species complexes.

A common observation among all phylogenetic studies is there is no consistent correlation between phylogenetic grouping and morphological features (Cooke et al. 2000; Kroon et al. 2004, 2012; Blair et al. 2008; Martin et al. 2014). While there is some correlation with sporangial type (clade 4,5 , and 10 have primarily papillate sporangia while clade 3 has primarily semipapillate sporangia and clades 6,7 , and 9 primarily nonpapillate sporangia), other clades show combinations of these 
features (clade 1, 2 and 8). Characteristics such as oogonial ornamentation, heterothallism, and mode of antheridial attachment are all polyphyletic.

Because of the large number of species, intraspecific variation of some morphological features, and overlapping morphology among closely related species, traditional methods of species identification can be challenging and require some level of expertise to be effective. The use of molecular criteria has simplified this task and provides a tool for delineating distinct taxa within morphologically similar species complexes. The most accurate molecular method for species identification is sequence analysis of specific markers. The internal transcribed spacer (ITS) region of the nuclear ribosomal DNA (rDNA) has been widely used and a large number of sequences are currently available in public databases. However, this marker may not be ideal for the identification of all species, especially those that are closely related. For example, many clade $1 \mathrm{C}$ species (P. infestans, $P$. mirabilis) cannot be distinguished using this marker alone, nor can $P$. fragariae and P. rubi. More recently a portion of the coxl gene, along with the ITS region, have been proposed as the markers to use in the Barcode of Life Database (www. boldsystems.org) and representative sequences for all described and some provisional species have been deposited (Robideau et al. 2011).

Several nuclear (60S ribosomal protein L10, $\beta$-tubulin, enolase, heat shock protein 90, large subunit rRNA, TigA gene fusion, translation elongation factor $1 \alpha$; (Blair et al. 2008; Kroon et al. 2004; Villa et al. 2006)) and mitochondrial (cox1, nad1, cox2, nad9, rps10 and secY; (Kroon et al. 2004; Martin 2008; Martin and Tooley 2003a, b; Martin et al. 2014) markers have been sequenced for phylogenetic analysis of Phytophthora and can also be used for species identification. Background information for amplification and sequencing of many of these markers, as well as the capability for BLAST searches against a curated database for isolate identification, may be found at the Phytophthora Database (www. phytophthoradb.org). A dataset for ITS and coxl and 2 spacer sequences is also available at Phytophthora ID ((Grünwald et al. 2011), www.phytophthora-id.org) and sequence data for several markers (ITS, $\beta$-tubulin, elongation factor 1 alpha, and $\operatorname{cox} 1$ ), along with pictures of morphological features, may be found at Q-Bank (www.q-bank.eu).

There are several caveats to consider when using BLAST analysis to identify isolates to species level to prevent misidentification (Kang et al. 2010; Nilsson et al. 2012). BLAST scores are dependent on the length of the aligned sequences as well as the level of sequence identity; instances where high levels of sequence identity occur for only a portion of the target sequence may result in incorrect species identification. Also, it is common to encounter situations where scores are similar among multiple species, making it difficult to draw conclusions about an isolate's identity (this can be especially problematic for isolates within or related to species complexes). In addition, the use of markers known to contain intraspecific polymorphisms may lead to inaccurate species identifications due to potentially lower similarities among closely related sequences. Heterozygosity in nuclear markers may also complicate identification efforts; while the presence of distinct alleles may indicate outcrossing (as Phytophthora is a known diploid), heterozygosity may also result from hybridization events between distinct lineages (as described above). Phylogenetic analysis of several markers is therefore suggested to confirm species identification, especially when working with species complexes. Additional gel based techniques, such as PCR-RFLP, SSCP, random amplified polymorphic DNAs (RAPDs), amplified fragment length polymorphisms (AFLP) and simple sequence repeat (SSR) analysis, for species identification and population analysis are reviewed in Martin et al. (2012).

\section{Recommended genetic markers}

The following genetic markers have been found to amplify well across all species and provided a similar level of phylogenetic resolution as a concatenated dataset of seven nuclear and four mitochondrial genes (Martin et al. 2014). Information on amplification and sequencing primers for these genes may be found at the Phytophthora Database (www.phytophthoradb.org).

Nuclear genes-LSU, $\beta$-tubulin

Mitochondrial-cox2, nad9, rps 10

\section{Phytophthora Data}

Sequence alignments of the seven nuclear and four mitochondrial markers used in Martin et al. (2014) and Fig. 20 may be downloaded at TreeBASE (http://purl. org/phylo/treebase/phylows/study/TB2:S14595). A table with additional information on isolates used in the analysis may be found in Martin et al. (2014) with GenBank accession numbers listed in the supplementary material of this citation. These sequences can also be downloaded from the Phytophthora Database (www.phytophthoradb.org).

\section{Pythium}

Background

Pythium is classified as belonging to the family Pythiaceae sensu lato (s.l.), order Peronosporales s.l., class Peronosporomycetes, phylum Oomycota, and kingdom 
Straminipila (Beakes et al. 2014). Although many species are considered to be saprobes, the genus is known primarily for its parasitic interactions with plants. Several species also parasitize algae (green and red), fungi, other oomycetes, nematodes, insects, crustaceans, and fish. One species, $P$. insidiosum, is the causal agent of pythiosis in mammals, including humans (Van der Plaats-Niterink 1981; de Cock et al. 1987). Plant pathogenic Pythium species often target young below-ground plant parts such as fine roots, germinating seeds and emerging growth, resulting in damping-off, root rot and poor crop stands with stunted plants and reduced yield. Some species can also cause fruit rot, and at least one species, $P$. vexans, has been associated with trunk cankers of rubber trees (Van der PlaatsNiterink 1981; Zeng et al. 2005). Although some species have a limited host range, such as $P$. arrhenomanes that seems to be exclusively associated with gramineous crops, species like $P$. aphanidermatum, $P$. irregulare and $P$. ultimum are known for being highly virulent on an extensive range of plant hosts (Van der Plaats-Niterink 1981). However, not all Pythium species have a negative impact on the plants they are associated with. Besides saprobes, others can benefit plants by acting as biocontrol agents that parasitize pathogenic fungi and/or induce host resistance, e.g. Pythium oligandrum (Benhamou et al. 1997). Other species of Pythium have also been reported to stimulate plant growth (Mazzola et al. 2002). Recent genome sequencing of six Pythium species found high levels of variation in the number of CRN ("Crinkler") effectors found in the different species, possibly suggesting species-specific infection strategies (Adhikari et al. 2013) that may contribute to the range of interactions of Pythium species with their hosts. Such species-specific host-interactions along with the ubiquitous nature of the genus in soils all over the world make accurate species identification necessary to facilitate disease diagnosis and management.

Debates regarding possible genera within Pythium were initially sparked by differences in sporangial morphology. Based on these characters some of the novel genera that have been proposed are Nematosporangium (for species with filamentous zoosporangia), Rheosporangium (species with lobulate zoosporangia), and Sphaerosporangium (species with ovoid, spherical or citriform sporangia) (Schröter 1897; Sparrow 1931). The legitimacies of these genera have been questioned for various reasons (Sideris 1931a; Sparrow 1932; Van der Plaats-Niterink 1981), and aside from some attempts at transferring Pythium species to Nematosporangium (Jaczewski and Jaczewski 1931; Sideris 1931b) the scientific community has stuck with the generic classification of Pythium versus these genera. As molecular taxonomy became a more popular approach to studying systematics, the paraphyletic nature of Pythium became apparent and the debate on splitting the genus was rekindled. Early sequence-based phylogenies provided strong arguments for $P$. vexans to be part of a separate genus (Briard et al. 1995; Cooke et al. 2000). The ITS and 28S phylogenies of Lévesque and de Cock (2004) divided Pythium into 11 clades $(\mathrm{A}-\mathrm{K})$ of which clade $\mathrm{K}$ (including $P$. vexans) is more closely related to Phytophthora than to the rest of the Pythium clades (Villa et al. 2006). A new genus, Phytopythium, was subsequently erected to include all clade $\mathrm{K}$ species, with Phytopythium sindhum as type species (Bala et al. 2010), although the official transfer of all clade K Pythium species to Phytopythium has not yet been published. The remaining ten clades (A-J) can be divided into two groups: species with filamentous zoosporangia (clades A-D) and species with globose zoosporangia (clades E-J) (Lévesque and de Cock 2004), calling to mind early suggestions of splitting the genus based on this character (Schröter 1893; Sparrow 1931). This division is echoed to varying degrees by phylogenies of the $28 \mathrm{~S}$ rRNA, ITS, cytochrome c oxidase subunits 1 and 2 ( $\operatorname{cox} 1$ and $\operatorname{cox} 2)$, and $\beta$-tubulin, although the different gene trees are often incongruent and support for internal nodes low or absent (Martin 2000; Riethmüller et al. 2002; Villa et al. 2006; Hulvey et al. 2010; Robideau et al. 2011). Despite the shortcomings of these gene regions, Uzuhashi et al. (2010) used 28S and cox2 phylogenies to divide Pythium into five genera: Pythium (clades A-D), Globisporangium (clades E-G, I and J), Elongisporangium (clade H), Ovatisporangium (clade K, syn. Phytopythium), and Pilasporangium (distinct from any of the aforementioned 11 clades). Although this division is more or less in agreement with previous phylogenetic studies, it is problematic with regards to a lack of bootstrap support for the Pythium and Globisporangium clades, and the relationship and distinction between Elongisporangium and Globisporangium is not resolved with support (Fig. 21, Uzuhashi et al. 2010). Additionally, the genera Pythiogeton and Lagena seem to be phylogenetically situated within, or closely related to Pythium emend Uzuhashi, Tojo and Kakishima (Fig. 21, Huang et al. 2013a), so even this revised version of Pythium is paraphyletic. For these reasons investigators have generally been slow to adopt the proposed genera. Following this trend references to "Pythium" in this manuscript refer to Pythium s.l. (i.e. Pythium Pringsheim) unless stated otherwise.

Species identification and numbers

A combined list of Pythium species in MycoBank (2014) and Index Fungorum (2014) includes a total of

Fig. 21 Maximum likelihood phylogeny of Pythium s.l. and related genera based on the concatenated $18 \mathrm{~S}$ rRNA, ITS, 28S rRNA, cytochrome $\mathrm{c}$ oxidase subunit $2(\operatorname{cox} 2)$, and $\beta$-tubulin regions. Bootstrap support values below $60 \%$ are not indicated. Strains in bold typeface represent type-derived material, authentic strains or strains used by Van der Plaats-Niterink (1981) for descriptions. The 11 clades (A-K) of Lévesque and de Cock (2004) and the genera erected by Bala et al. (2010) and Uzuhashi et al. (2010) are indicated on the right along with related taxa such as Phytophthora, Lagenidium, Lagena, and Pythiogeton 


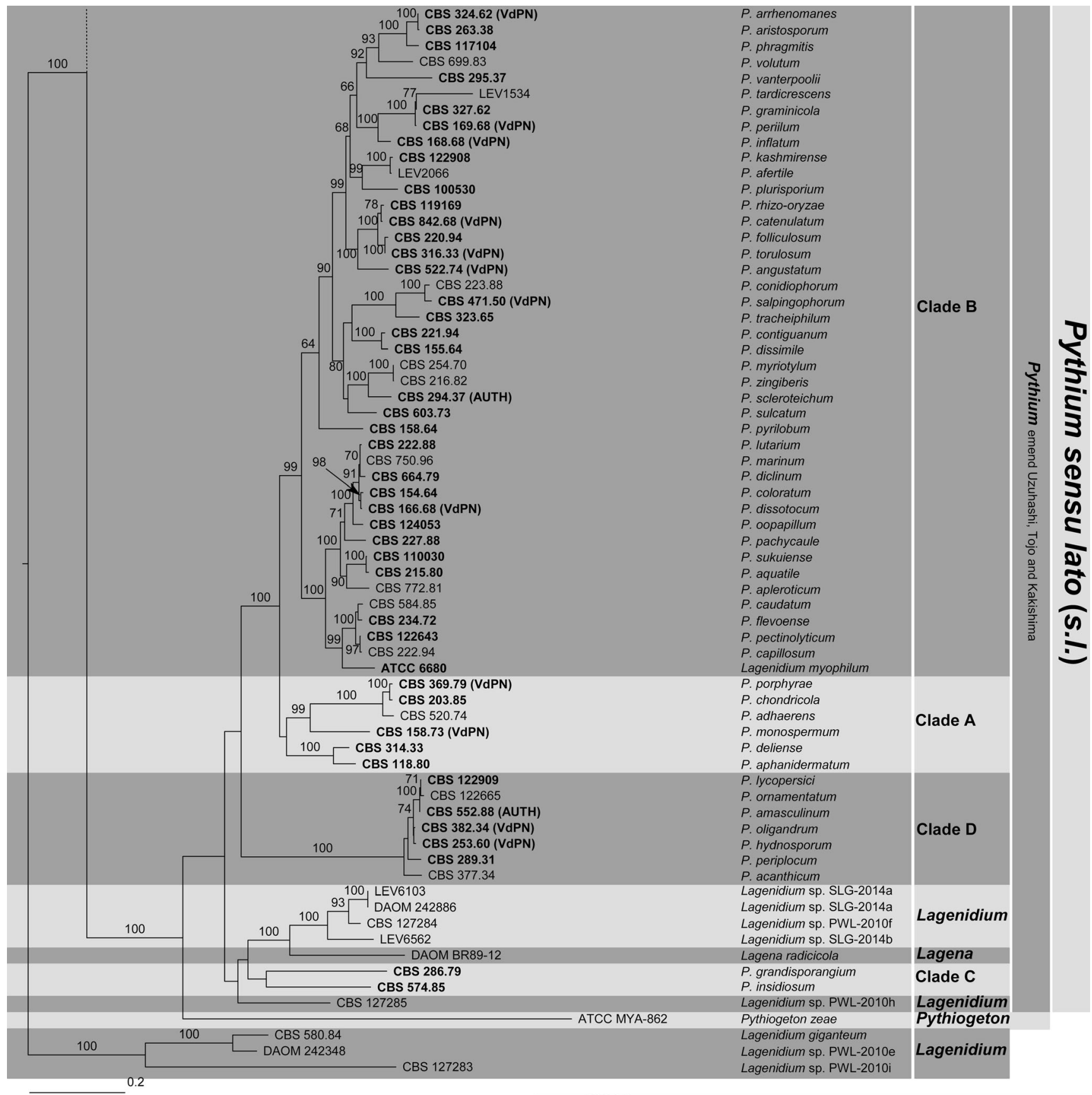

328 names of which several are either synonyms, orthographic variants or varieties that are rarely referred to and are possibly synonyms of other species (i.e. all varieties excluding varieties of $P$. ultimum). Excluding such cases along with putative synonyms based on cox 1 and ITS sequence homology as identified by Robideau et al. (2011) leaves more or less 230 species of Pythium. Undoubtedly this number still includes species that should be synonymized and/or transferred to genera other than Pythium (Van der Plaats-Niterink 1981; Dick 1990, 2001), but for now this should serve as a rough estimate of the number of actual Pythium species discovered to date. Of these species $152(66 \%)$ are known to be represented by sequence(s) in GenBank, including at least $123(53 \%)$ species for which type-material, extype strains or strains described by Van der PlaatsNiterink (1981) were used to generate sequence data (Table 19, Fig. 21).

Identification of Pythium isolates to the species level is generally straightforward when comparing both ITS and $\operatorname{cox} 1$ sequences to that of ex-type, authentic or other reliable representative strains. For this purpose the sequences 


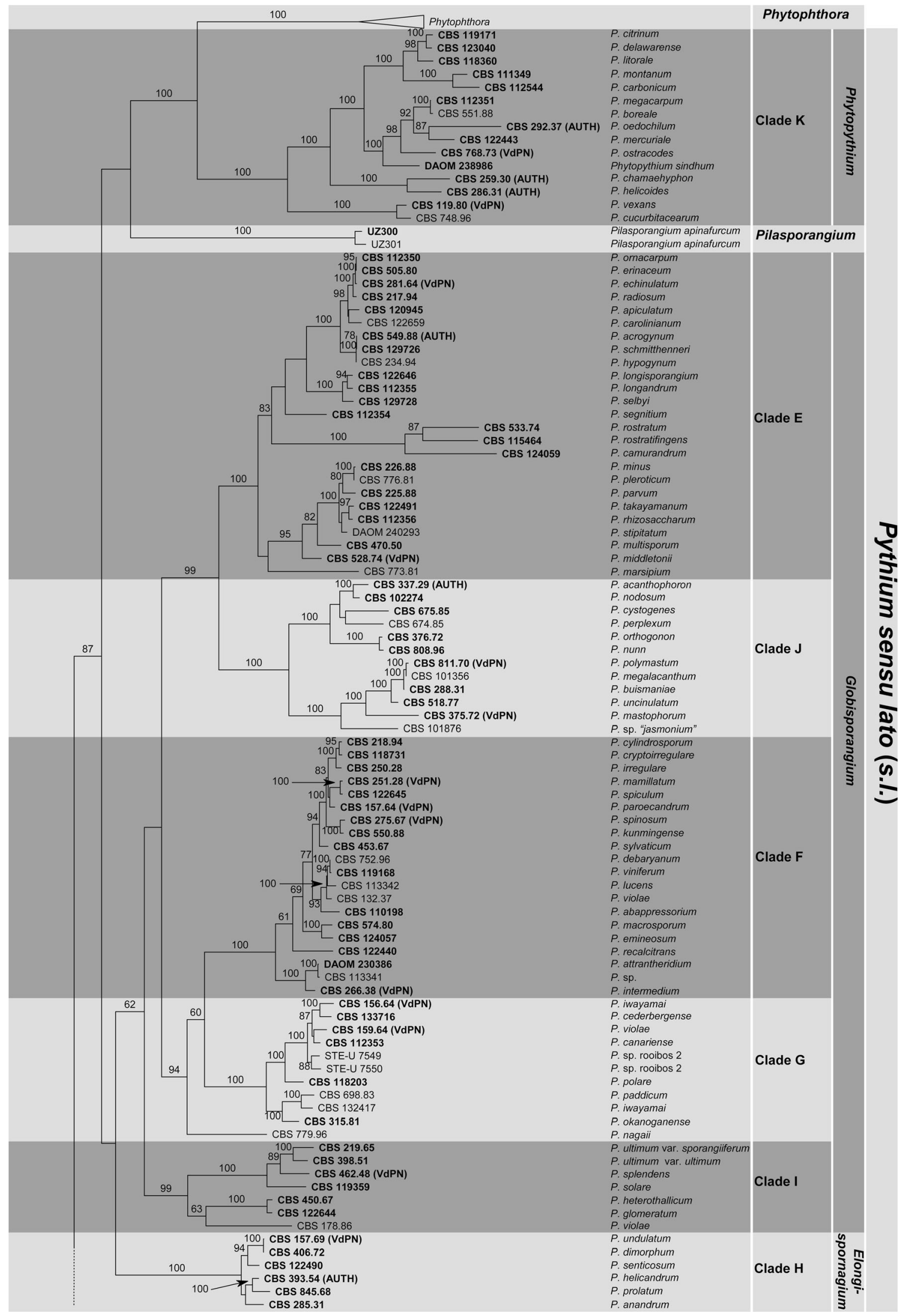

Fig. 21 (continued) 


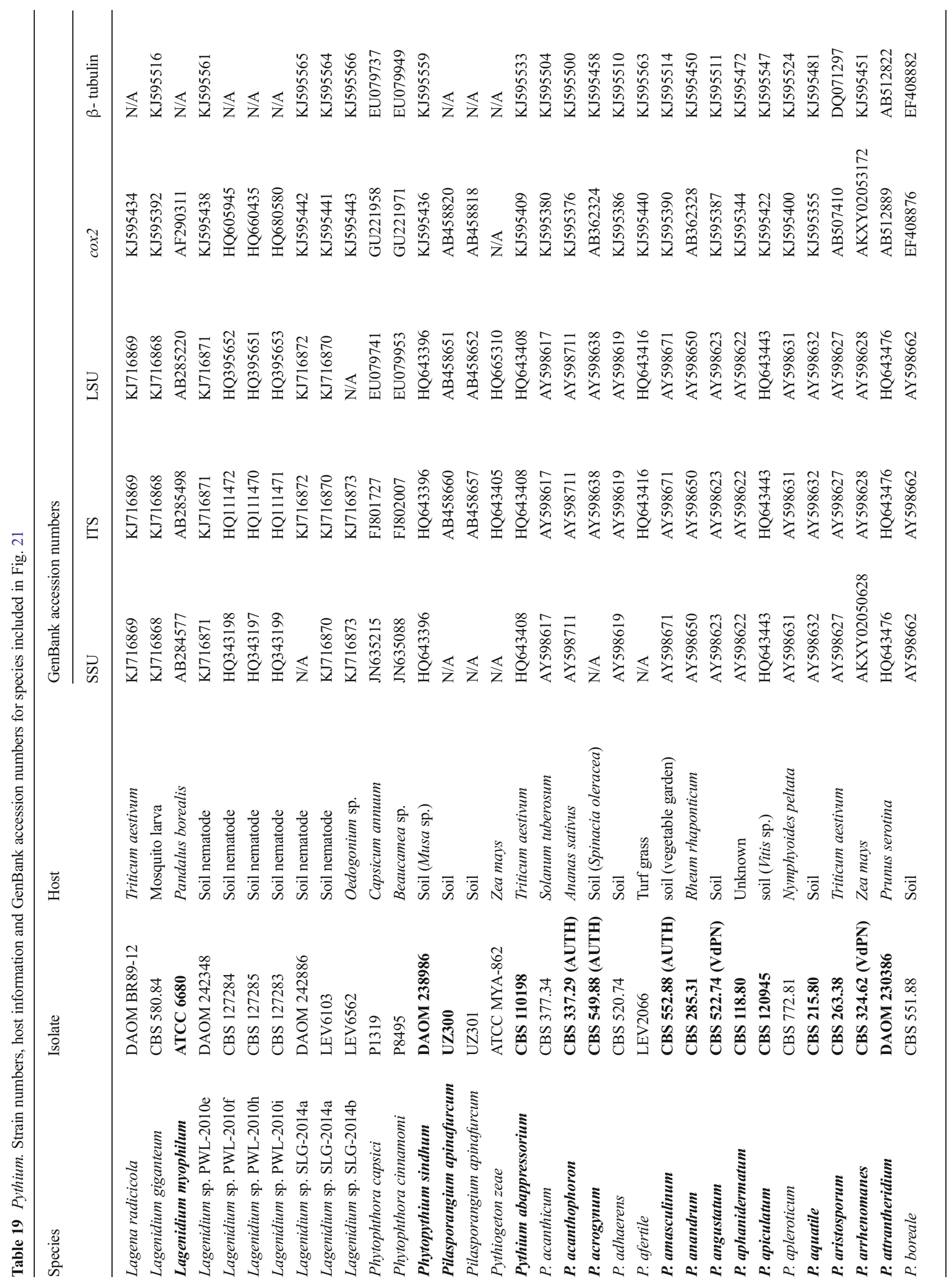




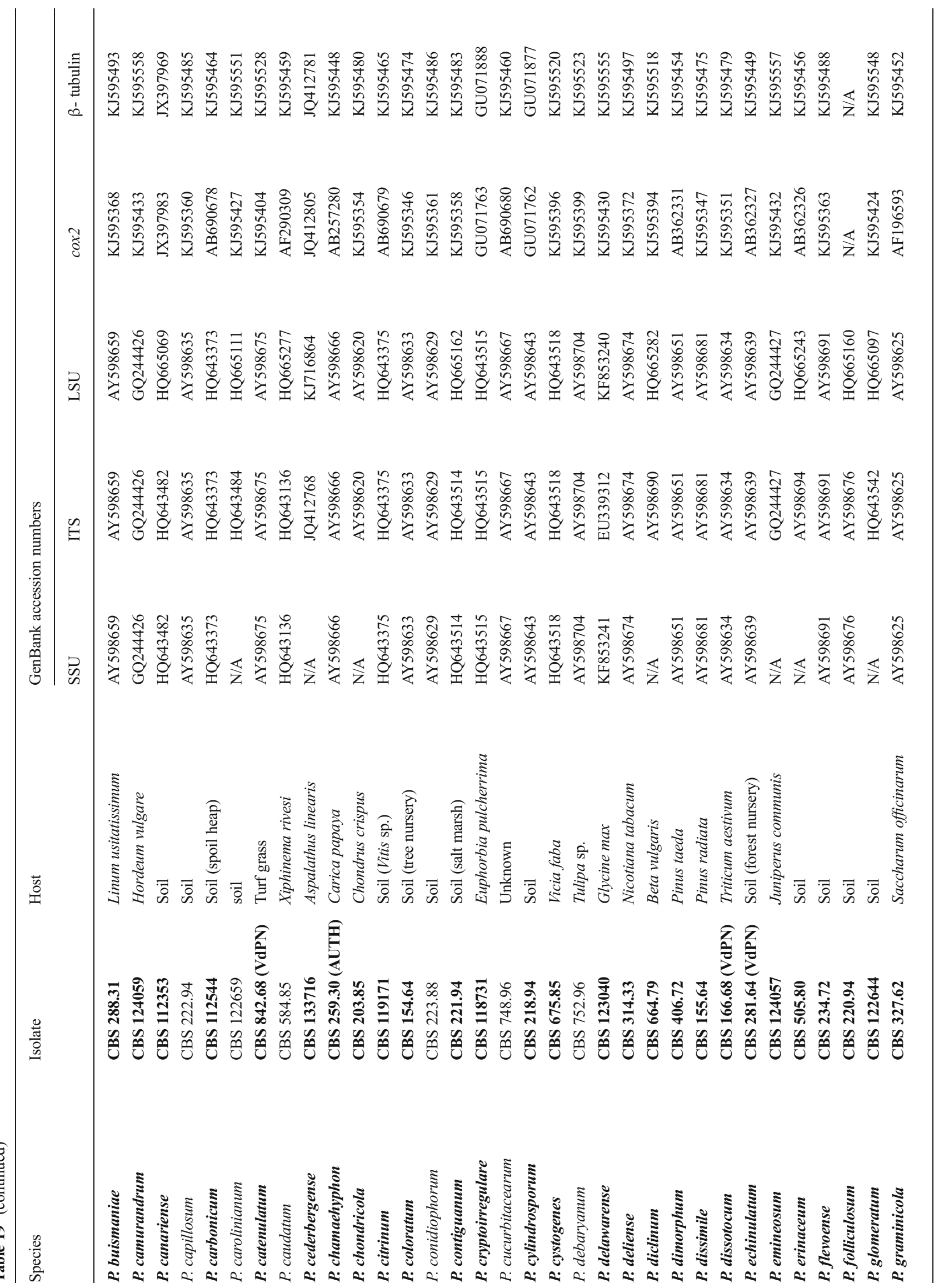




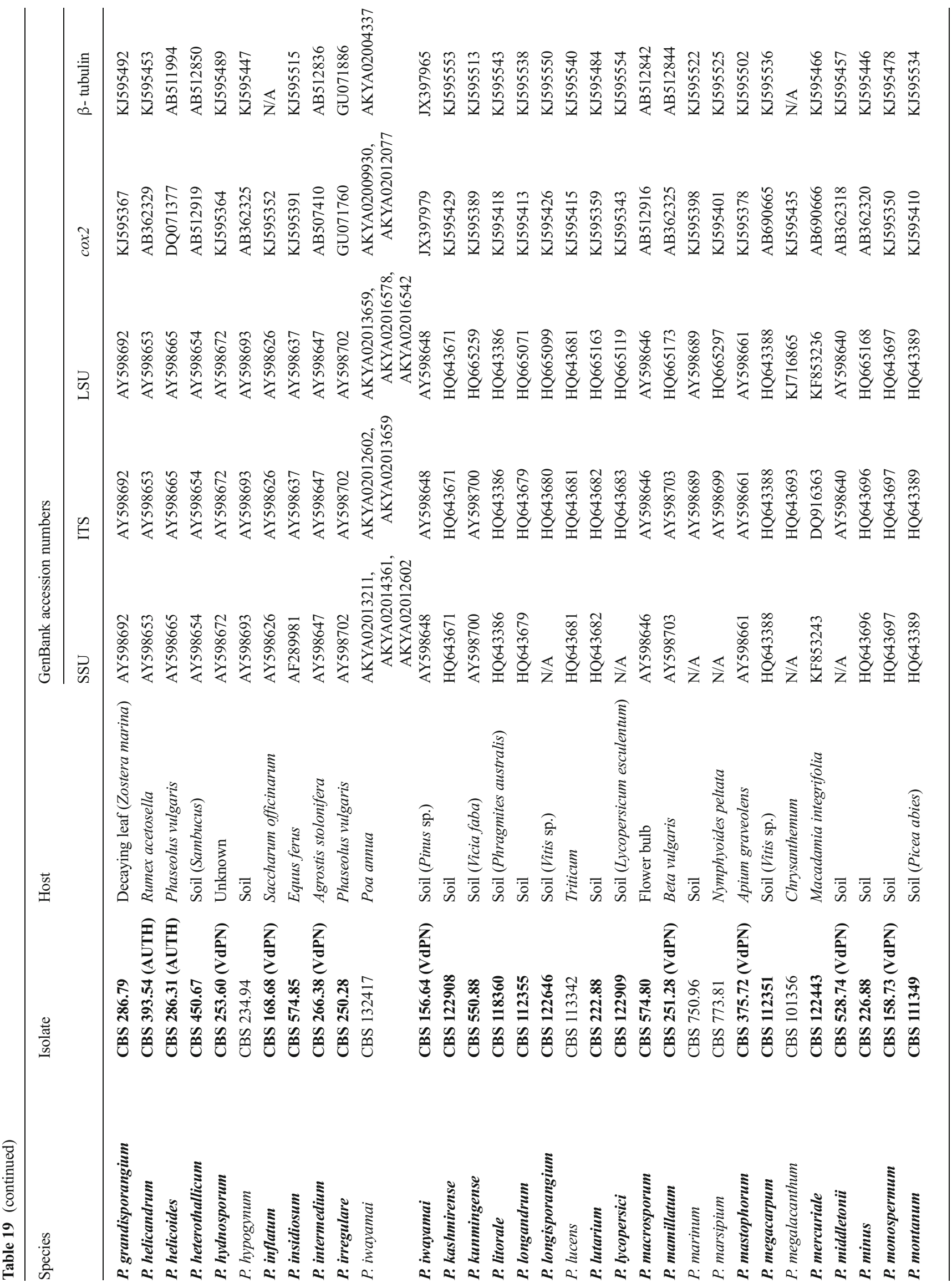




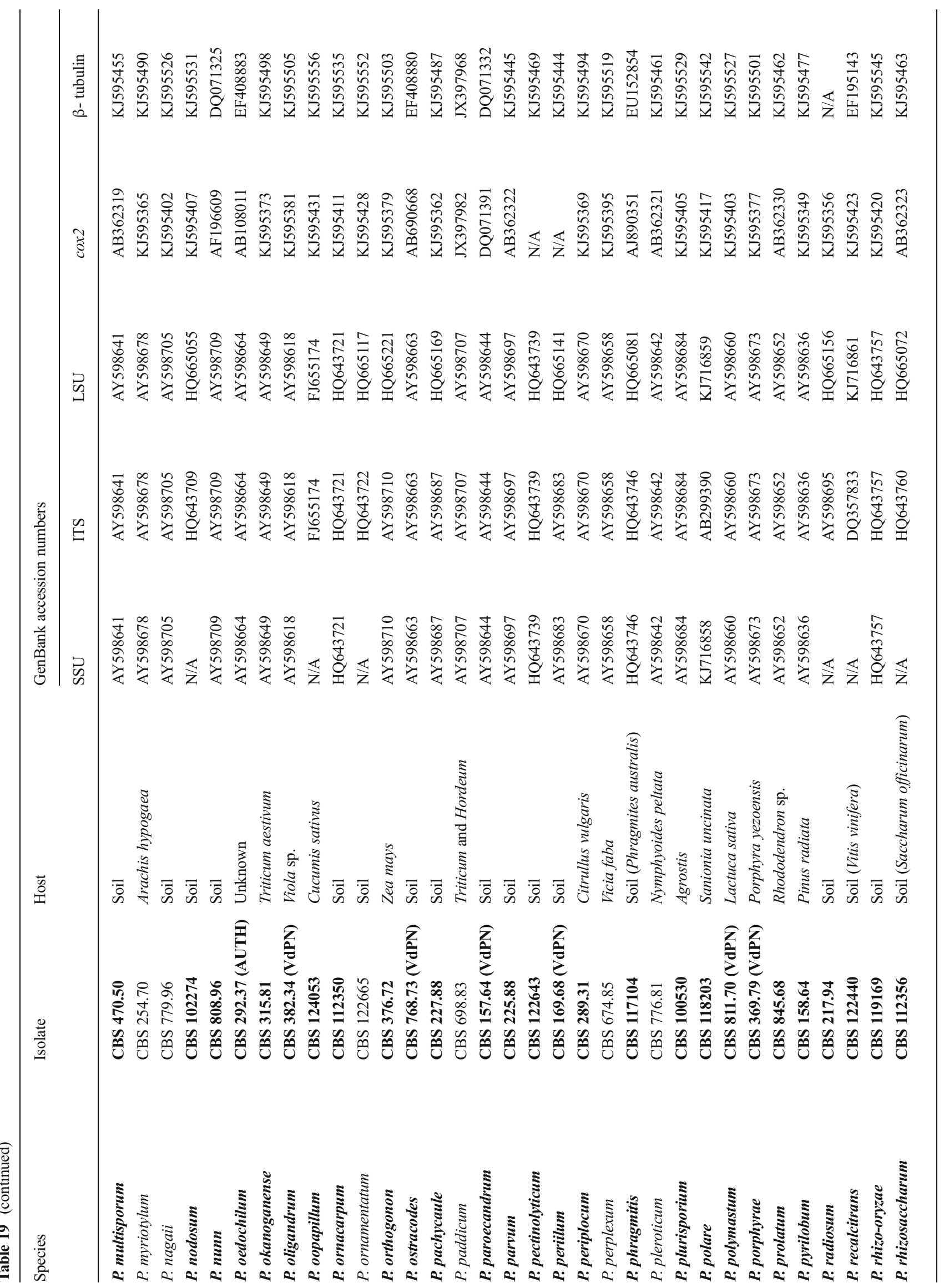




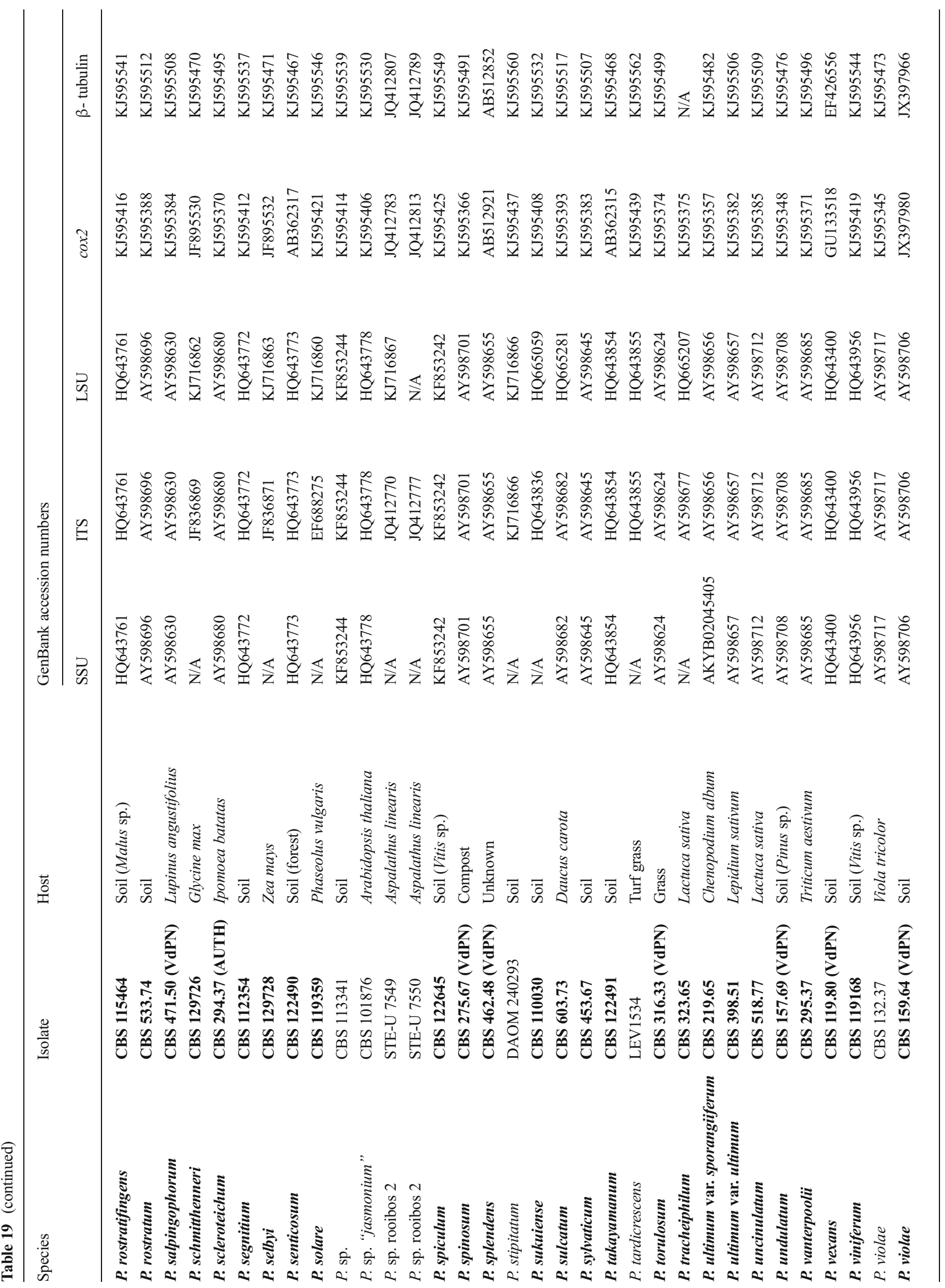


generated by Lévesque and de Cock (2004) and Robideau et al. (2011) are excellent resources. Using only the ITS region would more often than not allow suitably accurate species identification, but some species are indistinguishable using ITS and require coxl sequences for further identification (see Text S1A of Robideau et al. 2011). Several other species are indistinguishable even when both ITS and coxl sequences are compared (see Text S1B of Robideau et al. 2011), and many of these should probably be formally synonymized pending more thorough investigations with multiple hypervariable genes. This approach should also resolve species complexes found in the group formed by $P$. irregulare, $P$. paroecandrum, $P$. cylindrosporum, $P$. cryptoirregulare and P. mamillatum (Barr et al. 1997; Matsumoto et al. 2000; Garzón et al. 2007; Spies et al. 2011a), the varieties of P. ultimum (Barr et al. 1996), and the P. vexans and P. cucurbitacearum group (Spies et al. 2011b). Some species epithets have been applied to multiple phylogenetic species due to imprecise species descriptions and/or misidentifications. Examples of these include $P$. iwayamai, P. okanoganense and P. violae (Lévesque and de Cock 2004; McLeod et al. 2009; Bahramisharif et al. 2013). Mislabelling or contamination of reference strains and/or data cause similar problems, as illustrated by the case of $P$. terrestre (published as "terrestris") of which the holotype strain ITS sequence published with the description suggests phylogenetic placement in clade E (Paul 2002), while the ITS and coxl sequences generated for the ex-type strain available from the Centraal Bureau voor Schimmelcultures (CBS) suggests phylogenetic placement in clade F (Robideau et al. 2011). Species identification within genetically diverse species complexes (see Text S1C of Robideau et al. 2011 for a partial list) can also be tricky, more due to uncertain species boundaries than due to the ineffectiveness of ITS and/or coxl as barcoding regions. The onus is on the investigator to keep such issues in mind when identifying strains to the species level and to consider the identification in context of the taxonomic history of the species and its closest relatives.

Molecular phylogeny

The first molecular phylogenies of Pythium were inferred from sequences of the 28S, ITS, and cox 2 regions respectively, and although each analysis included only a few species, the observed variation merited speculation regarding the polyphyletic nature of Pythium at least for the ITS and 28S phylogenies (Briard et al. 1995; Cooke et al. 2000; Martin 2000). The first study to provide an extensive DNA sequence based phylogeny of Pythium was that of Lévesque and de Cock (2004) who sequenced the $28 \mathrm{~S}$ region of 51 species and complete ITS region (ITS1-5.8S rRNA-ITS2) region of 116 species. Although a two-marker phylogeny of the ITS-28S region was presented by 
Lévesque and de Cock (2004), these markers are adjacent multi-copy markers that might not accurately represent the evolutionary relationships in Pythium. Villa et al. (2006) used multiple markers (ITS, cox2, $\beta$-tubulin) in individual phylogenetic analyses with 39 species and confirmed previous suggestions of an intermediate evolutionary position of clade K species between Pythium and Phytophthora, but also suggested that clade $\mathrm{H}$ species (represented by Phytophthora undulata $\equiv$ Pythium undulatum) occupy a similar intermediate position, which contrasted the position of this clade nestled among clades E, F, G, I, and J as suggested by Lévesque and de Cock (2004). The multimarker phylogeny (18S-ITS-28S, cox 2 and $\beta$-tubulin) of 152 Pythium species and some related taxa presented here confirms the association of clade K with Phytophthora, but fails to provide support for the evolutionary association of clade $\mathrm{H}$ with any of the other recognized groups within Pythium (Fig. 21). Furthermore, organisms such as the obligate root pathogen Lagena radicicola and strains resembling Lagenidium form an unresolved cluster of taxa related to clade C (Fig. 21). In itself this phylogenetic placement of the genus Lagena necessitates a further taxonomic revision of the genus Pythium that can only be achieved once the internal nodes of the Pythium phylogeny have been resolved with support. Despite the fact that the phylogeny in Fig. 21 represents the most extensive sampling of taxa and genetic markers in a multi-marker phylogeny of Pythium to date, it still fails to achieve this goal. Phylogenetic markers additional or alternative to those currently used in Pythium systematics are needed to resolve these issues and elucidate taxon boundaries.

\section{Recommended genetic markers}

- The 18S (small subunit, SSU) and 28S (large subunit, LSU) nuclear rRNA genes-generic level phylogenies within Pythium s.l.

- The internal transcribed spacers (ITS including ITS1, 5.8S rRNA, and ITS2), cytochrome c oxidase subunit 2 (cox2)sub-generic, inter- and intra-specific level phylogenies

- ITS and coxl-non-phylogenetic species identification

Mitochondrial regions such as cox 1 and $\operatorname{cox} 2$ should be used with consideration of the fact that they mainly reflect evolution of maternal lineages and can produce incongruent phylogenies. This is especially true for coxl, which is why this region was not included in Fig. 21. The $\beta$-tubulin region has also been used to a limited extent in Pythium phylogenies (Villa et al. 2006; Belbahri et al. 2008; Spies et al. 2011a, b). Although this region fails to resolve Pythium into the genera observed when using the dataset from Fig. 21 (data not shown) and has limited power in resolving species-level phylogenies (Spies et al. 2011a, b), it amplifies and sequences well for most Pythium species and is an easy resource for use in concatenated datasets (e.g. Bahramisharif et al. 2013; Fig. 21).

\section{Pyrenophora}

\section{Background}

Pyrenophora represents a genus of plant pathogenic fungi associated with a wide variety of substrates. Fries (1849) list the genus as Pyrenophora typified with Pyrenophora phaeocomes. The genus Pyrenophora clusters in the suborder Pleosporineae of the family Pleosporaceae (Berbee 1996; Zhang and Berbee 2001; Hyde et al. 2013a, b; Zhang et al. 2012; Ariyawansa et al. 2014). Recent studies using multigene analysis and some coupled with morphology have provided the groundwork for classification of species in Pyrenophora (Berbee 1996; Zhang and Berbee 2001; Hyde et al. 2013a, b; Zhang et al. 2012).

Pyrenophora has been linked to asexual morphs in Drechslera. Pyrenophora species are important plant pathogens as well as saprobes. Many species cause disease on their graminicolous hosts and are usually present in their asexual state (Drechslera) (Zhang and Berbee 2001). Species of Pyrenophora are serious plant pathogens (Zhang and Berbee 2001). Pyrenophora teres (Drechslera teres) is a necrotrophic pathogen of economically important crops, such as barley (Gupta and Loughman 2001; Kingsland 1991). Pyrenophora graminea (Drechslera graminea) causes barley stripe resulting in significant yield losses (Tekauz 1983, 1990). Pyrenophora graminea lives within barley kernels as mycelium, and when seeds germinate, hyphae enter the seedling through the coleorrhiza, causing a systemic infection (Platenkamp 1976; Porta-Puglia et al. 1986). Pyrenophora tritici-repentis causes tan spot of wheat (Lamari and Bernier 1989) which occurs in all the major wheat-growing areas of the world and causes 3 to $50 \%$ yield losses (Ballance et al. 1996). Its prevalence has increased recently.

Some Pyrenophora species have been used as biocontrol agents. Bromus tectorum is a dominant winter annual weed in cold deserts of the western United States (Meyer et al. 2007). Together with other annual brome grasses it has invaded many ecosystems of the western United States creating nearmonocultures in which the native vegetation cannot compete (Meyer et al. 2007). Pyrenophora semeniperda has be used as a biocontrol agent to kill the dormant seeds of Bromus tectorum (Meyer et al. 2007). Several studies have assessed chemical production by Pyrenophora species. A new phytotoxic sesquiterpenoid penta-2,4-dienoic acid (pyrenophoric acid) was isolated from solid wheat seed culture of P. semeniperda. 
Species identification and numbers

Pyrenophora is characterized by immersed, erumpent to nearly superficial ascomata, indefinite pseudoparaphyses, clavate to saccate asci usually with a large apical ring, and muriform terete ascospores. Morphologically, the terete ascospores of Pyrenophora can be easily distinguished from Clathrospora and Platyspora. The indefinite pseudoparaphyses and smaller ascospores of Pyrenophora can be clearly separated from those of Pleospora (Sivanesan 1984). Pyrenophora species can easy be distinguished from species in Cochliobolus and Setosphaeria on the basis of the shape, septation and colour of the ascospores (Zhang and Berbee 2001). Drechslera species were initially categorized in Helminthosporium on the basis of their dark colour, transversely septate conidia and a graminicolous habitat (Shoemaker 1959). Consequently, graminicolous Helminthosporium species were segregated into three genera, Bipolaris, Drechslera, and Exserohilum, defined based on their association with their sexual states Cochliobolus, Pyrenophora, or Setosphaeria, respectively (Zhang and Berbee 2001). Currently 198 species of Pyrenophora and 135 species of Drechslera are listed in Index Fungorum (2014).

\section{Molecular phylogeny}

Rapid identification of diseases caused by Pyrenophora has been determined via different DNA markers. Identification of molecular genetic markers in Pyrenophora teres f. teres associated with low virulence on 'Harbin' barley was assessed by random amplified polymorphic DNA (RAPD) (Weiland et al. 1999) and five RAPD markers were obtained that were associated in coupling with low virulence. The data suggested that the RAPD technique can be used to tag genetic determinants for virulence in P. teres f. teres (Weiland et al. 1999). Specific polymerase chain reaction (PCR) primers were developed from amplified fragment length polymorphism (AFLP) fragments of $P$. teres, in order to distinguish the two forms, P. teres f. teres (which cause net form blotch on barley leaves) and P. teres f. maculata (which causes spot form); the two forms are morphologically very similar in culture (Leisova et al. 2005). The PCR assay was certified with 60 samples of Pyrenophora species. The amplification with four designed PCR primer pairs provided $P$. teres form-specific products. No cross-reaction was observed with DNA of several other species, such as $P$. tritici-repentis and P. graminea (Leisova et al. 2005). Pyrenophora graminea is the causal agent of barley leaf stripe disease (Mokrani et al. 2012). Two leaf stripe isolates PgSy3 (exhibiting high virulence on the barley cultivar 'Arabi Abiad') and PgSy1 (exhibiting low virulence on Arabi Abiad), were mated and 63 progeny were isolated and phenotyped for the reaction on Arabi Abiad (Mokrani et al. 2012). From 96 AFLP markers, three AFLP markers,
E37M50-400, E35M59-100 and E38M47-800 were linked to the virulence locus VHv1 in isolate PgSy3. Lubna et al. (2012) suggested that the three markers are closely linked to VHv1 and are unique to isolates carrying the virulence locus. Pecchia et al. (1998) developed an efficient PCR protocol for amplification of the IGS region in P. graminea and to characterize this region by restriction fragment analysis. During the study based on the length of the IGS-PCR product, ca. 3.8 or $4.4 \mathrm{~kb}$, two groups of isolates were identified from six cultures i.e. I3/88 (Italy; CBS 100862), I7/88 (Italy; CBS100861), 60/ 93 (Austria; CBS 100866), I10/95 (Tunisia; CBS 100863), I28/95 (Tunisia; CBS 100864), I33/95 (Tunisia; CBS 100865). The RFLP patterns of isolates obtained with the 6base cutting enzymes ApaI, BglII, DraI, EcoRV, HindIII and SacI were similar within each group and different between the two groups (Pecchia et al. 1998). Restriction patterns of IGSPCR products digested with the 4-base cutting enzyme AluI were polymorphic among isolates in spite of their IGS-PCR product length (Pecchia et al. 1998).

Molecular studies of Pyrenophora/Drechslera species have detailed the taxonomic placement of the genus. Initially the 18S rRNA gene was used for the classification of Pyrenophora/Drechslera and related genera (Berbee 1996). Phylogenetic analysis based on $18 \mathrm{~S}$ rRNA showed Pyrenophora to cluster within the Pleosporaceae (Zhang and Berbee 2001) rather than in Pyrenophoraceae (Zhang and Berbee 2001). Later, phylogenetic analysis of the ITS and $g d p$ data showed that Pyrenophora is monophyletic (Zhang and Berbee 2001), and the asexual state Drechslera clustered with their predicted sexual relatives (Table 20, Fig. 22).

\section{Recommended genetic markers}

- Large small subunits of nrDNA (LSU)-generic level

- ITS and $g d p$-inter-specific delineation

Based on our phylogeny, we observed that $g d p$ gives high resolution compared to ITS and LSU, such that it can be readily used to determine the placement of Pyrenophora species.

\section{Puccinia}

Background

Puccinia is the type genus of the family Pucciniaceae in the order of rust fungi, Pucciniales (Basidiomycota). Puccinia has approximately 4,000 named species (Kirk et al. 2008), and is a widespread genus of plant pathogens that has shaped history. For example, Puccinia graminis, the type species of Puccinia, 
Table 20 Pyrenophora. Details of the isolates used in the phylogenetic tree
Ex-type (ex-epitype) strains are bolded and marked with an * and voucher stains are bolded

\begin{tabular}{|c|c|c|c|c|}
\hline \multirow[t]{2}{*}{ Species } & \multirow[t]{2}{*}{ Isolate } & \multicolumn{3}{|c|}{ GenBank accession numbers } \\
\hline & & ITS & LSU & GPDH \\
\hline Drechslera andersenii & CBS 258.80 & AY004804 & & AY004835 \\
\hline D. andersenii & CBS 967.87 & AY004805 & & \\
\hline D. andersenii & DAOM 229292 & JN943646 & JN940084 & \\
\hline D. avenae & CBS 189.29 & AY004795 & & AY004827 \\
\hline D. avenae & CBS 279.31 & AY004796 & & AY004828 \\
\hline D. biseptata & DAOM 208987 & AY004786 & & AY004817 \\
\hline D. biseptata & CBS 308.69 & JN712464 & JN712530 & AY004819 \\
\hline D. biseptata & CBS 599.7 & AY004787 & & AY004818 \\
\hline D. biseptata & CBS 108940 & AY004788 & & \\
\hline D. campanulata & BRIP15927 & AF163058 & & \\
\hline D. catenaria & DAOM 63665A & AY004802 & & AY004833 \\
\hline D. catenaria & CBS 191.29 & AY004803 & & AY004834 \\
\hline D. dactylidis & DAOM 92161 & AY004781 & & AY004812 \\
\hline D. dematioidea & CBS 108963 & AY004789 & JN712532 & AY004820 \\
\hline D. dematioidea & DAOM 229295 & JN943648 & JN940094 & \\
\hline D. dematioidea & CBS 108962 & JN712465 & JN712531 & \\
\hline D.dematioidea & CBS 108962 & AY004790 & JN712531 & AY004821 \\
\hline Drechslera dictyoides & DAOM 63666 & AY004806 & JN940080 & AY004836 \\
\hline D. erythrospila & CBS 108941 & AY004782 & & AY004813 \\
\hline D. erythrospila & DAOM 55122 & AY004783 & & AY004814 \\
\hline D. fugax & CBS 509.77 & AY004791 & & AY004822 \\
\hline D.nobleae & CBS 259.80 & AY004792 & & AY004823 \\
\hline D. nobleae & DAOM 229296 & JN943647 & JN940095 & \\
\hline D. nobleae & CBS 966.87 & AY004793 & & AY004824 \\
\hline D. nobleae & CBS 316.69 & AY004794 & & AY004825 \\
\hline D. phlei & CBS 315.69 & AY004807 & & AY004837 \\
\hline D. phlei & DAOM 225627 & JN943656 & JN940077 & \\
\hline D. poae & DAOM 145373 & AY004801 & JN940082 & AY004832 \\
\hline D. poae & DAOM 169240 & JN943651 & & \\
\hline D. siccans & DAOM 115701 & AY004797 & JN940078 & \\
\hline D. siccans & DAOM 115702 & AY004799 & & \\
\hline Drechslera sp. & DAOM126766 & AY004800 & & AY004831 \\
\hline Drechslera sp. & DAOM126772 & AY004784 & & AY004815 \\
\hline Drechslera sp & CBS313.69 & AY004785 & & AY004816 \\
\hline D. triseptata & NZ6120 & AF163059 & & \\
\hline Pleospora herbarum & CBS 191.86* & DQ491516 & DQ247804 & AY316969 \\
\hline Pyrenophora bromi & DAOM 127414 & AY004809 & JN940074 & AY004839 \\
\hline P. chaetomioides & DAOM 208989 & AF081445 & JN940091 & AF081371 \\
\hline P. dictyoides & DAOM 75616 & JN943654 & JN940079 & \\
\hline P. japonica & DAOM 169286 & AF071347 & & AF081369 \\
\hline P. lolii & CBS 318.69 & AY004798 & & AY004829 \\
\hline P. phaeocomes & DAOM 222769 & JN943649 & DQ499596 & \\
\hline P. semeniperda & DAOM 213153 & AF081446 & JN940089 & AY004826 \\
\hline P. tetrarrhenae & DAOM 171966 & JN943663 & JN940090 & \\
\hline P. tritici-repentis & DAOM 226213 & JN943670 & AY544672 & AF081370 \\
\hline P. tritici-repentis & DAOM 208990 & AF071348 & JN940071 & AY004838 \\
\hline P. tritici-repentis & DAOM 107224 & AY004808 & DQ384097 & \\
\hline P. graminea & 11 & Y10748 & & \\
\hline P. teres & PM2 & Y08746 & & AY004830 \\
\hline
\end{tabular}




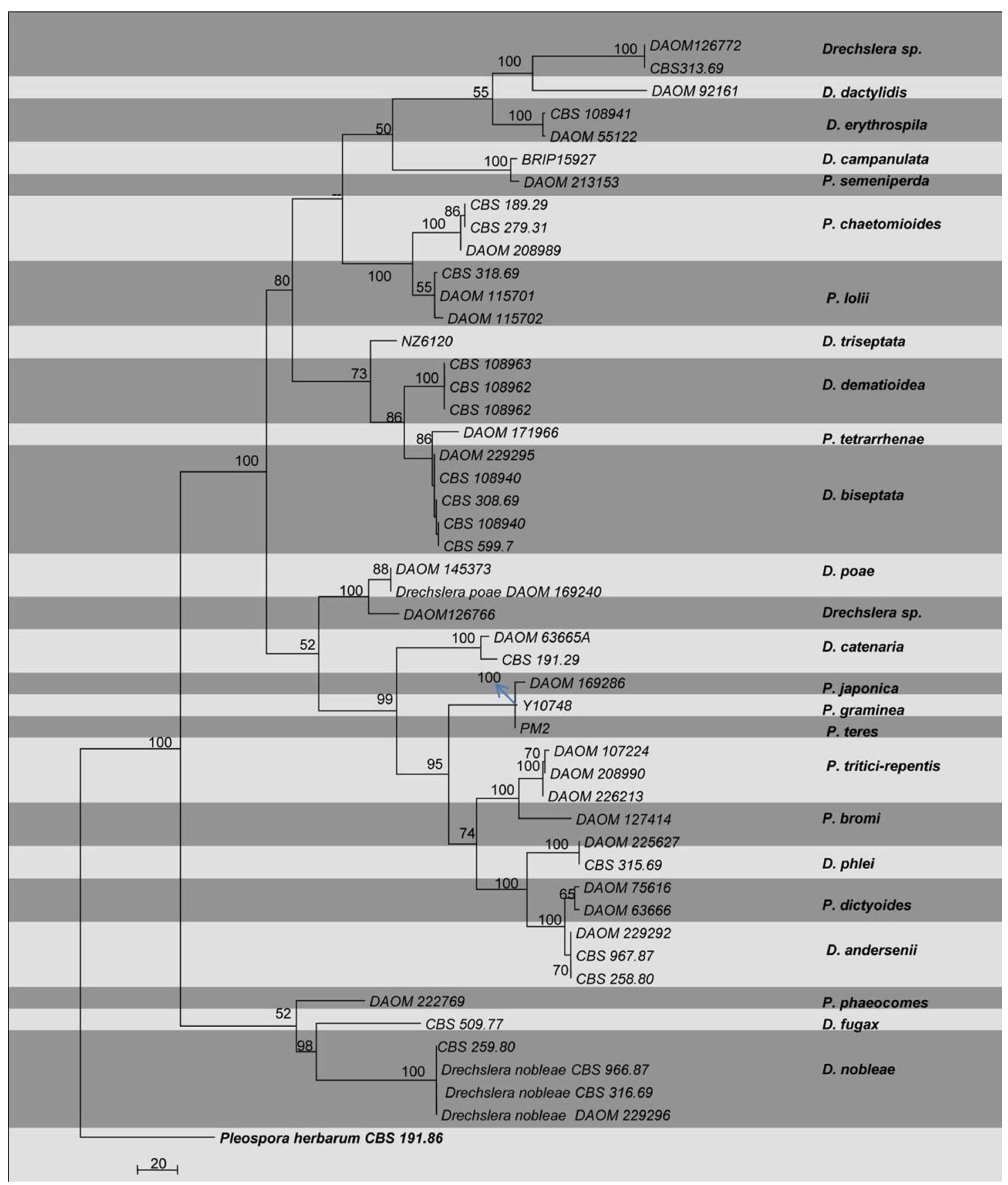

Fig. 22 Phylogram generated from parsimony analysis based on combined of ITS, $g d p$ and LSU sequenced data of Pyrenophora. Parsimony bootstrap support values greater than $50 \%$ are indicated above the nodes.
The ex-type (ex-epitype) and voucher strains are in bold. The tree is rooted with Pleospora herbarum CBS 276.37

P. coronata and P. striiformis (Kirk et al. 2008). Rusts of Asteraceae, e.g., P. helianthi, and rusts of Fabaceae in the closely related genus Uromyces, e.g., U. viciae-fabae, $U$. appendiculatus and U. ciceris-arietini, are important pathogens of cultivated fodder and food crops.

Among the ca. 120 to 160 genera of rust fungi (Cummins and Hiratsuka 2003; Kirk et al. 2008), Puccinia is readily recognized by the two-celled teliospores and the shape of are also serious pathogens of grasses (Poaceae), including 
the spermogonia (Cummins and Hiratsuka 2003). Uromyces with one-celled teliospores is typically differentiated from Puccinia, although some species of Puccinia have both onecelled (mesospores) and two-celled teliospores, e.g., $P$. lagenophorae. Teliospore morphology is homoplasious, and Puccinia and Uromyces were polyphyletic in systematic studies based on the LSU and SSU regions of nuclear ribosomal DNA (Maier et al. 2007; Aime 2006), and the two nuclear genes: elongation factor and $\beta$ - tubulin (Van der Merwe et al. 2007). Some rust fungi have teliospores morphologically similar to Puccinia, but are not closely related or have an uncertain systematic position. For example, Allodus podophylli has two-celled teliospores convergent with Puccinia. A systematic analysis based on the nLSU and nSSU regions of rDNA determined Allodus and Puccinia were unrelated (Minnis et al. 2012). Puccinia psidii, which spread from South America to much of the Pacific region and South Africa, now infects 30 genera of Myrtaceae out of its natural host range (Pegg et al. 2013). It has two-celled teliospores, but its placement within the Pucciniales is unknown. Phylogenetic analyses of the nLSU and nSSU (Pegg et al. 2013) and the protein coding gene beta-tubulin (Van Der Merwe et al. 2008) indicated that P. psidii was sister to the Pucciniaceae. Several families and genera of rust fungi are polyphyletic, namely the Raveneliaceae, Phakopsoraceae and Pucciniaceae. These polyphyletic families and genera await resolution by molecular phylogenetic analyses.

\section{Species identification and numbers}

Rust fungi are usually considered host specific (Cummins and Hiratsuka 2003), although some, e.g., Puccinia psidii and $P$. lagenophorae, infect multiple host genera (McTaggart et al. 2014; Pegg et al. 2013). Some species of rust fungi are heteroecious, requiring two hosts in different families to complete their life cycle, e.g., P. graminis on Triticum (Poaceae) and Berberis (Berberidaceae).

Rust fungi have a complicated life cycle with up to five spore states (Cummins and Hiratsuka 2003). Consequently, up to three names have been proposed for the same taxon based on different life cycle stages. To add to the confusion, there are two systems of terminology that describe these spore states, one based on morphology (Laundon 1967), and the other on ontogeny (Arthur and Kern 1926; Cummins and Hiratsuka 2003; Hiratsuka 1973). These systems of terminology were summarised by Hennen and Hennen (2000).

Species of rust fungi are often identified on the basis of their host specificity, and monographs were organised by plant family (Sydow and Sydow 1904; McAlpine 1906; Cummins 1971, 1978). Morphological characters of the teliospores and urediniospores, such as size, apex shape and wall thickness, ornamentation, and germ pore position and number, are useful for species identification.
Molecular diagnostic tools have been developed for some species of Puccinia based on the ITS region of rDNA, e.g., P. coronata (Beirn et al. 2011; Pfunder et al. 2001), P. kuehnii (Glynn et al. 2010) and P. psidii (Langrell et al. 2008). The ITS region has successfully distinguished phylogenetic species in Uromyces (Barilli et al. 2011) and it was used in combination with TEF to resolve the taxonomy of $P$. melampodii (Seier et al. 2009). However, the ITS region was polymorphic in Puccinia lagenophorae (Littlefield et al. 2005; Scholler et al. 2011), and Morin et al. (2009) discovered a paralagous copy of the ITS region, which may have resulted from a hybridization event. A paralagous copy of the ITS region was also reported in P. kuehnii in the study by Virtudazo et al. (2001). Polymorphisms and paralogous copies are caveats for studies based on the ITS region in rust fungi.

\section{Molecular phylogeny}

Large-scale systematic studies of rust fungi have focused mainly on the SSU and LSU regions of rDNA (Aime 2006; Beenken et al. 2012; Dixon et al. 2010; Maier et al. 2003, 2007; Minnis et al. 2012; Wingfield et al. 2004; Yun et al. 2011) (Table 21). Protein coding genes such as beta-tubulin (Morin et al. 2009; Van der Merwe et al. 2007, 2008) and elongation factor (TEF) (Seier et al. 2009; Van der Merwe et al. 2007) were successfully used at the family, genus and species level in rust fungi, although beta-tubulin required cloning rather than direct sequencing of PCR product. Liu et al. (2013) included ITS, beta-tubulin, ribosomal polymerase subunit 2 (RPB2) and cytochrome c oxidase subunit 1 (COI) in a systematic study to resolve the $P$. coronata species complex. They discussed the difficulty of PCR amplification of older herbarium specimens, and that DNA repair was successful in some cases. Vialle et al. (2009) compared mitochondrial genes to rDNA markers in two genera of rusts, Chrysomyxa and Melampsora. They found rDNA had better species resolution than mitochondrial genes. Mitochondrial genes were since used in studies of the genera Chrysomyxa (Feau et al. 2011) and Dasyspora (Beenken et al. 2012), but have not yet been used for Puccinia.

Recommended genetic markers

- The large subunit of nrDNA (LSU)-is useful for genus and species level identification of all rust fungi

- The internal transcribed spacer (ITS)-is useful for species level identification, but may contain polymorphic sites and paralagous copies. Rust specific primers are recommended.

Rusts are obligate biotrophs and difficult to maintain in pure culture, which has posed a challenge for DNA extraction 
Table 21 Puccinia. Details of the isolates used in the phylogenetic tree

\begin{tabular}{|c|c|c|c|c|}
\hline \multirow[t]{2}{*}{ Species } & \multirow[t]{2}{*}{ Isolate } & \multirow[t]{2}{*}{ Host } & \multicolumn{2}{|c|}{ GenBank accession no. } \\
\hline & & & LSU & SSU \\
\hline Aecidium kalanchoe & BPI 843633 & Kalanchoe blossfeldiana & AY463163 & DQ354524 \\
\hline Allodus podophylli & BPI 842277 & Podophyllum peltatum & DQ354543 & DQ354544 \\
\hline Caeoma torreyae & ECS 553 & Torreya californica & AF522183 & AY123284 \\
\hline Cumminsiella mirabilissima & BPI 871101 & Mahonia aquifolium & DQ354531 & DQ354530 \\
\hline Helicobasidium purpureum & CBS324.47 & Not provided & AY885168 & D85648 \\
\hline Dietelia portoricensis & BPI 844288 & Mikania micrantha & DQ354516 & AY125414 \\
\hline Miyagia pseudosphaeria & BPI 842230 & Sonchus oleraceus & DQ354517 & AY125411 \\
\hline Pileolaria toxicodendri & BPI 871761 & Toxicodendron sp. & DQ323924 & AY123314 \\
\hline Prospodium lippiae & BPI 843901 & Aloysia plystachya & DQ354555 & DQ831024 \\
\hline P. tuberculatum & BRIP 57630 & Lantana camara & KJ396195 & KJ396196 \\
\hline Puccinia caricis & BPI 871515 & Grossularia sp. & DQ354514 & DQ354515 \\
\hline P. convolvuli & BPI 871465 & Calystegia sepium & DQ354512 & DQ354511 \\
\hline P. coronata & & Rhamnus cathartica & DQ354526 & DQ354525 \\
\hline P. dampierae & BRIP 57724 & Dampiera linearis & KF690688 & NA \\
\hline P. gilgiana & BRIP 57719 & Lechenaultia linarioides & KF690691 & NA \\
\hline P. graminis & NA & Not provided & AF522177 ${ }^{9}$ & NA \\
\hline P. haemodori & BRIP 56965 & Anigozanthus sp. & KF690692 & NA \\
\hline P. hemerocallidis & BPI 843967 & Hemerocallis sp. & DQ354519 & DQ354518 \\
\hline P. hordei & BPI 871109 & Poaceae & DQ354527 & DQ415278 \\
\hline P. lagenophorae & BRIP 57563 & Emilia sonchifolia & KF690696 & NA \\
\hline P. menthae & BPI 871110 & Cunila origanoides & DQ354513 & AY123315 \\
\hline P. psidii & BRIP 57991 & Melaleuca leucadendra & KF318443 & KF318455 \\
\hline P. poarum & NA & Tussilago sp. & DQ831028 & DQ831029 \\
\hline P. polysora & BPI 863756 & Zea mays & GU058024 & NA \\
\hline P. saccardoi & BRIP 57725 & Scaevola spinescens & KF690701 & NA \\
\hline P. smilacis & BPI 871784 & Smilax rotundifolia & DQ354533 & DQ354532 \\
\hline P. stylidii & BRIP 60107 & Stylidium armeria & KJ622214 & NA \\
\hline P. ursiniae & BRIP 57993 & Ursinia anthemoides & KF690705 & NA \\
\hline P. violae & BPI 842321 & Viola cucullata & DQ354509 & DQ354508 \\
\hline P. xanthosiae & BRIP 57729 & Xanthosia rotundifolia & KF690706 & NA \\
\hline Pucciniosira solani & NA & Solanum aphyodendron & EU851137 & NA \\
\hline Uromyces appendiculatus & NA & Phaseolus vulgaris & AY745704 & DQ354510 \\
\hline U. ari-triphylli & BPI 871111 & Arisaena triphyllum & DQ354529 & DQ354528 \\
\hline U. scaevolae & BRIP 60113 & Selliera radicans & KJ622213 & NA \\
\hline U. viciae-fabae & NA & Pisum sp. & AY745695 & NA \\
\hline
\end{tabular}

(Aime 2006). This is reflected by the relatively few species of Puccinia represented in GenBank, for example, there are $\sim 110$ species of Puccinia represented by the ITS and LSU regions of rDNA. This is less than $3 \%$ of the estimated 4,000 species of Puccinia (Kirk et al. 2008). Reliance on molecular identification for some species of Puccinia is not recommended. For example, McTaggart et al. (2014) determined that several species of Puccinia on different plant families in Australia had near-identical ITS and LSU rDNA sequences (Fig. 23 Puccinia).

\section{Rhizopus}

\section{Background}

Rhizopus is a genus of cosmopolitan saprotrophic fungi, currently included in the family Rhizopodaceae within the Mucorales (former Zygomycota; Hoffmann et al. 2013). Many Rhizopus species are common postharvest pathogens, causing fruit rots, and spoilage of crops, vegetables and wide range of stored foods (Pitt and Hocking 2009; Ray and Ravi 


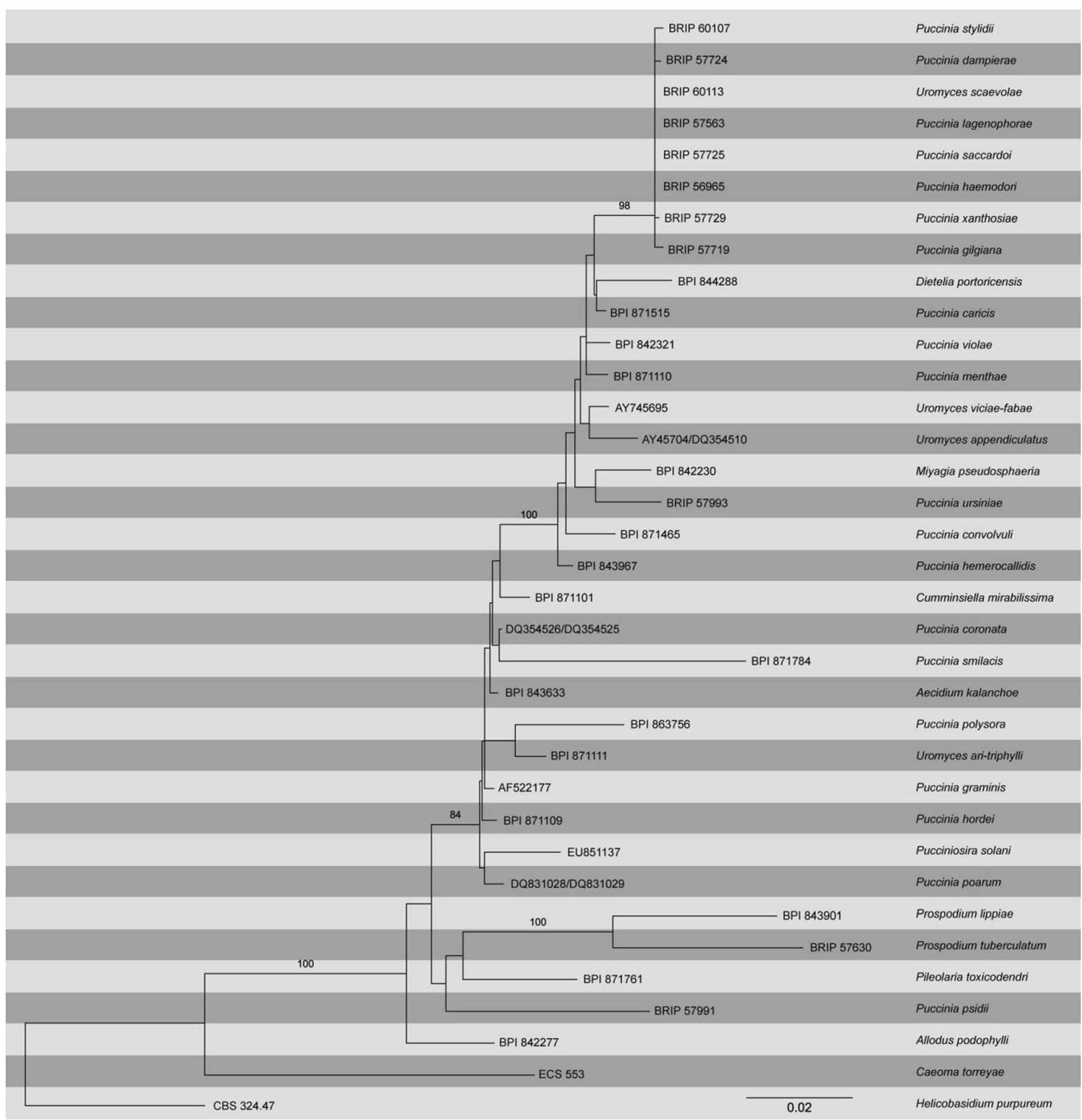

Fig. 23 Puccinia. Phylogram obtained from a ML search in RAxML with the SSU and LSU regions of nrDNA. Bootstrap values $(\geq 70 \%)$ from a ML search with 1,000 replicates above nodes; posterior probabilities $(\geq 0.95)$ from Bayesian inference below nodes. Puccinia and Uromyces

2005; Shtienberg 1997). Some species of this genus (e.g. $R$. arrhizus, $R$. microsporus and $R$. stolonifer) may also cause head rot disease in sunflowers (Yildirim et al. 2010). Among all Rhizopus species, R. arrhizus (syn. R. oryzae), and $R$. stolonifer are of particular importance, taking into account the frequency of isolation records (Farr and Rossman 2014). Extremely fast growth rates and abundant production of early are polyphyletic, and genera such as Cumminsiella, Dieteila, Miyagia and Pucciniosira are paraphyletic. The LSU region is not sufficient to distinguish closely related taxa in Australia as seen in the P. lagenophorae clade

maturing dry sporangiospores by Rhizopus species facilitate rapid spread of infection (Pitt and Hocking 2009). According to USDA Fungus-Host Database (Farr and Rossman 2014), Rhizopus species have been isolated from a wide range of plant taxa, both angiosperms and gymnosperms. Several members of the genus, among them $R$. arrhizus and $R$. microsporus are reported to cause human mucormycoses 
(Pitt and Hocking 2009), mostly in immunocompromised patients (Roden et al. 2005; Pitt and Hocking 2009; Chakrabarti et al. 2010; Skiada et al. 2011). Nevertheless, Rhizopus species are used by humans. Fermentation process of several kinds of Asian food and beverage strongly depends on Rhizopus strains (Henkel 2005; Nout and Aidoo 2010).

Species identification and numbers

Identification of Rhizopus species was traditionally based on the complexity of rhizoids, the length of the sporangiophores and the size of the sporangia along with the ability to grow in certain temperatures. In their revision, Schipper and Stalpers (1984) recognized five species in three major complexes. Later several new species and varieties were described (e.g. Ellis 1985; Schipper and Samson 1994). Following a comprehensive morphological revision, Zheng et al. (2007) recognized ten species and seven varieties. Molecular analyses (Abe et al. 2006, 2010; Hoffmann et al. 2013; Walther et al. 2013) supported the three complexes defined by Schipper and Stalpers (1984), but revealed that Rhizopus is paraphyletic containing Sporodiniella umbellata and Syzygites megalocarpus (Hoffmann et al. 2013; Walther et al. 2013). Based on molecular phylogenetic analyses several species were recognized to represent synonyms: e.g. Amylomyces rouxii is now treated as synonymous with $R$. arrhizus (Abe et al. 2006), $R$. reflexus was recognized as a synonym of $R$. lyococcus (Liou et al. 2007), and $R$. azygosporus was revealed to be conspecific with $R$. microsporus (Abe et al. 2006). Dolatabadi et al. (2014b) showed that the morphologically defined varieties of $R$. microsporus are not recognized in multi-marker phylogenies and consequently they reduced the varieties to synonyms. Abe et al. (2007) revealed that strains of $R$. arrhizus (as $R$. oryzae) split into producers of lactic acid and producers of fumaric and malic acid and that these two groups were molecular phylogenetically distinct. As a consequence, the authors treated fumaric-malic acid producers as a separate species, $R$. delemar, formerly regarded as a variety by Zheng et al. (2007). Gryganskyi et al. (2010) supported this concept by molecular phylogenetic studies based on several markers including mating type genes. In agreement with the previous studies, Dolatabadi et al. (2014a) recognized two phylogenetic species. However, they treated them as varieties of a single biological species because of the formation of zygospores between strains of the arrhizus- and strains of the delemar-group, the lack of differences in morphology and ecology and the small genetic distance between the two groups compared to the remaining species in Rhizopus. Variety tonkinensis, a third variety besides var. arrhizus and var. delemar, was recognized morphologically (Zheng et al. 2007) and through the use of short tandem repeat motives of IGS rDNA sequences (Liu et al. 2008), but it has not come out as a separate lineage in molecular phylogenetic studies (Walther et al. 2013; Dolatabadi et al. 2014a) and is regarded as doubtful. Abe et al. (2010) consider $R$. americanus and $R$. sexualis as varieties of $R$. stolonifer, while other authors (e.g. Zheng et al. 2007) recognize them as separate species. However, the large genetic distances of the ITS region among these taxa (Walther et al. 2013) rather suggest separate species. In the ITS trees of Walther et al. (2013), the strains morphologically defined as $R$. stolonifer form two distinctly separated groups suggesting the existence of an undescribed species. Currently seven species are accepted in Rhizopus: $R$. americanus, $R$. arrhizus including var. arrhizus and var. delemar, R. homothallicus, R. lyococcus, $R$. microsporus, $R$. sexualis, and R. stolonifer (Table 22).

\section{Molecular phylogeny}

The marker of choice for species identification in the genus Rhizopus is the ITS region (Walther et al. 2013) that can also distinguish the two varieties of $R$. arrhizus: var. arrhizus and var. delemar (Fig. 24). For the three species $R$. americanus, $R$. sexualis and $R$. stolonifer, sequencing of the ITS is often hampered by extended polyA- and poly-T-regions but the large subunit of the ribosomal DNA (LSU) can be sequenced for species identification in these cases because it can also resolve these species (Walther et al. 2013). In case of R. americanus, multiple different ITS sequences within one strain were found, which should be considered in molecular identification (Liu et al. 2007; Abe et al. 2010).

Several molecular markers have been applied for phylogenetic inference in this genus by using general fungal primers: actin (Abe et al. 2007, 2010; Dolatabadi et al. 2014a, b), ITS (Abe et al. 2006, 2007, 2010; Gryganskyi et al. 2010; Walther et al. 2013; Dolatabadi et al. 2014a, b), LSU (Abe et al. 2006; Liou et al. 2007; Walther et al. 2013; Dolatabadi et al. 2014a, b,), orotidine-5'-monophosphate decarboxylase gene (pyrG gene) (Liu et al. 2007), rpb1 (RNA polymerase II largest subunit gene) (Dolatabadi et al. 2014a), SSU (small subunit of the ribosomal DNA gene) (Abe et al. 2006), and tef (translation elongation factor gene) (Abe et al. 2007, 2010; Dolatabadi et al. 2014a, b). For $R$. arrhizus s.l., specific primers were designed for the rpb2 (RNA polymerase II second largest subunit gene) and the RNA helicase and the TP transporter gene of the mating locus by Gryganskyi et al. (2010) as well as for the lactate dehydrogenase B by Abe et al. (2007).

The tef marker cannot be recommended for phylogenetic studies because the gene is found in several different copies at least in R. arrhizus; these copies typically differ in the third base of numerous codons of this marker (Dolatabadi et al. 2014a). In the multi-marker study of Dolatabadi et al. (2014a), the rpb1 was the most variable gene. 
Table 22 Rhizopus. Details of the isolates used in the phylogenetic tree

\begin{tabular}{|c|c|c|c|}
\hline Species & Isolate & Host/source & $\begin{array}{l}\text { GenBank } \\
\text { accession } \\
\text { no. }\end{array}$ \\
\hline Rhizopus arrhizus & CBS111231 & - & JN206338 \\
\hline R. arrhizus & CBS544.80 & Sorghum malt & JN206337 \\
\hline R. arrhizus & CBS120.12 & - & AB181318 \\
\hline R. arrhizus & IFO5438 & - & DQ641276 \\
\hline R. arrhizus & CBS112.07 & - & JN206323 \\
\hline R. arrhizus & CBS146.90 & Homo sapiens & JN206324 \\
\hline R. arrhizus & NRRL1469* & - & DQ641279 \\
\hline R. microsporus & CBS357.93 & Tempeh & JN206343 \\
\hline R. microsporus & CBS631.82 & Bread & JN206344 \\
\hline R. microsporus & CBS536.80 & Sorghum malt & HM999971 \\
\hline R. microsporus & AS3.1145 & - & DQ641305 \\
\hline R. microsporus & CBS337.62 & - & JN206362 \\
\hline R. microsporus & CBS699.68* & Soil & HM999970 \\
\hline R. homothallicus & CBS336.62* & Soil & HM999968 \\
\hline R. homothallicus & CBS111232 & - & JN206365 \\
\hline R. caespitosus & CBS427.87* & - & HM999965 \\
\hline R. caespitosus & 33515 & - & AF115730 \\
\hline R. schipperae & CBS138.95* & Homo sapiens & HМ999969 \\
\hline \multirow[t]{2}{*}{$\begin{array}{l}\text { Syzygites } \\
\quad \text { megalocarpus }\end{array}$} & CBS108947 & $\begin{array}{l}\text { Amanita } \\
\quad \text { rubescens }\end{array}$ & JN206370 \\
\hline & & & JN206371 \\
\hline $\begin{array}{c}\text { Sporodiniella } \\
\text { umbellate }\end{array}$ & CBS195.77 & Umbonia & JN206372 \\
\hline R. stolonifer & CBS389.95* & - & DQ641318 \\
\hline $\begin{array}{l}\text { Rhizopus sp. } \\
\text { 'stolonifer' }\end{array}$ & CBS442.74 & Coffee-ground & JN206367 \\
\hline R. stolonifer & $\begin{array}{r}\text { AFTOL- } \\
\text { ID632 }\end{array}$ & - & AY997085 \\
\hline R. sexualis & CBS336.39* & Fragaria & AB113017 \\
\hline R. americanus & CBS340.62* & Air & HM999967 \\
\hline R. lyococcus & CBS319.35 & - & AB100449 \\
\hline R. lyococcus & CBS117.43 & $\begin{array}{l}\text { Hordeum } \\
\text { vulgare }\end{array}$ & JN206375 \\
\hline R. lyococcus & JCM5589* & - & DQ641319 \\
\hline Backusella sp. & CBS538.80 & Medicago sativa & HM999964 \\
\hline
\end{tabular}

Ex-type (ex-epitype) strains are bolded and marked with an * and voucher stains are bolded

\section{Recommended genetic markers}

- The internal transcribed spacer (ITS)-generic and species level

- The RNA polymerase II largest subunit gene (RPB1)generic and species level

- The large and small subunits of nrDNA (LSU and SSU)placement within the Mucorales order, higher-level phylogeny

- The partial actin gene (ACT)-higher-level phylogeny

\section{Stagonosporopsis}

Background

Stagonosporopsis is a coelomycetous genus in Didymellaceae (de Gruyter et al. 2009), accommodating several important phytopathogenic species, some of which have well-described sexual forms in Didymella (Diedicke 1912; Aveskamp et al. 2010). Many Stagonosporopsis species are considered serious quarantine organisms in many parts of the world. Some species have a global distribution. Stagonosporopsis andigena, the cause of black blight of potato (Turkensteen 1978), and S. crystalliniformis, a destructive pathogen of tomato and potato (Loerakker et al. 1986; Noordeloos et al. 1993), have only been reported in the Andes region, and thus listed as A1 quarantine organisms (EPPO 2014). Stagonosporopsis chrysanthemi and $S$. inoxydabilis are the cause of ray (flower) blight of Asteraceae (Stevens 1907; Van der Aa et al. 1990; Vaghefi et al. 2012), and A2 quarantine organisms (EPPO 2014) (listed as Didymella ligulicola). In Australia, $S$. tanaceti is known as the causal agent of ray blight of pyrethrum, capable of causing complete yield loss (Pethybridge et al. 2008). Stagonosporopsis cucurbitacearum (sexual state Didymella bryoniae) is a destructive seed-borne pathogen of Cucurbitaceae worldwide, causing gummy stem blight and black fruit rot (Punithalingam and Holliday 1972; Lee et al. 1984; Zitter and Kyle 1992). Stagonosporopsis species have also been reported from other plant families including Amaranthaceae, Campanulaceae, Caryophyllaceae, Fabaceae, Lamiaceae, Ranunculaceae, and Valerianaceae. The only species not isolated from a plant substrate is $S$. oculohominis, which was reported from human corneal ulcer in the USA (Punithalingam 1976).

Species identification and numbers

Stagonosporopsis was originally separated from Ascochyta on the basis of occasional formation of multi-septate (Stagonospora-like) conidia (Diedicke 1912). No type material was specified by Diedicke (1912) such that the first species combination described, S. actaeae, was interpreted as the generic type by some authors (Boerema et al. 1997, 2004). However, S. boltshauseri, currently known as S. hortensis (Boerema and Verhoeven 1979), was designated as the lectotype by Clements and Shear (1931).

In vitro, $S$. hortensis predominantly produces non-septate Phoma-like conidia, resembling those of Boeremia exigua var. exigua, while a few larger septate conidia can occasionally be found. In vivo, however, S. hortensis can be distinguished from B. exigua by predominance of one-septate (Ascochytalike) conidia and occasional occurrence of two- or multiseptate (Stagonospora-like) spores. It is thus not a typical Ascochyta or Stagonospora, both of which produce septate 
Fig. 24 Phylogram generated from Maximum likelihood analysis based on ITS sequenced data of Rhizopus. Bootstrap support values greater than $50 \%$ are indicated above the nodes. The ex-type (ex-epitype) and voucher strains are in bold

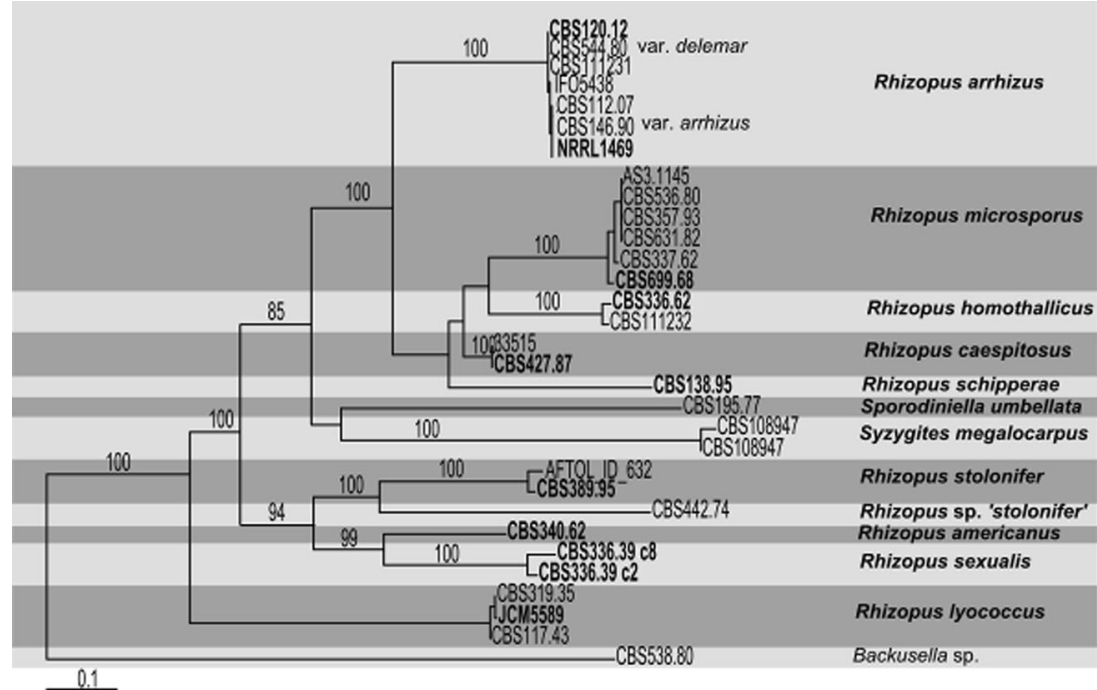

conidia both in vivo and in vitro, and was classified under the genus Stagonosporopsis (Boerema and Verhoeven 1979).

Boerema et al. (1997, 1999) described multiple Stagonosporopsis spp. to be synanamorphs for several Phoma species in section Heterospora. The characteristic of section Heterospora is the in vivo production of distinctly large conidia (ascochytoid /stagonosporoid) in addition to relatively small (phomoid) conidia. The large conidial phenotypes may be dominant in vivo, hence described as Stagonosporopsis synanamorphs (Boerema et al. 1997, 1999, 2004).

Recent phylogenetic delineation of Phoma and allied genera placed the presumed Stagonosporopsis types in the family Didymellaceae (de Gruyter et al. 2009), and an emended description of the genus was proposed (Aveskamp et al. 2010). Some of the heterosporous Phoma species with known Stagonosporopsis synanamorphs were retrieved outside the Stagonosporopsis clade. On the other hand, many species from sections Heterospora, Phoma and Phyllostictoides, for which no records of a Stagonosporopsis synanamorph had been made, clustered with Stagonosporopsis spp. This indicated that the connection of Stagonosporopsis with heterosporous Phoma species was not justified. It also suggested that presence of Stagonospora-like spores is not a reliable criterion for identification of Stagonosporopsis species. Stagonosporopsis dorenboschiae, S. loticola, and $S$. ajacis lack the Stagonospora-like spores and any further features than a plain, globose pycnidium, and aseptate, hyaline conidia (Aveskamp et al. 2010). Due to unreliability of morphological characters, phylogenetic species recognition is essential for identification of Stagonosporopsis species.

Stagonosporopsis in its original description by Diedicke (1912) accommodated seven species, and currently more than 40 species are linked to this genus (data from MycoBank and Index Fungorum). However, only 21
Stagonosporopsis species have thus far been recognised based on multi-gene phylogenies (Table 23) (Aveskamp et al. 2010; Vaghefi et al. 2012). The phylogenetic reassessment of Didymellaceae (Aveskamp et al. 2010) included only those Stagonosporopsis species that had been designated as Phoma synanmorphs by Boerema et al. (1997, 1999). Molecular data for multiple other Stagonosporopsis species are still lacking and, therefore, the taxonomy of the genus Stagonosporopsis remains to be comprehensively reviewed.

\section{Molecular phylogeny}

Few phylogenetic analyses of Stagonosporopsis species are available (Pethybridge et al. 2004; Aveskamp et al. 2010; de Gruyter et al. 2012; Vaghefi et al. 2012, 2014), with the most comprehensive analysis being the three-marker phylogeny performed by Aveskamp et al. (2010). The phylogeny of combined sequences of large subunit nrDNA (LSU), the internal transcribed spacers and the 5.8 S nrRNA (ITS), and $\beta$-tubulin regions resulted in the recognition of 19 species (Aveskamp et al. 2010). Phylogenies based on the partial actin (ACT) sequence were later found to be congruent with the LSU- ITS- $\beta$ - tubulin phylogeny (de Gruyter et al. 2012; Vaghefi et al. 2012). A four-marker phylogeny of the Stagonosporopsis spp. for which these DNA sequence data are available is shown (Fig. 25).

\section{Recommended genetic markers}

- The internal transcribed spacer(ITS)-family/generic level

- $\beta$ - tubulin and ACT-inter-specific delineation

A high level of infra-specific variation has been recorded for calmodulin (CAL) in Phoma-like species, however, it may be difficult to amplify in some Stagonosposopsis species, and 


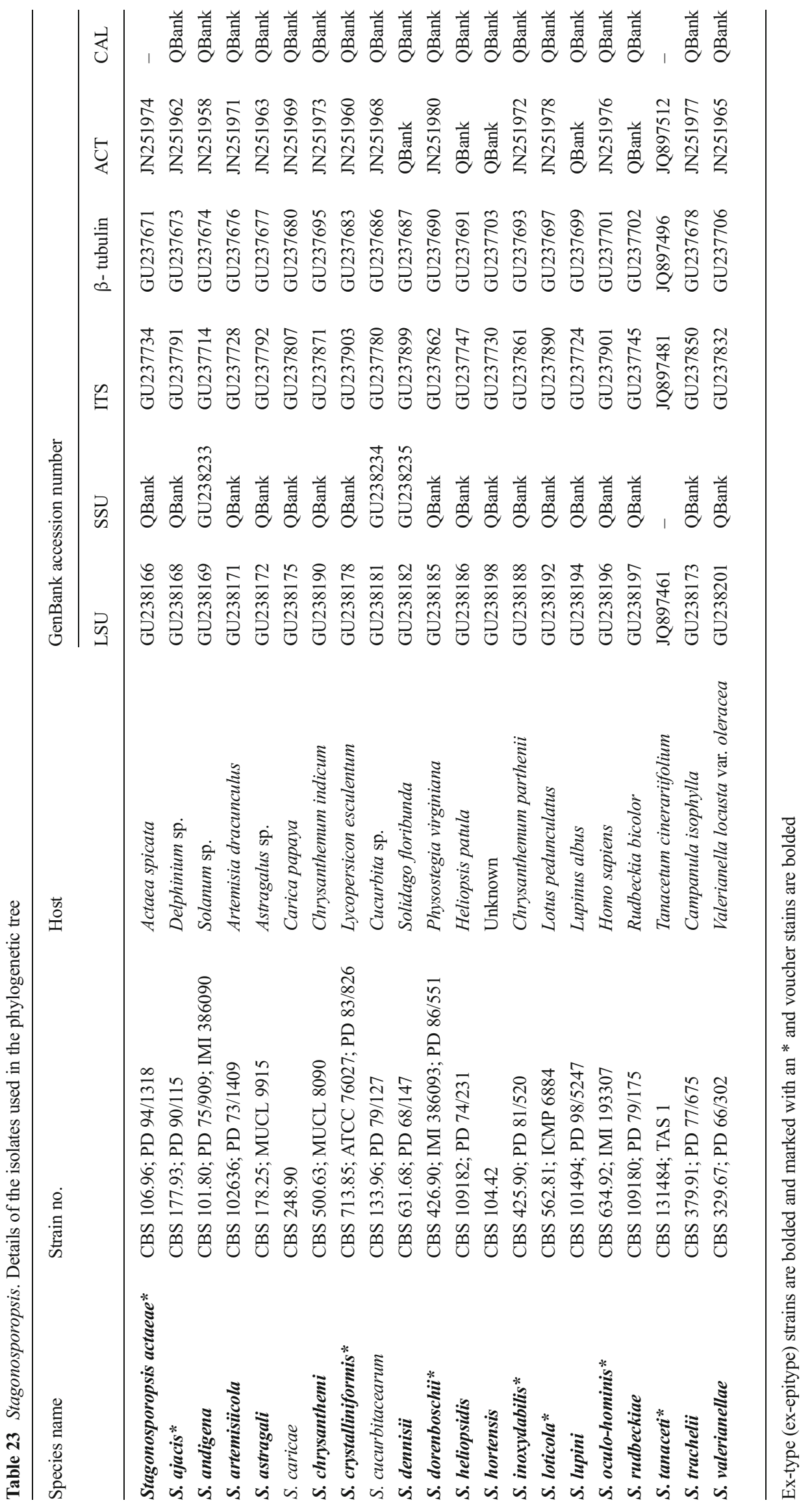




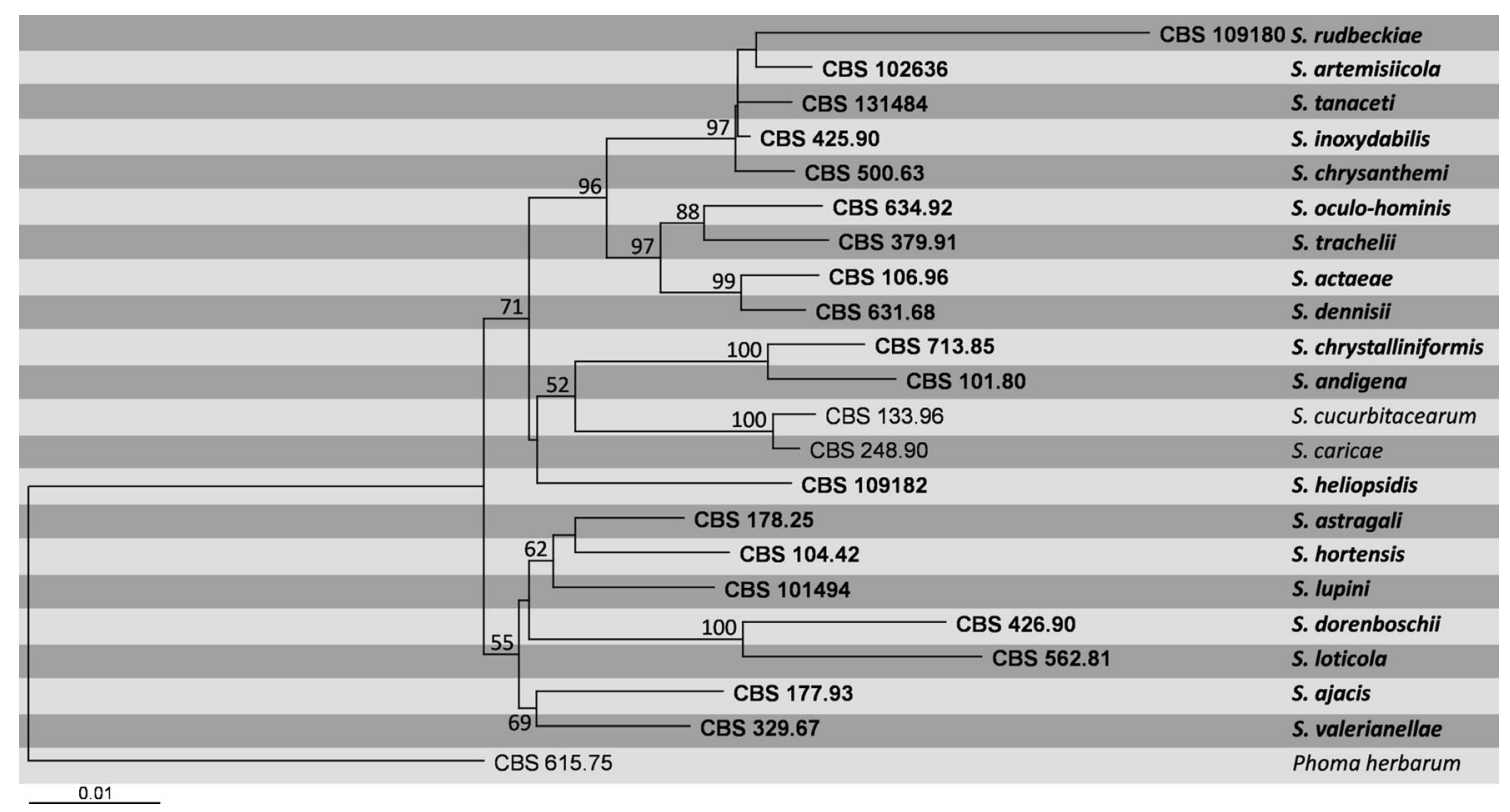

Fig. 25 Phylogram generated from Maximum likelihood analysis based on combined LSU, ITS, $\beta$ - tubulin and ACT sequenced data of Stagonosporopsis. Bootstrap support values greater than $50 \%$ are

requires optimization using different degenerate primers (Aveskamp et al. 2009, 2010; Vaghefi et al. 2012). Thus use of $\beta$ - tubulin and ACT is suggested as they will give sufficient distinction between species, and are easier to amplify.

\section{Ustilago}

\section{Background}

Ustilago is the largest genus of the Ustilaginaceae in the order of smut fungi, Ustilaginales, with about 200 currently accepted species (Vánky 2013). Ustilago and related genera contain many important plant pathogens that destroy the inflorescence or culms of grasses (Poaceae) (Vánky 2011). Some agriculturally important pathogens of grain and edible crops are $U$. tritici on wheat (Triticum), U. hordei on barley (Hordeum) and U. maydis on corn (Zea mays). Species of Ustilago have been used as model organisms for the study of plant disease pathways and mating types (Andrews et al. 2000; Bakkeren et al. 2008; Kellner et al. 2011), as well as for studies in the coevolution of pathogens with their hosts (Begerow et al. 2004). The genomes of $U$. maydis and $U$. hordei were released in 2003 and 2012, respectively (Kamper et al. 2006; Laurie et al. 2012).

Ustilago was until recently a catch-all genus for smut fungi on a diversity of host families, including the Carophyllaceae, Cyperaceae, Poaceae, Polygonaceae, Restionaceae, and Tilliaceae (McTaggart et al. 2012b). Closely related genera were not easily distinguished from Ustilago by morphology, and formed a complex (Stoll et al. 2003, 2005). Subsequent indicated above the nodes. The ex-type (ex-epitype) and voucher strains are in bold. The tree is rooted with Phoma herbarum CBS 615.75

systematic studies reserved Ustilago $s$. lat. for species that infected Poaceae, with Ustilago s. str. restricted to the tribe Pooideae (McTaggart et al. 2012a; Stoll et al. 2005). Soral morphology and host range were later found to be synapomorphic character states for the smut genera Anthracocystis, Langdonia, Sporisorium, Stollia and Triodiomyces, which were differentiated from Ustilago (McTaggart et al. 2012c). Melanopsichium is closely related to Ustilago, and appears to have jumped hosts from Poaceae to Polygonaceae (Begerow et al. 2004; Stoll et al. 2005).

Species identification and numbers

The diversity of smuts in the Ustilaginaceae on Poaceae encompasses over 530 species (Vánky 2011). Cryptic species are certain to be revealed when species complexes, e.g., Macalpinomyces eriachnes, are investigated. Vánky (2011) recognised approximately 170 species of Ustilago, which were delimited by host and spore morphology. It is likely the species number of Ustilago will decrease when generic concepts are resolved in the Ustilaginaceae. Species currently recognized as Ustilago will be transferred to new or other genera delimited by sorus morphology and host range. For example, U. maydis does not fit the concept of Ustilago s. str. and warrants transfer to the earliest valid genus, Mycosarcoma, when these closely related genera are resolved (McTaggart et al. 2012a; Stoll et al. 2005; Vánky and Lutz 2011; Piepenbring et al. 2002) (Table 24). 
Table 24 Ustilago. Details of the isolates used in the phylogenetic tree

\begin{tabular}{|c|c|c|c|c|}
\hline \multirow[t]{2}{*}{ Species } & \multirow[t]{2}{*}{ Isolate } & \multirow[t]{2}{*}{ Host } & \multicolumn{2}{|c|}{ Marker/GenBank accession no. } \\
\hline & & & ITS & LSU \\
\hline Anomalomyces panici & BRIP 46421 & Panicum trachyrachis & DQ459348 & DQ459347 \\
\hline Anthracocystis destruens & Ust. Exs. 472 & Panicum miliaceum & AY344976 & AY747077 \\
\hline Langdonia aristidae & BRIP 52755 & Aristida hygrometrica & HQ013096 & NA \\
\hline Macalpinomyces eriachnes & $56573(\mathrm{M})$ & Eriachne aristidea & AY740037 & AY740090 \\
\hline M. mackinlayi & BRIP 52549 & Eulalia mackinlayi & GU014817 & HQ013131 \\
\hline M. neglectus & RB 2056 (TUB) & Setaria pumila & AY740056 & AY740109 \\
\hline M. simplex & $56577(\mathrm{M})$ & Loudetia simplex & AY740152 & NA \\
\hline \multirow[t]{2}{*}{ M. spermophorus } & HUV 13634 & Eragrostis ferruginea & AY740171 & NA \\
\hline & BRIP 51858 & Sporobolus australasicus & NA & HQ013130 \\
\hline M. viridans & BRIP 49133 & Sporobolus actinocladus & HQ013089 & HQ013125 \\
\hline Melanopsichium pennsylvanicum & HUV 17548 & Polygonum glabrum & AY740040 & AY740093 \\
\hline Moesziomyces bullatus & Ust. Exs. 833 & Paspalum distichum & AY740153 & AY740153 \\
\hline Sporisorium aegyptiacum & Ust. Exs. 756 & Schismus arabicus & AY344970 & AY740129 \\
\hline S. sorghi & MP 2036a (USJ) & Sorgum bicolor & AY740021 & AF009872 \\
\hline S. spinulosum & HMAS 193085 & Capillipedium parviflorum & GU139172 & GU139171 \\
\hline Stollia ewartii & BRIP 51818 & Sarga timorense & HQ013087 & HQ013127 \\
\hline \multirow[t]{2}{*}{ Triodiomyces altilis } & Ust. Exs. 418 & Triodia pungens & AY740166 & NA \\
\hline & BRIP 52543 & Triodia sp. & NA & HQ013136 \\
\hline T. triodiae & HUV 17662 & Triodia microstachya & AY740074 & AY740126 \\
\hline Tubisorus pachycarpus & HUV 21891 & Mnesithea rottboellioides & JN871718 & JN871717 \\
\hline Ustilago affinis & MP 692 & Stenotaphrum secundatum & AY344995 & AF133581 \\
\hline U. austro-africana & $56516(\mathrm{M})$ & Enneapogon cenchroides & AY740061 & AY740115 \\
\hline U. avenae & DB 559 (TUB) & Avena barbata & AY344997 & AF453933 \\
\hline U. bouriqueti & $56517(\mathrm{M})$ & Stenotaphrum dimidiatum & AY740167 & NA \\
\hline U. bromivora & HUV 19322 & Bromus catharticus & AY740064 & AY740118 \\
\hline U. bullata & MP 2363 (TUB) & Bromus diandrus & AY344998 & AF453935 \\
\hline U. calamagrostidis & $56518(\mathrm{M})$ & Calamagrostis epigeios & AY740065 & AY740119 \\
\hline U. crameri & Ust. Exs. 995 & Setaria italica & AY344999 & AY740143 \\
\hline U. curta & Ust. Exs. 1090 & Tripogon loliiformis & AY740165 & HQ013123 \\
\hline U. cynodontis & MP 1838 & Cynodon dactylon & AY345000 & AF009881 \\
\hline U. davisii & HUV 19252 & Glyceria multiflora & AY740169 & NA \\
\hline U. drakensbergiana & $56523(\mathrm{M})$ & Digitaria tricholaenoides & AY740170 & \\
\hline U. echinata & Ust. Exs. 540 & Phalaris arundinacea & AY345001 & AY740144 \\
\hline U. esculenta & Ust. Exs. 590 & Zizania latifolia & AY345002 & AF453937 \\
\hline U. filiformis & RB 3011 (TUB) & Glyceria fluitans & AY740066 & AY740120 \\
\hline U. hordei & Ust. Exs. 784 & Hordeum vulgare & AY345003 & AF453943 \\
\hline U. ixophori & MP 2194 & Ixophorus unisetus & AY740067 & AY740121 \\
\hline \multirow[t]{2}{*}{ U. maydis } & RB 3093 & Zea mays & AY345004 & NA \\
\hline & NA & Zea mays & NA & AF453938 \\
\hline U. nuda & HUV 17782 & Hordeum leporinum & AY740069 & AJ236139 \\
\hline U. pamirica & Ust. Exs. 789 & Bromus gracillimus & AY345005 & AY740145 \\
\hline U. schmidtiae & BRIP 51848 & Enneapogon sp. & HQ013121 & HQ013129 \\
\hline U. schroeteriana & Ust. Exs. 887 & Paspalum paniculatum & AY345006 & AY740146 \\
\hline U. sparsa & Ust. Exs. 892 & Dactyloctenium radulans & AY345008 & NA \\
\hline U. sporoboli-indici & BRIP 39706 & Sporobolous pyramidalis & AY772736 & NA \\
\hline U. striiformis & HUV 18286 & Alopecurus pratensis & AY740172 & DQ875375 \\
\hline U. syntherismae & Ust. Exs. 998 & Digitaria ternata & AY740071 & AY740123 \\
\hline
\end{tabular}


Table 24 (continued)

\begin{tabular}{|c|c|c|c|c|}
\hline \multirow[t]{2}{*}{ Species } & \multirow[t]{2}{*}{ Isolate } & \multirow[t]{2}{*}{ Host } & \multicolumn{2}{|c|}{ Marker/GenBank accession no. } \\
\hline & & & ITS & LSU \\
\hline U. tragana & $56562(\mathrm{M})$ & Tragus berteronianus & AY740072 $2^{3}$ & AY740124 \\
\hline U. tritici & NA & Triticum aestivum & $\mathrm{AF} 135424^{11}$ & NA \\
\hline U. trichophora & $56564(\mathrm{M})$ & Echinochloa colona & AY345009 3 & AY740148 \\
\hline U. turcomanica & HUV 23 & Eremopyrum distans & $\mathrm{AY} 345011^{3}$ & AF453936 \\
\hline U. vetiveriae & HUV 17954 & Vetiveria zizanioides & AY345011 3 & $\mathrm{AF} 453937^{3}$ \\
\hline U. xerochloae & Ust. Exs. 1000 & Xerochloa imberbis & $\mathrm{AY} 345012^{3}$ & $\mathrm{AF} 453938^{3}$ \\
\hline
\end{tabular}

Ex-type (ex-epitype) strains are bolded and marked with an * and voucher stains are bolded

Molecular phylogeny

Relationships between Ustilago and closely related genera are still unresolved, and Ustilago is polyphyletic (Fig. 26 Ustilago). Systematic studies based on the nLSU or ITS regions of rDNA have assigned taxa within these closely related genera (Shivas et al. 2013a; Vánky and Lutz 2011; McTaggart et al. 2012c). Nuclear genes (EF1 $\alpha$, GPDH, RPB1 and RPB2), another ribosomal gene (SSU) and mating loci were explored as markers for the evolution of smut fungi in the Ustilaginaceae (Kellner et al. 2011; McTaggart et al. 2012a; Munkacsi et al. 2007). At this stage, these markers are not as widely used as ITS and LSU, which are recommended for species identification and generic placement, respectively.

Recommended genetic markers

- The large subunit (LSU) of nrDNA-generic level

- The internal transcribed spacer (ITS) of nrDNA-species level

\section{Verticillium}

\section{Background}

Verticillium belongs in the family Plectosphaerellaceae of the Ascomycota. Verticillium species are soilborne, vascular, fungal plant pathogens that cause Verticillium wilt disease in many important agricultural crops throughout the world (Pegg and Brady 2002). Based on susceptibility, 410 plant species that include nearly 80 plant genera have been recorded as being infected by Verticillium species (Pegg and Brady 2002). Correct species identification is important for determining the ecological roles of Verticillium species and for diagnosing disease. Sexual stages have not been identified for Verticillium species although mating type idiomorphs MAT1-1 and MAT12 have been identified in separate isolates of $V$. dahliae, V. albo- atrum, $V$. longisporum, $V$. alfalfa and $V$. nonalfalfae, indicating that these species are potentially heterothallic (Inderbitzin et al. 2011a, b; Usami et al. 2009).

Species identification and numbers

The genus Verticillium sensu stricto refers to a monophyletic group of plant pathogens comprising $V$. dahliae as the type of Verticillium (Gams et al. 2005). The genus can be identified based on its distinct 'verticillate conidiophores' with flaskshaped conidiophores arranged in whorls attached along a main axis that comprise the spore forming cells (Pegg and Brady 2002). The genus Verticillium has a long taxonomic history and approximately 190 species were originally classified by Zare et al. (2004). Recently Inderbitzin et al. (2011a) used fourmarker phylogenetic analysis to identify ten Verticillium species.

Earlier studies identified Verticillium species primarily on the basis of morphology and sub-specific groups by virulence and aggressiveness on various hosts (Rowe 1995). Variation in conidial morphology of Verticillium species is minor and thus cannot be used to separate species (Rowe 1995). Resting structure morphology has been the major morphological character used to differentiate species of Verticillium.

Verticillium albo-atrum and V. dahliae are the most important plant pathogenic species. Verticillium albo-atrum was first described in Germany, 1879, by Reinke and Berthold as the causal agent of potato wilt. The resting structures identified from the diseased plant tissue were brown-pigmented hyphae which were described as 'Dauermycelien'. Later this pigmented hyphae was termed dark 'resting mycelium' which had only transverse walls and no lateral budding (Isaac 1949). No microsclerotia were produced by V. albo-atrum .

Verticillium dahliae was first isolated by Klebahn in 1913 from wilting Dahlia. The isolate produces smaller and oval to elongate microsclerotia as a resting structure from budding hyphae, but not dark resting mycelium (Smith 1965). Verticillium tricorpus forms large and irregular microsclerotia with melanised hyphae and chlamydospores (hence the prefix “tri"). Moreover, V. tricorpus often produces yellow colonies 


\begin{tabular}{|c|c|c|}
\hline & ${ }^{80}$ MP 2363 (TUB) & Ustilago bullata \\
\hline & L Ust. Exs. 789 & Ustilago pamirica \\
\hline & - HUV 19322 & Ustilago bromivora \\
\hline & L AF135424 & Ustilago tritici \\
\hline & L HUV 23 & Ustilago turcomanica \\
\hline & Г DB 599 (TUB) & Ustilago avenae \\
\hline & $83-$ HUV 17782 & Ustilago nuda \\
\hline & L Ust. Exs. 784 & Ustilago hordei \\
\hline & MP 1838 & Ustilago cynodontis \\
\hline & $92 \quad \square=\square$ Ust. Exs. 892 & Ustilago sparsa \\
\hline & L_ Ust. Exs. 1000 & Ustilago xerochloae \\
\hline & $96 \quad 56518(\mathrm{M})$ & Ustilago calamagrostidis \\
\hline & ᄂ HUV 18286 & Ustilago striiformis \\
\hline & $56577(\mathrm{M})$ & Macalpinomyces simplex \\
\hline & - BRIP 39706 & Ustilago sporoboli-indici \\
\hline & RB 3011 (TUB) & Ustilago filiformis \\
\hline & L HUV 19252 & Ustilago davisii \\
\hline & - Ust. Exs. 887 & Ustilago schroeteriana \\
\hline & $-56564(\mathrm{M})$ & Ustilago trichophora \\
\hline & Ust. Exs. 756 & Sporisorium aegypticum \\
\hline & $56562(\mathrm{M})$ & Ustilago tragana \\
\hline & - HUV 17548 & Melanopsichium pennsylvanicum \\
\hline & — Ust. Exs. 540 & Ustilago echinata \\
\hline & 一 Ust. Exs. 590 & Ustilago esculenta \\
\hline & - BRIP 52549 & Macalpinomyces mackinlayi \\
\hline & $56517(\mathrm{M})$ & Ustilago bouriquetii \\
\hline & RB 3093 & Ustilago maydis \\
\hline & - HUV 21891 & Tubisorus pachycarpus \\
\hline & - HUV 17954 & Ustilago vetiveriae \\
\hline & MP 2036a (USJ) & Sporisorium sorghi \\
\hline & HMAS 193085 & Sporisorium spinulosum \\
\hline & BRIP 46421 & Anomalomyces panici \\
\hline & 一 Ust. Exs. 472 & Anthracocystis destruens \\
\hline & 一 BRIP 51818 & Stollia ewartii \\
\hline & Ust. Exs. 418 & Triodiomyces altilis \\
\hline 95 & HUV 17662 & Triodiomyces triodiae \\
\hline & - BRIP 51848 & Ustilago schmidtiae \\
\hline & $95-$ Ust. Exs. 995 & Ustilago crameri \\
\hline & RB 2056 (TUB) & Macalpinomyces neglectus \\
\hline & MP 692 & Ustilago affinis \\
\hline & Ust. Exs. 998 & Ustilago syntherismae \\
\hline & $56523(\mathrm{M})$ & Ustilago drakensbergiana \\
\hline$\Gamma$ & $99 \quad$ HUV 13634/BRIP 51858 & Macalpinomyces spermophorus \\
\hline & $56516(\mathrm{M})$ & Ustilago austro-africana \\
\hline L & BRIP 49133 & Macalpinomyces viridans \\
\hline & - MP 2194 & Ustilago ixophori \\
\hline & Ust. Exs. 1090 & Ustilago curta \\
\hline & — BRIP 52755 & Langdonia aristidae \\
\hline & $-56573(M)$ & Macalpinomyces eriachnes \\
\hline & 0.0 & Moesziomyces bullatus \\
\hline
\end{tabular}

Fig. 26 Phylogram generated from ML search in RA $\times$ ML based on combined ITS and LSU sequenced data of Ustilago. Bootstrap support values greater than $70 \%$ are indicated above the nodes. The ex-type (ex-epitype) and voucher strains are in bold

on PDA upon first isolation (Goud et al. 2003). Verticillium nubilum produces only rounded to elongate chlamydospores, individually or in chains (Inderbitzin et al. 2011a). Verticillium longisporum refers to the species proposed by Karapapa et al.
(1997) that infected hosts in the family Brassicaceae. Isolates of this species produce microsclerotia which are rounded to elongate with relatively long conidia, and nearly double the nuclear DNA content (Inderbitzin et al. 2011a). 
Molecular techniques have been used in the characterisation and identification of Verticillium species for both species identification and phylogenetic comparisons (Collins et al. 2003; Collado-Romero et al. 2008). Using restriction fragment length polymorphism (RFLP) analysis, Typas et al. (1992) reported that mitochondrial DNA of Verticillium species were distinctive and easily differentiated $V$. albo-atrum (from alfalfa) from other $V$. albo-atrum isolates. Carder and Barbara (1991) used RFLP analysis to differentiate $V$. dahliae from all isolates of $V$. albo-atrum and found intraspecific variation within $V$. dahliae isolates. Subsequently, Okoli et al. (1993) probed Southern blots derived from 17 isolates of $V$. dahliae with 71 random genomic clones from $V$. dahliae and found that 15 isolates fitted clearly into two RFLP groups designated A and B. Although these groups correlated with isozyme patterns they did not show any correlation with host plant or geographic origin. Random amplified polymorphic DNA (RAPD) markers clearly differentiated $15 \mathrm{~V}$. albo-atrum potato isolates from 20 alfalfa $V$. albo-atrum isolates and found that these two groups were genetically distinct (Barasubiye et al. 1995). Komatsu et al. (2001) used repetitive extragenic palindromic polymerase chain reaction (REPPCR) and RAPD markers to show that $V$. dahliae isolates from potato were similar in genetic background, regardless of geographic origin.

In North America, characterization of vegetative compatibility groups (VCGs have the ability to undergo hyphal anastomosis with other isolates) using molecular markers confirmed that VCG 4A isolates of $V$. dahliae were more highly virulent than VCG 4B isolates (Dobinson et al. 2000). Molecular characterization of VCGs has been determined in many other crops (Collado-Romero et al. 2006, 2009; Dobinson et al. 1998).

\section{Molecular phylogeny}

Nazar et al. (1991) found only five nucleotide differences between $V$. dahliae and $V$. albo-atrum on the basis of the non-conserved ITS region (ITS 1 and ITS 2) of rDNA. Robb et al. (1993) reported 17 nucleotide differences between $V$. dahliae and $V$. tricorpus and 12 between V. albo-atrum and V. tricorpus (Moukhamedov et al. 1994). Phylogenetic analysis of the complete intergenic spacer (IGS) region of the nuclear ribosomal RNA (rDNA) and the $\beta$-tubulin gene showed distinct groups comprising isolates of $V$. albo-atrum, $V$. tricorpus, and $V$. dahliae from cruciferous and noncruciferous hosts (Qin et al. 2006).

Fahleson et al. (2004) studied three different markers (mitochondrial cytochrome $b$ gene $(c o b)$, the mitochondrial small subunit rRNA gene $(r n s)$ and the nuclear ITS2 region) sequences from five plant pathogenic isolates of Verticillium and found five monophyletic groups corresponding to the Verticillium species. In addition,
$V$. tricorpus displayed a closer relationship to $V$. alboatrum, $V$. dahliae and $V$. longisporum. But $V$. nigrescens was distantly related to the other species. Based on nuclear large subunit ribosomal DNA (LSU) and ITS sequences, Zare et al. (2007) proposed Gibellulopsis as a genus to accommodate $V$. nigrescens.

Recent molecular phylogenetic studies by Inderbitzin et al. (2011a) using four gene sequences viz actin, elongation factor 1-alpha, glyceraldehyde-3-phosphate dehydrogenase and tryptophan synthase, divided Verticillium into two separate groups, corresponding to the production of yellow pigment in culture (clade Flavexudans), or the lack of yellow pigment (clade Flavnonexudans). The species Verticillium albo-atrum, V. tricorpus, V. zaregamsianum, V. isaacii and V. klebahnii were placed in the Flavexudans clade of which the latter two species were morphologically indistinguishable from V. tricorpus. The species Verticillium dahliae, V. nubilum, $V$. longisporum, $V$. alfalfae and $V$. nonalfalfae were placed in the clade Flavnonexudans (Inderbitzin et al. 2011a). Interestingly, $V$. longisporum which is a diploid hybrid had alleles in different clades including the $V$. dahliae clade thus reflecting the ancestral origin of the hybrid. According to Inderbitzin et al. (2011b), each $V$. longisporum isolate contained two alleles at each locus with allele A1 being present in all isolates in addition to alleles D1, D2 or D3. Therefore, according to Inderbitzin et al. (2011a), V. longisporum should remain a polyphyletic species.

The phylogenetic tree of the ten species adopted by Inderbitzin et al. (2011a) did not include the ribosomal internal transcribed spacer region ITS, because $V$. longisporum isolates only had one ITS allele consistent with all other Verticillium species and hence this gene sequence could not retrace the evolution of the species (Inderbitzin et al. 2011b). Nevertheless, neither the four gene phylogenetic analysis nor the single ITS phylogenetic tree were able to differentiate $V$. longisporum alleles $\mathrm{D} 2$ and $\mathrm{D} 3$ from $V$. dahliae (Inderbitzin et al. 2011b).

In contrast to the above results, a four gene phylogenetic tree composed of only the type isolates (Fig. 27) failed to differentiate $V$. isaacii from $V$. klebahnii; while $V$. alfalfa was identical to $V$. nonalfalfae; and $V$. dahliae was identical to $V$. longisporum allele D2. Nevertheless, the phylogenetic tree based only on ITS (Fig. 28) provided better discrimination to differentiate $V$. isaacii from $V$. klebahnii, and $V$. alfalfa from $V$. nonalfalfae, albeit with weak bootstrap supports.

Another anomaly with the four gene phylogenetic tree based on only type isolates was that $V$. nubilum claded with the yellow pigment forming Flavexudans species whereas in the tree by Inderbitzin et al. (2011a), V. nubilum claded with the Flavnonexudans species. Nevertheless, the phylogenetic tree based only 


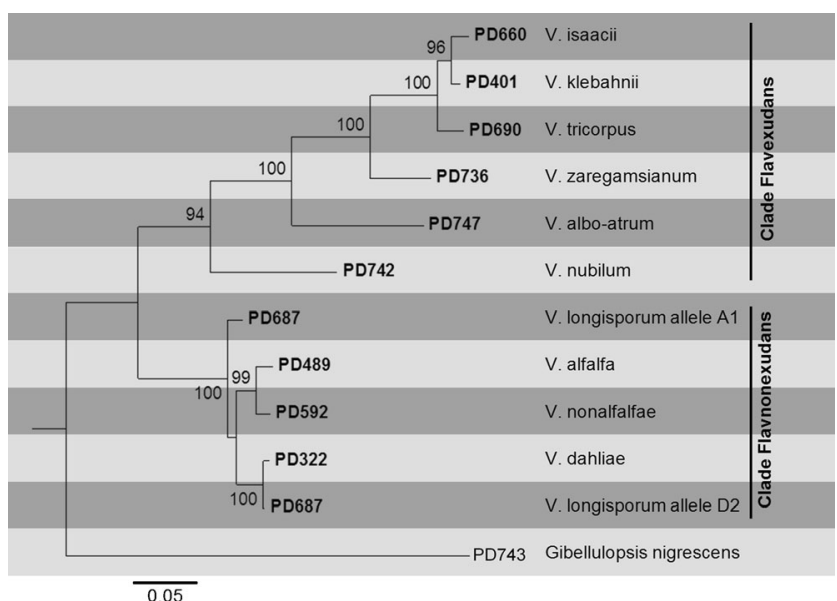

Fig. 27 Phylogram generated from parsimony analysis based on combined ACT, TEF, GPD and TS sequenced data of Verticillium. Parsimony bootstrap support values greater than $50 \%$ are indicated above the nodes. The ex-type (ex-epitype) and voucher strains are in bold. The tree is rooted with Gibellulopsis nigrescens

on ITS (Fig. 28) placed V. nubilum in the Flavnonexudans species group. In fact $V$. nubilum does not produce yellow pigment in culture, such that it is better placed in the Flavnonexudans species group.

\section{Recommended genetic markers}

Most of the ten Verticillium species can be identified using the ITS sequences of the type isolates (Table 25, Fig. 28) however, strong bootstrap support is provided for most clades using four gene sequences (Table 25, Fig. 27).

- Internal transcribed spacer(ITS)-species level

- Actin (ACT)-generic/species level

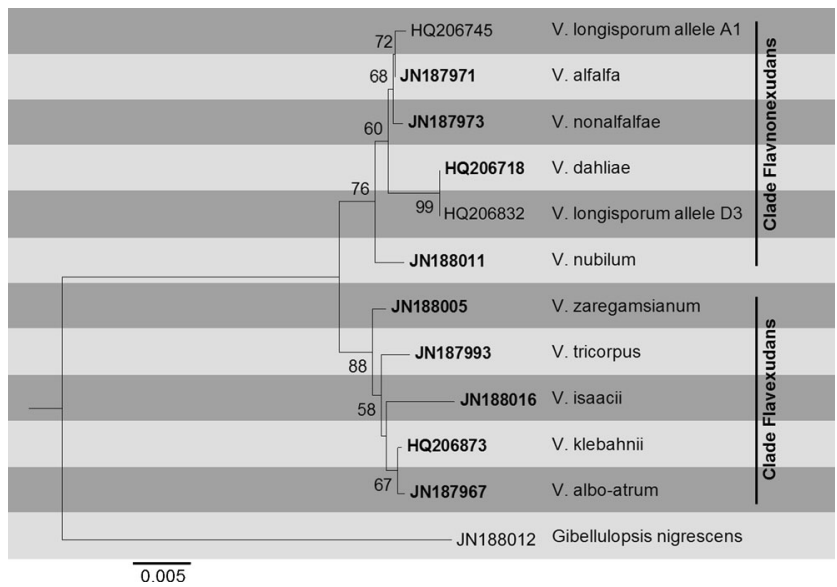

Fig. 28 Phylogram generated from parsimony analysis based on ITS sequenced data of Verticillium. Parsimony bootstrap support values greater than $50 \%$ are indicated above the nodes. The ex-type (ex-epitype) and voucher strains are in bold. The tree is rooted with Gibellulopsis nigrescens
- Elongation factor 1-alpha (EF)-generic/ species level

- Glyceraldehyde-3-phosphate dehydrogenase (GPD)generic/ species level

- Tryptophan synthase (TS)-generic/ species level

\section{Discussion}

The present effort is far from exhaustive, and the selection of fungal lineages reflects the backgrounds of the authors rather than degree of pathogenicity or economic impact of the underlying fungi. Indeed, several of the groups covered are pathogens on plants that are used neither in agriculture nor forestry. Furthermore, the fact that a group is addressed in the present study should not be taken to mean that no further discoveries or insights in the group are likely to emerge; the opposite is certain to be true for all of the groups studied here. Knowledge of phytopathogenic fungi accumulates at a high pace, and we hope that the readers will use this study as a starting point in their pursuit. Towards that end, we aim to maintain rich, updated backbone trees of as many groups of plant pathogenic fungi as we can. These will be published as a joint paper on an annual or biennial basis as new data are produced. Researchers who can cover any group not presently covered-or improve on any of the groups that are covered already-are warmly invited to take part in this effort by contacting the corresponding author.

As one of the pursuits of this effort, we have attempted to address the question of which genes and genetic markers that will provide the highest phylogenetic/taxonomic resolution in various groups of plant pathogenic fungi. These differ markedly among groups. At the same time, for someone examining a sample of an unknown phytopathology-related fungus, the choice of initial genetic markers is easy. The ITS region-the formal fungal barcode-is the most commonly sequenced marker in mycology, such that a rich array of reference sequences is available. Although the ITS region will not always provide resolution at the species level, it will nearly always provide enough resolution to support assignment of the species to at least the level of subgenus/species complex. This information is likely to be enough for many applications; for others, it makes it much easier to make an informed choice of what genes to sequence next. However, researchers sometimes recover fungal ITS sequences that are not easily fitted into the corpus of reference ITS sequences. The next most sequenced marker in mycology is the nuclear ribosomal large subunit (nLSU; Begerow et al. 2010), which is significantly more conserved than the ITS region and offers resolution at the genus to order level. The nLSU is something of the mainstay of large-scale phylogenetic inference in fungi (Blackwell et al. 2006), and nearly all fungal nLSU sequences can be assigned to at least the ordinal level. For unknown samples, we thus advice researchers to sequence the ITS and nLSU regions as a first step. 
Table 25 Verticillium. Details of the isolates used in the phylogenetic tree

\begin{tabular}{|c|c|c|c|c|c|c|c|}
\hline \multirow[t]{2}{*}{ Species } & \multirow[t]{2}{*}{ Isolate } & \multirow[t]{2}{*}{ Host } & \multicolumn{5}{|c|}{ GenBank accession number } \\
\hline & & & ITS & $\mathrm{ACT}$ & $\mathrm{EF}$ & GPD & TS \\
\hline V. dahliae & PD322* & Lettuce & HQ206718 & HQ206718 & HQ414624 & HQ414719 & HQ414909 \\
\hline V. alfalfae & PD489* & Alfalfae & JN187971 & JN188097 & JN188225 & JN188161 & JN188033 \\
\hline V. nubilum & PD742* & Soil & JN188011 & JN188139 & JN188267 & JN188203 & JN188075 \\
\hline V. isaacii & PD660* & Lettuce & HQ206873 & HQ206985 & HQ414688 & HQ414783 & HQ414973 \\
\hline V. nonalfalfae & PD592* & Irish Potato & JN187973 & JN188099 & JN188227 & JN188163 & JN188035 \\
\hline V. albo-atrum & PD747* & Potato Soil & JN188016 & JN188144 & JN188272 & JN188208 & JN188080 \\
\hline V. zaregamsianum & PD736* & Lettuce & JN188005 & JN188133 & JN188261 & JN188197 & JN188069 \\
\hline V. tricorpus & PD690* & Garden Tomato & JN187993 & JN188121 & JN188249 & JN188185 & JN188057 \\
\hline V. klebahnii & PD401* & Lettuce & JN187967 & JN188093 & JN188221 & JN188157 & JN188029 \\
\hline V. longisporum & PD687* Allele D2 & Horseradish & & HQ206994 & HQ414697 & HQ414792 & HQ414982 \\
\hline V. longisporum & PD687* Allele A1 & Horseradish & & HQ206993 & HQ414696 & HQ414791 & HQ414981 \\
\hline
\end{tabular}

Ex-type (ex-epitype) strains are bolded and marked with an * and voucher stains are bolded

Fungal plant pathogens attract the attention of numerous scientific and applied fields, including mycology, botany, agriculture, horticulture, silviculture, and medicine. In many cases this attention will centre on establishing, or ruling out, a pathogenic nature of specific fungal samples; and in many cases, such efforts will be based on molecular data. Molecular identification of fungi-DNA barcodinghas a long and rich history but was only recently formalized (Bruns et al. 1990; Schoch et al. 2012). Indeed, many parts of its realization still loom on the horizon. For instance, central barcoding resources and databases of wide acceptance in the mycological community are largely lacking. Most researchers, when processing newly generated fungal sequences, turn to GenBank (Benson et al. 2014) for sequence identification. Many entries in GenBank suffer from technical complications or low-resolution annotations, but efforts to standardize and improve on the data and level of metadata given are under way (Nilsson et al. 2014; Schoch et al. 2014). The largest database focusing on the formal fungal barcoding region-ITS-is UNITE (Kõljalg et al. 2013). Sharing data with GenBank, UNITE serves as the provider of reference fungal ITS datasets for a long range of applications and downstream uses. The results of the present effort-in particular, the sequences from type material-are being implemented in UNITE for all its diverse uses and for subsequent distribution to GenBank. We hope that this will lead to increased scientific resolution for researchers recovering any of the fungal lineages treated in this study.

The heterogeneous user base of data pertaining to phytopathogenic fungi suggests that many users of data pertaining to phytopathogenic fungi will not be-and cannot expected to be-up to date on recent developments in mycology, systematics, or the use of molecular data in biology. It is thus largely up to mycologists to provide the scientific community with as accurate and easily interpreted information on fungi and phytopathological fungal species as possible. The mycological community lives up to that expectation with various degrees of success. Improvement is particularly needed in the public sequence databases, where many researchers routinely submit phytopathologically relevant fungal sequences without any notion of taxonomic affiliation, host association, or country of collection (notably "Uncultured fungus"). Such sequences will be excluded from, or treated only superficially in, most research efforts and sequence comparisons, leading to reduced scientific resolution and explanatory power. We urge mycologists with a phytopathological inclination-indeed, with any inclination-to set good examples in this regard by providing rich, reliable annotations for their sequences. Guidelines on how to establish the integrity and improve the wide usefulness of fungal sequence data are readily available for consideration (Nilsson et al. 2012; Hyde et al. 2013a, b; Schoch et al. 2014). We similarly hope that all mycologists, when describing new species, will make it a habit to bundle at least one DNA sequence-starting with the ITS region-with the description (cf. Seifert and Rossman 2010). This will help others to interpret the name and will go a long way to make it available to the general scientific audience. Enclosing molecular data with species descriptions is not required by the current nomenclatural code governing fungi (McNeill et al. 2012), but we feel that this is a good opportunity for mycology to show its progressive nature. In a time where mycology finds it increasingly hard to compete for funding with disciplines deemed more cutting-edge, mycologists should make every effort to propagate their results and findings to the widest audience possible. 
Acknowledgments We would like to thank the CGIAR Research Program 1.2-Humidtropics: Integrated systems for the humid tropics, for partially funding this work. Kevin D. Hyde thanks the Chinese Academy of Sciences, project number 2013T2S0030, for the award of Visiting Professorship for Senior International Scientists at Kunming Institute of Botany. Thank to Plant Germplasm and Genomics Center in Germplasm Bank of Wild Species. Sajeewa Maharachchikumbura thanks the National Research Council of Thailand (grant for Pestalotiopsis No: 55201020008) and Mae Fah Luang University (grant for Pestalotiopsis No: 55101020004) for financial support. S.A. Alias thanks the University of Malaya for grant number RU006H-2014 entitled "diversity and importance of fungal mangrove disease". Financial support to Julia Pawłowska and Marta Wrzosek was partially provided by the Polish Ministry of Science and Higher Education (MNiSW), grant no. NN303 548839. Henrik Nilsson acknowledges financial support from FORMĀS (215-2011-498).

Open Access This article is distributed under the terms of the Creative Commons Attribution License which permits any use, distribution, and reproduction in any medium, provided the original author(s) and the source are credited.

\section{References}

Abdel-Motaal FF, El-Sayed MA, El-Zayat SA, Nassar MSM, Schin-ichi I (2010) Choanephora rot of floral tops of Hyoscyamus muticus caused by Choanephora cucurbitarum. J Gen Plant Pathol 76(5): 358-361

Abdollahzadeh J, Javadi A, Goltapeh EM, Zare R, Phillips AJL (2010) Phylogeny and morphology of four new species of Lasiodiplodia from Iran. Persoonia 25:1-10

Abdollahzadeh J, Zare R, Phillips AJL (2013) Phylogeny and taxonomy of Botryosphaeria and Neofusicoccum species in Iran, with description of Botryosphaeria scharifii sp. nov. Mycologia 105:210-220

Abdollahzadeh J, Javadi A, Zare R, Phillips A (2014) A phylogenetic study of Dothiorella and Spencermartinsia species associated with woody plants in Iran, New Zealand, Portugal and Spain. Persoonia 32:1-12

Abe A, Oda Y, Asano K, Sone T (2006) The molecular phylogeny of the genus Rhizopus based on rDNA sequences. Biosci Biotechnol Biochem 70:2387-2393

Abe A, Oda Y, Asano K, Sone T (2007) Rhizopus delemar is the proper name for Rhizopus oryzae fumaric-malic acid producers. Mycologia 99:714-722

Abe A, Asano K, Sone T (2010) A molecular phylogeny-based taxonomy of the genus Rhizopus. Biosci Biotechnol Biochem 74:1325-1331

Adegbite AA, Amusa NA (2008) The major economic field diseases of cowpea on the humid agro-ecologies of South-Western Nigeria. Afr J Biotechnol 7:4706-4712

Adhikari BN, Hamilton JP, Zerillo MM, Tisserat N, Lévesque CA, Buell CR (2013) Comparative genomics reveals insight into virulence strategies of plant pathogenic oomycetes. PLoS One 8(10):e75072

Agrios GN (2005) Plant pathology, 5th edn. Academic, New York

Aime MC (2006) Toward resolving family-level relationships in rust fungi (Uredinales). Mycoscience 47(3):112-122. doi:10.1007/ s10267-006-0281-0

Akinbode OA, Ikotun T (2008) Evaluation of some bioagents and botanicals in in vitro control of Colletotrichum destructivum. Afr J Biotechnol 7:868-872

Alcorn JL (1988) The taxonomy of Helminthosporium species. Annu Rev Phytopathol 26:37-56

Álvarez E, Cano J, Stchigel AM, Sutton DA, Fothergill AW, Salas V, Rinaldi MG, Guarro J (2011) Two new species of Mucor from clinical samples. Med Mycol 49:62-72
Alves A, Correia A, Luque J, Phillips AJL (2004) Botryosphaeria corticola, sp. nov. on Quercus species, with notes and description of Botryosphaeria stevensii and its anamorph, Diplodia mutila. Mycologia 96:598-613

Alves A, Correia A, Phillips AJL (2006) Multigene genealogies and morphological data support Diplodia cupressi sp. nov., previously recognized as Diplodia pinea f. sp. cupressi as a distinct species. Fungal Divers 23:1-15

Alves A, Crous PW, Correia A, Phillips AJL (2008) Morphological and molecular data reveal cryptic species in Lasiodiplodia theobromae. Fungal Divers 28(1):1-13

Alves A, Linaldeddu BT, Deidda A, Scanu B, Phillips AJL (2014) The complex of Diplodia species associated with Fraxinus and some other woody hosts in Italy and Portugal. Fungal Divers. doi:10. 1007/s13225-014-0282-9

Aly AH, Debbab A, Kjer J, Proksch P (2010) Fungal endophytes from higher plants: a prolific source of phytochemicals and other bioactive natural products. Fungal Divers 41:1-16

Amselem J, Cuomo CA, van Kan JAL, Viaud M, Benito EP, Couloux A, Coutinho PM, de Vries RP, Dyer PS, Fillinger S, Fournier E, Gout L, Hahn M, Kohn L, Lapalu N, Plummer KM, Pradier J-M, Quévillon E, Sharon A, Simon A, ten Have A, Tudzynski B, Tudzynski P, Wincker P, Andrew M, Anthouard V, Beever RE, Beffa R, Benoit I, Bouzid O, Brault B, Chen Z, Choquer M, Collémare J, Cotton P, Danchin EG, Da Silva C, Gautier A, Giraud C, Giraud T, Gonzalez C, Grossetete S, Güldener U, Henrissat B, Howlett BJ, Kodira C, Kretschmer M, Lappartient A, Leroch M, Levis C, Mauceli E, Neuvéglise C, Oeser B, Pearson M, Poulain J, Poussereau N, Quesneville H, Rascle C, Schumacher J, Ségurens B, Sexton A, Silva E, Sirven C, Soanes DM, Talbot NJ, Templeton M, Yandava C, Yarden O, Zeng Q, Rollins JA, Lebrun M-H, Dickman M (2011) Genomic analysis of the necrotrophic fungal pathogens Sclerotinia sclerotiorum and Botrytis cinerea. PLoS Genet 7:e1002230

Amusa NA, Baiyewu RA (1999) Storage and market disease of yam tubers in southwestern Nigeria. Ogun J Agric Res (Nig) 11:211-225

Amusa NA, Adegbite AA, Muhammed S, Baiyewu RA (2003) Yam diseases and its management in Nigeria. Afr J Biotechnol 2(12):497-502

Andrew M, Barua R, Short SM, Kohn LM (2012) Evidence for a common toolbox based on necrotrophy in a fungal lineage spanning necrotrophs, biotrophs, endophytes, host generalists and specialists. PLoS ONE 7:e29943

Andrews DL, Egan JD, Mayorga ME, Gold SE (2000) The Ustilago maydis ubc4 and ubc5 genes encode members of a MAP kinase cascade required for filamentous growth. Mol Plant-Microbe Interact 13(7):781-786

Aoki T, O’Donnell K, Scandiani MM (2005) Sudden death syndrome of soybean in South America is caused by four species of Fusarium: Fusarium brasiliense sp. nov., F. cuneirostrum sp. nov., F. tucumaniae, and $F$. virguliforme. Mycoscience 46:162-183

Ariyawansa HA, Phookamsak R, Tibpromma S, Kang JC, Hyde KD (2014) A molecular and morphological reassessment of Diademaceae. Sci World J 2014:1-11

Ariyawansa HA, Kang JC, Alias SA, Chukeatirote E, Hyde KD (2014) Pyrenophora. Mycosphere 5(2):351-362

Arthur JC, Kern FD (1926) The problem of terminology in the rusts. Mycologia 18(2):90-93. doi:10.2307/3753658

Asakura M, Ninomiya S, Sugimoto M, Oku M, Yamashita S, Okuno T, Sakai Y, Takano Y (2009) Atg26-mediated pexophagy is required for host invasion by the plant pathogenic fungus Colletotrichum orbiculare. Plant Cell 21:1291-1304

Aveskamp MM, De Gruyter J, Crous PW (2008) Biology and recent developments in the systematics of Phoma, a complex genus of major quarantine significance. Fungal Divers 31:1-18

Aveskamp MM, Woudenberg JH, De Gruyter J, Turco E, Groenewald JZ, Crous PW (2009) Development of taxon-specific sequence 
characterized amplified region (SCAR) markers based on actin sequences and DNA amplification fingerprinting (DAF): a case study in the Phoma exigua species complex. Mol Plant Pathol 10(3):403-414

Aveskamp M, De Gruyter J, Woudenberg J, Verkley G, Crous PW (2010) Highlights of the Didymellaceae: a polyphasic approach to characterise Phoma and related pleosporalean genera. Stud Mycol 65(1): $1-60$

Baayen R, Bonants P, Verkley G, Carroll GC, Van Der Aa HA, de Weerdt M, van Brouwershaven IR, Schutte GC, Maccheroni W Jr, de Blanco CG, Azevedo JL (2002) Nonpathogenic isolates of the citrus black spot fungus, Guignardia citricarpa, identified as a cosmopolitan endophyte of woody plants, G. mangiferae (Phyllosticta capitalensis). Phytopathology 92(5):464-477

Bahramisharif A, Lamprecht SC, Spies CFJ, Botha WJ, McLeod A (2013) Pythium cederbergense sp. nov. and related taxa from Pythium clade G associated with the South African indigenous plant Aspalathus linearis (rooibos). Mycologia 105(5):1174-1189. doi: 10.3852/12-322

Bakkeren G, Kämper J, Schirawski J (2008) Sex in smut fungi: structure, function and evolution of mating-type complexes. Fungal Genet Biol 45(Supplement 1):S15-S21

Bala K, Robideau GP, Levesque CA, de Cock AWAM, Abad G, Lodhi AM, Shahzad S, Ghaffar A, Coffey MD (2010) Phytopythium Abad, de Cock, Bala, Robideau, Lodhi \& Levesque, gen. nov. and Phytopythium sindhum Lodhi, Shahzad \& Levesque, sp. nov. Persoonia 24:136-137

Ballance GM, Lamari L, Kowatsch R, Bernier CC (1996) Cloning, expression and occurrence of the gene encoding the Ptr necrosis toxin from Pyrenophora tritici-repentis, Mol Plant Pathol On-Line [http://www.bspp.org.uk/mppol/1996/1209ballance]

Barasubiye T, Parent J, Hamelin RC, Laberge S, Richard C, Dostaler D (1995) Discrimination between alfalfa and potato isolates of Verticillium albo-atrum using RAPD markers. Mycol Res 99: 1507-1512

Barilli E, Satovic Z, Sillero JC, Rubiales D, Torres AM (2011) Phylogenetic analysis of uromyces species infecting grain and forage legumes by sequence analysis of nuclear ribosomal internal transcribed spacer region. J Phytopathol 159(3):137-145. doi:10. $1111 / j .1439-0434.2010 .01736 . x$

Barr ME (1972) Preliminary studies on the Dothideales in temperate North America. Contrib Univ Michi Herb 9:523-638

Barr ME (1975) Pestalosphaeria, a new genus in the Amphisphaeriaceae. Mycologia 67:187-194

Barr ME (1987) Prodromus to class Class Loculoascomycetes. Published by the author, Amherst, Massachusetts, USA

Barr DJS, Warwick SI, Désaulniers NL (1996) Isozyme variation, morphology, and growth response to temperature in Pythium ultimum. Can J Bot 74(5):753-761

Barr DJS, Warwick SI, Désaulniers NL (1997) Isozyme variation, morphology, and growth response to temperature in Pythium irregulare. Can J Bot 75(12):2073-2081. doi:10.1139/b97-918

Beakes G, Sekimoto S (2009) The evolutionary phylogeny of Oomycetes-insights gained from studies of holocarpic parasites of algae and invertebrates. In: Lamour K, Kamoun S (eds) Oomycete genetics and genomics: diversity, interactions, and research tools. John Wiley and Sons, pp 1-24

Beakes GW, Honda D, Thines M (2014) Systematics of the Straminipila: Labyrinthulomycota, Hyphochytriomycota and Oomycota. In: McLaughlin J, Spathaphora JW (eds) Mycota VIIA (systematics and evolution), 2nd edn. Springer, New York

Beckman CH (1987) The nature of wilt diseases in plants. APS Press, St. Paul

Beenken L, Zoller S, Berndt R (2012) Rust fungi on Annonaceae II: the genus Dasyspora Berk. \& M.A. Curtis. Mycologia 104(3):659-681. doi:10.3852/11-068
Beever RE, Parkes SL (1993) Mating behaviour and genetics of fungicide resistance of Botrytis cinerea in New Zealand. N Z J Crop Hortic Sci 21:303-310

Begerow D, Göker M, Lutz M, Stoll M (2004) On the evolution of smut fungi on their hosts. In: Agerer R, Piepenbring M, Blanz P (eds) Frontiers in basidiomycote mycology. pp 81-98

Begerow D, Nilsson RH, Unterseher M, Maier W (2010) Current state and perspectives of fungal DNA barcoding and rapid identification procedures. Appl Microbiol Biotechnol 87:99-108

Begoude BAD, Slippers B, Wingfield MJ, Roux J (2010) Botryosphaeriaceae associated with Terminalia catappa in Cameroon, South Africa and Madagascar. Mycol Prog 9:101-123

Beirn LA, Moy M, Meyer WA, Clarke BB, Crouch JA (2011) Molecular analysis of turfgrass rusts reveals the widespread distribution of puccinia Puccinia coronata as a pathogen of Kentucky Bluegrass in the United States. Plant Dis 95(12):1547-1557. doi:10.1094/pdis01-11-0073

Belbahri L, McLeod A, Paul B, Calmin G, Moralejo E, Spies CFJ, Botha WJ, Clement A, Descals E, Sánchez-Hernández E, Lefort F (2008) Intraspecific and within-isolate sequence variation in the ITS rRNA gene region of Pythium mercuriale sp. nov. (Pythiaceae). FEMS Microbiol Lett 284:17-27

Benhamou N, Rey P, Chérif M, Hockenhull J, Tirilly Y (1997) Treatment with the mycoparasite Pythium oligandrum triggers induction of defense-related reactions in tomato roots when challenged with Fusarium oxysporum f. sp. radicis-lycopersici. Phytopathology 87(1):108-122. doi:10.1094/PHYTO.1997.87.1.108

Benny GL (1991) Gilbertellaceae, a new family of the Mucorales (Zygomycetes). Mycologia 83:150-157

Benson DA, Clark K, Karsch-Mizrachi I, Lipman DJ, Ostell J, Sayers EW (2014) GenBank. Nucleic Acids Res 42:D32-D37

Berbee ML (1996) Loculoascomycete origins and evolution of filamentous ascomycete morphology based on $18 \mathrm{~s}$ rrna gene sequence data. Mol Biol Evol 13(3):462-470

Berbee ML, Pirseyedi M, Hubbard S (1999) Cochliobolus phylogenetics and the origin of known, highly virulent pathogens, inferred from ITS and glyceraldehyde-3-phosphate dehydrogenase gene sequences. Mycologia 91:964-977

Bergquist RR, Lorbeer JW (1972) Apothecial production, compatibility and sex in Botryotinia squamosa. Mycologia 64:1270-1281

Bertier L, Brouwer H, de Cock AWAM, Cooke DEL, Olsson CHB, Hofte M (2013) The expansion of Phytophthora clade 8b: three new species associated with winter grown vegetable crops. Persoonia 31:63-76

Bertrand P, Saulie-Carter J (1980) Mucor rots of pears and apples. Ore State Univ Agric Exp Stn Spec Rep 568:21

Bilodeau GJ, Lévesque CA, de Cock AWAM, Duchaine C, Briére S, Uribe P, Martin FN, Hamelin RC (2007) Molecular detection of Phytophthora ramorum by real-time polymerase chain reaction using TaqMan, SYBR Green, and molecular beacons. Phytopathology 97:632-642

Blackwell M, Hibbett DS, Taylor JW, Spatafora JW (2006) Research coordination networks: a phylogeny for kingdom fungi (Deep Hypha). Mycologia 98:829-837

Blair JE, Coffey MD, Park SY, Geiser DM, Kang S (2008) A multi-locus phylogeny for Phytophthora utilizing markers derived from complete genome sequences. Fungal Genet Biol 45:266-277

Blair JE, Coffey MD, Martin FN (2012) Species tree estimation for the late blight pathogen, Phytophthora infestans, and close relatives. PLoS One 7:e37003. doi:10.1371/journal/pone.0037003

Boedijn KB (1933) Über einige phragmosporen Dematiazen. Bull Jard Bot Buitenzorg 13:120-134

Boerema G, Verhoeven AA (1979) Check-list for scientific names of common parasitic fungi. Series $2 \mathrm{c}$ : fungi on field crops: pulse (legumes) and forage crops (herbage legumes). Neth J Plant Pathol 85(4):151-181 
Boerema G, DeGruyter J, Noordeloos M (1997) Contributions towards a monograph of Phoma (Coelomycetes). 4. Section Heterospora: taxa with large sized conidial dimorphs, in vivo sometimes as Stagonosporopsis synanamorphs. Persoonia 16:335-371

Boerema G, de Gruyter J, van de Graaf P (1999) Contributions towards a monograph of Phoma (Coelomycetes) IV-supplement: an addition to section Heterospora: Phoma schneiderae spec. nov., synanamorph Stagonosporopsis lupini (Boerema \& R. Schneid.) comb. nov. Persoonia 17(2):281-285

Boerema G, De Gruyter J, Noordeloos M, Hamers ME (2004) Phoma identification manual. G Phoma sect. Plenodomus, CABI Publishing, UK, pp 364-366

Bonants PJM, Hagenaar-De Weerdt M, Man In 't Veld WA, Baayen RP (2000) Molecular characterization of natural hybrids of Phytophthora nicotianae and P. cactorum. Phytopathology 90:867-874

Børve J, Vangdal E (2007) Fungal pathogens causing fruit decay on plum (Prunus domestica L.) in Norway. Acta Horticult 734:367-369

Brasier CM (2007) Phytophthora biodiversity: how many Phytopthora species are there? In: Goheen EM, Frankel SJ (eds) USDA, Forest Service, Pacific Southwest Research Station, pp 101-115

Brasier CM, Cooke DEL, Duncan JM (1999) Origin of a new Phytophthora pathogen through interspecific hybridization. Proc Natl Acad Sci U S A 96:5878-5883

Brasier CM, Cooke DEL, Duncan JM, Hansen EM (2003) Multiple new phenotypic taxa from trees and riparian ecosystems in Phytophthora gonapodyides-P. megasperma ITS Clade 6, which tend to be hightemperature tolerant and either inbreeding or sterile. Mycol Res 107: 277-290

Briard M, Dutertre M, Rouxel F, Brygoo Y (1995) Ribosomal RNA sequence divergence within the Pythiaceae. Mycol Res 99(9): 1119-1127. doi:10.1016/S0953-7562(09)80782-X

Bridge PD, Spooner BM, Roberts PJ (2005) The impact of molecular data in fungal systematics. Adv Bot Res 42:33-67

Bruns TD, Fogel R, Taylor JW (1990) Amplification and sequencing of DNA from fungal herbarium specimens. Mycologia $82: 175-184$

Buchwald N (1953) Botryotinia (Sclerotinia) globosa sp. n. on Allium ursinum, the perfect stage of Botrytis globosa Raabe. Phytopathol Z 20:241-254

Budziszewska J, Piątkowska J, Wrzosek M (2010) Taxonomic position of Mucor hiemalis f. luteus. Mycotaxon 111:75-85

Burgess TI, Barber PA, Hardy G, St J (2005) Botryosphaeria spp. associated with eucalypts in Western Australia, including the description of Fusicoccum macroclavatum sp. nov. Australas Plant Pathol 34:557-567

Burgess TI, Barber PA, Mohali S, Pegg G, de Beer W, Wingfield MJ (2006) Three new Lasiodiplodia spp. from the tropics, recognized based on DNA sequence comparisons and morphology. Mycologia 98:423-435

Burgess TI, Stukely MJC, Jung T, White D, Hüberli D, Hardy GESJ (2010) Molecular characterisation of a Phytophthora hybrid swarm in native ecosystems and waterways in Western Australia, 5th IUFRO Phytophthora Diseases in Forests and Natural Ecosystems, 7-12 March, Auckland and Rotorua, New Zealand

Butler EE, Ogawa JM, Shalla T (1960) Bull Torrey Bot Club 87(6):397-401

Cai L, Hyde KD, Taylor PWJ, Weir B, Waller JM, Abang MM, Zang JC, Yang YL, Phouliyong S, Prihastuti ZY, Shivas RG, McKenzie EHC, Johnston PR (2009) A polyphasic approach for studying Colletotrichum. Fungal Divers 39:183-204

Cai L, Udayanga D, Manamgoda DS, Maharachchikumbura SSN, McKenzie EHC, Guo LD, Liu XZ, Bahkali A, Hyde KD (2011) The need to carry out re-inventory of plant pathogenic fungi. Trop Plant Pathol 36:205-213

Campbell MA, Rokas A, Slot JC (2012) Horizontal transfer and death of a fungal secondary metabolic gene cluster. Genome Biol Evol 4: 289-293
Cannon PF, Bridge PD, Monte E (2000) Linking the past, present, and future of Colletotrichum systematics. In: Prusky D, Freeman S, Dickman M (eds) Colletotrichum: host specificity, pathology, and host-pathogen interaction. APS Press, St Paul, pp 1-20

Cannon PF, Buddie AG, Bridge PD (2008) The typification of Colletotrichum gloeosporioides. Mycotaxon 104:189-204

Cannon PF, Damm U, Johnston PR, Weir BS (2012) Colletotrichumcurrent status and future directions. Stud Mycol 73:181-213

Carbone I, Kohn LM (1999) A method for designing primer sets for speciation studies in filamentous ascomycetes. Mycologia 91:553-556

Carder JH, Barbara DJ (1991) Molecular variation and restriction fragment length polymorphisms (RFLPs) within and between six species of Verticillium. Mycol Res 95:935-942

Castlebury L (2005) The Diaporthe vaccinii complex of fruit pathogens. Inoculum 56:12

Castlebury LA, Mengistu A (2006) Phylogenetic distinction of Diaporthe/Phomopsis isolates from soybeans. Syst Mycol Microbiol 57:1-13

Castlebury LA, Farr DF, Rossman AY (2001) Phylogenetic distinction of Phomopsis isolates from cucurbits. Inoculum 52:25

Cesati V, de Notaris G (1863) Schema di classificazione degli sferiacei italici aschigeri piu' o meno appartenenti al genere Sphaeria nell'antico significato attribuitoglide Persoon. Commentario della Società Crittogamologica Italiana 1(4):177-240

Chakrabarti A, Marak RSK, Shivaprakash MR, Gupta S, Garg R, Sakhuja V, Singhal S, Baghela A, Dixit A, Garg MK, Padhye AA (2010) Cavitary pulmonary zygomycosis caused by Rhizopus homothallicus. J Clin Microbiol 48:1965-1969

Chen SF, Pavlic D, Roux J, Slippers B, Xie YJ, Wingfield MJ, Zhou XD (2011) Characterization of Botryosphaeriaceae from plantation grown Eucalyptus species in South China. Plant Pathol 60:739-751

Cheng JY, Hu FM (1965) A new species of Gilbertella. J Univ Chin Acad Sci 10(2):105-109

Clements F, Shear C (1931) The genera of fungi. Wilson, New York Clendenin I (1896) Lasiodiplodia E. \& E., n. gen. Bot Gaz 21(2):92

Cline ET, Farr DF, Rossman AY (2008) A synopsis of Phytophthora with accurate scientific names, host range, and geographic distribution. Online. Plant Health Prog. doi:10.1094/PHP-2008-0318-01-RS

Collado-Romero M, Mercado-Blanco J, Olivares-Garcia C, ValverdeCorredor A, Jimenez-Diaz RM (2006) Molecular variability within and among Verticillium dahliae vegetative compatibility groups determined by fluorescent amplified fragment length polymorphism and polymerase chain reaction markers. Phytopathology 96:485-495

Collado-Romero M, Mercado-Blanco J, Olivares-García C, JiménezDíaz RM (2008) Phylogenetic analysis of Verticillium dahliae vegetative compatibility groups. Phytopathology 98:1019-1028

Collado-Romero M, Berbegal M, Jimenez-Diaz RM, Armengol J, Mercado-Blanco J (2009) A PCR-based 'molecular tool box' for in planta differential detection of Verticillium dahliae vegetative compatibility groups infecting artichoke. Plant Pathol 58:515-526

Collins A, Okoli CAN, Morton A, Parry D, Edwards SG, Barbara DJ (2003) Isolates of Verticillium dahliae pathogenic to crucifers are of at least three distinct molecular types. Phytopathology 93:364-376

Cooke DEL, Duncan JM (1997) Phylogenetic analysis of Phytophthora species based on ITS1 and ITS2 sequences of the ribosomal RNA gene repeat. Mycol Res 101:667-677

Cooke DEL, Drenth A, Duncan JM, Wagels G, Brasier CM (2000) A molecular phylogeny of Phytophthora and related oomycetes. Fungal Genet Biol 30(1):17-32. doi:10.1006/fgbi.2000.1202

Corda ACI (1831) Die Pilze Deutschlands. In: Sturm J (ed) Deutschlands Flora in Abbildungen nach der Natur mit Beschreibungen. Sturm, Nürnberg vol. 3, Abt. 12:33-64, tab. 21-32

Crawford AR, Bassam BJ, Drenth A, Maclean DJ, Irwin JAG (1996) Evolutionary relationships among Phytophthora species deduced from rDNA sequence analysis. Mycol Res 100:437-443 
Crouch JA (2014) Colletotrichum caudatum s.l. is a species complex. IMA Fungus 5:1-30

Crouch JA, Tredway LP, Clarke BB, Hillman BI (2009a) Phylogenetic and population genetic divergence correspond with habitat for the pathogen Colletotrichum cereale and allied taxa across diverse grass communities. Mol Ecol 18:123-135

Crouch JA, Clarke BB, Hillman BI (2009b) What is the value of ITS sequence data in Colletotrichum systematics and species diagnosis? A case study using the falcate-spored graminicolous Colletotrichum group. Mycologia 101(5):648-656

Crouch JA, Clarke BB, White JF, Hillman BI (2009c) Systematic analysis of the falcate-spored graminicolous Colletotrichum and a description of six new species from warm season grasses. Mycologia 101: $717-732$

Crous PW, Groenewald J (2005) Hosts, species and genotypes: opinions versus data. Australas Plant Pathol 34:463-470

Crous PW, Palm ME (1999) Reassessment of the anamorph genera Botryodiplodia, Dothiorella and Fusicoccum. Sydowia 51(2):167-175

Crous PW, Seifert KA, Castañeda Ruiz RF (1996) Microfungi associated with Podocarpus leaf litter in South Africa. S Afr J Bot 62:89-98

Crous PW, Groenewald JZ, Risede J-M, Hywel-Jones NL (2004) Calonectria species and their Cylindrocladium anamorphs: species with sphaeropedunculate vesicles. Stud Mycol 50:415-430

Crous PW, Slippers B, Wingfield MJ, Rheeder J, Marasas WFO, Philips AJL, Alves A, Burgess TI, Barber PA, Groenewald JZ (2006) Phylogenetic lineages in the Botryosphaeriaceae. Stud Mycol 55: 235-253

Cuesta Arenas Y, Kalkman ERIC, Schouten A, Dieho M, Vredenbregt P, Uwumukiza B, Osés Ruiz M, van Kan JAL (2010) Functional analysis and mode of action of phytotoxic Nep1-like proteins of Botrytis cinerea. Physiol Mol Plant Pathol 74:376-386

Cummins GB (1971) The rust fungi of cereals, grasses and bamboos. Springer, New York

Cummins GB (1978) Rust fungi on legumes and composites in North America. The University of Arizona Press, Tucson

Cummins GB, Hiratsuka Y (2003) Illustrated genera of rust fungi, 3rd edn. Am Phytopathol Soc, St. Paul

Currey F (1873) Note on Cunninghamia infundibulifera. Bot J Linn Soc 13:578

da Cunha KC, Sutton DA, Fothergill AW, Gené J, Cano J, Madrid $\mathrm{H}$, de Hoog S, Crous PW, Guarro J (2013) In vitro antifungal susceptibility and molecular identity of 99 clinical isolates of the opportunistic fungal genus Curvularia. Diagn Microbiol Infect Dis 76:168-174

Damm U, Crous PW, Fourie PH (2007) Botryosphaeriaceae as potential pathogens of Prunus species in South Africa, with descriptions of Diplodia africana and Lasiodiplodia plurivora sp. nov. Mycologia 99:664-680

Damm U, Woudenberg JHC, Cannon PF, Crous PW (2009) Colletotrichum species with curved conidia from herbaceous hosts. Fungal Divers 39:45-87

Damm U, Cannon PF, Woudenberg JHC, Crous PW (2012a) The Colletotrichum acutatum species complex. Stud Mycol 73:37-113

Damm U, Cannon PF, Woudenberg JHC, Johnston PR, Weir B, Tan YP, Shivas RG, Crous PW (2012b) The Colletotrichum boninense species complex. Stud Mycol 73:1-36

Damm U, Cannon PF, Liu F, Barreto RW, Guatimosim E, Crous PW (2013) The Colletotrichum orbiculare species complex: important pathogens of field and weeds. Fungal Divers 61:29-59

de Cock AWAM, Mendoza L, Padhye A, Ajello L, Kaufman L (1987) Pythium insidiosum sp. nov., the etiologic agent of pythiosis. J Clin Microbiol 25(2):344

de Gruyter J, Aveskamp MM, Woudenberg JH, Verkley GJ, Groenewald JZ, Crous PW (2009) Molecular phylogeny of Phoma and allied anamorph genera: towards a reclassification of the Phoma complex. Mycol Res 113(4):508-519 de Gruyter J, Woudenberg JH, Aveskamp MM, Verkley GJ, Groenewald JZ, Crous PW (2010) Systematic reappraisal of species in Phoma section Paraphoma, Pyrenochaeta and Pleurophoma. Mycologia 102(5): 1066-1081

de Gruyter J, van Gent-Pelzer MP, Woudenberg JH, van Rijswick PC, Meekes ET, Crous PW, Bonants PJ (2012) The development of a validated real-time (TaqMan) PCR for detection of Stagonosporopsis andigena and S. crystalliniformis in infected leaves of potato and tomato. Eur J Plant Pathol 134(2):301-313

de Hoog GS, Gerrits Van den Ende AHG (1998) Molecular diagnostics of clinical strains of filamentous Basidiomycetes. Mycoses 41:183-189

de Luna LZ, Watson AK, Paulitz TC (2002) Reaction of rice (Oryza sativa) cultivars to penetration and infection by Curvularia tuberculata and C. oryzae. Plant Dis 86:470-476

De Wet J, Burgess T, Slippers B, Preisig O, Wingfield BD, Wingfield MJ (2003) Multiple gene genealogies and microsatellite markers reflect relationships between morphotypes of Sphaeropsis sapinea and distinguish a new species of Diplodia. Mycol Res 107:557-566

Dean R, van Kan JAL, Pretorius ZA, Hammond-Kosack KE, Di Pietro A, Spanu PD, Rudd JJ, Dickman M, Kahmann R, Ellis J, Foster GD (2012) The top 10 fungal pathogens in molecular plant pathology. Mol Plant Pathol 13:414-430

Delaye L, García-Guzmán G, Heil M (2013) Endophytes versus biotrophic and necrotrophic pathogens - are fungal lifestyles evolutionarily stable traits? Fungal Divers 60:125-135

Denman S, Crous PW, Taylor JE, Kang JC, Pascoe I, Wingfield MJ (2000) An overview of the taxonomic history of Botryosphaeria, and a re-evaluation of its anamorphs based on morphology and ITS rDNA phylogeny. Stud Mycol 45:129-140

Denman S, Crous PW, Groenewald JZE, Slippers B, Wingfield BD, Wingfield MJ (2003) Circumscription of Botryosphaeria species associated with Proteaceae based on morphology and DNA sequence data. Mycologia 95:294-307

Dennis C, Davis RP (1977) Susceptibility of strawberry varieties to postharvest fungal spoilage. J Appl Bacteriol 42(2):197-206

Desjardins AE (2003) Gibberella from A(venaceum) to Z(eae). Annu Rev Phytopathol 41:177-198

Desjardins AE (2005) Fusarium mycotoxins: chemistry, genetics and biology. APS Press, St. Paul

Desmazieres MJBHJ (1847) Quatorzieme notice sur les plantes cryptogames recemment decouvertes en france. Ann Sci Nat Bot Ser 3(8):9-37

Dick MW (1990) Keys to Pythium. MW Dick, Reading

Dick MW (2001) Straminipilous fungi : systematics of the peronosporomycetes, including accounts of the marine straminipilous protists, the plasmodiophorids, and similar organisms. Kluwer Acad Pub, Dordrecht; Boston

Diedicke H (1912) Die Abteilung Hyalodidymae der Sphaerioideen. Ann Mycol 10:135-152

Diogo ELF, Santos JM, Phillips AJL (2010) Phylogeny, morphology and pathogenicity of Diaporthe and Phomopsis species on almond in Portugal. Fungal Divers 44:107-115

Diolez A, Marches F, Fortini D, Brygoo Y (1995) Boty, a long-terminalrepeat retroelement in the phytopathogenic fungus Botrytis cinerea. Appl Environ Microbiol 61:103-108

Dixon LJ, Castlebury LA, Aime MC, Glynn NC, Comstock JC (2010) Phylogenetic relationships of sugarcane rust fungi. Mycol Prog 9(4): 459-468. doi:10.1007/s11557-009-0649-6

Dobinson KF, Patterson NA, White GT, Grant S (1998) DNA fingerprinting and vegetative compatibility analysis indicate multiple origins for Verticillium dahliae race 2 tomato isolates from Ontario, Canada. Mycol Res 102:1089-1095

Dobinson KF, Harrington MA, Omer M, Rowe RC (2000) Molecular characterization of vegetative compatibility group $4 \mathrm{~A}$ and $4 \mathrm{~B}$ isolates of Verticillium dahliae associated with potato early dying. Plant Dis 84:1241-1245 
Dolatabadi S, Walther G, Gerrits van de Ende AHG, de Hoog GS (2014a) Diversity and delimitation of Rhizopus microsporus. Fungal Divers 64:145-163

Dolatabadi S, Klaassen CHW, GS de Hoog GS de, Walther G (2014b) Species boundaries and correct nomenclature in the Rhizopus arrhizus (syn. $R$. oryzae) group. Mycoses, in press

Doyle VP, Oudemans PV, Rehner SA, Litt A (2013) Habitat and host indicate lineage identity in Colletotrichum gloeosporioides s.l. from wild and agricultural landscape in North America. PLoS ONE 8(5):1-21

Drechsler C (1934) Phytopathological and taxonomical aspects of Ophilobolus, Pyrenophora, Helminthosporium and a new genus Cochliobolus. Phytopathology 24:953-983

Drummond AJ, Suchard MA, Xie D, Rambaut A (2012) Bayesian phylogenetics with BEAUti and the BEAST 1.7. Mol Phylogenet Evol 29:1969-1973

Du M, Schardl CL, Nuckles EM, Vaillancourt LJ (2005) Using matingtype gene sequences for improved phylogenetic resolution of Colletotrichum species complexes. Mycologia 97:641-658

Durán A, Gryzenhout M, Slippers B, Ahumada R, Rotella A, Flores F, Wingfield BD, Wingfield MJ (2008) Phytophthora pinifolia sp. nov. associated with a serious needle disease of Pinus radiata in Chile. Plant Pathol 57:715-727

Eddy ED (1925) A storage rot of peaches caused by a new species of Choanephora. Phytopathology 15:607-610

Eggertson Q (2012) Resolving the Pythium ultimum species complex. Dissertation, Carleton University. https://curve.carleton.ca/system/ files/theses/28596.pdf

Elliott ME (1964) Self-fertility in Botryotinia porri. Can J Bot 42:1393-1395

Ellis MB (1971) Dematiaceous hyphomycetes. Commonw Mycol Inst, Kew, pp 400-460

Ellis JJ (1985) Species and the varieties in the Rhizopus arrhizusRhizopus oryzae group as indicated by their DNA complementarity. Mycologia 77(2):243-247

El-Sayed H, El-Sajed Z (2013) First report of pod blight of okra caused by Choanephora cucurbitarum in Egypt. J Agric Technol 9(1): $135-140$

EPPO (2014) European and Mediterranean Plant Protection Organisation database on quarantine pests http://www.eppo.int/DATABASES/ databases.htm

Erwin DC, Ribeiro OK (1996) Phytophthora diseases. Worldwide APS Press, St. Paul

Espinoza JG, Briceno EX, Keith LM, Latorre BA (2008) Canker and twig dieback of blueberry caused by Pestalotiopsis spp. and a Truncatella sp. in Chile. Plant Dis 92:1407-1414

Esterio M, Muñoz G, Ramos C, Cofré G, Estévez R, Salinas A, Auger J (2011) Characterization of Botrytis cinerea isolates present in Thompson seedless table grapes in the Central Valley of Chile. Plant Dis 95:683-690

Evidente A, Cimmino A, Andolfi A, Vurro M, Zonno MC, Motta A (2008a) Phyllostoxin and phyllostin, bioactive metabolites produced by Phyllosticta cirsii, a potential mycoherbicide for Cirsium arvense biocontrol. J Agric Food Chem 56(3):884-888

Evidente A, Cimmino A, Andolfi A, Vurro M, Zonno MC, Cantrell CL, Motta A (2008b) Phyllostictines A-D, oxazatricycloalkenones produced by Phyllosticta cirsii, a potential mycoherbicide for Cirsium arvense biocontrol. Tetrahedron 64(8):1612-1619

Fahleson J, Hu Q, Dixelius C (2004) Phylogenetic analysis of Verticillium species based on nuclear and mitochondrial sequences. Arch Microbiol 181:435-442

Faretra F, Antonacci E (1987) Production of apothecia of Botryotinia fuckeliana (de Bary) Whetz. under controlled environmental conditions. Phytopathol Mediterr 26:29-35

Faretra F, Antonacci E, Pollastro S (1988) Sexual behaviour and mating system of Botryotinia fuckeliana, teleomorph of Botrytis cinerea. J Gen Microbiol 134:2543-2550
Farr DF, Rossman AY (2014) Fungal databases systematic mycology and microbiology laboratory, ARS, USDA. http://nt.ars-grin.gov/ fungaldatabases/

Farr DF, Castlebury LA, Rossman AY, Putnam ML (2002a) A new species of Phomopsis causing twig dieback of Vaccinium vitis-idaea (lingonberry). Mycol Res 106:745-752

Farr DF, Castlebury LA, Rossman AY (2002b) Morphological and molecular characterization of Phomopsis vaccinii and additional isolates of Phomopsis from blueberry and cranberry in the eastern United States. Mycologia 94:494-504

Feau N, Vialle A, Allaire M, Maier W, Hamelin RC (2011) DNA barcoding in the rust genus Chrysomyxa and its implications for the phylogeny of the genus. Mycologia 103(6):1250-1266. doi:10. 3852/10-426

Fisher MC, Henk DA, Briggs CJ, Brownstein JS, Madoff LC, McCraw SL, Gurr SJ (2012) Emerging fungal threats to animal, plant and ecosystem health. Nature 484:186-194

Förster H, Cummings MP, Coffey MD (2000) Phylogenetic relationships of Phytophthora species based on ribosomal ITS I DNA sequence analysis with emphasis on Waterhouse groups V and VI. Mycol Res 104:1055-1061

Fournier E, Giraud T (2008) Sympatric genetic differentiation of a generalist pathogenic fungus, Botrytis cinerea, on two different host plants, grapevine and bramble. J Evol Biol 21:122-132

Fournier E, Giraud T, Albertini C, Brygoo Y (2005) Partition of the Botrytis cinerea complex in France using multiple gene genealogies. Mycologia 97:1251-1267

Freeman S, Minz D, Jurkevitch E, Maymon M, Shabi E (2000) Molecular analyses of Colletotrichum species from almond and other fruits. Phytopathology 90:608-614

Fresenius G (1850) Beiträge zur Mykologie 1. Heinrich Ludwig Brömmer Verlag, Frankfurt, p 38

Fries E (1821) Systema mycologicum : sistens fungorum ordines, genera et species, huc usque cognitas, quas ad normam methodi naturalis determinavit

Fries EM (1849) Summa vegetabilium Scandinaviae, pp 1-572

Fujihara N, Sakaguchi A, Tanaka S, Fujii S, Tsuji G, Shiraishi T, O'Connell R, Kubo Y (2010) Peroxisome biogenesis factor PEX13 is required for appressorium-mediated plant infection by the anthracnose fungus Colletotrichum orbiculare. Mol PlantMicrobe Interact 23:436-445

Fukumori Y, Nakajima M, Akutsu K (2004) Microconidia act the role as spermatia in the sexual reproduction of Botrytis cinerea. J Gen Plant Pathol 70:256-260

Gallegly M, Hong C (2008) Phytophthora. Identifying species by morphology and DNA fingerprints. APS Press, St. Paul

Gams W, Zare R, Summerbell RC (2005) (1654) Proposal to conserve the generic name Verticillium (anamorphic Ascomycetes) with a conserved type. Taxon 54(1):179

García PE, Schönswetter P, Aguilar JF, Feliner GN, Schneeweiss GM (2009) Five molecular markers reveal extensive morphologicalhomoplasy and reticulate evolution in the Malva alliance(Malvaceae). Mol Phylogenet Evol 50:226239

Garcia-Reyne A, Lopez-Medrano F, Morales JM, Garcia Esteban C, Martin I, Erana I, Meije Y, Lalueza A, Alastruey-Izquierdo A, Rodriguez-Tudela JL, Aguado JM (2011) Cutaneous infection by Phomopsis longicolla in a renal transplant recipient from Guinea: first report of human infection by this fungus. Transpl Infect Dis 13: 204-207

Gardes M, Bruns TD (1993) ITS primers with enhanced specificity of basidiomycetes: application to the identification of mycorrhizae and rusts. Mol Ecol 2:113-118

Garzón CD, Yánez JM, Moorman GW (2007) Pythium cryptoirregulare, a new species within the P. irregulare complex. Mycologia 99(2): 291-301. doi:10.3852/mycol ogia.99.2.291 
Geiser DM, Jimenez-Gasco M, Kang S, Makalowska I, Veeraraghavan N, Ward TJ, Zhang N, Kuldau GA, O’Donnell K (2004) FUSARIUM-ID v. 1.0: A DNA sequence database for identifying Fusarium. Eur J Plant Pathol 110:473-479

Geiser DM, Aoki T, Bacon CW, Baker SE, Bhattacharyya MK, Brandt ME, Brown DW, Burgess LW, Chulze S, Coleman JJ, Correll JC, Covert SF, Crous PW, Cuomo CA, De Hoog GS, Di Pietro A, Elmer WH, Epstein L, Frandsen RJN, Freeman S, Gagkaeva T, Glenn AE, Gordon TR, Gregory NF, Hammond-Kosack KE, Hanson LE, del Mar Jímenez-Gasco M, Kang S, Kistler HC, Kuldau GA, Leslie JF, Logrieco A, Lu G, Lysøe E, Ma L-J, McCormick SP, Migheli Q, Moretti A, Munaut F, O’Donnell K, Pfenning L, Ploetz RC, Proctor RH, Rehner SA, Robert VARG, Rooney AP, Bin Salleh B, Scandiani MM, Scauflaire J, Short DPG, Steenkamp E, Suga H, Summerell BA, Sutton DA, Thrane U, Trail F, Van Diepeningen A, VanEtten HD, Viljoen A, Waalwijk C, Ward TJ, Wingfield MJ, Xu J-R, Yang X-B, Yli-Mattila T, Zhang N (2013) One fungus, one name: defining the genus Fusarium in a scientifically robust way that preserves longstanding use. Phytopathology 103:400-408

Ghimire SR, Charlton ND, Bell JD, Krishnamurthy YL, Craven KD (2011) Biodiversity of fungal endophyte communities inhabiting switchgrass (Panicum virgatum L.) growing in the native tallgrass prairie of northern Oklahoma. Fungal Divers 47:19-27

Giaretta DR, Bogo A, Coleho CMM, Guidolin AF, Dantas ACM, Gomes EA (2010) ITS-rDNA phylogeny of Colletotrichum spp. causal agent of apple Glomerella leaf spot. Ciência Rural, Santa Maria 40:806-812

Ginting C, Zehr EI, Westcott SW III (1996) Inoculum sources and characterization of isolates of Gilbertella persicaria from peach fruit in South Carolina. Plant Dis 80:1129-1134

Giraud T, Fortini D, Levis C, Leroux P, Brygoo Y (1997) RFLP markers show genetic recombination in Botryotinia fuckeliana (Botrytis cinerea) and transposable elements reveal two sympatric species. Mol Biol Evol 14:1177-1185

Giraud T, Fortini D, Levis C, Lamarque C, Leroux P, LoBuglio K, Brygoo Y (1999) Two sibling species of the Botrytis cinerea complex, transposa and vacuma, are found in sympatry on numerous host plants. Phytopathology 89:967-973

Glass NL, Donaldson GC (1995) Development of primer sets designed for use with the PCR to amplify conserved genes from filamentous ascomycetes. Appl Environ Microbiol 61:1323-1330

Glienke C, Pereira O, Stringari D, Fabris J, Kava-Cordeiro V, Galli-Terasawa L, Cunnington J, Shivas RG, Groenewald JZ, Crous PW (2011) Endophytic and pathogenic Phyllosticta species, with reference to those associated with Citrus Black Spot. Persoonia 26(1):47-56

Glynn NC, Dixon LJ, Castlebury LA, Szabo LJ, Comstock JC (2010) PCR assays for the sugarcane rust pathogens Puccinia kuehnii and P. melanocephala and detection of a SNP associated with geographical distribution in P. kuehnii. Plant Pathol 59(4):703-711. doi:10. 1111/j.1365-3059.2010.02299.x

Goh KT, Hyde KD, Lee KLD (1998) Generic distinction in Helminthosporium complex based on restriction analysis of the nuclear ribosomal RNA gene. Fungal Divers 1:85-107

Gomes RR, Glienke C, Videira SIR, Lombard L, Groenewald JZ, Crous PW (2013) Diaporthe: a genus of endophytic, saprobic and plant pathogenic fungi. Persoonia $31: 1-41$

González V, Tello ML (2011) The endophytic mycota associated with Vitis vinifera in central Spain. Fungal Divers 47:29-42

Goss EM, Cardenas MC, Myers K, Forbes GA, Fry WE, Restrepo S, Grunwald NJ (2011) The plant pathogen Phytophthora andina emerged via hybridization of an unknown Phytohthora species and the Irish potato famine pathogen, $P$. infestans. PLoS One 6: e24543

Goud JC, Termorshuizen J, Gams W (2003) Morphology of Verticillium dahliae and V. tricorpus on semi-selective media used for the detection of $V$. dahliae in soil. Mycol Res 107: $822-830$

Gräfenhan T, Schroers H-J, Nirenberg HI, Seifert KA (2011) An overview of the taxonomy, phylogeny and typification of nectriaceous fungi in Cosmospora, Acremonium, Fusarium, Stilbella and Volutella. Stud Mycol 68:79-113

Grant-Downton RT, Terhem RB, Kapralov MV, Mehdi S, RodriguezEnriquez MJ, Gurr SJ, van Kan JAL, Dewey FM (2014) A novel Botrytis species is associated with a newly emergent foliar disease in cultivated Hemerocallis. PLoS One 9(6):e89272. doi:10.1371/ journal.pone. 0089272

Groves JW, Loveland CA (1953) The connection between Botryotinia fuckeliana and Botrytis cinerea. Mycologia 45:415-425

Grünwald NJ, Martin FN, Larsen MM, Sullivan CM, Press CM, Coffey MD, Hansen EM, Parke JL (2011) Phytophthora-ID.org: a sequence-based Phytophthora identification tool. Plant Dis 95: 337-342

Gryganskyi AP, Lee SC, Litvintseva AP, Smith ME, Bonito G, Porter TM, Anishchenko IM, Heitman J, Vilgalys R (2010) Structure, function, and phylogeny of the mating locus in the Rhizopus oryzae complex. PLoS ONE 5:e15273

Guba EF (1961) Monograph of Pestalotia and Monochaetia. Harvard University Press, Cambridge

Guerber JC, Liu B, Correll JC, Johnston PR (2003) Characterization of diversity in Colletotrichum acutatum sensu lato by sequence analysis of two gene introns, mtDNA and intron RFLPs, and mating compatibility. Mycologia 95:872-895

Guindon S, Dufayard JF, Lefort V, Anisimova M, Hordijk W, Gascuel O (2010) New algorithms and methods to estimate maximumlikelihood phylogenies: assessing the performance of PhyML 3.0. Syst Biol 59:307-321

Gunjan S, Navinder K, Weir BS, Hyde KD, Shenoy BD (2013) Apmat gene can resolve Colletotrichum species: a case study with Mangifera indica. Fungal Divers 61:117-138. doi:10.1007/ s13225-013-0247-4

Guo LW, Wu XY, Mao ZC, Ho HH, He YQ (2012) Storage rot of dragon fruit caused by Gilbertella persicaria. Plant Dis 96(12):1826

Gupta S, Loughman R (2001) Current virulence of Pyrenophora teres on barley in Western Australia. Plant Dis 85(9):960-966

Gure A, Slippers B, Stenlid J (2005) Seed-borne Botryosphaeria spp. from native Prunus and Podocarpus trees in Ethiopia, with a description of the anamorph Diplodia rosulata sp. nov. Mycol Res 109:1005-1014

Hansen EM, Wilcox WF, Reeser PW, Sutton W (2009) Phytophthora rosacearum and $P$. sansomeana, new species segregated from the Phytophthora megasperma "complex". Mycologia 101:129135

Hantsch L, Braun U, Haase J, Purschke O, Scherer-Lorenzen M, Bruelheide H (2014) No plant functional diversity effects on foliar fungal pathogens in experimental tree communities. Fungal Divers. doi:10.1007/s13225-013-0273-2

Hawksworth DL, Kirk PM, Sutton BC, Pegler DN (1995) Ainsworth \& Bisby's dictionary of the fungi, 5th edn. Wallingford, CAB International

Henkel TW (2005) Parakari, an indigenous fermented beverage using amylolytic Rhizopus in Guyana. Mycologia 97:1-11

Hennebert G, Groves J (1963) Three new species of Botryotinia on Ranunculaceae. Can J Bot 41:341-370

Hennen JF, Hennen MMW (2000) Terminology applied to sori and life cycles of rust fungi (Uredinales) from 1729 to 2000. Palestra 62(1): $113-126$

Hermet A, Méheust D, Mounier J, Barbier G, Jany JL (2012) Molecular systematics within the genus Mucor with special regard to species encountered in cheese. Fungal Biol 116:692-705

Hesseltine CW (1953) A revision of the Choanephoraceae. Am Midl Nat 50(1):248-256 
Hesseltine CW (1960) Gilbertella gen. nov. (Mucorales). Bull Torrey Bot Club 87:21-30

Heyman F, Blair JE, Persson L, Wikstrom M (2013) Root rot of pea and faba beans in Southern Swenden caused by Phytophthora pisi sp. nov. Plant Dis 97(4):461-472

Hibbett DS, Binder M, Bischoff JF, Blackwell M, Cannon PF, Eriksson OE, Huhndorf S, James T, Kirk PM, Lücking R, Thorsten Lumbsch H, Lutzoni F, Matheny PB, Mclaughlin DJ, Powell MJ, Redhead S, Schoch CL, Spatafora JW, Stalpers JA, Vilgalys R, Aime MC, Aptroot A, Bauer R, Begerow D, Benny GL, Castlebury LA, Crous PW, Dai YC, Gams W, Geiser DM, Griffith GW, Gueidan C, Hawksworth DL, Hestmark G, Hosaka K, Humber RA, Hyde KD, Ironside JE, Kõljalg U, Kurtzman CP, Larsson KH, Lichtwardt R, Longcore J, Miadlikowska J, Miller A, Moncalvo JM, Mozley-Standridge S, Oberwinkler F, Parmasto E, Reeb V, Rogers JD, Roux C, Ryvarden L, Sampaio JP, Schüßler A, Sugiyama J, Thorn RG, Tibell L, Untereiner WA, Walker C, Wang Z, Weir A, Weiss M, White MM, Winka K, Yao YJ, Zhang N (2007) A higher-level phylogenetic classification of the fungi. Mycol Res 111:509-547

Hiratsuka Y (1973) The nuclear cycle and the terminology of spore states in Uredinales. Mycologia 65(2):432-443. doi:10.2307/3758114

Hoffmann K, Pawłowska J, Walther G, Wrzosek M, de Hoog GS, Benny GL, Kirk PM, Voigt K (2013) The family structure of the Mucorales: a synoptic revision based on comprehensive multigene-genealogies. Persoonia 30:57-76

Hofstetter V, Buyck B, Croll D, Viret O, Couloux A, Gindro K (2012) What if esca disease of grapevine were not a fungal disease? Fungal Divers 54:51-67. doi:10.1007/s13225-012-0171-z

Holst-Jensen A, Vaage M, Schumacher T (1998) An approximation to the phylogeny of Sclerotinia and related genera. Nord J Bot 18:705-719

Hu HL, Jeewon R, Zhou DQ, Zhou TX, Hyde KD (2007) Phylogenetic diversity of endophytic Pestalotiopsis species in Pinus armandii and Ribes spp.: evidence from rDNA and $\beta$ - tubulin gene phylogenies. Fungal Divers 24:1-22

Huang WY, Cai YZ, Hyde KD, Corke H, Sun M (2008) Biodiversity of endophytic fungi associated with 29 traditional Chinese medicinal plants. Fungal Divers 33:61-75

Huang J-H, Chen C-Y, Lin Y-S, Ann P-J, Huang H-C, Chung W-H (2013a) Six new species of Pythiogeton in Taiwan, with an account of the molecular phylogeny of this genus. Mycoscience 54(2):130 147. doi:10.1016/j.myc.2012.09.007

Huang F, Chen GQ, Hou X, Fu YS, Cai L, Hyde KD, Li HY (2013b) Colletotrichum species associated with cultivated citrus in China. Fungal Divers 61:61-74

Hüberli D, St J, Hardy GE, White D, Williams N, Burgess TI (2013) Fishing for Phytophthora from Western Australia's waterways: a distribution and diversity survey. Australas Plant Pathol 42:251-260

Hudspeth DSS, Nadler SA, Hudspeth MES (2000) A COX2 molecular phylogeny of the Peronosporomycetes. Mycologia 92:674-684

Huelsenbeck JP, Ronquist F (2001) MRBAYES: Bayesian inference of phylogenetic trees. Bioinformatics 17:754-755

Hulvey J, Telle S, Nigrelli L, Lamour K, Thines M (2010) Salisapiliaceae - a new family of oomycetes from marsh grass litter of southeastern north America. Persoonia 25:109

Hurtado-Gonzales OP, Aragon-Caballero LM, Flores-Torres JG, Man W, Lamour KH (2009) Molecular comparison of natural hybrids of Phytophthora nicotianae and P. cactorum infecting loquat trees in Peru and Taiwan. Mycologia 101:496-502

Huser A, Takahara H, Schmalenbach W, O'Connell R (2009) Discovery of pathogenicity genes in the crucifer anthracnose fungus, Colletotrichum higginsianum, using random insertional mutagenesis. Mol Plant-Microbe Interact 22:143-156

Hyde KD (1995) Fungi from palms. XX. The genus Guignardia. Sydowia 47:180-198
Hyde KD, Cai L, McKenzie EHC, Yang YL, Zhang JZ, Prihastuti H (2009a) Colletotrichum: a catalogue of confusion. Fungal Divers 39:1-17

Hyde KD, Cai L, Cannon PF, Crouch JA, Crous PW, Damm U, Goodwin PH, Chen H, Johnston PR, Jones EBG, Liu ZY, McKenzie EHC, Moriwaki J, Noireung P, Pennycook SR, Pfenning LH, Prihastuti H, Sato T, Shivas RG, Tan YP, Taylor PWJ, Weir BS, Yang YL, Zhang JZ (2009b) Colletotrichum - names in current use. Fungal Divers 39:147-182

Hyde KD, Abd-Elsalam K, Cai L (2010) Morphology: still essential in a molecular world. Mycotaxon 114(1):439-451

Hyde KD, McKenzie EHC, KoKo TW (2011) Towards incorporating anamorphic fungi in a natural classification-checklist and notes for 2010. Mycosphere 2(1):1-88

Hyde KD, Udayanga D, Manamgoda DS, Tedersoo L, Larsson E, Abarenkov K, Bertrand YJK, Oxelman B, Hartmann M, Kauserud H, Ryberg M, Kristiansson E, Nilsson RH (2013a) Incorporating molecular data in fungal systematics: a guide for aspiring researchers. Curr Res Environ Appl Mycol 3:1-32

Hyde KD, Jones EBG, Liu JK, Ariyawansa H, Boehm E, Boonmee S, Braun U, Chomnunti P, Crous PW, Dai DQ, Diederich P, Dissanayake A, Doilom M, Doveri F, Hongsanan S, Jayawardena R, Lawrey JD, Li YM, Liu YX, Lücking R, Monkai J, Muggia L, Nelsen MP, Pang KL, Phookamsak R, Senanayake I, Shearer CA, Suetrong S, Tanaka K, Thambugala KM, Wijayawardene NN, Wikee S, Wu HX, Zhang Y, Aguirre-Hudson B, Alias SA, Aptroot A, Bahkali AH, Bezerra JL, Bhat DJ, Camporesi E, Chukeatirote E, Gueidan C, Hawksworth DL, Hirayama K, Hoog SD, Kang JC, Knudsen K, Li WJ, Li XH, Liu ZY, Mapook A, McKenzie EHC, Miller AN, Mortimer PE, Phillips AJL, Raja HA, Scheuer C, Schumm F, Taylor JE, Tian Q, Tibpromma S, Wanasinghe DN, Wang Y, Xu JC, Yan JY, Yacharoen S, Zhang M (2013b) Families of Dothideomycetes. Fungal Divers 63:1-313. doi:10.1007/s13225013-0263-4

Inderbitzin P, Bostock RM, Davis RM, Usami T, Platt HW, Subbarao KV (2011a) Phylogenetics and taxonomy of the fungal vascular wilt pathogen Verticillium, with the descriptions of five new species. PLoS ONE 6:e28341

Inderbitzin P, Davis RM, Bostock RM, Subbarao KV (2011b) The ascomycete Verticillium longisporum is a hybrid and a plant pathogen with an expanded host range. PLoS ONE 6(3):e18260

Index Fungorum (2014) http://www.indexfungorum.org/names/names. asp, Accession Date- January-March 2014

Isaac I (1949) A comparative study of pathogenic isolates of Verticillium. Trans Br Mycol Soc 32:137-156

Isaka M, Jaturapat A, Rukseree K, Danwisetkanjana K, Tanticharoen M, Thebtaranonth Y (2001) Phomoxanthones A and B, novel xanthone dimers from the endophytic fungus Phomopsis species. J Nat Prod 64:1015-1018

Iwama T (2006) Mucor Rot of Long Chinese Yam (Dioscorea batatas) caused by Mucor piriformis. Annu Rep Plant Protect N Jpn $57: 33-37$

Jacobs K, Botha A (2008) Mucor renisporus sp. nov., a new coprophilous species from Southern Africa. Fungal Divers 29:27-35

Jacobs K, Rehner S (1998) Comparison of cultural and morphological characters and ITS sequences in anamorphs of Botryosphaeria and related taxa. Mycologia 90:601-610

Jacobs A, Van Wyk PS, Marasas WFO, Wingfield BD, Wingfield MJ, Coutinho TA (2010) Fusarium ananatum sp. nov. in the Gibberella fujikuroi species complex from pineapples with fruit rot in South Africa. Fungal Biol 114:515-527

Jaczewski AA, Jaczewski PA (1931) Opredelitel'gribov. Sovershennye Griby (diploidnye stadii). Tom I Fikomitsety 3rd edn. Sel'kolkhozgiz, Moskva-Leningrad [In Russian]

Jami F, Slippers B, Wingfield MJ, Gryzenhout M (2012) Five new species of the Botryosphaeriaceae from Acacia karroo in South Africa. Cryptog Mycolog 33:245-266 
Jarvis WR (1977) Botryotinia and Botrytis species: taxonomy, physiology and pathogenicity: a guide to the literature. Monograph 15, Research Branch, Can Depart Agric

Jeewon R, Liew ECY, Hyde KD (2004) Phylogenetic evaluation of species nomenclature of Pestalotiopsis in relation to host association. Fungal Divers 17:39-55

Johnson GI (2008) Status of Mango Postharvest Disease Management R \& D: options and solutions for the Australian mango industry. Hortic Aus Final Rep proj MG08017, Hortic 4 Develop, Canberra, 130 p

Johnston PR, Hoksbergen K, Park D, Beever RE (2013) Genetic diversity of Botrytis in New Zealand vineyards and the significance of its seasonal and regional variation. Plant Pathol:n/a-n/a. doi:10.1111/ ppa. 12143

Jung T, Burgess TI, Huberli D, Hardy GESJ (2011a) Phytophthora fuliavis. Fungal Planet 87:147

Jung T, Stukely MJC, Hardy GESJ, White D, Paap T, Dunstan WA, Burgess TI (2011b) Multiple new Phytophthora species from ITS clade 6 associated with natural ecosystems in Australia: evolutionary and ecological implications. Persoonia 26:13-39

Kagiwada S, Kayano Y, Hoshi H, Kawanishi T, Oshima K, Hamamoto H, Horie H, Namba S (2010) First report of Choanephora rot of ice plant (Mesembryanthemum crystallinum) caused by Choanephora cucurbitarum in Japan. J Gen Plant Pathol 76:345-347

Kamper J, Kahmann R, Bolker M, Ma LJ, Brefort T, Saville BJ, Banuett F, Kronstad JW, Gold SE, Muller O, Perlin MH, Wosten HAB, de Vries R, Ruiz-Herrera J, Reynaga-Pena CG, Snetselaar K, McCann M, Perez-Martin J, Feldbrugge M, Basse CW, Steinberg G, Ibeas JI, Holloman W, Guzman P, Farman M, Stajich JE, Sentandreu R, Gonzalez-Prieto JM, Kennell JC, Molina L, Schirawski J, Mendoza-Mendoza A, Greilinger D, Munch K, Rossel N, Scherer M, Vranes M, Ladendorf O, Vincon V, Fuchs U, Sandrock B, Meng S, Ho ECH, Cahill MJ, Boyce KJ, Klose J, Klosterman SJ, Deelstra HJ, Ortiz-Castellanos L, Li WX, Sanchez-Alonso P, Schreier PH, Hauser-Hahn I, Vaupel M, Koopmann E, Friedrich G, Voss H, Schluter T, Margolis J, Platt D, Swimmer C, Gnirke A, Chen F, Vysotskaia V, Mannhaupt G, Guldener U, Munsterkotter M, Haase D, Oesterheld M, Mewes HW, Mauceli EW, DeCaprio D, Wade CM, Butler J, Young S, Jaffe DB, Calvo S, Nusbaum C, Galagan J, Birren BW (2006) Insights from the genome of the biotrophic fungal plant pathogen Ustilago maydis. Nature 444(7115):97-101

Kang JC, Kong RYC, Hyde KD (1998) Studies on the Amphisphaeriales I. Amphisphaeriaceae (sensu stricto) and its phylogenetic relationships inferred from 5.8 S rDNA and ITS2 sequences. Fungal Divers 1:147-157

Kang S, Mansfield MA, Park B, Geiser DM, Ivors KL, Coffey MD, Grunwald NJ, Martin FN, Lévesque CA, Blair JE (2010) The promise and pitfalls of sequence-based identification of plantpathogenic fungi and oomycetes. Phytopathology 100:732-737

Karapapa VK, Bainbridge BW, Heale JB (1997) Morphological and molecular characterization of Verticillium longisporum comb. nov., pathogenic to oilseed rape. Mycol Res 101:1281-1294

Katoh K, Misawa K, Kuma K, Miyata T (2002) MAFFT: a novel method for rapid multiple sequence alignment based on fast Fourier transform. Nucleic Acids Res 30(14):3059-3066. doi:10.1093/nar/ gkf436

Kaul S, Gupta S, Ahmed M, Dhar MK (2012) Endophytic fungi from medicinal plants: a treasure hunt for bioactive metabolites. Phytochem Rev 11(4):487-505

Kellner R, Vollmeister E, Feldbrügge M, Begerow D (2011) Interspecific sex in grass smuts and the genetic diversity of their pheromonereceptor system. PLoS Genet 7(12):e1002436. doi:10.1371/journal. pgen. 1002436

Kerssies A, Bosker-van Zessen AI, Wagemakers CAM, van Kan JAL (1997) Variation in pathogenicity and DNA polymorphism among Botrytis cinerea isolates sampled inside and outside a glasshouse. Plant Dis 81(7):781-786. doi:10.1094/pdis.1997. 81.7.781
Khan MI, Marroni V, Keenan S, Scott IW, Viljanen-Rollinson SH, Bulman S (2013) Enhanced molecular identification of Botrytis spp. from New Zealand onions. Eur J Plant Pathol 136(3):495507. doi:10.1007/s10658-013-0182-y

Kingsland GC (1991) Spot lesion of barley net blotch disease caused by Drechslera teres f. sp. maculata observed in South Carolina. Plant Dis 75:537

Kirk PM (1984) A monograph of the Choanephoraceae. Mycol Pap 152: $1-6$

Kirk PM, Cannon PF, Minter DW, Stalpers JA (2008) Ainsworth and Bisby's dictionary of the fungi, 10th edn. CAB International, Wallingford

Kirk PM, Stalpers JA, Braun U, Crous PW, Hansen K, Hawksworth DL, Hyde KD, Lücking R, Lumbsch TH, Rossman AY, Seifert KA, Stadler M (2013) A without-prejudice list of generic names of fungi for protection under the International Code of Nomenclature for algae, fungi and plants. IMA Fungus 4:381-443

Ko TWK, Stephenson SL, Bahkali AH, Hyde KD (2011) From morphology to molecular biology: can we use sequence data to identify fungal endophytes? Fungal Divers 50:113-120

Kohlmeyer J, Kohlmeyer VB (2001) Fungi on Juncus roemerianus 16. More new coelomycetes, including Tetranacriella gen. nov. Bot Mar 44:147-156

Kõljalg U, Nilsson RH, Abarenkov K, Tedersoo L, Taylor AFS, Bahram M, Bates ST, Bruns TT, Bengtsson-Palme J, Callaghan TM, Douglas B, Drenkhan T, Eberhardt U, Dueñas M, Grebenc T, Griffith GW, Hartmann M, Kirk PM, Kohout P, Larsson E, Lindahl BD, Lücking R, Martín MP, Matheny PB, Nguyen NH, Niskanen T, Oja J, Peay KG, Peintner U, Peterson M, Põldmaa K, Saag L, Saar I, Schüßler A, Senés C, Smith ME, Suija A, Taylor DE, Telleria MT, Weiß M, Larsson KH (2013) Towards a unified paradigm for sequence-based identification of fungi. Mol Ecol 22:5271-5277

Komatsu T, Sumino A, Kageyama K (2001) Characterization of Verticillium dahliae isolates from potato on Hokkaido by Random Amplified Polymorphic DNA (RAPD) and REP-PCR analyses. J Gen Plant Pathol 67:23-27

Kroon LPNM, Bakker FT, Van Den Bosch GBM, Bonants PJM, Flier WG (2004) Phylogenetic analysis of Phytophthora species based on mitochondrial and nuclear DNA sequences. Fungal Genet Biol 41: 766-782

Kroon LPNM, Brouwer H, de Cock AWAM, Govers F (2012) The genus Phytophthora anno. Phytopathology 102:348-364

Kucharek T, Simone G (1983) Wet rot of vegetable crops. University of Florida, Gainesville

Kunimoto RK, Ito PJ, Ko WH (1977) Mucor rot of guava fruits by Mucor hiemalis. Trop Agric (Trinidad) 54:185-187

Kwon J-H, Hong S-B (2005) Soft rot of tomato caused by Mucor racemosus in Korea. Mycobiology 33(4):240-242

Kwon J-H, Ahn G-H, Park C-S (2004) Fruit soft rot of sweet persimmon caused by Mucor piriformis in Korea. Mycobiology 32(2):98-101

Lamari L, Bernier CC (1989) Evaluation of wheat lines and cultivars to tan spot [Pyrenophora tritici-repentis] based on lesion type. Can J Plant Pathol 11(1):49-56

Langrell SRH, Glen M, Alfenas AC (2008) Molecular diagnosis of Puccinia psidii (guava rust) - a quarantine threat to Australian eucalypt and Myrtaceae biodiversity. Plant Pathol 57(4):687-701. doi: 10.1111/j.1365-3059.2008.01844.x

Laundon GF (1967) Terminology in the rust fungi. Trans Br Mycol Soc 50(2):189-194. doi:10.1016/S0007-1536(67)80029-9

Laurence MH, Summerell BA, Burgess LW, Liew ECY (2011) Fusarium burgessii sp. nov. representing a novel lineage in the genus Fusarium. Fungal Divers 49:101-112

Laurence MH, Burgess LW, Summerell BA, Liew ECY (2014) Genealogical concordance phylogenetic species recognition in the Fusarium oxysporum species complex. Fungal Biol 118: 374-384 
Laurie JD, Ali S, Linning R, Mannhaupt G, Wong P, Guldener U, Munsterkotter M, Moore R, Kahmann R, Bakkeren G, Schirawski J (2012) Genome comparison of barley and maize smut fungi reveals targeted loss of RNA silencing components and speciesspecific presence of TEs. Plant Cell 24:1733-1745

Lazzizera C, Frisullo S, Alves A, Lopes J, Phillips AJL (2008) Phylogeny and morphology of Diplodia species on olives in southern Italy and description of Diplodia olivarum. Fungal Divers 31:63-71

Lee DH, Mathur S, Neergaard P (1984) Detection and location of seed borne inoculum of Didymella bryoniae and its transmission in seedlings of cucumber and pumpkin. J Phytopathol 109(4):301-308

Leisova L, Kucera L, Minarikova V (2005) AFLP-based PCR markers that differentiate spot and net forms of Pyrenophora teres. Plant Pathol 54(1):66-73

Lenne JM (2002) Some major plant diseases. In: Waller JM, Lenne JM, Waller SJ (eds) Plant pathologist's pocketbook, 3rd edn. CABI, Wallingford, pp 4-18

Leroch M, Plesken C, Weber RWS, Kauff F, Scalliet G, Hahn M (2013) Gray mold populations in German strawberry fields are resistant to multiple fungicides and dominated by a novel clade closely related to Botrytis cinerea. Appl Environ Microbiol 79:159-167

Leslie JF, Summerell BA (2006) The Fusarium Laboratory Manual. Blackwell Publishing, Ames, p 388

Lévesque CA, de Cock AWAM (2004) Molecular phylogeny and taxonomy of the genus Pythium. Mycol Res 108(12):1363-1383. doi:10. 1017/S0953756204001431

Levis C, Fortini D, Brygoo Y (1997) Flipper, a mobile Fot1-like transposable element in Botrytis cinerea. Mol Gen Genet MGG 254(6): 674-680. doi:10.1007/s0043800 50465

Li S, Hartman GL, Boykin DL (2010a) Aggressiveness of Phomopsis longicolla and other Phomopsis spp. on soybean. Plant Dis 94: $1035-1040$

Li YY, Wang MZ, Huang YJ, Shen YM (2010b) Secondary metabolites from Phomopsis sp. A123. Mycology 1:254-261

Li CH, Cervantes M, Springer DJ, Boekhout T, Ruiz-Vazquez RM, Torres-Martinez SR, Heitman J, Lee SC (2011) Sporangiospore size dimorphism is linked to virulence of Mucor circinelloides. PLoS Pathog 7:e1002086

Li X, Kerrigan J, Chai W, Schnabel G (2012) Botrytis caroliniana, a new species isolated from blackberry in South Carolina. Mycologia 104(3):650-658. doi:10.3852/11-218

Lima NB, Vinicius de A Batista M, De Morais MA Jr, Barbosa MAG, Michereff SJ, Hyde KD, Câmara MPS (2013) Five Colletotrichum species are responsible for mango anthracnose in northeastern Brazil. Fungal Divers 61:75-88

Linaldeddu BT, Franceschini A, Alves A, Phillips AJL (2013) Diplodia quercivora sp. nov.: a new species of Diplodia found on declining Quercus canariensis trees in Tunisia. Mycologia 105:1266-1274

Line RF, Griffith CS (2001) Research on the epidemiology of stem rust of wheat during the cold war. In: Peterson PD (ed) Stem rust of wheat, from ancient enemy to modern foe. APS Press, St. Paul, pp 83-118

Link HF (1809) Observationes in ordines plantarum naturales. Dissertatio Magazin der Gesellschaft Naturforschenden Freunde Berlin 3

Liou GY, Chen GY, Wei YH, Lee FL, Fu HM, Yuan GF, Stalpers JA (2007) Polyphasic approach to the taxonomy of the Rhizopus stolonifer group. Mycol Res 111:196-203

Littlefield LJ, Marek SM, Tyrl RJ, Winkelman KS (2005) Morphological and molecular characterisation of Puccinia lagenophorae, now present in central North America. Ann Appl Biol 147(1):35-42. doi:10.1111/j.1744-7348.2005.00010.x

Liu XY, Huang H, Zheng RY (2007) Molecular phylogenetic relationships within Rhizopus based on combined analyses of ITS rDNA and pyrG gene sequences. Sydowia 59:235-253

Liu XY, Huang H, Zheng RY (2008) Delimitation of Rhizopus varieties based on IGS rDNA. Sydowia 60:93-112
Liu J, He L, Zhou G (2009a) Specific and rapid detection of Camellia oleifera anthracnose pathogen by nested-PCR. Afr J Biotechnol 8: 1056-1061

Liu K, Ding X, Deng B, Chen W (2009b) Isolation and characterization of endophytic taxol-producing fungi from Taxus chinensis. J Ind Microbiol Biotechnol 36:1171-1177

Liu AR, Chen SC, Wu SY, Xu T, Guo LD, Jeewon R, Wei JG (2010) Cultural studies coupled with DNA based sequence analyses and its implication on pigmentation as a phylogenetic marker in Pestalotiopsis taxonomy. Mol Phylogenet Evol 57:528-535

Liu F, Hyde KD, Cai L (2011a) Neotypification of Colletotrichum coccodes, the causal agent of potato black dot disease and tomato anthracnose. Mycology 2(4):248-254

Liu JK, Phookamsak R, Jones EBG, Zhang Y, Ko-Ko TW, Hu HL, Boonmee S, Doilom M, Chukeatirote E, Bahkali AH, Wang Y, Hyde KD (2011b) Astrosphaeriella is polyphyletic, with species in Fissuroma gen. nov., and Neoastrosphaeriella gen. nov. Fungal Divers 51:135-154

Liu JK, Phookamsak R, Doilom M, Wikee S, Li YM, Ariyawansa H, Boonmee S, Chomnunti P, Dai DQ, Bhat JD, Romero AI, Zhuang WY, Monkai J, Jones EBG, Chukeatirote E, Ko Ko TW, Zhao YC, Wang Y, Hyde KD (2012) Towards a natural classification of Botryosphaeriales. Fungal Divers 57:149-210

Liu F, Damm U, Cai L, Crous P (2013) Species of the Colletotrichum gloeosporioides complex associated with anthracnose diseases of Proteaceae. Fungal Divers 61:89-105

Loerakker W, Navarro B, Lobo M, Turkensteen L (1986) Phoma andina var. crystalliniformis var. nov., a new pathogen of tomato and potato in the Andes. Fitopatología 21(2):99-102

Lu XL, Najafzadeh MJ, Dolatabadi S, Ran YP, Gerrits van den Ende AHG, Shen YN, Li CY, Xi LY, Hao F, Zhang QQ, Li RY, Hu ZM, Lu GX, Wang JJ, Drogari-Apiranthitou M, Klaassen C, Meis JF, Hagen F, Liu WD, de Hoog GS (2013) Taxonomy and epidemiology of Mucor irregularis, agent of chronic cutaneous mucormycosis. Persoonia 30:48-56

Lumbsch HT, Huhndorf SM (2010) Myconet volume 14: part two. Notes on Ascomycete Systematics. Nos. 4751-5113. Fieldiana: Life Earth Sci NS 1:42-64

Luttrell ES (1963) Taxonomic criteria in Helminthosporium. Mycologia 55:643-674

Lynch SC, Eskalen A, Zambino PJ, Mayorquin JS, Wang DH (2013) Identification and pathogenicity of Botryosphaeriaceae species associated with coast live oak (Quercus agrifolia) decline in southern California. Mycologia 105:124-140

Madden AA, Stchigel AM, Guarro J, Sutton DA, Starks PT (2011) Mucor nidicola sp. nov., a novel fungal species isolated from an invasive paper wasp nest. Int J Syst Evol Microbiol 62:1710-1714. doi:10. 1099/ijs.0.033050-0

Maharachchikumbura SSN, Guo LD, Chukeatirote E, Bahkali AH, Hyde KD (2011) Pestalotiopsis-morphology, phylogeny, biochemistry and diversity. Fungal Divers 50:167-187

Maharachchikumbura SSN, Guo LD, Cai L, Chukeatirote E, Wu WP, Sun X, Crous PW, Bhat DJ, McKenzie EHC, Bahkali AH, Hyde KD (2012) A multi-locus backbone tree for Pestalotiopsis, with a polyphasic characterization of 14 new species. Fungal Divers 56:95-129

Maharachchikumbura SSN, Guo LD, Chukeatirote E, McKenzie EHC, Hyde KD (2013a) A destructive new disease of Syzygium samarangense in Thailand caused by the new species Pestalotiopsis samarangensis. Trop Plant Pathol 38(3):227-235

Maharachchikumbura SSN, Chukeatirote E, Guo LD, Crous PW, McKenzie EHC, Hyde KD (2013b) Pestalotiopsis species associated with Camellia sinensis (tea). Mycotaxon 123:47-61

Maharachchikumbura SSN, Guo LD, Chukeatirote E, Hyde KD (2013c) Improving the backbone tree for the genus Pestalotiopsis; addition of P. steyaertii and P. magna sp. nov. Mycol Prog. doi:10.1007/ s11557-013-0944-0 
Maier W, Begerow D, Weiß M, Oberwinkler F (2003) Phylogeny of the rust fungi: an approach using nuclear large subunit ribosomal DNA sequences. Can J Bot 81(1):12-23

Maier W, Wingfield BD, Mennicken M, Wingfield MJ (2007) Polyphyly and two emerging lineages in the rust genera Puccinia and Uromyces. Mycol Res 111:176-185. doi:10.1016/j.mycres.2006. 11.005

Man in 't Veld WA, Veenbaas-Rijks WJ, Ilieva E, De Cock AWAM, Bonants PJM, Pieters R (1998) Natural hybrids of Phytophthora nicotianae and Phytophthora cactorum demonstrated by isozyme analysis and random amplified polymorphic DNA. Phytopathology 88:922-929

Man in 't Veld WA, de Cock AWAM, Ilieva E, Lévesque CA (2002) Gene flow analysis of Phytophthora porri reveals a new species: Phytophthora brassicae sp. nov. Eur J Plant Pathol 108:51-62

Man in 't Veld WA, De Cock AWAM, Summerbell RC (2007) Natural hybrids of resident and introduced Phytophthora species proliferating on multiple new hosts. Eur J Plant Pathol 117:25-33

Man in 't Veld W, Rosendahl KCHM, Hong C (2012) Phytophthora $x$ serendipita $\mathrm{sp}$. nov. and $P$. $x$ pelgrandis, two destructive pathogens generated by natural hybridization. Mycologia 104: $1390-1396$

Manamgoda DS, Cai L, Bahkali AH, Chukeatirote E, Hyde KD (2011) Cochliobolus: an overview and current status of species. Fungal Divers 51:3-42

Manamgoda DS, Cai L, McKenzie EHC, Crous PW, Madrid H (2012a) A phylogenetic and taxonomic re-evaluation of the BipolarisCochliobolus-Curvularia complex. Fungal Divers 56:131-144

Manamgoda DS, Cai L, Chukeatirote E, Hyde KD (2012b) Two new Curvularia species from northern Thailand. Sydowia 64: 255-266

Manamgoda DS, Udayanga D, Cai L, Chukeatirote E, Hyde KD (2013) Endophytic Colletotrichum from tropical grasses with a new species C. endophytica. Fungal Divers 61:107-115

Marcelino J, Giordano R, Gouli S, Gouli V, Parker BL, Skinner M, TeBeest D, Cesnik R (2008) Colletotrichum acutatum var. fioriniae (teleomorph: Glomerella acutata var. fioriniae var. nov.) infection of a scale insect. Mycologia 100(3):353-374

Mari M, Cembali T, Casalini L, Pratella GC (2000) Mucor species in orchard soil-population dynamics and pathogenicity on pear fruit. Eur J Plant Pathol 106:449-454

Marincowitz S, Groenewald JZ, Wingfield MJ, Crous PW (2008) Species of Botryosphaeriaceae occurring on Proteaceae. Persoonia 21:111118

Marthey S, Aguileta G, Rodolphe F, Gendrault A, Giraud T, Fournier E, Lopez-Villavicencio M, Gautier A, Lebrun M-H, Chiapello H (2008) FUNYBASE: a FUNgal phYlogenomic dataBASE. BMC Bioinforma 9(1):456

Martin FN (2000) Phylogenetic relationships among some Pythium species inferred from sequence analysis of the mitochondrially encoded cytochrome oxidase II gene. Mycologia 92:711-727

Martin FN (2008) Mitochondrial haplotype determination in the oomycete plant pathogen Phytophthora ramorum. Curr Genet 54:23-34

Martin FN, Tooley PW (2003a) Phylogenetic relationships of Phytophthora ramorum, P. nemorosa and $P$. pseudosyringae, three species recovered from areas in California with sudden oak death. Mycol Res 107:1379-1391

Martin FN, Tooley PW (2003b) Phylogenetic relationships among Phytophthora species inferred from sequence analysis of mitochondrially encoded cytochrome oxidase I and II genes. Mycologia 95:269-284

Martin FN, Abad G, Balci Y, Ivors K (2012) Identification and detection of Phytophthora: Reviewing our progress, identifying our needs. Plant Dis 96:1080-1103
Martin FN, Blair JE, Coffey MD (2014) A combined mitochondrial and nuclear multilocus phylogeny of the genus Phytophthora. Fungal Genet Biol 64. doi:10.1016/j.fgb.2014.02.006

Martinez F, Blancard D, Lecomte P, Levis C, Dubos B, Fermaud M (2003) Phenotypic differences between vacuma and transposa subpopulations of Botrytis cinerea. Eur J Plant Pathol 109(5):479-488. doi:10.1023/a:1024222206991

Matsumoto C, Kageyama K, Suga H, Hyakumachi M (2000) Intraspecific DNA polymorphisms of Pythium irregulare. Mycol Res 104(11):1333-1341. doi:10.1017/S0953756200002744

Mattei AS, Severo CB, Guazzelli LS, Oliveira FM, Gené J, Guarro J, Cano J, Severo LC (2013) Cutaneous infection by Diaporthe phaseolorum in Brazil. Med Mycol Case Rep 1(4):2012-2014. doi:10.1016/j.mmcr.2013.03.001

Mazzola M, Andrews PK, Reganold JP, Lévesque CA (2002) Frequency, virulence, and metalaxyl sensitivity of Pythium spp. isolated from apple roots under conventional and organic production systems. Plant Dis 86(6):669-675. doi:10.1094/PDIS.2002. 86.6.669

McAlpine D (1906) The rusts of Australia: their structure, nature and classification. Government Printer, Melbourne

McKenzie SJ, Peres NA, Barquero MP, Arauz LF, Timmer LW (2009) Host range and genetic relatedness of Colletotrichum acutatum isolates from fruit crops and leatherleaf fern in Florida. Phytopathology 99:620-631

McLeod A, Botha WJ, Meitz JC, Spies CFJ, Tewoldemedhin YT, Mostert L (2009) Morphological and phylogenetic analyses of Pythium species in South Africa. Mycol Res 113(9):933-951. doi:10.1016/ j.mycres.2009.04.009

McManus PS (1998) First report of early rot of cranberry caused by Phyllosticta vaccinii in Wisconsin. Plant Dis 82(3):350

McMillan JRT (1972) Choanephora wet-rot of pole beans. Plant Dis Rep 56(11):967-968

McNeill J, Barrie FR, Buck WR, Demoulin V, Greuter W, Hawksworth DL, Herendeen PS, Knapp S, Marhold K, Prado J, Van Reine WFP, Smith GF, Wiersema JH, Turland NJ (2012) International Code of Nomenclature for algae, fungi, and plants (Melbourne Code). In: McNeill (ed) Regnum Vegetabile. Koeltz Scientific Books, Königstein, Volume 154, p 240

McTaggart AR, Shivas RG, Geering ADW, Callaghan B, Vánky K, Scharaschkin T (2012a) Soral synapomorphies are significant for the systematics of the Ustilago-Sporisorium-Macalpinomyces compex (Ustilaginaceae). Persoonia 29:63-77

McTaggart AR, Shivas RG, Geering ADW, Vánky K, Scharaschkin T (2012b) A review of the Ustilago-Sporisorium-Macalpinomyces complex. Persoonia 29:55-62

McTaggart AR, Shivas RG, Geering ADW, Vánky K, Scharaschkin T (2012c) Taxonomic revision of Ustilago, Sporisorium and Macalpinomyces. Persoonia 29:116-132

McTaggart AR, Geering ADW, Shivas RG (2014) The rusts on Goodeniaceae and Stylidiaceae. Mycol Prog 1-9

Mehrotra MD (1963a) Fruit rot of pear caused by Gilbertella persicaria var. indica. Sydowia 17:124-125

Mehrotra MD (1963b) Fruit rot of tomato caused by Gilbertella persicaria. Sydowia 17:17-19

Mehrotra MD (1966) Fruit rot of peach by Gilbertella persicaria var. indica from India. Mycopathol Mycol Appl 29:151-154

Meyer SE, Quinney D, Nelson DL, Weaver J (2007) Impact of the pathogen Pyrenophora semeniperda on Bromus tectorum seedbank dynamics in North American cold deserts. Weed Res 47(1):54-62

Michailides TJ (1991) Characterization and comparative studies of Mucor isolates from stone fruits from California and Chile. Plant Dis 75:373-380

Michailides TJ, Spotts RA (1986) Factors affecting dispersal of Mucor piriformis in pear orchard and into the packinghouse. Plant Dis 70: 1060-1063 
Michailides TJ, Spotts RA (1990a) Postharvest diseases of pome and stone fruits caused by Mucor piriformis in the Pacific Northwest and California. Plant Dis 74:537-543

Michailides TJ, Spotts RA (1990b) Transmission of Mucor piriformis to fruit of Prunus persica by Carpophilus spp. and Drosophila melanogaster. Plant Dis 74:287-291

Michailides TJ, Morgan DP, Spotts RA, Beglinger C, Odiet P-A (1992) Role of nitidulid beetles and vinegar flies in the sexual cycle of Mucor piriformis in tree fruit orchards. Mycologia 84(4):488-496

Milko AA, Beljakova LA (1970) The genus Choanephora Currey (Mucorales). Mikrobiologiya 38:894-902

Minnis D, McTaggart AR, Rossman A, Aime MC (2012) Taxonomy of mayapple rust: the genus Allodus resurrected. Mycologia 104(4): 942-950. doi:10.3852/11-350

Mohali S, Slippers B, Wingfield MJ (2007) Identification of Botryosphaeriaceae from Eucalyptus, Acacia and Pinus in Venezuela. Fungal Divers 25:103-125

Mokrani L, Jawhar M, Shoaib A, Arabi MIE (2012) Characterization of Pyrenophora graminea markers associated with a locus conferring virulence on barley. Plant Pathol 28(3):290-294

Moline HE, Kuti JO (1984) Comparative studies of two Mucor species causing postharvest decay in tomato and their control. Plant Dis 68(6):524-526

Moline HE, Millner PD (1981) Identification of Mucor mucedo as a postharvest pathogen of fresh market tomato. Phytopathology 71(8):895

Monden Y, Yamamoto S, Yamakawa R, Sunada A, Asari S, Makimura K, Inoue Y (2013) First case of fungal keratitis caused by Pestalotiopsis clavispora. Clin Ophthalmol 7:2261-2264

Montagne JFC (1834) Notice sur les plantes cryptogames récemment découvertes en France contenant aussi l'indication précis des localités de quelques espèces les plus rares de la flore française. Ann Sci Nat Bot Sér 2(1):295-307

Morin L, van der Merwe M, Hartley D, Müller P (2009) Putative natural hybrid between Puccinia lagenophorae and an unknown rust fungus on Senecio madagascariensis in KwaZulu-Natal, South Africa. Mycol Res 113(6-7):725-736. doi:10.1016/j.mycres.2009.02.008

Moriwaki J, Sato T, Tsukiboshi T (2003) Morphological and molecular characterization of Colletotrichum boninense sp. nov. from Japan. Mycoscience 44:47-53

Mostert L, Crous PW, Kang JC, Phillips AJL (2001) Species of Phomopsis and a Libertella sp. occurring on grapevines with specific reference to South Africa: morphological, cultural, molecular and pathological characterization. Mycologia 93:146-167

Mostowfizadeh-Ghalamfarsa R, Panabieres F, Banihashemi Z, Cooke DEL (2010) Phylogenetic relationship of Phytophthora cryptogea Pethybr. \& Laff and P. drechsleri Tucker. Fungal Biol 114:325-339

Motohashi K, Araki I, Nakashima C (2008) Four new species of Phyllosticta, one new species of Pseudocercospora, and one new combination in Passalora from Japan. Mycoscience 49(2):138-146

Moukhamedov R, Hu X, Nazar RN, Robb J (1994) Use of polymerase chain reaction-amplified ribosomal intergenic sequences for the diagnosis of Verticillium tricorpus. Phytopathology 84:256-259

Munkacsi AB, Stoxen S, May G (2007) Domestication of maize, sorghum, and sugarcane did not drive the divergence of their smut pathogens. Evolution 61(2):388-403

Muñoz G, Hinrichsen P, Brygoo Y, Giraud T (2002) Genetic characterisation of Botrytis cinerea populations in Chile. Mycol Res 106(5): 594-601. doi:10.1017/S0953756202005981

Murali TS, Suryanarayanan TS, Geeta R (2006) Endophytic Phomopsis species: host range and implications for diversity estimates. Can J Microbiol 52:673-680

MycoBank (2014) http://www.mycobank.org/Biolomics.aspx?Table= Mycobank\&Page $=200 \&$ ViewMode $=$ Basic, Accession DateMarch 2014
Myllys L, Stenroos S, Thell A (2002) New genes for phylogenetic studies of lichenized fungi: glyceraldehyde-3-phosphate dehydrogenase and beta-tubulin genes. Lichenologist 34:237-246

Nag Rag TR (1993) Coelomycetous anamorphs with appendage bearing conidia. Mycologue, Waterloo

Nagel JH, Gryzenhout M, Slippers B, Wingfield MJ, St J, Hardy GE, Stukely MJC, Burgess TI (2013) Characterization of Phytophthora hybrids from ITS clade 6 associated with riparian ecosystems in South Africa and Australia. Fungal Biol 117:329 347

Nazar RN, Hu X, Schmidt J, Culham D, Robb J (1991) Potential use of PCR-amplified ribosomal intergenic sequences in the detection and differentiation of verticillium wilt pathogens. Physiol Mol Plant Pathol 39:1-11

Nechwatal J, Bakonyi J, Cacciola SO, Cooke DEL, Jung T, Nagy ZÁ, Vannini A, Vettraino AM, Brasier CM (2012) The morphology, behaviour and molecular phylogeny of Phytophthora taxon Salixsoil and its redesignation as Phytophthora lacustris sp. nov. Plant Pathol 62(2):355-369

Nelson RR (1960a) Cochliobolus victoriae, the perfect stage of Helminthosporium victoriae. Phytopathology 50:774-775

Nelson RR (1960b) A correlationship of intraspecific fertility and conidial morphology in specis of Helminthosporium exhibiting bipolar germination. Mycologia 52:753-761

Nielsen K, Yohalem DS (2001) Origin of a polyploid Botrytis pathogen through interspecific hybridization between Botrytis aclada and B. byssoidea. Mycologia 93(6):1064-1071. doi:10.2307/3761668

Nilsson RH, Tedersoo L, Abarenkov K, Ryberg M, Kristiansson E, Hartmann M, Schoch CL, Nylander JAA, Bergsten J, Porter TM, Jumpponen A, Vaishampayan P, Ovaskainen O, Hallenberg N, Bengtsson J, Eriksson KM, Larsson K-H, Larsson E (2012) Five simple guidelines for establishing basic authenticity and reliability of newly generated fungal ITS sequences. MycoKeys 4:37-63

Nilsson RH, Hyde KD, Pawłowska J, Ryberg M, Tedersoo L, Aas AB, Alias SA, Alves A, Anderson CL, Antonelli A, Arnold AE, Bahnmann B, Bahram M, Bengtsson-Palme J, Berlin A, Branco S, Chomnunti P, Dissanayake A, Drenkhan R, Friberg H, Frøslev TG, Halwachs B, Hartmann M, Henricot B, Jayawardena R, Jumpponen A, Kauserud H, Koskela S, Kulik T, Liimatainen K, Lindahl BD, Lindner D, Liu J-K, Maharachchikumbura S, Manamgoda D, Martinsson S, Neves MA, Niskanen T, Nylinder S, Pereira OL, Pinho DB, Porter TM, Queloz V, Riit T, Sánchez-García M, Sousa FD, Stefańczyk E, Tadych M, Takamatsu S, Tian Q, Udayanga D, Unterseher M, Wang Z, Wikee S, Yan J, Larsson E, Larsson K-H, Kõljalg U, Abarenkov K (2014) Improving ITS sequence data for identification of plant pathogenic fungi. Fungal Divers, Online 14 May 2014. doi:10.1007/s13225-014-0291-8

Nirenberg HI (1995) Morphological differentiation of Fusarium sambucinum Fuckel sensu stricto, F. torulosum (Berk. \& Curt.) Nirenberg comb. nov. and $F$. venenatum Nirenberg sp. nov. Mycopathologia 129:131-141

Nirenberg HI, Gerlach WF, Grafenhan T (2009) Phytophthora $x$ pelgrandis, a new natural hybrid pathogenic to Pelargonium grandiflorum hort. Mycologia 101:220-231

Noordeloos M, De Gruyter J, Van Eijk G, Roeijmans H (1993) Production of dendritic crystals in pure cultures of Phoma and Ascochyta and its value as a taxonomic character relative to morphology, pathology and cultural characteristics. Mycol Res 97(11): $1343-1350$

Nout MJR, Aidoo KE (2010) Asian fungal fermented food. In: Hofrichter M (ed) Industrial applications. The Mycota, volume 10, 2nd edn. Springer, Berlin, Heidelberg, pp 30-58

O'Connell RJ, Thon MR, Hacquard S, Amyotte SG, Kleemann J, Torres MF, Damm U, Buiate EA, Epstein L, Alkan N, Altmueller J, Alvarado-Balderrama L, Bauser CA, Becker C, Birren BW, Chen Z, Choi J, Crouch JA, Duvick JP, Farman MA, Gan P, Heiman D, 
Henrissat B, Howard RJ, Kabbage M, Koch C, Kracher B, Kubo Y, Law AD, Lebrun M-H, Lee Y-H, Miyara I, Moore N, Neumann U, Nordstroem K, Panaccione DG, Panstruga R, Place M, Proctor RH, Prusky D, Rech G, Reinhardt R, Rollins JA, Rounsley S, Schardl CL, Schwartz DC, Shenoy N, Shirasu K, Sikhakolli UR, Stueber K, Sukno SA, Sweigard JA, Takano Y, Takahara H, Trail F, van der Does HC, Voll LM, Will I, Young S, Zeng Q, Zhang J, Zhou S, Dickman MB, Schulze-Lefert P, van Themaat EVL, Ma L-J, Vaillancourt LJ (2012) Life-style transitions in plant pathogenic Colletotrichum fungi deciphered by genome and transcriptome analyses. Nat Genet 44:1060-1065

O'Donnel K (1993) Fusarium and its near relatives. The Fungal Holomorph: Mitotic, Meiotic and Pleomorphic Speciation in Fungal Systematics.CAB International, Wallingford, UK

O’Donnell K, Cigelnik E (1997) Two divergent intragenomic rDNA ITS2 types within a monophyletic lineage of the fungus Fusarium are nonorthologous. Mol Phylogenet Evol 7:103-116

O’Donnell K, Lutzoni FM, Ward TJ, Benny GL (2001) Evolutionary relationships among mucoralean fungi (Zygomycota): evidence for family polyphyly on a large scale. Mycologia 93:286-296

O’Donnell K, Ward TJ, Geiser DM, Kistler HC, Aoki T (2004) Genealogical concordance between the mating type locus and seven other nuclear genes supports for-mal recognition of nine phylogenetically distinct species within the Fusarium graminearum clade. Fungal Genet Biol 41:600-623

O’Donnell K, Gueidan C, Sink S, Johnston PR, Crous PW, Glenn A, Riley R, Zitomer NC, Colyer P, Waalwijk C, van der Leer T, Moretti A, Kang S, Kim H-S, Geiser DM, Juba JH, Baayen RP, Cromey MG, Bithell S, Sutton DA, Skovgaard K, Ploetz R, Kistler HC, Elliott M, Davis M, Sarver BAJ (2009) A two-locus DNA sequence database for typing plant and human pathogens within the Fusarium oxysporum species complex. Fungal Genet Biol 46:936-948

O'Donnell K, Sutton DA, Rinaldi MG, Sarver BA, Balajee SA, Schroers HJ, Summerbell RC, Robert VA, Crous PW, Zhang N, Aoki T, Jung K, Park J, Lee YH, Kang S, Park B, Geiser DM (2010) Internetaccessible DNA sequence database for identifying fusaria from human and animal infections. J Clin Microbiol 48:3708-3718

O’Donnell K, Rooney AP, Proctor RH, Brown DW, McCormick SP, Ward TJ, Frandsen RJN, Lysøe E, Rehner SA, Aoki T, Robert VARG, Crous PW, Kang S, Geiser DM (2013) RPB1 and RPB2 phylogeny supports an early Cretaceous origin and a strongly supported clade comprising all agriculturally and medically important fusaria. Fungal Genet Biol 52:20-31

O’Donnell K, Sutton DA, Fothergill A, McCarthy D, Rinaldi MG, Brandt ME, Zhang N, Geiser DM (2008) Molecular phylogenetic diversity, multilocus haplotype nomenclature, and in vitro antifungal resistance within the Fusarium solani species complex. J Clin Microbiol 46:2477-2490

O'Gorman DT, Sholberg PL, Stokes SC, Ginns J (2008) DNA sequence analysis of herbarium specimens facilitates the revival of Botrytis mali, a postharvest pathogen of apple. Mycologia 100:227-235

Oikawa K, Kuwata H, Shimada K, Washio S (1986) Preliminary experiment on choanephora rot of garden pea caused by Choanephora cucurbitarum and its chemical control. Annu Rep Soc Plant Protect N Jpn 37:83-86

Okoli CAN, Carder JH, Barbara DJ (1993) Molecular variation and subspecific groupings within Verticillium dahliae. Mycol Res 97:233-239

Olatinwo RO, Hanson EJ, Schilder AMC (2003) A first assessment of the cranberry fruit rot complex in Michigan. Plant Dis 87:550-556

Olson HA, Carbone I, Benson DM (2011) Phylogenetic history of Phytophthora cryptogea and Phytophthora drechsleri isolates from floriculture crops in North Carolina greenhouses. Phytopathology 101:1373-1384

Papp T, Acs K, Nyilasi I, Nagy E, Vágvölgyi C (2003) Phylogenetic relationship of the genus Gilbertella and related genera within the order Mucorales based on 5.8 S ribosomal DNA sequences. Acta Biol Hung 54(3-4):393-402

Paul B (2002) Pythium terrestris, a new species isolated from France, its ITS region, taxonomy and its comparison with related species. FEMS Microbiol Lett 212(2):255-260. doi:10.1111/j.1574-6968. 2002.tb11275.x

Paul A, Blackburn M (1986) Phyllosticta beaumarisii sp. nov.: a cause of leafspot on Muehlenbeckia adpressa. Aust Plant Pathol 15(2):40-41

Paul I, Van Jaarsveld A, Korsten L, Hattingh V (2005) The potential global geographical distribution of Citrus Black Spot caused by Guignardia citricarpa (Kiely): likelihood of disease establishment in the European Union. Crop Prot 24(4):297-308

Pavlic D, Slippers B, Coutinho TA, Gryzenhout M, Wingfield MJ (2004) Lasiodiplodia gonubiensis sp. nov., a new Botryosphaeria anamorph from native Syzygium cordatum in South Africa. Stud Mycol 50:313-322

Pavlic D, Slippers B, Coutinho TA, Wingfield MJ (2009a) Multiple gene genealogies and phenotypic data reveal cryptic species of the Botryosphaeriaceae: a case study on the Neofusicoccum parvum $/ N$. ribis complex. Mol Phylogenet Evol 51:259-268

Pavlic D, Slippers B, Coutinho TA, Wingfield MJ (2009b) Molecular and phenotypic characterisation of three phylogenetic species discovered within the Neofusicoccum parvum/N. ribis complex. Mycologia 101:636-647

Pecchia S, Mercatelli E, Vannacci G (1998) PCR amplification and characterization of the intergenic spacer region of the ribosomal DNA in Pyrenophora graminea. FEMS Microbiol 166(1):21-27

Pegg GF, Brady BL (2002) Verticillium wilts. CABI Publishing, New York, $\mathrm{p} 432$

Pegg GS, Giblin FR, McTaggart AR, Guymer GP, Taylor H, Ireland KB, Shivas RG, Perry S (2013) Puccinia psidii in Queensland, Australia: disease symptoms, distribution and impact. Plant Pathol:n/a-n/a. doi: 10.1111/ppa.12173

Peng LJ, Yang YL, Hyde KD, Bahkali AH, Liu Z (2012) Colletotrichum species on Citrus leaves in Guizhou and Yunnan provinces, China. Cryptog Mycolog 33:267-283

Peng LJ, Sun T, Yang YL, Cai L, Hyde KD, Bahkali HA, Liu ZY (2013) Colletotrichum species on grape in Guizhou and Yuannan provinces, China. Mycoscience 54(2013):29-41

Pennycook S, Samuels G (1985) Botryosphaeria and Fusicoccum species associated with ripe fruit rot of Actinidia deliciosa (kiwifruit) in New Zealand. Mycotaxon 24:445-458

Peres NAR, Kuramae EE, Dias MSC, Souza NL (2002) Identification and characterization of Colletotrichum spp. affecting fruit after harvest in Brazil. J Phytopathol 150:128-134

Pérez CA, Wingfield MJ, Slippers B, Altier NA, Blanchette RA (2010) Endophytic and canker-associated Botryosphaeriaceae occurring on non-native Eucalyptus and native Myrtaceae trees in Uruguay. Fungal Divers 41:53-69

Persoh D (2013) Factors shaping community structure of endophytic fungi-evidence from the Pinus-Viscum-system. Fungal Divers 60(1):55-69. doi:10.1007/s13225-013-0225-x

Persoon CH (1801) Synopsis methodica fungorum. H. Dieterich, Göttingen

Persoon CH (1818) Traite sur les champignons comestibles, contenant l'undication des especes nuisible precede d'une introduction a l'historie des Champignons-Paris

Pethybridge S, Scott J, Hay F (2004) Genetic relationships among isolates of Phoma ligulicola from pyrethrum and chrysanthemum based on ITS sequences and its detection by PCR. Australas Plant Pathol 33(2):173-181

Pethybridge SJ, Hay FS, Esker PD, Gent DH, Wilson CR, Groom T, Nutter FW Jr (2008) Diseases of pyrethrum in Tasmania: challenges and prospects for management. Plant Dis 92(9):1260-1272

Petrak F, Sydow H (1927) Die Gattungen der Pyrenmyzeten, Sphaeropsiddn und Melanconieen. I. Die Phacospen 
Sphacropsideen und die Gattung Macrophoma. Reprium Spec nov Regni veget Beih 42:1-551

Petrini O, Hake U, Deryfuss MM (1990) An analysis of fungal communities identified from fructicose lichens. Mycologia $82: 444-451$

Pfunder M, Schurch S, Roy BA (2001) Sequence variation and geographic distribution of pseudoflower-forming rust fungi (Uromyces pisi $\mathrm{s}$. lat.) on Euphorbia cyparissias. Mycol Res 105(01):57-66

Phillips AJL, Fonseca F, Povoa V, Castilho R, Nolasco G (2002) A reassessement of the anamorphic fungus Fusicoccum luteum and description of its teleomorph Botryosphaeria lutea sp. nov. Sydowia 54:59-77

Phillips AJL, Alves A, Correia A, Luque J (2005) Two new species of Botryosphaeria with brown, 1-septate ascospores and Dothiorella anamorphs. Mycologia 97(2):513-529

Phillips AJL, Oudemans PV, Correia A, Alves A (2006) Characterisation and epitypification of Botryosphaeria corticis, the cause of blueberry cane canker. Fungal Divers 21:141-155

Phillips AJL, Alves A, Pennycook SR, Johnston PR, Ramaley A, Akulov A, Crous PW (2008) Resolving the phylogenetic and taxonomic status of dark-spored teleomorph genera in the Botryosphaeriaceae. Persoonia 21:29-55

Phillips AJL, Lopes J, Abdollahzadeh J, Bobev S, Alves A (2012) Resolving the Diplodia complex on apple and other Rosaceae hosts. Persoonia 29:29-38

Phillips AJL, Alves A, Abdollahzadeh J, Slippers B, Wingfield MJ, Groenewald JZ, Crous PW (2013) The Botryosphaeriaceae: genera and species known from culture. Stud Mycol 76:51-167

Phoulivong S, Cai L, Chen H, McKenzie EHC, Abdelsalam K, Chukeatirote $\mathrm{E}$, Hyde KD (2010a) Colletotrichum gloeosporioides is not a common pathogen on tropical fruits. Fungal Divers 44(1):33-43

Phoulivong S, Cai L, Parinn N, Chen H, Abd-Elsalam KA, Chukeatirote E, Hyde KD (2010b) A new species of Colletotrichum from Cordyline fruticosa and Eugenia javanica causing anthracnose disease. Mycotaxon 114:247-257

Piepenbring M, Stoll M, Oberwinkler F (2002) The generic position of Ustilago maydis, Ustilago scitaminea, and Ustilago esculenta (Ustilaginales). Mycol Prog 1(1):71-80

Pitt JI, Hocking AD (2009) Fungi and food spoilage, 3rd edn. Springer, New York

Platenkamp R (1976) Investigation on the infection pathway of Drechslera graminea in germinating barley. Kongelige Veterinaerog Landbohoeiskoles Aarsskrift

Plesken C, Westrich L-D, Hahn M (2014) Genetic and phenotypic characterization of Botrytis calthae. Plant Pathol, in press. doi:10.1111/ ppa. 12240

Porta-Puglia A, Delogu G, Vannacci G (1986) Pyrenophora graminea on winter barley seed: effect on disease incidence and yield losses. J Phytopathol 117(1):26-33

Punithalingam E (1974) Studies on Spheropsidales in culture II. Mycol Pap 136:1-63

Punithalingam E (1976) Phoma oculo-hominis sp. nov. from corneal ulcer. Trans Br Mycol Soc 67(1):142-143

Punithalingam E, Holliday P (1972) Didymella bryoniae. CMI Descriptions of Pathogenic Fungi and Bacteria (332)

Qin Q-M, Vallad GE, Wu BM, Subbarao KV (2006) Phylogenetic analyses of phytopathogenic isolates of Verticillium spp. Phytopathology 96:582-592

Quaedvlieg W, Kema GHJ, Groenewald JZ, Verkley GJM, Seifbarghi S, Razavi M, Gohari AM, Mehrabi R, Crous PW (2011) Zymoseptoria gen. nov.: a new genus to accommodate Septoria-like species occurring on graminicolous hosts. Persoonia 26:57-69

Rai MK (1990) New records of fungi from India. Indian J Mycol Plant Pathol 20:199-201

Ray RC, Ravi V (2005) Post harvest spoilage of sweetpotato in tropics and control measures. Crit Rev Food Sci Nutr 45:623-644
Reeb V, Lutzoni F, Roux C, (2004). Contribution of RPB2 to multilocus phylogenetic studies of the euascomycetes (Pezizomycotina, Fungi) with special emphasis on the lichenforming Acarosporaceae and evolution of polyspory. Mol Phylogenet Evol 32, 1036-1060

Reeser P, Sutton CA, Hansen E (2013) Phytophthotra pluvialis, a new species from mixed tanoak-Douglas-fir forests of western Oregon, U.S.A. North American Fungi 8. doi:10.2509/naf2013.008.007

Rehner SA (2001) Primers for elongation factor 1-alpha (EF1-alpha). http://ocid.nacse.org/research/deephyphae/EF1 primer.pdf

Rehner SA, Samuels GJ (1994) Taxonomy and phylogeny of Gliocladium analysed from nuclear large subunit ribosomal DNA sequences. Mycol Res 98:625-634

Rehner SA, Uecker FA (1994) Nuclear ribosomal internal transcribed spacer phylogeny and host diversity in the coelomycete Phomopsis. Can J Bot 72:166-167

Restuccia C, Giusino F, Licciardello F, Randazzo C, Caggia C, Muratore G (2006) Biological control of peach fungal pathogens by commercial products and indigenous yeasts. J Food Prot 69(10):2465-2470

Riethmüller A, Voglmayr H, Göker M, Weiß M, Oberwinkler F (2002) Phylogenetic relationships of the downy mildews (Peronosporales) and related groups based on nuclear large subunit ribosomal DNA sequences. Mycologia 94(5):834-849

Ristaino JB (2011) A LUCID Key to the common Phytophthora species. Plant Dis 96:897-903

Robb J, Moukhamedov R, Hu X, Platt H, Nazar RN (1993) Putative subgroups of Verticillium albo-atrum distinguishable by PCR-based assays. Physiol Mol Plant Pathol 43:423-436

Robideau GP, De Cock AWAM, Coffey MD, Voglmayr H, Brouwer H, Bala K, Chitty DW, Desaulniers N, Eggertson QA, Gachon CMM, $\mathrm{Hu}$ CH, Kupper FC, Rintoul TL, Sarhan E, Verstappen ECP, Zhang Y, Bonants PJM, Ristaino JB, Andre Levesque C (2011) DNA barcoding of oomycetes with cytochrome $\mathrm{c}$ oxidase subunit I and internal transcribed spacer. Mol Ecol Resour 11:1002-1011. doi:10. 1111/j.17550998.2011.03041.x

Roden MM, Zautis TE, Buchanan WL, Knudsen TA, Sarkisova TA, Schaufele RL, Sein M, Sein T, Chiou CC, Chu JH, Kontoyiannis DP, Walsh TJ (2005) Epidemiology and outcome of zygomycosis: a review of 929 reported cases. Clin Infect Dis 41:634-653

Rossman AY, Manamgoda DS, Hyde KD (2013) Proposal to conserve the name Bipolaris against Cochliobolus (Ascomycota: Pleosporales: Pleosporaceae). Taxon 62:1331-1332

Rowe RC (1995) Recent progress in understanding relationships between Verticillium species and subspecific groups. Phytoparasitica 23:3138

Ruehle GD (1931) New apple-rot fungi in Washington. Phytopathology 21:1141-1152

Saccardo PA (1877) Fungi Veneti novi vel critici vel Mycologiae Venetae addendi, ser. VI. Michelia 1:1-72

Saccardo PA (1878) Michelia 1(2):133-221

Saccardo PA (1884) Sylloge Fungorum 3, Italy, p 552

Saccardo PA (1891) Sylloge Fungorum 9, Italy, pp 1-1141

Sakalidis ML, Hardy GESJ, Burgess TI (2011) Use of the Genealogical Sorting Index (GSI) to delineate species boundaries in the Neofusicoccum parvum-Neofusicoccum ribis species complex. Mol Phylogenet Evol 60(320):333-344

Samuel S, Veloukas T, Papavasileiou A, Karaoglanidis GS (2012) Differences in frequency of transposable elements presence in Botrytis cinerea populations from several hosts in Greece (Plant Disease). Plant Dis 96(9):1286-1290. doi:10.1094/pdis-01-120103-re

Sangeetha CG, Rawal RD (2010) Temperature requirement of different isolates of Colletotrichum gloeosporioides isolated from mango. Afr J Biotechnol 21:3086-3090 
Santos JM, Phillips AJL (2009) Resolving the complex of Diaporthe (Phomopsis) species occurring on Foeniculum vulgare in Portugal. Fungal Divers 34:109-125

Santos JM, Correia VG, Phillips AJL (2010) Primers for mating type diagnosis in Diaporthe and Phomopsis: their use in teleomorph induction in vitro and biological species definition. Fungal Biol $114: 255-270$

Santos JM, Vrandečić K, Ćosić J, Duvnjak T, Phillips AJL (2011) Resolving the Diaporthe species occurring on soybean in Croatia. Persoonia 27:9-19

Saroj A, Kumar A, Qamar N, Alam M, Singh HN, Khaliq A (2012) First report of wet rot of Withania somnifera caused by Choanephora cucurbitarum in India. Plant Dis 96(2):293

Scheffer RP (1997) The nature of disease in plants. Cambridge University Press, Cambridge

Schipper MAA (1973) A study on variability in Mucor hiemalis and related species. Stud Mycol, Baarn 4:1-40

Schipper MAA (1975) Mucor mucedo, Mucor flavus and related species. Stud Mycol, Baarn 10:1-33

Schipper MAA (1976) On Mucor circinelloides, Mucor racemosus and related species. Stud Mycol, Baarn 12:1-40

Schipper MAA (1978) On certain species of Mucor with a key to all accepted species. Stud Mycol, Baarn 17:1-52

Schipper MAA, Samson RA (1994) Miscellaneous notes on Mucoraceae. Mycotaxon 50:475-491

Schipper MAA, Stalpers JA (1984) Revision of the genus Rhizopus. Stud Mycol 25:1-34

Schoch CL, Shoemaker RA, Seifert KA, Hambleton S, Spatafora JW, Crous PW (2006) A multigene phylogeny of the Dothideomycetes using four nuclear loci. Mycologia 98:1041-1052

Schoch CL, Seifert KA, Huhndorf S, Robert V, Spouge JL, Levesque CA, Chen W, Fungal Barcoding Consortium (2012) Nuclear ribosomal internal transcribed spacer (ITS) region as a universal DNA barcode marker for Fungi. Proc Natl Acad Sci U S A 109(16):6241-6246

Schoch CL, Robbertse B, Robert V, Vu D, Cardinali G, Irinyi L, Meyer W, Nilsson RH, Hughes K, Miller AN, Kirk PM, Abarenkov K, Aime MC, Ariyawansa HA, Bidartondo M, Boekhout T, Buyck B, Cai Q, Chen J, Crespo A, Crous PW, Damm U, De Beer ZW, Dentinger BTM, Divakar PK, Dueñas M, Feau N, Fliegerova K, García MA, Ge Z-W, Griffith GW, Groenewald JZ, Groenewald M, Grube M, Gryzenhout M, Gueidan C, Guo L, Hambleton S, Hamelin R, Hansen K, Hofstetter V, Hong S-B, Houbraken J, Hyde KD, Inderbitzin P, Johnston PR, Karunarathna SC, Kõljalg U, Kovács GM, Kraichak E, Krizsan K, Kurtzman CP, Larsson K-H, Leavitt S, Letcher PM, Liimatainen K, Liu J-K, Lodge DJ, Luangsa-ard JJ, Lumbsch HT, Maharachchikumbura SSN, Manamgoda D, Martín MP, Minnis AM, Moncalvo J-M, Mulè G, Nakasone KK, Niskanen T, Olariaga I, Papp T, Petkovits T, Pino-Bodas R, Powell MJ, Raja HA, Redecker D, Sarmiento-Ramirez JM, Seifert KA, Shrestha B, Stenroos S, Stielow B, Suh S-O, Tanaka K, Tedersoo L, Telleria MT, Udayanga D, Untereiner WA, Uribeondo JD, Subbarao KV, Vágvölgyi C, Visagie C, Voigt K, Walker DM, Weir BS, Weiß M, Wijayawardene NN, Wingfield MJ, Xu JP, Yang ZL, Zhang N, Zhuang W-Y, Federhen S (2014) Finding needles in haystacks: linking scientific names, reference specimens and molecular data for Fungi. Database (Oxford) 2014:bau061. doi:10.1093/database/bau061

Scholler M, Lutz M, Wood A, Hagedorn G, Mennicken M (2011) Taxonomy and phylogeny of Puccinia lagenophorae: a study using rDNA sequence data, morphological and host range features. Mycol Prog 10(2):175-187. doi:10.1007/s11557-010-0687-0

Schroers HJ, O’Donnell K, Lamprecht SC, Kammeyer PL, Johnson S, Sutton DA, Rinaldi MG, Geiser DM, Summerbell RC (2009) Taxonomy and phylogeny of the Fusarium dimerum species group. Mycologia 101:44-70
Schröter J (1893) Saprolegniineae. In: Engler A (ed) Die natürlichen Pflanzenfamilien nebst ihren Gattungen und wichtigeren Arten insbesondere den den Nutzplanzen, unter Mitwirkung zahlreicher hervorragender Fachgelehrten begründet von A. Engler und K. Prantl. I. Teil, Abteilung 4, pp 93-10

Schröter J (1897) Saprolegniineae. In: Engler A, Prantl K. Die Naturlichen Pflanzenfamilien Lfg 93:93-105

Schumacher J, Gautier A, Morgant G, Studt L, Ducrot P-H, Le Pêcheur P, Azeddine S, Fillinger S, Leroux P, Tudzynski B, Viaud M (2013) A functional bikaverin biosynthesis gene cluster in rare strains of Botrytis cinerea is positively controlled by VELVET. PLoS ONE 8(1):e53729

Seier MK, Morin L, van der Merwe M, Evans HC, Romero Á (2009) Are the microcyclic rust species Puccinia melampodii and Puccinia xanthii conspecific? Mycol Res 113(11):1271-1282. doi:10.1016/ j.mycres.2009.08.009

Seifert KA (2001) Fusarium and anamorph generic concepts. In: Summerell BA, Leslie JF, Backhouse D, Bryden WL, Burgess LW (eds) Fusarium: Paul E. Nelson Memorial Symposium Am Phytopathol Soc, St. Paul, MN

Seifert KA, Rossman AY (2010) How to describe a new fungal species. IMA Fungus 1:109-116

Shenoy BD, Jeewon R, Lam WH, Bhat DJ, Than PP, Taylor PWJ, Hyde KD (2007) Morpho-molecular characterisation and epitypification of Colletotrichum capsici (Glomerellaceae, Sordariomycetes), the causative agent of anthracnose in chilli. Fungal Divers 27:197-211

Shipunov A, Newcombe G, Raghavendra AKH, Anderson CL (2008) Hidden diversity of endophytic fungi in an invasive plant. Am J Bot 95(9):1096-1108. doi:10.3732/ ajb.080 0024

Shivas RG, Tan YP (2009) A taxonomic re-assessment of Colletotrichum acutatum, introducing C. fioriniae comb. et stat. nov. and C. simmondsii sp. nov. Fungal Divers 39:111-122

Shivas RG, Lutz M, McTaggart AR, Vánky K (2013a) Emended description of Anomalomyces (Ustilaginales), including Anomalomyces yakirrae sp. nov. on Yakirra pauciflora (Poaceae) from Australia. Mycobiota 1:17-24

Shivas RG, Tan YP, Grice KRE (2013b) Phyllosticta species on orchids (Orchidaceae), introducing Phyllosticta speewahensis sp. nov. (Phyllostictaceae, Ascomycota) from northern Australia. Sydowia 65(1):139-146

Shoemaker RA (1959) Nomenclature of Drechslera and Bipolaris, grass parasites segregated from Helminthosporium. Can J Bot 37:879-887

Shoemaker RA (1964) Conidia states of some Botryosphaeria species on Vitis and Quercus. Can J Bot 42:1297-1301

Shtienberg D (1997) Rhizopus head rot of confectionery sunflower: effects on yield quantity and quality and implications for disease management. Phytopathology 87:1226-1232

Sideris CP (1931a) The classification of Pythium. Science 74(1928):596597. doi:10.2307/ 1657352

Sideris CP (1931b) Taxonomic studies in the family Pythiaceae: I. Nematosporangium. Mycologia 23(4):252-295

Silva DN, Talhinas P, Várzea V, Cai L, Paulo OS, Batista D (2012) Application of the Apn2/MAT locus to improve the systematics of the Colletotrichum gloeosporioides complex: an example from coffee (Coffea spp.) hosts. Mycologia 104:396-409

Singh RP, Hodson DP, Huerta-Espino J, Jin Y, Bhavani S, Njau P, Herrera-Foessel S, Singh PK, Singh S, Govindan V (2011) The Emergence of Ug99 races of the stem rust fungus is a threat to world wheat production. Annu Rev Phytopathol 49(1):465-481. doi:10. 1146/annurev-phyto-072910-095423

Sivanesan A (1984) The bitunicate Ascomycetes and their Anamorphs. Vaduz, Liechtenstein: J Cramer

Sivanesan A (1987) Graminicolous species of Bipolaris, Curvularia, Drechslera, Exserohilum and their teleomorphs. Mycol Pap 158: $1-261$ 
Skiada A, Pagano L, Groll A, Zimmerli S, Dupont B, Lagrou K, LassFlorl C, Bouza E, Klimko N, Gaustad P, Richardson M, Hamal P, Akova M, Meis JF, Rodriguez-Tudela JL, Roilides E, MitrousiaZiouval A, Petrikkos G, the European Confederation of Medical Mycology Working Group on Zygomycosis (2011) Zygomycosis in Europe: analysis of 230 cases accrued by the registry of the European Confederation of Medical Mycology (ECMM) Working Group on Zygomycosis between 2005 and 2007. Clin Microbiol Infect 17:1859-1867

Slippers B, Wingfield MJ (2007) Botryosphaeriaceae as endophytes and latent pathogens of woody plants: diversity, ecology and impact. Fungal Biol Rev 21(2-3):90-106

Slippers B, Crous PW, Denman S, Coutinho TA, Wingfield BD, Wingfield MJ (2004a) Combined multiple gene genealogies and phenotypic characters differentiate several species previously identified as Botryosphaeria dothidea. Mycologia 96: $83-101$

Slippers B, Fourie G, Crous PW, Coutinho TA, Wingfield BD, Carnegie AJ, Wingfield MJ (2004b) Speciation and distribution of Botryosphaeria spp. on native and introduced Eucalyptus trees in Australia and South Africa. Stud Mycol 50:343-358

Slippers B, Fourie G, Crous PW, Coutinho TA, Wingfield BD, Wingfield MJ (2004c) Multiple gene sequences delimit Botryosphaeria australis sp.nov.from B. lutea. Mycologia 96:1030-1104

Slippers B, Burgess T, Wingfield BD, Crous PW, Coutinho TA, Wingfield MJ (2004d) Development of simple sequence repeat markers for Botryosphaeria spp. with Fusicoccum anamorphs. Mol Ecol Notes 4:675-677

Slippers B, Boissin E, Phillips A, Groenewald J, Lombard L, Wingfield M, Postma A, Burgess T, Crous P (2013) Phylogenetic lineages in the Botryosphaeriales: a systematic and evolutionary framework. Stud Mycol 76(1):31-49

Smith HC (1965) The morphology of Verticillium albo-atrum, V. dahliae, and V. tricorpus. N Z J Agric Res 8:450-478

Smith DR, Stanosz GR (2001) Molecular and morphological differentiation of Botryosphaeria dothidea (anamorph Fusicoccum aesculi) from some other fungi with Fusicoccum anamorphs. Mycologia 93: $505-515$

Smith SN, Lyon AJE, Sahid IB (1976) The breakdown of paraquat and diquat by soil fungi. New Phytol 77:735-740

Smith WL Jr, Moline HE, Johnson KS (1979) Studies with Mucor species causing postharvest decay of fresh produce. Phytopathology 69: 865-869

Smith H, Wingfield MJ, Crous PW, Coutinho TA (1996) Sphaeropsis sapinea and Botryosphaeria dothidea endophytic in Pinus spp. and Eucalyptus spp. in South Africa. S Afr J Bot 62:86-88

Snowdon AL (1990) Post harvest diseases and disorders of fruits and vegetables. Vol. I. General introductions and fruits. CRC Press Inc, Boca Raton, $302 \mathrm{pp}$

Snowdon AL (1991) Post harvest diseases and disorders of fruits and vegetables. Vol. II. Vegetables. CRC Press Inc, Boca Raton, 416 pp

Sparrow FK (1931) The classification of Pythium. Science 73(1880):41-42

Sparrow FK (1932) The classification of Pythium. Mycologia 24(3):349351

Spies CFJ, Mazzola M, Botha WJ, Langenhoven SD, Mostert L, McLeod A (2011a) Molecular analyses of Pythium irregulare isolates from grapevines in South Africa suggest a single variable species. Fungal Biol 115(12):1210-1224. doi:10.1016/j.funbio.2011.08.006

Spies CFJ, Mazzola M, Botha WJ, van der Rijst M, Mostert L, McLeod A (2011b) Oogonial biometry and phylogenetic analyses of the Pythium vexans species group from woody agricultural hosts in South Africa reveal distinct groups within this taxon. Fungal Biol 115(2):157-168. doi:10.1016/j.funbio.2010.11.005

Spotts RA (1990) Mucor rot. In: Jones AL, Aldwinckle HS (eds) Compendium of apple and pear diseases. Am Phytopathol Soc Press, St. Paul, pp 57-58
Staats M, van Baarlen P, van Kan JAL (2005) Molecular phylogeny of the plant pathogenic genus Botrytis and the evolution of host specificity. Mol Biol Evol 22:333-346

Staats M, van Baarlen P, Schouten A, van Kan JAL, Bakker FT (2007a) Positive selection in phytotoxic protein-encoding genes of Botrytis species. Fungal Genet Biol 44:52-63

Staats M, Van Baarlen P, Schouten A, Van Kan JAL (2007b) Functional analysis of NLP genes from Botrytis elliptica. Mol Plant Pathol 8: 209-214

Stajich JE, Berbee ML, Blackwell M, Hibbett DS, James TY, Spatafora JW, Taylor JW (2009) The fungi. Curr Biol 19:R840-R845

Stamatakis A (2006) RAxML-VI-HPC: maximum likelihood-based phylogenetic analyses with thousands of taxa and mixed models. Bioinformatics 22(21):2688-2690

Stamatakis A, Hoover P, Rougemont J (2008) A rapid bootstrap algorithm for the RAx MLWeb servers. Syst Biol 57:758-771

Stevens F (1907) The chrysanthemum ray blight 1. Bot Gaz 44:241

Steyaert RL (1949) Contributions à l'étude monographique de Pestalotia de Not. et Monochaetia Sacc. (Truncatella gen. nov. et Pestalotiopsis gen. nov.). Bull Jard Bot Brux 19:285-354

Stoll M, Piepenbring M, Begerow D, Oberwinkler F (2003) Molecular phylogeny of Ustilago and Sporisorium species (Basidiomycota, Ustilaginales) based on internal transcribed spacer (ITS) sequences. Can J Bot Rev Can Bot 81(9):976-984

Stoll M, Begerow D, Oberwinkler F (2005) Molecular phylogeny of Ustilago, Sporisorium, and related taxa based on combined analyses of rDNA sequences. Mycol Res 109:342-356

Strobel G, Li JY, Ford E, Worapong J, Gary IB, Hess WM (2000) Pestalotiopsis jesteri, sp. nov. an endophyte from Fragraea bodenii Wernh, a common plant in the southern highlands of Papua New Guinea. Mycotaxon 76:257-266

Su YY, Cai L (2012) Polyphasic characterisation of three new Phyllosticta spp. Persoonia 28:76-84

Su YY, Noireung P, Liu F, Hyde KD, Moslem MA, Bahkali AH, AbdElsalam KA, Cai L (2011) Epitypification of Colletotrichum musae, the causative agent of banana anthracnose. Mycoscience 52: 376-382

Subramanian CV, Jain BL (1966) A revision of some graminicolous Helminthosporia. Curr Sci 35:352-355

Summerell BA, Salleh B, Leslie JF (2003) A utilitarian approach to identifying Fusarium species. Plant Dis 87:117-128

Summerell BA, Leslie JF, Liew ECY, Laurence MH, Bullock S, Petrovic T, Bentley AR, Howard CG, Peterson SA, Walsh JL, Burgess LW (2011) Fusarium species associated with plants in Australia. Fungal Divers 46:1-27

Sun S, Van K, Kim MY, Min KH, Lee YW, Lee SH (2012) Diaporthe phaseolorum var. caulivora, a causal agent for both stem canker and seed decay on soybean. Plant Pathol J 28:55-59

Sutton BC (1977) Coelomycetes. VI. Nomenclature of generic names proposed for Coelomycetes. Mycol Pap 141:1-253

Sutton BC (1980) The coelomycetes: fungi imperfecti with pycnidia, acervular and stromata. Commonw Mycol Inst, Kew

Swofford DL (2002) PAUP: phylogenetic analysis using parsimony, version 4.0 b10. Sinauer Associates, Sunderland

Sydow P, Sydow H (1904) Monographia Uredinearum seu Specierum Omnium ad hunc usque Diem Descriptio et Adumbratio Systematica. Volume 1. Genus Puccinia. Verlag Von J. Cramer, Lipsiae, Germany

Taba S, Nakazato M, Nasu K, Takushi T, Moromizato Z (2011) Gilbertella stem rot of pitaya (Hylocereus undatus), a new disease caused by Gilbertella persicaria. Jpn J Phytopathol 77:291-294

Tagne A, Mathur SB (2001) First report of chlorotic spot of maize caused by Pestalotiopsis neglecta. Plant Pathol 50:791

Tan YP, Edwards J, Grice KRE, Shivas RG (2012) Molecular phylogenetic analysis reveals six new species of Diaporthe from Australia. Fungal Divers 61:251-260 
Tao G, Liu ZY, Liu F, Gao YH, Cai L (2013) Endophytic Colletotrichum species from Bletilla ochracea (Orchidaceae), with description of seven new species. Fungal Divers 61:139-164

Taylor JE, Hyde KD (2003) Microfungi of tropical and temperate palms. Fungal Divers Res Ser 12:1-459

Tejesvi MV, Kini KR, Prakash HS, Subbiah V, Shetty HS (2007) Genetic diversity and antifungal activity of species of Pestalotiopsis isolated as endophytes from medicinal plants. Fungal Divers 24:37-54

Tekauz A (1983) Reaction of Canadian barley cultivars to Pyrenophora graminea, in the incitant of leaf stripe. Can J Physiol Pharmacol 5: 294-301

Tekauz A (1990) Characterization and distribution of pathogenic variation in Pyrenophora teres. Can J Plant Pathol 12(2): $141-148$

Templeton AR, Crandall KA, Sing CF (1992) A cladistic analysis of phenotypic associations with haplotypes inferred from restriction endonuclease mapping and DNA sequence data. III. Cladogram estimation. Genetics 132(2):619-633

Than PP, Jeewon R, Hyde KD, Pongsupasamit S, Mongkolporn O, Taylor PWJ (2008) Characterization and pathogenicity of Colletotrichum species associated with anthracnose on chilli (Capsicum spp.) in Thailand. Plant Pathol 57:562-572

Thaung MM (2008) Coelomycete systematics with special reference to Colletotrichum. Mycoscience 49:345-350

Thines M, Choi YJ, Kemen E, Ploch S, Holub EB, Shin DH, Jones JDG (2009) A new species of Albugo parasitic to Arabidopsis thaliana reveals new evolutionary patterns in white blister rusts (Albuginaceae). Persoonia 22:23-128

Thompson SM, Tan YP, Young AJ, Neate SM, Aitken EA, Shivas RG (2011) Stem cankers on sunflower (Helianthus annuus) in Australia reveal a complex of pathogenic Diaporthe (Phomopsis) species. Persoonia 27:80-89

Tsuji G, Fujii S, Fujihara N, Hirose C, Tsuge S, Shiraishi T, Kubi Y (2003) Agrobacterium tumefaciens-mediated transformation for random insertional mutagenesis in Colletotrichum lagenarium. J Gen Plant Pathol 69:230-239

Turkensteen L (1978) Tizón foliar de la papa en el Perú: I. Especies de Phoma asociadas. Fitopatología 13(1):67-69

Turkensteen LJ (1979) Choanephora blight of potatoes and other crops grown under tropical conditions in Peru. Neth J Plant Pathol 85:85-86

Typas MA, Griffen AM, Bainbridge BW, Heale JB (1992) Restriction fragment length polymorphisms in mitochondrial DNA and ribosomal RNA gene complexes as an aid to the characterization of species and sub-species populations in the genus Verticillium. FEMS Microbiol Lett 95:157-162

Uchida JY, Aragaki M (1980) Nomenclature, pathogenicity, and conidial germination of Phyllostictina pyriformis. Plant Dis 64:786-788

Udayanga D, Liu XX, McKenzie EHC, Chukeatirote E, Bahkali AH, Hyde KD (2011) The genus Phomopsis: biology, applications, species concepts and names of common phytopathogens. Fungal Divers 50:189-225

Udayanga D, Liu XX, Crous PW, McKenzie EHC, Chukeatirote E, Hyde KD (2012a) Multilocus phylogeny of Diaporthe reveals three new cryptic species from Thailand. Cryptog Mycolog 33: 295-309

Udayanga D, Xingzhong L, Crous PW, McKenzie EHC, Chukeatirote E, Hyde KD (2012b) A multi-locus phylogenetic evaluation of Diaporthe (Phomopsis). Fungal Divers 56:157-171

Udayanga D, Manamgoda DS, Liu XZ, Chukeatirote E, Hyde KD (2013) What are the common anthracnose pathogens of tropical fruits? Fungal Divers 61:165-179

Udayanga D, Castlebury LA, Rossman A, Hyde KD (2014a) Species limits in Diaporthe : a molecular reassessment of D. citri, D. cytosporella, D. foeniculina and D. rudis. Persoonia 32:83-101. doi:10.3767/003158514X679984
Udayanga D, Castlebury LA, Rossman AY, Cukeatirote E, Hyde KD (2014b) Insights in to the genus Diaporthe: Phylogenetic species delimitation in the $D$. eres species complex. Fungal Divers, accepted, FUDI-D-14-00090

Uecker FA (1988) A world list of Phomopsis names with notes on nomenclature, morphology, and biology. Mycol Mem 13:1-213

Ukeh JA, Chiejina NV (2012) Preliminary investigations of the cause of post-harvest fungal rot of tomato. IOSR J Pharm Biol Sci 4(5):36-39

Unterseher M, Peršoh D, Schnittler M (2013) Leaf-inhabiting endophytic fungi of European Beech (Fagus sylvatica L.) co-occur in leaf litter but are rare on decaying wood of the same host. Fungal Divers 60: $43-54$

Usami T, Itoh M, Amemiya Y (2009) Asexual fungus Verticillium dahliae is potentially heterothallic. J Gen Plant Pathol 75(6):422427

Uzuhashi S, Tojo M, Kakishima M (2010) Phylogeny of the genus Pythium and description of new genera. Mycoscience 51(5):337365. doi:10.1007/s10267-010-0046-7

Vaghefi N, Pethybridge S, Ford R, Nicolas M, Crous P, Taylor PWJ (2012) Stagonosporopsis spp. associated with ray blight disease of Asteraceae. Australas Plant Pathol 41(6):675-686

Vaghefi N, Ades PK, Hay FS, Pethybridge SJ, Ford R, Taylor PWJ (2014) Identification of MAT1 locus in Stagonosporopsis tanaceti, and exploring its potential for sexual reproduction in Australian pyrethrum fields. Fungal Biol (in press). doi:10.1016/j.funbio. 2014.04.004

Van der Aa HA (1973) Studies in Phyllosticta I. Stud Mycol 5:1-110

Van der Aa HA, Vanev S (2002) A revision of the species described in Phyllosticta. CBS, Utrecht

Van der Aa HA, Noordeloos ME, De Gruyter J (1990) Species concepts in some large genera of coelomycetes. Stud Mycol 32:3-19

Van der Merwe M, Ericson L, Walker J, Thrall PH, Burdon JJ (2007) Evolutionary relationships among species of Puccinia and Uromyces (Pucciniaceae, Uredinales) inferred from partial protein coding gene phylogenies. Mycol Res 111:163-175. doi:10.1016/j. mycres.2006.09.015

Van Der Merwe MM, Walker J, Ericson L, Burdon JJ (2008) Coevolution with higher taxonomic host groups within the Puccinia/Uromyces rust lineage obscured by host jumps. Mycol Res 112:1387-1408. doi:10.1016/j.mycres.2008.06.027

Van der Plaats-Niterink A (1981) Monograph of the genus Pythium. Stud Mycol 21:1-242

Van Der Vlugt-Bergmans CJB, Brandwagt BF, Vant't Klooster JW, Wagemakers CAM, Van Kan JAL (1993) Genetic variation and segregation of DNA polymorphisms in Botrytis cinerea. Mycol Res 97(10):1193-1200. doi:10.1016/S0953-7562(09)81284-7

Van Niekerk JM, Groenewald JZ, Farr DF, Fourie PH, Halleen F, Crous PW (2005) Reassessment of Phomopsis species on grapevine. Australas Plant Pathol 34:27-39

Van Rensburg JCJ, Lamprecht SC, Groenewald JZ, Castlebury LA, Crous PW (2006) Characterisation of Phomopsis spp. associated with die-back of rooibos (Aspalathus linearis) in South Africa. Stud Mycol 55:65-74

Vánky K (2011) Smut fungi of the world. APS Press, St. Paul

Vánky K (2013) Illustrated genera of smut fungi, 3rd edn. Am Phytopathol Soc, St. Paul

Vánky K, Lutz M (2011) Tubisorus, a new genus of smut fungi (Ustilaginomycetes) for Sporisorium pachycarpum. Mycol Balc 8: 129-135

Vialle A, Feau N, Allaire M, Didukh M, Martin F, Moncalvo J-M, Hamelin RC (2009) Evaluation of mitochondrial genes as DNA barcode for Basidiomycota. Mol Ecol Resour 9:99-113. doi:10. 1111/j.1755-0998.2009.02637.x

Vilgalys R, Hester M (1990) Rapid genetic identification and mapping of enzymatically amplified ribosomal DNA from several Cryptococcus species. J Bacteriol 172:4238-4246 
Villa NO, Kageyama K, Asano T, Suga H (2006) Phylogenetic relationships of Pythium and Phytophthora species based on ITS rDNA, cytochrome oxidase II and $\beta$-tubulin gene sequences. Mycologia 98(3):410-422. doi:10.3852/mycologia.98.3.410

Virtudazo E, Nakamura H, Kakishima M (2001) Ribosomal DNA-ITS sequence polymorphism in the sugarcane rust, Puccinia kuehnii. Mycoscience 42(5):447-453. doi:10.1007/bf02464341

Voigt K (2012) Zygomycota. In: Frey W (ed) Syllabus of plant families, 13th edn. Borntraeger, Stuttgart, pp 130-156

Voigt K, Kirk PM (2012) Rhizopodaceae. In: Kirk PM. Index fungorum 13:1

Voigt K, Wöstemeyer J (2001) Phylogeny and origin of 82 zygomycetes from all 54 genera of the Mucorales and Mortierellales based on combined analysis of actin and translation elongation factor EF- $1 \alpha$ genes. Gene 270:113-120

von Arx JA (1987) Plant-pathogenic fungi. J Cramer, Berlin

von Arx J, Müller E (1954) Die Gattungen der amerosporen Pyrenomyceten. Beitr Kryptogamenflora Schweiz 11(1):1-434

von Arx JA, Müller E (1975) A re-evaluation of the bitunicate ascomycetes with keys to families and genera. Stud Mycol 9:1-159

Von Haller A (1771) Biblioteca botanico qua scripta ad rem herbarium facienta a rerum initiis arecensenturum. Vol. 1. Zurich

Wainright PO, Hinkle G, Sogin ML, Stickel SK (1993) Monophyletic origins of the metazoa: an evolutionary link with fungi. Science 260: $340-342$

Walker A-S, Gautier A, Confais J, Martinho D, Viaud M, Le Pêcheur P, Dupont J, Fournier E (2011) Botrytis pseudocinerea, a new cryptic species causing gray mold in French vineyards in sympatry with Botrytis cinerea (Phytopathology). Phytopathology 101(12):14331445. doi:10.1094/phyto-04-11-0104

Waller JM, Lenné JM, Waller SJ (2002) Plant pathologists's pocketbook. CABI, Wallingford

Walsh JL, Laurence MH, Liew ECY, Sangalang AE, Burgess LW, Summerell BA, Petrovic T (2010) Fusarium: two endophytic novel species from tropical grasses from northern Australia. Fungal Divers 44:149-159

Walther G, Pawłowska J, Alastruey-Izquierdo A, Wrzosek M, RodriguezTudela JL, Dolatabadi S, Chakrabarti A, de Hoog SG (2013) DNA barcoding in Mucorales: an inventory of biodiversity. Persoonia 30: $11-47$

Wang X, Chen G, Huang F, Zhang J, Hyde KD, Li H (2012) Phyllosticta species associated with Citrus diseases in China. Fungal Divers 52: 209-224

Watanabe T (1994) Two new species of homothallic Mucor in Japan. Mycologia 86:691-695

Watanabe K, Nakazono T, Ono Y (2012) Morphology evolution and molecular phylogeny of Pestalotiopsis (Coelomycetes) based on ITS2 secondary structure. Mycoscience 53:227-237

Waterhouse GM (1963) Key to the species of Phytophthora de Bary. Commonw Mycol Inst, Kew

Wehmeyer LE (1933) The genus Diaporthe Nitschke and its segregates. Univ Mich Stud Sci Ser 9:1-34

Weiland JJ, Steffenson BJ, Cartwright RD, Webster RK (1999) Identification of molecular genetic markers in Pyrenophora teres $f$. teres associated with low virulence on 'Harbin' Barley. Phytopathology 89(2):176-181

Weir BS, Johnston PR (2010) Characterisation and neotypification of Gloeosporium kaki Hori as Colletotrichum horii nom. nov. Mycotaxon 111:209-219

Weir B, Johnston PR, Damm U (2012) The Colletotrichum gloeosporioides species complex. Stud Mycol 73:115-180

Whetzel HH (1945) A synopsis of the genera and species of the Sclerotiniaceae, a family of stromatic inoperculate discomycetes. Mycologia 37(6):648-714

White TJ, Bruns T, Lee S, Taylor JW (1990) Amplification and direct sequencing of fungal ribosomal RNA genes for phylogenetics. In: Innis MA, Gelfand DH, Sninsky JJ, White TJ (eds) PCR protocols: a guide to methods and applications. Academic Press, Inc., New York, pp 315-322

Wicht B, Petrini O, Jermini M, Gessler C, Broggini GAL (2012) Molecular, proteomic and morphological characterization of the ascomycete Guignardia bidwellii, agent of grape black rot: a polyphasic approach to fungal identification. Mycologia 104(5):1036-1045

Wijayawardene DNN, Mckenzie EHC, Hyde KD (2012) Towards incorporating anamorphic fungi in a natural classification-checklist and notes for 2011. Mycosphere 3(2):157-228

Wikee S, Udayanga D, Crous PW, Chukeatirote E, McKenzie EHC, Bahkali AH, Dai DQ, Hyde KD (2011) Phyllosticta - an overview of current status of species recognition. Fungal Divers 51:43-61

Wikee S, Wulandari NF, McKenzie EHC, Hyde KD (2012) Phyllosticta ophiopogonis sp. nov. from Ophiopogon japonicus (Liliaceae). Saudi J Biol Sci 19:13-16

Wikee S, Lombard L, Crous PW, Nakashima C, Motohashi K, Chukeatirote E, Alias SA, McKenzie EHC, Hyde KD (2013a) Phyllosticta capitalensis, a widespread endophyte of plants. Fungal Divers 60:91-105

Wikee S, Jaidee P, Wongkam S, Mckenzie EHC, Hyde KD, Chukeatirote E (2013b) Antimicrobial activity of crude extracts of Phyllosticta spp. Mycology 4(2):112-117

Wikee S, Lombard L, Nakashima C, Motohashi K, Chukeatirote E, Cheewangkoon R, McKenzie EHC, Hyde KD, Crous PW (2013c) A phylogenetic re-evaluation of Phyllosticta (Botryosphaeriales). Stud Mycol 76:1-29

Williamson B, Tudzynski B, Tudzynski P, van Kan JAL (2007) Botrytis cinerea: the cause of grey mould disease. Mol Plant Pathol 8:561-580

Windels CE (2000) Economic and social impacts of Fusarium head blight: changing farms and rural communities in the Northern Great Plains. Phytopathology 90:17-21

Wingfield BD, Ericson L, Szaro T, Burdon JJ (2004) Phylogenetic patterns in the Uredinales. Australas Plant Pathol 33(3):327-335. doi: $10.1071 / \mathrm{ap} 04020$

Wingfield MJ, De Beer ZW, Slippers B, Wingfield BD, Groenewald JZ, Lombard L, Crous PW (2012) One fungus, one name promotes progressive plant pathology. Mol Plant Pathol 13:604-613

Wong MH, Crous PW, Henderson J, Groenewald JZ, Drenth A (2012) Phyllosticta species associated with freckle disease of banana. Fungal Divers 56:173-187

Woudenberg JHC, Aveskamp MM, De Gruyter J, Spiers AG, Crous PW (2009) Multiple Didymella teleomorphs are linked to the Phoma clematidina morphotype. Persoonia 22:56-62

Wulandari N, To-Anun C, Hyde KD, Duong L, De Gruyter J, Meffert JP, Groenewald JZ, Crous PW (2009) Phyllosticta citriasiana sp. nov., the cause of Citrus tan spot of Citrus maxima in Asia. Fungal Divers 34:23-39

Wulandari NF, To-Anun C, Lei C, Abd-Elsalam KA, Hyde KD (2010) Guignardia/ Phyllosticta species on banana. Cryptogam Mycol 31(4):403-418

Xu J, Ebada SS, Proksch P (2010) Pestalotiopsis a highly creative genus: chemistry and bioactivity of secondary metabolites. Fungal Divers 44:15-31

Xu J, Yang X, Lin Q (2014) Chemistry and biology of Pestalotiopsisderived natural products. Fungal Divers 66:37-68

Yan X, Sikora RA, Zheng J (2011) Potential use of cucumber (Cucumis sativus L.) endophytic fungi as seed treatment agents against root knot nematode Meloidogyne incognita. J Zhejiang Univ (Sci B) 12(3):219-225

Yang YL, Liu ZY, Cai L, Hyde KD, Yu ZN, Mckenzie EHC (2009) Colletotrichum anthracnose of Amaryllidaceae. Fungal Divers 39: 123-146

Yang X, Copes WE, Hong C (2013) Phytophthora mississippiae sp. nov., a new species recovered from irrigation reservoirs at a plant nursery in Mississippi. J Plant Pathol Microbiol 4. doi:10.4172/2157-7471. 1000180 
Yang X, Copes WE, Hong C (2014) Two novel species representing a new clade and cluster of Phytophthora. Fungal Biol 118:72-82

Yildirim I, Turhan H, Özgen B (2010) The effect of head rot disease (Rhizopus stolonifer) on sunflower genotypes at two different growth stages. Turk J Field Crops 15(1):94-98

Yohalem DS, Nielsen K, Nicolaisen M (2003) Taxonomic and nomenclatural clarification of the onion neck rotting Botrytis species. Mycotaxon 85:175-182

Yun HY, Minnis AM, Kim YH, Castlebury LA, Aime MC (2011) The rust genus Frommeella revisited: a later synonym of Phragmidium after all. Mycologia 103(6):1451-1463

Zalar P, Hennebert GL, Gunde-Cimerman N, Cimerman A (1997) Mucor troglophilus, a new species from cave crickets. Mycotaxon 65:507-516

Zare R, Gams W, Schroers HJ (2004) The type species of Verticillium is not congeneric with the plant-pathogenic species placed in Verticillium and it is not the anamorph of 'Nectria' inventa. Mycol Res 108:576-582

Zare R, Gams W, Starink-Willemse M, Summerbell RC (2007) Gibellulopsis, a suitable genus for Verticillium nigrescens, and Musicillium, a new genus for $V$. theobromae. Nova Hedwigia 85: 463-489

Zeng H, Ho H, Zheng F (2005) Pythium vexans causing patch canker of rubber trees on Hainan Island, China. Mycopathologia 159(4):601606

Zeyen R, Ishimaru C, Dickman M, Richardson C (2014) Norman Borlaug: plant pathologist/ humanitarian. Am Phytopathol Soc. http://www.apsnet.org/publications/apsnetfeatures/Pages/ NormanBorlaug.aspx.2014
Zhang G, Berbee ML (2001) Pyrenophora phylogenetics inferred from ITS and glyceradehyde-3-phosphate dehydrogenase gene sequences. Mycologia 93(6):1048-1063

Zhang J, Wu M-D, Li G-Q, Yang L, Yu L, Jiang D-H, Huang H-C, Zhuang W-Y (2010a) Botrytis fabiopsis, a new species causing chocolate spot of broad bean in central China. Mycologia 102(5): 1114-1126. doi:10.3852/09-217

Zhang J, Zhang L, Li G-Q, Yang L, Jiang D-H, Zhuang W-Y, Huang H-C (2010b) Botrytis sinoallii: a new species of the grey mould pathogen on Allium crops in China. Mycoscience 51(6):421-431. doi:10. 1007/s10267-010-0057-4

Zhang Y, Crous PW, Schoch CL, Hyde KD (2012) Pleosporales. Fungal Divers 53:1-221

Zhang K, Zhang N, Cai L (2013a) Typification and phylogenetic study of Phyllosticta ampelicida and P. vaccinii. Mycologia 105:1030-1042

Zhang K, Su YY, Cai L (2013b) Morphological and phylogenetic characterisation of two new species of Phyllosticta from China. Mycol Prog 12:547-556

Zhang YM, Maharachchikumbura SSN, Tian Q, Hyde KD (2013c) Pestalotiopsis species on ornamental plants in Yunnan Province, China. Sydowia 65:59-74

Zheng RY, Chen GQ, Huang H, Liu XY (2007) A monograph of Rhizopus. Sydowia 59:273-372

Zhou S, Stanosz GR (2001) Relationships among Botryosphaeria species and associated anamorphic fungi inferred from the analyses of ITS and 5.8 S rDNA sequences. Mycologia 93(3):516-527

Zitter T, Kyle M (1992) Impact of powdery mildew and gummy stem blight on collapse of pumpkins (Cucurbita pepo L.). Cucurbit Genet Coop 15:93-96 